\title{
PLAN-VIEW EVOLUTION OF WAVE-DOMINATED DELTAS
}

\author{
By \\ Jaap H. Nienhuis \\ B.Sc., University of Twente, 2009 \\ M.Sc., University of Twente, 2011 \\ Submitted in partial fulfillment of the requirements for the degree of \\ Doctor of Philosophy \\ at the \\ MASSACHUSETTS INSTITUTE OF TECHNOLOGY \\ and the \\ WOODS HOLE OCEANOGRAPHIC INSTITUTION
}

February 2016

(C) 2016 Jaap H. Nienhuis.

All rights reserved.

The author hereby grants to MIT and WHOI permission to reproduce and to distribute publicly paper and electronic copies of this thesis document in whole or in part in any medium now known or hereafter created.

Signature of Author

Joint Program in Oceanography/Applied Ocean Science and Engineering Massachusetts Institute of Technology / Woods Hole Oceanographic Institution

Certified by

December 18, 2015

Andrew D. Ashton

Thesis Supervisor

Accepted by

Timothy L. Grove

Chair, Joint Committee for Marine Geology and Geophysics Massachusetts Institute of Technology / Woods Hole Oceanographic Institution 


\title{
Plan-view evolution of wave-dominated deltas
}

\section{By Jaap H. Nienhuis}

Submitted to the Joint Program in Oceanography/Applied Ocean Science and Engineering on December 18, 2015, in partial fulfillment of the requirements for the degree of Doctor of Philosophy.

\begin{abstract}
Ocean waves are a powerful sediment transport mechanism in the coastal zone. This thesis investigates how waves shape deltaic landforms and how small scale river mouth processes affect large-scale delta morphology. I have developed and applied models of plan-view delta shape and their channel dynamics. Simple parameterizations and key insights from these models have allowed us to transcend spatial scales from river mouths to delta plains and make morphologic predictions around the globe for every delta on Earth. I have applied models of delta morphology to backtrack the late Holocene evolution of the Ebro River delta in Spain and estimate timescales and magnitude of past climate change and human impacts. Currently, many deltas around the world face large sediment deficits because of river damming. I model deltaic response to reductions in sediment load and offer frameworks to predict future deltaic change in these dynamic and threatened coastal regions.
\end{abstract}

Thesis supervisor: dr. Andrew D. Ashton

Title: Associate Scientist, Department of Geology and Geophysics, Woods Hole Oceanographic Institution 


\section{Acknowledgements}

A is for Andrew, to whom I'm really grateful.

$\mathbf{B}$ is for Bruce, as he is quite playful.

$\mathbf{C}$ is for everyone at COFDL, including Rocky Geyer, Peter Traykovski, and the young COFDL group. They know a lot more of the shore.

D is for the daily fun times I had with everyone in Woods Hole, Boston, and beyond: Ruel, Arthur, Mike, Yodit, Ben, Brian, Andy, Max, Ben, Eva, Bram, William, Guilia, Rebecca, Jörn, Emily, Natasha, Aleja, Helen, Rene, Steve, Deepak, Kate, Dan, Melissa, Bryan, Alex, Jeff, Sara, Cat, Julia, Aimee, Sara, Roger, Christine, Gabi, and so many, many more.

$\mathbf{E}$ is of course for Elena, she gets her own line.

$\mathbf{F}$ is for the generous funding from MIT, WHOI, the NSF, and the GSA. It is a good sign.

$\mathbf{G}$ is for Geomorph fun on the 10th floor with Taylor, Kim, Maya, Paul, Dino, Ken, Scott, Seulgi and impeccable knowledge.

$\mathbf{H}$ is for happy time in EAPS, I will gratefully acknowledge.

I is for improve, this line could make some leaps.

$\mathbf{J}$ is for Johan, Janet, Pieter, Pieter, Lieuwe and Hilde, the best of all peeps.

$\mathbf{K}$ is for kindness, yes Yodit that's you.

$\mathbf{L}$ is for Liviu I really couldn't have done it without your delta view.

$\mathbf{M}$ is for Mam. Thank you for being my mom!

$\mathbf{N}$ is for those who are never together! Niya, Laura, Christopher and Tom.

$\mathbf{O}$ is for Oma Nienhuis and Oma Hospers I miss you a lot.

$\mathbf{P}$ is for Papa thank you for all that you taught.

$\mathbf{Q}$ is for quality time with friends from Holland, Wing, Reinier, Stephan, Rick, Elma, Mark, Tim, Jan -dash- Willem, Allard, Tim, Wouter, Dar, NJ, Luuk, Meta, Christof, Rinske, Liselot, Marten, Chil, Alje, Koen and Bert, all whom I haven't seen in quite a while.

$\mathbf{R}$ is for Rima and Romas that taught me the good Lithuanian style.

$\mathbf{S}$ is for the smile when I think about Tante Mien and Jan. I am grateful to have you around.

$\mathbf{T}$ is for Taylor. You have taught me so much about the shape of Earth's ground.

$\mathbf{U}$ is for Unihoc, and all of my friends playing along. It's been real.

$\mathbf{V}$ is for Vincas, Laurie and Lily. I'm really happy you were part of the deal.

W is for WHOI G\&G, thank you Jeff, Rob, Aleja, Jorge, Richard, Steph and many more of the coastal gram.

$\mathbf{X}$ is for Xerox, never passing for a midnight jam! 
$\mathbf{Y}$ is for you, and making it through.

$\mathbf{Z}$ is for Zircon, this is the last one, I am happy you brought Elena to MIT too. 


\section{Table of Contents}

$\begin{array}{ll}\text { Introduction } & 8\end{array}$

$1 \quad$ What makes a delta wave-dominated? 12

2 Littoral steering of deltaic channels 26

$3 \quad$ Alongshore sediment bypassing as a control on river mouth morphodynamics $\quad 57$

$4 \quad$ Wave reworking of abandoned deltas 95

$5 \quad$ Using simple models to constrain the evolution of the Ebro delta 109

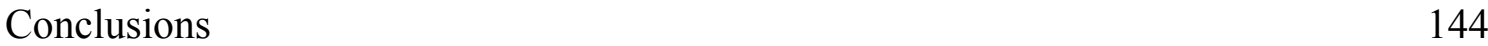

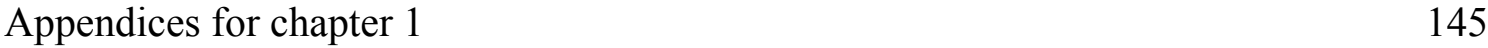

Appendices for chapter $2 \quad 153$

Appendices for chapter $3 \quad 156$

$\begin{array}{ll}\text { Appendices for chapter } 4 & 165\end{array}$

$\begin{array}{ll}\text { Bibliography } & 167\end{array}$ 


\section{Introduction}

As continents collect precipitation that gets carried downhill by rivers, Earth's surface slowly erodes and is transported along as well, grain by grain. Downstream, at a river's mouth, sediment settles close to shore, and, over time, forms a deposit we call a river delta [Credner, 1878; Gilbert, 1885]. Not only do close to half a billion people live on delta deposits [Syvitski and Saito, 2007], deltas also, over millions of years, bury the organic debris from continents that will eventually form oil and gas fields [Fisher and McGowen, 1969]. River deltas therefore have captured tremendous interest from many scientists, engineers, and policy makers, in particular because of potential future impacts of engineering works and sea-level rise [Ericson et al., 2006; Syvitski and Saito, 2007].

In his landmark study, Galloway [1975] considered river deltas to be primarily shaped by three important forces: the river, tides, and ocean waves. River-dominated deltas, such as the Mississippi River delta [Coleman et al., 1998], develop in environments with relatively small influence of waves and tides, and exhibit intricate structures of many distributary channels and crenulated shoreline shapes [Wright and Coleman, 1973]. Tides redistribute deltaic sediment up and down distributary channels, forming alluvial estuaries rather than river mouths; estuaries can stay active even after sediment supply from the river stops [Fagherazzi, 2008]. This thesis is focused on the third force: waves. Waves are a powerful dispersive agent, spreading out sediment alongshore to make coastlines straight and form deltas into a cuspate shape [Komar, 1973].

This thesis will revolve around a simple question: how do waves shape river deltas? If we know how waves move sediment around, and we have information about the river dynamics, can we predict the delta plan-view shape? I will address this problem by first considering why the shape of wave-dominated deltas is different from the shape of river-dominated deltas. This foundation provides a good starting point for the analysis of other aspects of delta morphology. Equipped with an understanding of the general shape of wave-dominated deltas, I then will focus on two applications: how will these deltas evolve into the coming century in response severe reductions in the fluvial sediment supply, and if we know what shapes wave-dominated deltas now, can we use the modern morphology of deltas to investigate the past conditions under which they formed? 
In Chapter 1 [see also Nienhuis et al., 2015c], I propose and test an analytical theory stating the wave energy required to shape deltaic sediment into a cuspate shape. I show how river dominated deltas develop in environments with insufficient wave energy to spread deltaic sediment alongshore.

Aside from their cuspate plan-form shape, wave-influenced deltas exhibit many other interesting features, one of which is the channel pattern. If waves approach the cuspate delta primarily from one side, they generate a net alongshore current that makes the delta asymmetrical about the river mouth [Bhattacharya and Giosan, 2003]. In Chapter 2, I continue the long tradition of reduced complexity modeling [Murray, 2007] of plan-view wave-dominated deltas [Grijm, 1960; Bakker and Edelman, 1964; Komar, 1973; Larson et al., 1987; Ashton and Giosan, 2011] to investigate the controls on the channel orientation.

An interesting conclusion from Chapter 2 is that the quantity of wave-driven littoral sediment that can bypass the river mouth greatly affects the overall shape of the delta. In Chapter 3 I further investigate controls on river mouth bypassing using a detailed hydrodynamics and morphodynamics model Delft3D [Deltares, 2014], highlighting the tight coupling between the river mouth jet momentum flux, alongshore sediment bypassing and river mouth migration rates.

Many modern river deltas currently receive only a fraction of their natural sediment supply because of dams upstream in the river that reduce floods and impound sediment [Syvitski and Saito, 2007]. Whereas chapter 1 was concerned with the equilibrium shape of wavedominated deltas, in chapter 4 [see also Nienhuis et al., 2013] I model the response of a delta to a decrease in sediment supply and studied how and how fast waves erode the coastline.

Another important reason to study deltas is that by being a long-term deposit of riverderived sediment, deltas provide records of past environmental change [Gilbert, 1885]. In chapter 5, through simplified quantitative analysis, I attempt to use the modern shape of the wave-influenced Ebro delta in Spain to estimate timescales and magnitude of past climate change and human impacts. 


\section{References}

Ashton, A. D., and L. Giosan (2011), Wave-angle control of delta evolution, Geophys. Res. Lett., 38(13), L13405, doi:10.1029/2011GL047630.

Bakker, W. T. J. N. P., and T. Edelman (1964), The Coastline of River-deltas, in Proc. of the 9th Conf. on Coastal Engineering, Rijkswaterstaat, Lisbon.

Bhattacharya, J. P., and L. Giosan (2003), Wave-influenced deltas: geomorphological implications for facies reconstuction, Sedimentology, 50(1), 187-210, doi:10.1046/j.13653091.2003.00545.x.

Coleman, J. M., H. H. Roberts, and G. W. Stone (1998), Mississippi River Delta: an Overview, J. Coast. Res., 14(3), 698-716.

Credner, G. R. (1878), Die Deltas, edited by A. Peterman, Justus Perthes, Gotha.

Deltares (2014), User Manual Delft3D, Deltares, Delft, The Netherlands.

Ericson, J., C. Vorosmarty, S. Dingman, L. Ward, and M. Meybeck (2006), Effective sea-level rise and deltas: Causes of change and human dimension implications, Glob. Planet. Change, 50(1-2), 63-82, doi:10.1016/j.gloplacha.2005.07.004.

Fagherazzi, S. (2008), Self-organization of tidal deltas, PNAS, 105(48), 18692-18695.

Fisher, W. L., and J. H. McGowen (1969), Depositional Systems in Wilcox Group (Eocene) of Texas and Their Relation to Occurrence of Oil and Gas, Am. Assoc. Pet. Geol. Bull., 53(1), 34-50.

Galloway, W. D. (1975), Process Framework for describing the morphologic and stratigraphic evolution of deltaic depositional systems, in Deltas, Models for Exploration, edited by M. L. Broussard, pp. 86-98, Houston Geological Society, Houston, TX.

Gilbert, G. K. (1885), The topographic features of lake shores, Washington DC, USA.

Grijm, W. (1960), Theoretical forms of shorelines, in IXth Conference on Coastal Engineering, vol. 2.13, pp. 197-202, Lisbon.

Komar, P. D. (1973), Computer models of delta growth due to sediment input from rivers and longshore transport, Bull. Geol. Soc. Am., 84(7), 2217-2226, doi:10.1130/00167606(1973)84<2217:CMODGD>2.0.CO;2.

Larson, M., H. Hanson, and N. C. Kraus (1987), Analytical solutions of the one-line model of shoreline change, US Army Waterw. Exp. Stn., Vicksburg.

Murray, A. B. (2007), Reducing model complexity for explanation and prediction, Geomorphology, 90(3-4), 178-191, doi:10.1016/j.geomorph.2006.10.020.

Nienhuis, J. H., A. D. Ashton, P. C. Roos, S. J. M. H. Hulscher, and L. Giosan (2013), Wave reworking of abandoned deltas, Geophys. Res. Lett., 40(22), 5899-5903, doi:10.1002/2013GL058231.

Nienhuis, J. H., A. D. Ashton, and L. Giosan (2015), What makes a delta wave-dominated?, Geology, 43(6), 511-514, doi:10.1130/G36518.1. 
Syvitski, J. P. M. M., and Y. Saito (2007), Morphodynamics of deltas under the influence of humans, Glob. Planet. Change, 57(3-4), 261-282, doi:10.1016/j.gloplacha.2006.12.001.

Wright, L. D., and J. M. Coleman (1973), Variations in morphology of major river deltas as functions on ocean wave and river discharge regimes, Am. Assoc. Pet. Geol. Bull., 57(2), 370-398. 


\section{What makes a delta wave-dominated?}

Jaap H. Nienhuis ${ }^{1,2, *}$, Andrew D. Ashton ${ }^{1}$, and Liviu Giosan ${ }^{1}$

${ }^{1}$ Department of Geology and Geophysics, Woods Hole Oceanographic Institution, 266 Woods Hole Road, MS 22, Woods Hole, Massachusetts 02543, USA

${ }^{2}$ Department of Earth, Atmospheric and Planetary Science, Massachusetts Institute of Technology, 77 Massachusetts Avenue, Cambridge, Massachusetts 02139, USA

*E-mail address: jnienhuis@whoi.edu

Reprinted with permission of the Geological Society of America.

Citation: Nienhuis, J. H., A. D. Ashton, and L. Giosan (2015), What makes a delta wavedominated?, Geology, 43(6), 511-514, doi:10.1130/G36518.1. 


\begin{abstract}
River deltas, low-lying landforms that host high concentrations of human population and ecosystem services, face a new, and mostly unknown, future over the coming decades and centuries. Even as some deltas experience decreased sediment supply from damming, others will see increased sediment discharge from land-use changes. There are proposals to actively use riverine sediment supply to build new land and counteract delta loss. We present a novel approach to understanding the morphology of deltas by quantifying the balance between river inputs and the largely overlooked ability of waves to spread sediments along the coast. Defining a fluvial dominance ratio - river sediment input versus the potential maximum alongshore sediment transport away from the delta mouth - allows a quantitative assessment of this sediment transport balance. For a series of deltas on Java, Indonesia, which exhibit a large range of sediment loads but have a homogenous drainage lithology and wave climate, and more eclectic global examples, shoreline deflection increases along with this fluvial dominance ratio. The fluvial dominance ratio also predicts the observed transition from cuspate, wave-dominated deltas to fluvially-dominated deltas with protruding, crenulated shorelines. Not only does this approach provide a more quantitative foundation for paleoenvironmental reconstructions and delta management, perhaps more importantly this simple metric of fluvial dominance has a predictive application in determining potential morphology of deltas created by engineered sediment diversions.
\end{abstract}




\section{$1 \quad$ Introduction}

Deltas are dynamic depositional landforms, sensitive to changes in both the terrestrial and marine environments [Syvitski and Milliman, 2007; Nienhuis et al., 2013]. Quantitative, predictive tools for delta morphology are currently particularly relevant given that many deltas receive only a fraction of historical fluvial sediment supply [Syvitski et al., 2009]; climate change and sea-level rise will significantly modify the marine environment [Ericson et al., 2006]; and new human-built deltas are proposed for coastal defense [Paola et al., 2011]. Here, we present a metric that estimates whether a delta would be fluvially- or wave-dominated for any given sediment supply and wave climate, allowing a quantitative assessment of wave influence on deltas and providing means to understand how delta morphology may respond to major environmental changes. We then test the metric on a set of small deltas on the island of Java, Indonesia, which experience a homogenous climate and have a similar watershed geology, as well as on other sample deltas from across the world

\section{$2 \quad$ Background}

In the absence of waves and tides, channel leveeing and bifurcation lead to the development of crenulated shorelines typical of fluvial dominance, with plan-view morphologies determined by sediment size [Orton and Reading, 1993; Caldwell and Edmonds, 2014] and cohesion [Edmonds and Slingerland, 2009]. Wind waves discourage accumulation of finegrained sediment at the delta mouth, and tend to sculpt delta shorelines into a cuspate shape consisting of sandy shorelines composed of shoreline-parallel beach ridges [Curray et al., 1969]. Waves also affect the river mouth jet by increasing bottom friction, thereby enhancing plume spreading and limiting the growth of river mouth bars [Nardin et al., 2013]. By suppressing the formation of mouth bars, waves alter delta distributary networks, and channel length statistics can be used to quantify the importance of waves [Jerolmack and Swenson, 2007]. Other metrics have been developed that compare deltas in terms of the relative importance of delta-shaping processes [Wright and Coleman, 1973; Galloway, 1975; Mikhailova, 1995; Bhattacharya and Giosan, 2003]. Although these previous studies provide much insight into the origin of the variability in delta morphology, they do not address mechanistic links between fluvial and marine sediment fluxes, making prediction and testing difficult. 
Modeling studies [Komar, 1973; Ashton and Giosan, 2011] of wave-influenced deltas demonstrate a straightforward feedback between fluvial sediment delivery and the shoreline orientation near a delta's mouth - delivery of sediment to the nearshore zone increasingly deflects (reorients) the shoreline, and this deflection increases alongshore transport away from the mouth until a steady state is reached. This steady state develops early and is maintained as a delta grows [Ashton and Giosan, 2011]. Obliquity in the wave approach generates a littoral transport difference between the updrift and downdrift delta flanks and can result in asymmetrical delta development with the potential for the formation of barrier islands, spits and migrating alongshore sand waves on the downdrift flank [Bhattacharya and Giosan, 2003; Ashton and Giosan, 2011]. 

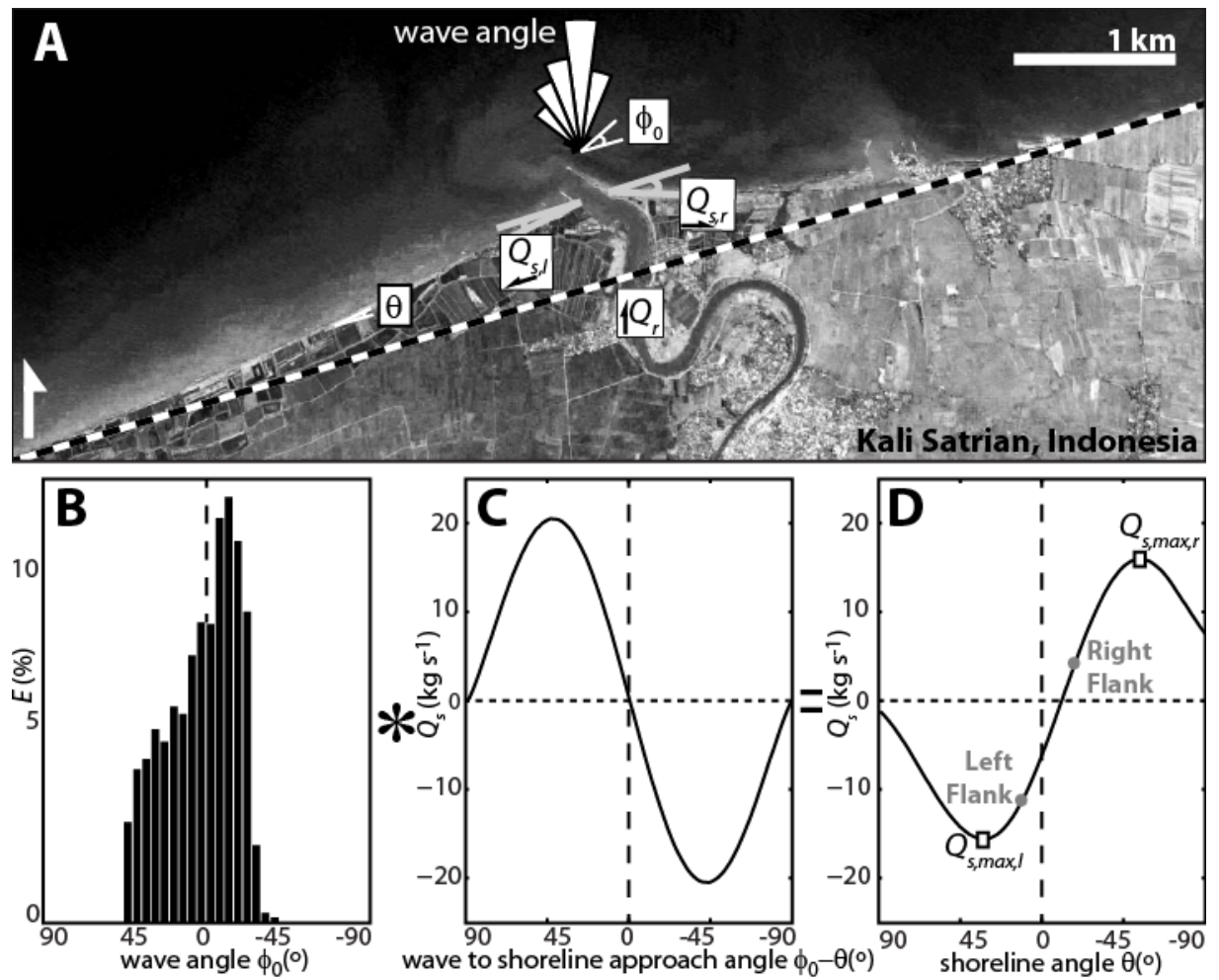

Figure 1. Shoreline deflection by fluvial sediment input for (a) the Kali Satrian delta in Indonesia. Example method of calculating $Q_{s, \max }$ (see Supplemental Methods) by convolving (b) the probability distribution of wave 'energy' $\mathrm{E}\left(\sim H_{0}{ }^{12 / 5}\right)$ with (c) the littoral transport as a function of wave approach angle yields (d) the littoral transport $Q_{s}$ as function of the shoreline orientation $\theta$ in the current wave climate, demonstrating that the observed delta configuration has orientations such that $Q_{s}$ is below $Q_{s, \max }$ (square symbols in d). The dashed black line in (a) is the reference shoreline $\left(\theta=0^{\circ}\right)$ from which flank angle is measured. 


\section{$3 \quad$ Potential Littoral Transport}

As a result of the feedback between shoreline angle and alongshore sediment transport, a wave-influenced delta is at steady state when its shoreline is deflected such that there is a balance between wave-driven littoral transport away from the river mouth $\left(Q_{s}\right)$ and the fluvial sediment retained nearshore $\left(Q_{r}\right)$,

$$
Q_{r}=Q_{s, r}-Q_{s, l}
$$

where $Q_{s, r}$ and $Q_{s, l}$ are the littoral sediment flux directed to the right and left of the river mouth (in $\mathrm{kgs}^{-1}$, positive moving right looking offshore) (Fig. 1a). As waves transport fine-grained river-borne sediments offshore and away from the littoral zone, muddy sediments are generally deposited as deltaic foresets below the shoreface toe. We therefore make the primary assumption that fine-grained sediments do not significantly affect the mass balance of the delta mouth [Geleynse et al., 2011]. The littoral grade fluvial flux that is retained nearshore is then roughly proportional to the sand fraction. We also assume that both the river channel and the wavedominated shoreface prograde on top of a prodelta platform, and therefore the infilling depths for the fluvial and littoral systems are approximately equivalent.

Alongshore sediment transport is maximized when waves in deep water (at the toe of the shoreface) approach the shoreline at $\sim 45$ degrees (Fig. 1c) [Ashton and Murray, 2006a]. Conceptually, there are two expectations for the interplay between fluvial sediment delivery and shoreline evolution as a consequence of this maximum in alongshore sediment transport. First, the tendency for fluvial input to deflect the coast as a delta grows is counteracted by waves, which tend to flatten the delta shoreline protrusion by moving sediment alongshore away from the river mouth. This phenomenon can be understood by considering an example of a delta exposed to waves approaching only head-on (i.e., crests and coast parallel). In this case, there is no net alongshore sediment transport until the shoreline is deflected at the river mouth as the delta starts to prograde. Deflection of the shoreline increases sediment transport away from the mouth, and, if the fluvial sediment supply is less than the maximum potential littoral transport, the angle of shoreline deflection at the river mouth rapidly comes into steady state with the rate of fluvial input [Ashton and Giosan, 2011]. Second, if fluvial sediment delivery is significantly large, there is no shoreline orientation that can transfer sediment away from the river mouth. 
Thus, we hypothesize that a delta will be river-dominated when the fluvial sand flux $\left(Q_{r}\right)$ is larger than the combined maximum possible littoral transport to the left and right of the river mouth $\left(Q_{s, \max }\right)$. This balance can be expressed non-dimensionally as $R$, the fluvial dominance ratio:

$$
R=\frac{Q_{r}}{Q_{s, \max }}
$$

This fluvial dominance ratio yields two scenarios for both characteristic delta growth and plan-view morphology for a single distributary channel. In the case of $R<1$, a configuration of shoreline angles exists that is capable of removing sediment alongshore as rapidly as it is delivered by the fluvial source. This leads to a cuspate delta with shoreline angles that are generally less than the maximizing angle (Fig. 1d). If $R>1$, there is no deltaic shoreline angle that would be able to transport the provided fluvial sediment - the delta is fluvially-dominated.

Equation (2) suggests a linear relationship between the retained fluvial flux $Q_{r}$ and the fluvial dominance $R$ : a doubling in fluvial sediment results in a doubling of the fluvial influence on the delta. The dependence of the wave climate on the fluvial dominance is more complicated. A spread in the wave approach reduces the ability for waves to diffuse the shoreline [Ashton and Giosan, 2011]. Increased wave spread also changes the shoreline angle at which the transport maximum occurs $\left(\theta_{\max }\right)$ such that deltas with a wide spread of wave approach angles will be more pointy for similar values of $R$ (Supplementary Fig. 1).

Asymmetry in the wave climate marginally affects the maximum for $Q_{s}$, but displaces $\theta_{\max }$ for both the left and right flank of the delta (Supplementary Fig. 1). As $R$ approaches 1, asymmetry in delta morphology can develop [Bhattacharya and Giosan, 2003; Ashton and Giosan, 2011]. The maximizing angle will be reached more easily along the downdrift coast; if this maximum is surpassed on one side, subsequent feedbacks will tend to trap more sediment on the updrift coast and drive that coast to higher angles that approach the transport-maximizing angle [Ashton and Giosan, 2011]. A delta exposed to an asymmetric wave climate will therefore also be river-dominated once $Q_{r}$ exceeds the sum of the left and right littoral transport maxima directed away from the river mouth (Supplementary Fig. 1). 


\section{$4 \quad$ Application}

We tested the application of the fluvial dominance ratio on 25 deltas on the north shore of Java, Indonesia (Fig. 2, Supplementary Table 1). Sedimentation on this shallow continental shelf generates a wide variety of delta morphologies, transitioning from cuspate wave-dominated deltas to fluvial-dominated morphologies. The mountainous rivers on Java have some of the world's highest sediment yields [Milliman and Meade, 1983], enabling delta growth from small drainage basins. These deltas have similar wave climates, so the spectrum of delta forms appears to be related to large differences in the size of the drainage basins (Supplementary Fig. 2), particularly as minimal variation in lithology reduces the potential variability in terrestrial sediment characteristics such as type, size, and sorting, which can affect alongshore sediment transport rates [Komar, 1998]. Additionally, the Java Sea is microtidal [Ray et al., 2005], enabling us to focus on the interaction of waves and fluvial processes alone; as such, the northern Java coast presents an ideal test bed for studying the effects of sediment flux variation on waveinfluenced delta morphology.

Using the BQART function [Syvitski and Milliman, 2007] (see Supplemental Methods) to estimate the fluvial yield, we find that the angles of deltaic shoreline deflection increase as the computed sediment flux increases for these 25 deltas (Fig. 2a). The river-dominated deltas all have relatively large drainage basins and correspondingly large computed fluvial sediment flux. Using the CERC formula [Komar, 1998, see supplemental methods] convoluted with directional wave climate data (Fig 1), we determine the maximum potential littoral transport away from each delta. The fluvial dominance ratio $R$ spans a significant range from 0.05 for cuspate cases to more than 4 for river-dominated deltas (Fig. 2b). At approximately $R=1$, there is a transition from single-channel deltas having smooth sandy coasts to multi-channel deltas with more protruding, crenulated shorelines. Cuspate deltas typically have shoreline angles below the angle of maximum transport $\left(|\theta|<\theta_{\max }\right.$, black symbols in Fig. 2B). 

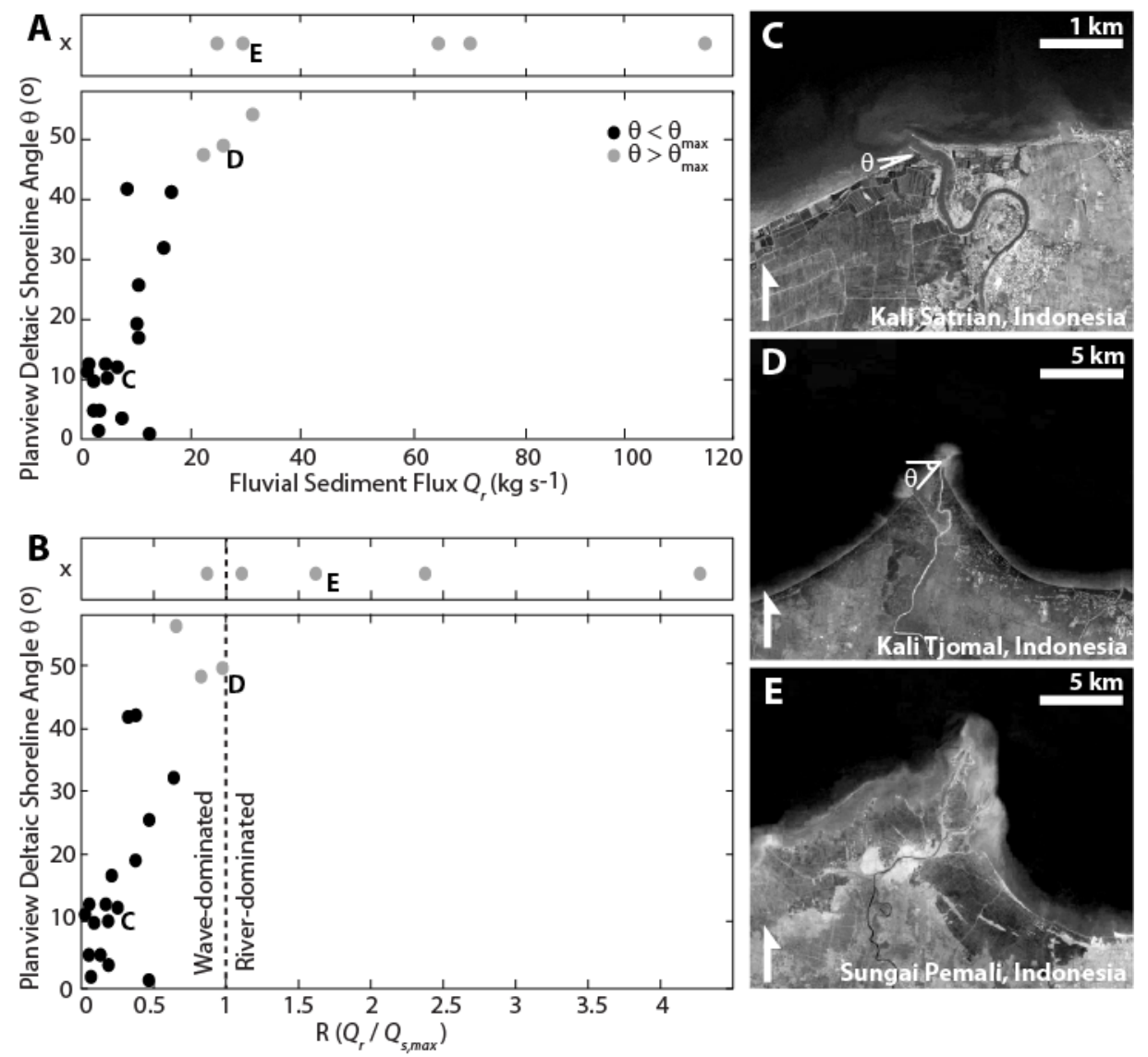

Figure 2. Average plan-view deltaic shoreline angle versus (a) fluvial sediment flux $\left(Q_{r}\right)$ and (b) fluvial dominance ratio $R$. Note that river-dominated deltas do not generally have smooth shoreline orientations and are therefore plotted independently and denoted with an $\mathrm{x}$. Deltas with gray symbols have shoreline angles above $\theta_{\max }$ (c), (d) and (e) are examples corresponding to the letters plotted in (a) and (b). The angle definition in (c) and (d) shows the plan-view deltaic shoreline angle $\theta$. River-dominated deltas (e) have no characteristic shoreline angle. Note that a diversion on the Sungai Pemali in 2005 created a new river-dominated delta lobe close to the original delta lobe. 
We also compute the fluvial dominance ratio $R$ for several well-documented deltas, the Senegal $(R \approx 0.04)$, the Sao Francisco $(R \approx 0.3)$, the Tinajones lobe of the Sinu $(R \approx 2)$, and the Belize lobe of the Mississippi $(R \approx 7)$ (Fig. 3). Deltas with larger $R$ increasingly protrude from the coast, transitioning toward river dominance for $R>1$.

Interestingly, the Tinajones, with clearly defined beach ridges and a smooth shoreline indicative of wave dominance, has an estimated $R \cong 2$, which suggests fluvial dominance. Aerial photographs show that between 1938 and 1945, when this historic delta was formed by an avulsion [Suarez, 2004], the single-thread channel (which carried the entire fluvial flux) was river-dominated and prone to mouth bar formation. After two bifurcations leading to three simultaneously active channels, fluvial sediment delivery to each channel accordingly reduced to approximately one-third of the original $Q_{r}$. However, the littoral drift potential remains the same at every river mouth. This example suggests that, through bifurcation, a marginally riverdominated delta (lobe) could transition into wave dominance [e.g., the modern Chilia lobe of the Danube delta, see Filip and Giosan, 2014]. This discharge splitting ultimately reaches a spatial limit when distributary shorelines interact with one another [Wolinsky et al., 2010].

Our approach also applies to the expected behavior of engineered river diversions, such as those suggested for the Mississippi delta [Kim et al., 2009b]. Estimates of the development of a full diversion of the Mississippi River are based on the assumption that the ensuing morphology will resemble a fan shape much like the modern Wax Lake Delta [Kim et al., 2009a]. Indeed, for the modern Belize lobe of the Mississippi River, USA, our computation of $R \approx 7$ suggests that a diversion of the full Mississippi would likely take a fluvially-dominated form; however, this fluvial dominance is not necessarily an indication of a weak wave climate but rather that the Mississippi River drains a large continental area and has a correspondingly large sediment discharge.

Wave reworking of abandoned lobes of the Mississippi has resulted in the formation of barrier islands such as Grand Isle and the Chandeleur Islands. Breton Sound and Barataria Bay, two sites of proposed diversion [Kim et al., 2009b], are protected from waves by these barrier islands. A diversion of 25\% of the current Mississippi River flux [Kim et al., 2009b] would be fluvially-dominated. However, as sea-level rise continues to threaten the existence of barrier 
islands [Lorenzo-Trueba and Ashton, 2014], these sites might in the future become increasingly exposed to waves. The Brazos River delta, Texas, USA, diverted in 1929, is an example where exposure to waves led to the growth of wave-sculpted shorelines [Rodriguez et al., 2000]. The differences in morphologic expression for wave-dominated and fluvially-dominated deltas has significant implications for the growth, ecological development, and the potential influence of vegetation on deposition for an engineered river diversion.

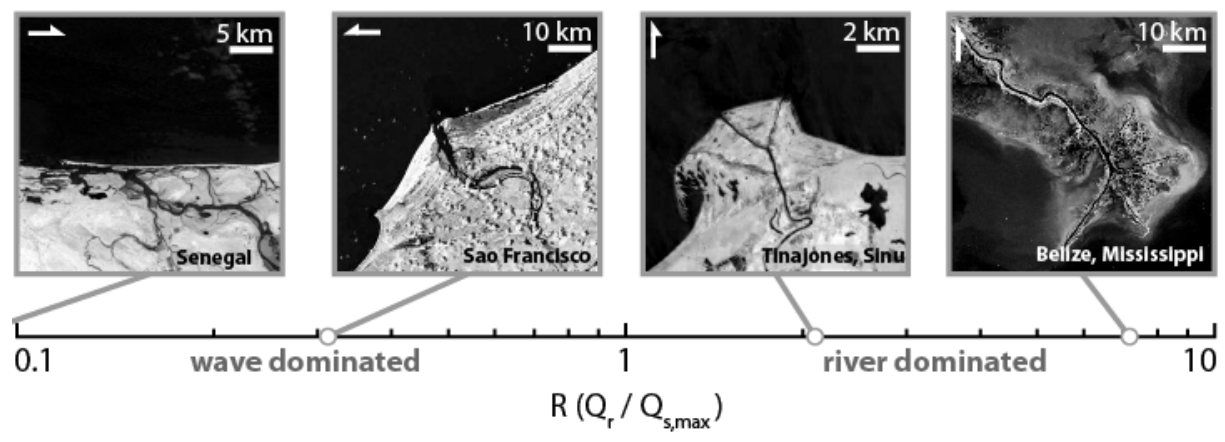

Figure 3. The fluvial dominance ratio $R$ for sample world deltas. Images $\mathbb{C}$ Google Maps and NASA. See Supplementary Table 3 for values used.

\section{$5 \quad$ Discussion and Conclusions}

The ratio of fluvial sediment flux to the alongshore transport maximum $(R)$ predicts delta morphology in steady state. However, $R$ is dependent on fluvial and wave characteristics, which have substantial temporal variability. Because timescales of delta distributary formation are $O$ (50 yr.) [Jerolmack and Swenson, 2007], we average across seasonal and interannual fluctuations. However, over longer timescales, discharge variation and avulsions can reduce sediment load and substantially alter delta morphology [Nienhuis et al., 2013].

Even as $R$ represents a straightforward metric, note that its computation can be rather inexact given the imprecise nature of sediment transport formulations. Calculation of fluvial sediment delivery is always an estimate - in our case for the deltas on Java, computed fluxes are uncalibrated, and we use a best estimate for the sand fraction. Furthermore, the CERC coefficient for littoral sediment transport can vary widely [Komar, 1998]. However, even given the inexact 
nature in its estimation, the orders of magnitude variability we see in the fluvial dominance ratio suggests that $R$ can serve as a diagnostic tool.

The fluvial dominance metric proposed here can determine the steady state of growing deltas and aid in the future management of existing deltas and proposed sediment diversions. Using a process-based metric allows us to quantitatively relate deltaic morphology to shaping processes in the modern and the ancient, thus serving as a paleo-environmental indicator. For example, we envision analyzing relict beach ridges and using modern or modeled wave data to calculate paleo-fluvial sediment fluxes, and vice versa. In consideration of the many threats to deltas in the coming centuries, our results suggest that deltas with highly deflected shorelines close to the transition between fluvial and wave-dominated morphologies are particularly sensitive to variations in environmental driving conditions.

\section{Acknowledgements}

This research was supported by NSF grant EAR-0952146. We thank Albert Kettner for assistance in extracting the NOAA WaveWatch data and Taylor Perron for help with the USGS HydroSHEDS database. We appreciate the helpful comments of Doug Edmonds, Toru Tamura, and an anonymous reviewer.

\section{$7 \quad$ References}

Ashton, A. D., and L. Giosan (2011), Wave-angle control of delta evolution, Geophys. Res. Lett., 38(13), L13405, doi:10.1029/2011GL047630.

Ashton, A. D., and A. B. Murray (2006), High-angle wave instability and emergent shoreline shapes: 1. Modeling of sand waves, flying spits, and capes, J. Geophys. Res., 111(F4), F04011, doi:10.1029/2005JF000422.

Bhattacharya, J. P., and L. Giosan (2003), Wave-influenced deltas: geomorphological implications for facies reconstuction, Sedimentology, 50(1), 187-210, doi:10.1046/j.13653091.2003.00545.x.

Caldwell, R. L., and D. A. Edmonds (2014), The effects of sediment properties on deltaic processes and morphologies: A numerical modeling study, J. Geophys. Res. Earth Surf., 119(5), 961-982, doi:10.1002/2013JF002965.

Curray, J. R., F. J. Emmel, and P. J. S. Crampton (1969), Holocene history of a strand plain, lagoonal coast, Nayarit, Mexico, in Lagunas Costeras, Un Simposio. Mem. Simp. Intern. Lagunas Costeras, edited by A. A. Castanares and F. B. Phleger, pp. 63-100, UNAMUNESCO, Mexico City, Mexico. 
Edmonds, D. A., and R. L. Slingerland (2009), Significant effect of sediment cohesion on delta morphology, Nat. Geosci., 3(2), 105-109, doi:10.1038/ngeo730.

Ericson, J., C. Vorosmarty, S. Dingman, L. Ward, and M. Meybeck (2006), Effective sea-level rise and deltas: Causes of change and human dimension implications, Glob. Planet. Change, 50(1-2), 63-82, doi:10.1016/j.gloplacha.2005.07.004.

Filip, F., and L. Giosan (2014), Evolution of Chilia lobes of the Danube delta: Reorganization of deltaic processes under cultural pressures, Anthropocene, 5, 65-70, doi:10.1016/j.ancene.2014.07.003.

Galloway, W. D. (1975), Process Framework for describing the morphologic and stratigraphic evolution of deltaic depositional systems, in Deltas, Models for Exploration, edited by M. L. Broussard, pp. 86-98, Houston Geological Society, Houston, TX.

Geleynse, N., J. E. A. Storms, D.-J. R. Walstra, H. R. A. Jagers, Z. B. Wang, and M. J. F. Stive (2011), Controls on river delta formation; insights from numerical modelling, Earth Planet. Sci. Lett., 302(1-2), 217-226, doi:10.1016/j.epsl.2010.12.013.

Jerolmack, D. J., and J. B. Swenson (2007), Scaling relationships and evolution of distributary networks on wave-influenced deltas, Geophys. Res. Lett., 34(23), L23402, doi:10.1029/2007g1031823.

Kim, W., A. Dai, T. Muto, and G. Parker (2009a), Delta progradation driven by an advancing sediment source: Coupled theory and experiment describing the evolution of elongated deltas, Water Resour. Res., 45(6), W06428, doi:10.1029/2008WR007382.

Kim, W., D. Mohrig, R. Twilley, C. Paola, and G. Parker (2009b), Is It Feasible to Build New Land in the Mississippi River Delta?, Eos, Trans. Am. Geophys. Union, 90(42), 373-374, doi:10.1029/2009EO420001.

Komar, P. D. (1973), Computer models of delta growth due to sediment input from rivers and longshore transport, Bull. Geol. Soc. Am., 84(7), 2217-2226, doi:10.1130/00167606(1973)84<2217:CMODGD>2.0.CO;2.

Komar, P. D. (1998), Beach processes and sedimentation, 2e ed., Prentice Hall, Upper Saddle River, NJ.

Lorenzo-Trueba, J., and A. D. Ashton (2014), Rollover, drowning, and discontinuous retreat: Distinct modes of barrier response to sea-level rise arising from a simple morphodynamic model, J. Geophys. Res. Earth Surf., 119(4), 779-801, doi:10.1002/2013JF002941.

Mikhailova, M. V. (1995), Sediment Balance in Nontidal River Mouths and Method of Calculation of Protruding Delta Formation, Water Resour., 22(5), 502-510.

Milliman, J. D., and R. H. Meade (1983), World-Wide Delivery of River Sediment to the Oceans, J. Geol., 91(1), 1-21, doi:10.1086/628741.

Nardin, W., G. Mariotti, D. A. Edmonds, R. Guercio, and S. Fagherazzi (2013), Growth of river mouth bars in sheltered bays in the presence of frontal waves, J. Geophys. Res. Earth Surf., 118(2), 872-886, doi:10.1002/jgrf.20057. 
Nienhuis, J. H., A. D. Ashton, P. C. Roos, S. J. M. H. Hulscher, and L. Giosan (2013), Wave reworking of abandoned deltas, Geophys. Res. Lett., 40(22), 5899-5903, doi:10.1002/2013GL058231.

Orton, G. J., and H. G. Reading (1993), Variability of deltaic processes in terms of sediment supply, with particular emphasis on grain size, Sedimentology, 40(3), 475-512, doi:10.1111/j.1365-3091.1993.tb01347.x.

Paola, C., R. R. Twilley, D. A. Edmonds, W. Kim, D. Mohrig, G. Parker, E. Viparelli, and V. R. Voller (2011), Natural processes in delta restoration: application to the Mississippi Delta., Ann. Rev. Mar. Sci., 3(1), 67-91, doi:10.1146/annurev-marine-120709-142856.

Ray, R., G. Egbert, and S. Erofeeva (2005), A Brief Overview of Tides in the Indonesian Seas, Oceanography, 18(4), 74-79, doi:10.5670/oceanog.2005.07.

Rodriguez, A. B., M. D. Hamilton, and J. B. Anderson (2000), Facies and evolution of the modern Brazos Delta, Texas: wave versus flood influence, J. Sediment. Res., 70(2), 283295, doi:10.1306/2dc40911-0e47-11d7-8643000102c1865d.

Suarez, B. E. S. (2004), The Sinú river delta on the northwestern Caribbean coast of Colombia: Bay infilling associated with delta development, J. South Am. Earth Sci., 16(7), 623-631, doi:10.1016/j.jsames.2003.10.005.

Syvitski, J. P. M. et al. (2009), Sinking deltas due to human activities, Nat. Geosci., 2(10), 681686, doi:10.1038/Ngeo629.

Syvitski, J. P. M. P. M., and J. D. D. Milliman (2007), Geology, Geography, and Humans Battle for Dominance over the Delivery of Fluvial Sediment to the Coastal Ocean, J. Geol., 115(1), 1-19, doi:10.1086/509246.

Wolinsky, M. A., D. A. Edmonds, J. Martin, and C. Paola (2010), Delta allometry: Growth laws for river deltas, Geophys. Res. Lett., 37(21), L21403, doi:10.1029/2010GL044592.

Wright, L. D., and J. M. Coleman (1973), Variations in morphology of major river deltas as functions on ocean wave and river discharge regimes, Am. Assoc. Pet. Geol. Bull., 57(2), 370-398. 


\section{Littoral steering of deltaic channels}

Jaap Nienhuis ${ }^{1,2}$, Andrew Ashton ${ }^{1}$, Liviu Giosan ${ }^{1}$

${ }^{1}$ Department of Geology and Geophysics, Woods Hole Oceanographic Institution, Woods Hole, MA

${ }^{2}$ Earth, Atmospheric and Planetary Sciences, Massachusetts Institute of Technology, Cambridge, MA

* Corresponding author: 266 Woods Hole Road, MS 22, Woods Hole Oceanographic Institution, Woods Hole, MA, jnienhuis@whoi.edu

Highlights (85 characters incl. spaces)

1. New wave-influenced delta model with littoral bypassing and dynamic channel orientation

2. Feedbacks between waves, fluvial sediment and littoral bypassing set channel orientation

3. Increase in fluvial sediment supply can change channel from downdrift to updrift migration 


\begin{abstract}
Deltas around the world show striking differences in their channel orientations, with some that are oriented into the incoming wave direction (Ombrone, Krishna), and others that are oriented away from the waves (Godavari, Sao Francisco). Because channel orientation greatly influences deltaic morphology and sedimentology both subaerially and in the deep sea environment, we explore channel orientation and consequent feedbacks with local shoreline dynamics using a plan-form numerical model of delta evolution. The model treats fluvial sediment delivery to a wave-dominated coast in two ways: 1) channels are assumed to prograde in a direction perpendicular to the local shoreline orientation and 2) only a fraction of the littoral sediment transport can bypass the river mouth. Model results suggest that channels migrate downdrift when there is a significant net littoral transport and alongshore transport bypassing of the river mouth is limited. However, model results suggest that river channels should tend to orient themselves into the waves when the shoreline of the downdrift delta flank has reached the orientation of maximum potential sediment transport for that wave climate. Using model results, we developed a framework to estimate channel orientations for wave-influenced deltas that shows good agreement with natural examples. Analogous to the recent changes of the Ombrone delta in Italy, we show how and why the deltaic channel orientation can respond to upstream changes in the fluvial sediment supply to the delta. Our results inform paleoclimate studies by linking channel orientation to fluvial sediment flux and wave energy. In particular, our approach provides a mechanism to quantify paleo wave direction, a parameter that is notoriously difficult to constrain.
\end{abstract}




\section{Introduction}

Primary channels of many wave-influenced deltas are frequently not straight. Why do some deltaic channels turn into the wave direction, while other deltaic channels are oriented away from it? (Fig. 1). It has been hypothesized that a delta's channel orientation arises from the interaction between fluvial channel-building processes and littoral sediment transport [Pranzini, 2001; Bhattacharya and Giosan, 2003]. However, a mechanistic understanding of the basic controls on channel orientation is lacking. A mechanistic understanding not only allows us to predict the channel orientation for modern deltas, but, as wave-influenced deltas are primarily shaped by the wave-driven alongshore transport of fluvial sediment [Tanner, 1958], their channel orientation has the potential to inform us about past and present fluvial and alongshore sediment transport fluxes.

To investigate the mechanisms and controls that set the channel orientations on waveinfluenced deltas, we conducted model experiments using an exploratory model of plan-view delta evolution [modified from Ashton and Giosan, 2011] where local shoreline dynamics determine the channel orientation. Furthermore, the river mouth now not only passively supplies sand to the coastal environment, but can also limit bypassing of littoral sediment [Zenkovich, 1967; Bhattacharya and Giosan, 2003]. We compare these results from model experiments to natural examples in a newly developed predictive framework for channel orientation on waveinfluenced deltas. 

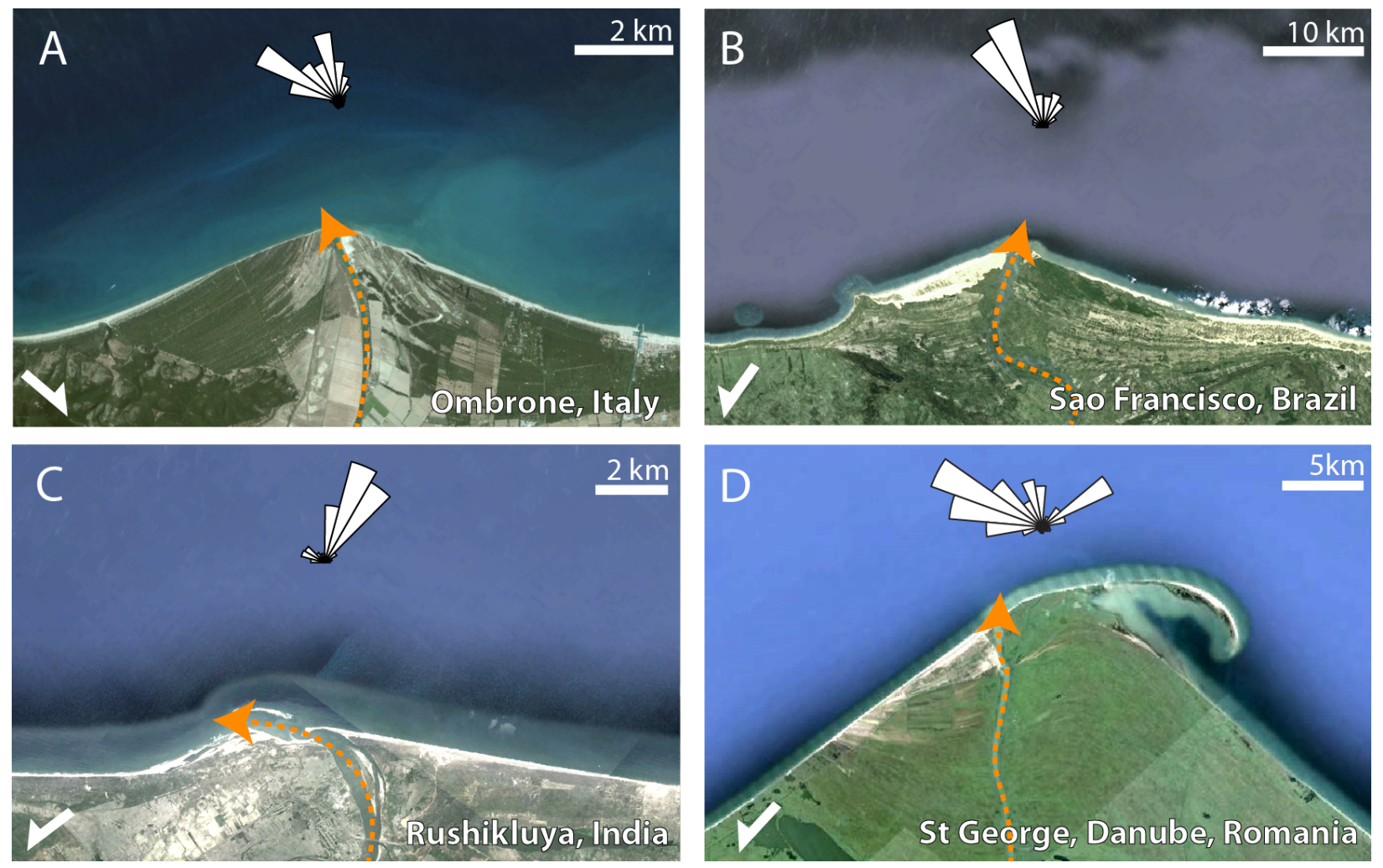

Figure 1. Examples of wave-influenced deltas with differing channel orientations. (A) Ombrone, Italy, (B) Sao Francisco, Brazil, (C) Rushikulya, India and (D) Danube, Romania. The orange arrows indicate the channels on these deltas. The wave roses show the angular distribution of wave energy, wave data from NOAA WaveWatch. Images (C) Google Earth.

\section{$2 \quad$ Background}

\subsection{Asymmetric Wave-influenced Deltas}

In the absence of waves, river deltas often have intricate networks of distributary channels resulting from mouth-bar formation and channel avulsions. However, waves move sediment, and as such can suppress emergence of these small scale distributaries, generally leading to the growth of a single major channel [Wright and Coleman, 1973] and a cuspate delta shape [Grijm, 1960].

Alongshore transport of fluvial sediment is the primary mechanism shaping waveinfluenced deltas [Tanner, 1958; Bakker and Edelman, 1964]. Waves breaking at an angle to the coastline drive a flux of sediment alongshore [Komar, 1971]; this flux is maximized for incoming waves with an offshore direction of about 45 degrees [Fig. 2, see also Ashton and 
Murray, 2006a]. Alongshore sediment transport also defines when a delta adopts a cuspate, wave-dominated morphology by rating the fluvial sediment supply relative to the maximum potential alongshore sediment transport. If the fluvial sediment supply is less than the maximum potential alongshore sediment transport (the maxima in Fig. 2a), both delta flanks can be oriented such that all the fluvial sediment supply can be transported away from the river mouth by alongshore sediment transport to form a cuspate delta shape [Nienhuis et al., 2015c].

Because of the angle dependence of alongshore sediment transport (Fig. 2a), oblique waves can generate a net alongshore drift resulting in delta plan-view asymmetry [Bhattacharya and Giosan, 2003; Ashton and Giosan, 2011]. In asymmetric deltas, accumulating sediments come not only for the "dip-feeding" river but also from updrift sources via the wave -driven "strike-feeding" littoral region [Dominguez, 1996; Giosan, 1998]. When waves approach the downdrift flank of a cuspate delta at very oblique angles of more than $45^{\circ}$, spits and shoreline sandwaves can form extending and migrating along the downdrift flank [Ashton and Giosan, 2011].

To characterize the morphologic and sedimentological asymmetry of deltas, Bhattacharya and Giosan [2003] proposed an asymmetry index, A: net alongshore drift at the river mouth (in $\left.\mathrm{m}^{3} \mathrm{yr}^{-1}\right)$ divided by river water discharge (in $\left.10^{6} \mathrm{~m}^{3} \mathrm{month}^{-1}\right)$. For low values of $\mathrm{A}(<200)$, deltas tend to be symmetric, and both delta flanks have similar morphologies. For large values of A $(>200)$, deltas are asymmetric and the updrift flank is sourced from the littoral system whereas the downdrift flank is composed of fluvial sediments [Bhattacharya and Giosan, 2003]. For example, in its later history Sao Francisco delta built beach plains on the north side, whereas fluvial fine-grained sediments fed the downdrift and accumulated, interspersed with beach ridges, on the south side flank [Fig. 1b, Dominguez, 1996]. The morphology of delta or delta lobe could change to asymmetric at various stages during its development dependent on the balance between fluvial and marine controls (Bhattacharya and Giosan, 2003; cf., Rossetti et al., 2015). As wave climate asymmetry is manifested in delta sedimentology, a quantitative framework of deltaic channel orientation therefore has the potential to reinforce studies, and provide predictions, of delta sedimentology. 

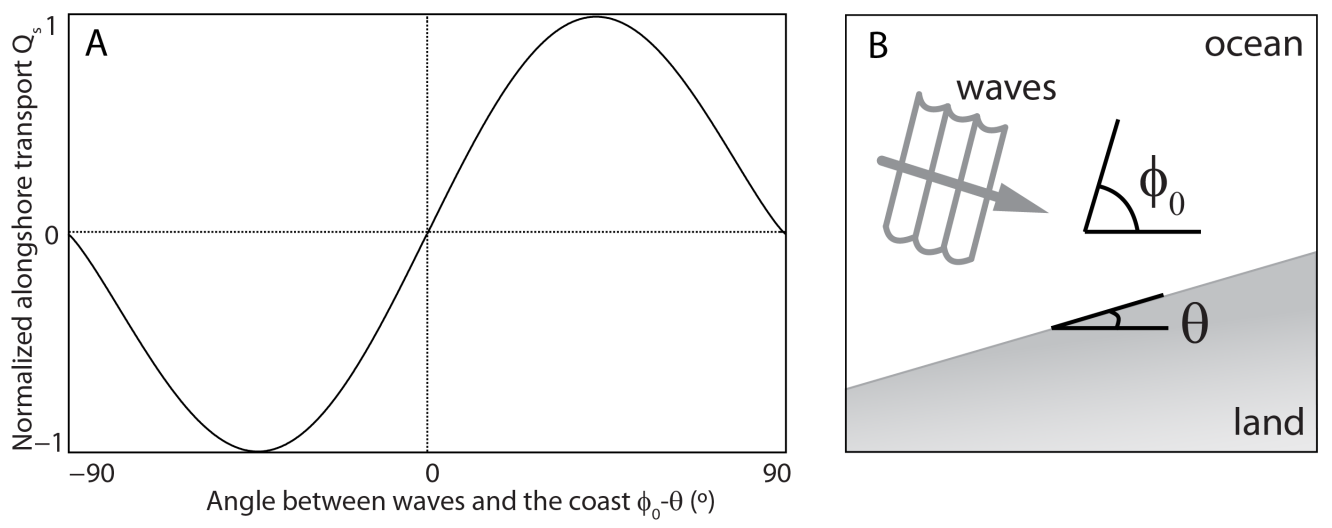

Figure 2. (A) The alongshore sediment flux $Q_{s}$ as a function of the deep-water wave approach angle, normalized to $Q_{s, r, \max }$. (B) Definition of the deep-water wave approach angle and the local shoreline orientation.

\subsection{Channels on Deltas}

Of the many complexities river deltas show, its distributary channels are markedly devoid of the common meandering patterns that many alluvial channels exhibit farther upstream [Jerolmack and Mohrig, 2007]. The absence of meanders is a direct result of the lack of lateral channel migration [Kolb, 1963; Hudson and Kesel, 2000]. Lamb et al. [Lamb et al., 2012] postulated that backwater dynamics create an efficient fluvial sediment transport regime through the lower reaches of the channel, and that the associated erosion limits point bar formation and meander initiation. Without post-depositional lateral migration mechanisms, deltaic channel patterns must be the result of depositional history at the delta coastline [e.g., Bates, 1953].

However, at first impression the channel orientation of wave-influenced deltas, shaped by alongshore sediment transport, are not straightforward; channels can move either along with or against the direction of net littoral drift. For example, the Ombrone delta in Italy (Fig. 1a) is growing into the direction of wave approach. Other deltaic channels (e.g. Nile, Sao Francisco) have migrated away from the waves (Fig. 1b, 1c), or display no dominant direction (Fig. 1d).

Pranzini [2001] showed that channels of the Ombrone and the Arno delta migrated into the net alongshore drift during a period of increased sediment load associated with land use changes. He noted that delta progradation into a more pointy cuspate shape increased the wave energy per meter coast on the updrift flank but decreased the wave energy per meter coast on the downdrift flank. This energy imbalance would increase sediment transport away from the river 
mouth along the updrift flank, and reorient the channel into the direction of wave approach [Pranzini, 2001].

Even earlier, investigating the orientation of small streams along the coastline of a larger cuspate delta, Gulliver [1896] noted downflank deflection close to the main channel, while further away these smaller streams display no dominant orientation. He associated this pattern to nearshore currents deflecting small river mouths. Zenkovich [1967] attributed the migration of channels to breaking-wave driven alongshore sediment transport, causing channels to migrate in the direction of littoral drift. Although the coupling between alongshore sediment transport and channel orientation is intuitive, there have been no studies to date that offer a predictive characterization of channel orientation, or studies that have shown how the continuum of delta morphologies could lead to a continuum of channel orientations

\subsection{Alongshore Sediment Bypassing the River Mouth}

A river mouth can act as a 'hydraulic' groin along a sandy coastline and partially or entirely block alongshore transport, trapping sediments updrift and limiting supply to downdrift beaches [Zenkovich, 1967]. Alongshore sediment that is blocked by the river mouth can form river mouth spits and initiate river mouth migration [Zenkovich, 1967; Dominguez, 1996]. The efficacy of alongshore sediment bypassing is important for coastal management, but also for long-term delta morphology, sediment provenance, and sedimentology.

Aibulatov and Shadrin [1961] used tracers to study littoral sediment bypassing the river mouth and found pathways around the river mouth bar. Another study, by Balouin et al. [2006], found instead that sediment was bypassed through the channel to the downdrift beach. For the Rakaia river in New Zealand, bypassing occurs either through bar bypassing after floods or through spit breaching, where the relocation of the river mouth can be thought of as a large instantaneous bypassing event [Kirk, 1991]. Alongshore sediment bypassing affects the morphology around river mouths: Zenkovich [1967] noted the formation, elongation and breaching of bars in front of the river mouth as a longer, discontinuous form of alongshore sediment bypassing.

Observed river mouth bypassing mechanisms share many similarities to bypassing mechanisms observed at tidal inlets [e.g., Fitzgerald, 1982]. To examine the importance of bar 
bypassing versus channel bypassing around tidal inlets, Bruun and Gerritsen [1961] developed a criterion based on the ratio between the alongshore sediment transport rate and the maximum water discharge during spring tide. For high alongshore sediment transport rates, inlets tend to be deflected or close up, whereas high tidal discharge results in bypassing through the tidal channel [Bruun and Gerritsen, 1961]. This inverse relationship between water discharge and alongshore sediment bypassing corresponds to observations of river mouths, which tend to have low bypassing rates at moderate discharge conditions and high bypassing rates for low discharge conditions [Kirk, 1991]. The dependence on discharge gives alongshore sediment bypassing a strongly seasonal character [Cooper, 1994].

Sediment bypassing occurs on longer timescales at distributary mouths of large wavedominated deltas [Bhattacharya and Giosan, 2003] such as the St. George lobe of the Danube delta . Large subaqueous shoals that develop during exceptional 100-year floods can lead to a feedback between the trapping of fluvial sediment near the river mouth and the blocking of littoral sediments that further expands the subaqueous delta [Giosan et al., 2005]. Eventual emergence, elongation and amalgamation of a river mouth spit is a long term bypassing mechanism with timescales of multiple centuries. On the Danube delta, bypassing is intertwined with the simultaneous dynamics of littoral transport along the wave-dominated coastline (Giosan, 2007; Giosan et al, 2013). Bypassing and other river mouth processes could affect the delta channel orientation by controlling the partitioning of fluvial and littoral sediments between both delta flanks.

\section{$2.4 \quad$ Modeling Wave-influenced Deltas}

The plan-view dynamics of wave-influenced deltas has been modeled analytically [Grijm, 1960; Bakker and Edelman, 1964; Larson et al., 1987] and numerically [Komar, 1973; Ashton and Giosan, 2011; Nienhuis et al., 2013]. Although these analytical and numerical delta models use straight channels, it is interesting to observe the deltaic asymmetry under those conditions. By employing a simple formula relating wave energy to littoral transport [e.g. CERC equation, see Komar, 1971] and using the one-contour-line approach, gradients in alongshore sediment transport fluxes are linearly related to shoreline accretion or erosion. Sediment deposition by a river mouth is modeled as a point-source somewhere alongshore such that a classic cuspate shape arises. In the model of Larson et al. [1987], alongshore sediment transport 
is linearly related to the wave approach angle (small angle approximation of the CERC equation, Fig. 2a), and coastal evolution reduces to a classic diffusion problem with no morphologic differences between the updrift and downdrift delta flank. Accounting for non-linearity but not for wave refraction, Bakker and Edelman [1964] demonstrate how oblique wave incidence can result in a morphologic groin effect: preferential growth of the updrift delta flank when shoreline instability, and an associated decrease in alongshore sediment transport, occurs along the downdrift flank.

Recently, Ashton and Giosan [2011] studied the effect of wave angle on wave-influenced deltas in the Coastline Evolution Model [CEM, Ashton and Murray, 2006a] assuming a river course perpendicular to the regional coastline trend. The model results, which account for nonlinearity and wave refraction, suggest the morphologic groin effect occurs due to a decrease in wave height along the downdrift coast, even when waves break at relatively small angles. Furthermore, Ashton and Giosan's [2011] results also indicated that the spread of incoming wave direction acts as an important control on the delta plan-view shape. Further analytical exploration by Nienhuis et al. [2015c] suggested that the spread of incoming waves can even control whether a delta will attain a wave-dominated or river-dominated shape. Using CEM, Ashton et al. [2013] modeled two channels that randomly rotate laterally. By coupling channel length via channel slope to the fluvial sediment flux partitioning, their study showed feedbacks that tend to equilibrate channel lengths and result in more regularly cuspate delta shapes even with multiple active distributaries. All of these previous model applications treated the river mouth solely as an additional sediment source-littoral sediment was freely able to bypass the river mouth.

Here, we expand CEM by incorporating two aspects of wave dominated deltas that have been ignored in earlier modeling studies: (1) the potential for feedbacks at the shoreline to reorient the channel course, and (2) the ability of the river mouth to partially block bypassing of some of the alongshore sediment transport flux. We use an exploratory modeling approach [Murray, 2003] to analyze and quantify the potential effect of wave climate, fluvial sediment load, and alongshore sediment bypassing on channel orientation. 


\section{Methods}

\subsection{Coastline Evolution Model}

To investigate the controls on channel orientation, we modified an existing plan-view model of shoreline dynamics, the Coastline Evolution Model [CEM, see Ashton and Murray, 2006a]. CEM assumes a constant shoreface cross-sectional profile, such that the divergence of littoral fluxes along the coast corresponds directly to advance or retreat of the shoreline position [Ashton and Murray, 2006a]. Assuming refraction over shore-parallel shoreface contours, the wave energy and wave direction then drive a sediment flux alongshore $\left(Q_{s}\right)$, calculated with the CERC formula for littoral transport [Fig. 2a, Komar, 1971]. The plan-view domain is divided into cells (cell size is $40 \mathrm{~m}$ ) that are filled (land), empty (sea) or partially filled (shoreline). The percentage filled in each cell sets the cross-shore location of the shoreline within the cell and is used to calculate the shoreline orientation with respect to neighboring cells [Fig. 3a, Ashton and Murray, 2006a].

Every time step (one day), a deep-water wave direction is picked from a probability distribution function representing the directional wave climate. We define the directional spectrum of incoming waves using two parameters. The fraction of waves coming from the left looking offshore (wave asymmetry, $A$ ), and the proportion of waves coming approaching from high angles $\left(\left|\phi_{0}-\theta\right|>45, U\right)$. In the results presented here we have varied the wave asymmetry $A$ between 0.5 and 0.8 , the high-angle proportion $U$ between 0.1 and 0.3 , and the wave height between $h 0.8$ and 1.2 meters. We use a constant wave period of 5 seconds.

\subsection{Fluvial Sediment Flux and Dynamic Channel Orientation}

In the Coastline Evolution Model, one cell alongshore is defined as the river mouth cell (with method described below) and includes a fluvial sediment flux $\left(Q_{r}\right)$ in addition to the littoral sediment flux. By doing this, we assume that the fine-grained sediment is transported offshore by wave suspension and that the coarse-grained sediment directly amalgamates to the shoreface [Ashton and Giosan, 2011]. The fluvial sediment flux $\left(Q_{r}\right)$ should therefore be interpreted as the coarse-grained or sand load fraction of the total fluvial sediment flux $\left(Q_{r, \text { total }}\right)$. The model assumes, through the use of periodic boundary conditions, that deltas grow out along an infinitely long sandy coastline with a continuous supply of sediment from the updrift delta coast. 
Ashton and Giosan [2011] and Ashton et al. [2013] modified CEM such that straight channels grew from a nodal point upstream on the delta plain, either in a predefined or randomly selected direction. Channel direction was therefore independent of local shoreline conditions. Here, we have modified CEM such that the channel no longer grows in a predefined direction, instead allowing feedbacks between the shoreline and fluvial sediment delivery to the coast to redirect the channel. To allow these feedbacks, we apply a phenomenological rule, a type of ansatz, such that the river grows perpendicularly to the local shoreline orientation set between the two neighboring cells (Fig 3b). This shore-perpendicular approach is the adoption of the idea that river mouth morphology acts as the primary control on river mouth hydrodynamics and the resulting sedimentation and erosion patterns [Roelvink et al., 1998]: if sediment is primarily deposited on one end of the channel, it would likely redirect the flow and the resulting deposition to become more perpendicular to the local topography contours. Although there is an ad hoc element to this river steering rule, analysis of several deltas worldwide shows that the channel trajectory is often perpendicular to the local $(\sim 100 \mathrm{~m})$ shoreline orientation, typically varying only a few degrees (Supplemental Materials Table 1). Our model results therefore are in part a test of this shore-perpendicular initial rule, which, in keeping with our exploratory modeling approach, allows us to examine feedbacks between shoreline orientation and channel direction.

In our model, we project the perpendicular vector from the shoreline position within the river mouth cell (Fig. 3b) at every time step. As the delta grows, the intersection of this vector with the model grid is used to determine new river mouth cells. By allowing for reorientation, the channel is able to respond dynamically to changing forcing conditions such as the fluvial sediment supply and wave climate. Sensitivity tests show that the channel path is not sensitive to grid resolutions between $20 \mathrm{~m}$ and $100 \mathrm{~m}$.

\subsection{Channel Bypassing}

The other modification to CEM is a limit in the amount of littoral sediment that is allowed to bypass the river mouth. Previously, all sediment was able to bypass as the river mouth was only incorporated passively as an addition to the local littoral sediment budget. Now, if there is a sediment flux from a neighboring cell into the river mouth cell, this flux is limited by the fraction (1- $\beta$ ), such that $\beta$ represents the fraction of alongshore sediment that is allowed to move into the river mouth cell (Fig. 3b). When $\beta=0$, the river mouth acts as a perfect groin and blocks 
all the updrift sediment. For $\beta=1$, the original model of Ashton and Giosan [2011], all sediment is freely able to bypass the river mouth, and transport across the river mouth is only based on the local shoreline orientation. The bypassing fraction is applied to each wave condition, and can therefore block sediment transport going into the river mouth cell from both the left and right neighbors.

Note that we do not model river mouth processes directly, rather we assume an average sediment bypassing fraction and investigate its effects on delta dynamics. Even though the assumption of any bypassing fraction is a simplification of the natural bypassing process, this approach allows for straightforward understanding of the end member cases $\beta=0$ and $\beta=1$, and is in keeping with our exploratory modeling approach. We ran model experiments for fluvial sediment fluxes between $10 \mathrm{kgs}^{-1}$ and $80 \mathrm{kgs}^{-1}$ and $\beta$ for $0,0.5$ and 1 . 

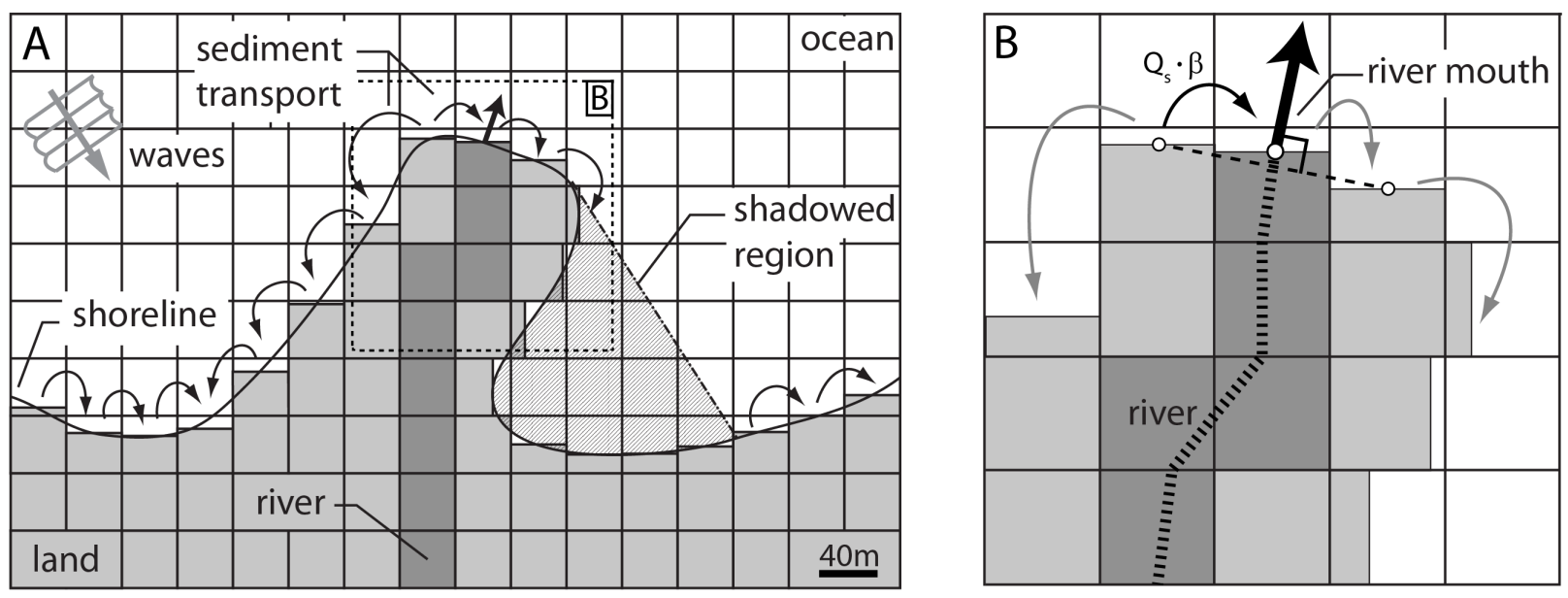

Figure 3. (A) Model domain schematic of CEM. The dashed box is enlarged in panel B. (B) Schematic depiction of the two modifications to CEM: (1) the ability of the channel to reorient itself to be perpendicular to the local shoreline orientation, (2) the restriction in alongshore sediment flux allowed to bypass the river mouth cell by a fraction $\beta$.

\section{$4 \quad$ Results}

\subsection{Styles of Channel Orientation}

We have modeled delta formation under different scenarios for fluvial sediment supply $\left(Q_{r}\right)$, wave energy, angular wave distribution, and alongshore sediment bypassing $(\beta)$ to investigate morphologic control on deltaic channel orientation. After $\sim 10$ model years under constant forcing $\left(Q_{r}, \beta\right.$, and wave climate), the deltas reach a dynamic steady state with intermittent variability in river channel orientation arising from the stochastic wave angle selection. At this steady state, deltas continue to grow with constant (or near constant) shoreline orientation and channel orientation (Fig. 4).

We observe three styles of channel orientation of the modeled deltas that we term: (i) symmetric growth, (ii) downdrift migration, and (iii) updrift migration (Fig. 4). Symmetric growth occurs for symmetrical wave climates because there is no net alongshore sediment flux across the river mouth and the shoreline angles on both flanks remain identical. Symmetric growth also develops in asymmetrical wave climates for low $Q_{r}$ and full bypassing (Fig. 4); shoreline reorientation is limited such that the small angle approximation of the alongshore sediment transport function can be justified. This keeps the alongshore transport linearly related to the shoreline angle (Fig. 2a) and the shoreline orientation close to the river mouth 
symmetrical. Low $Q_{r}$ leads to a downdrift migration only if a small fraction of alongshore sediment is allowed to bypass the river mouth. For high $Q_{r}$, channels migrate updrift in the direction of dominant wave approach, an effect that is accentuated by low alongshore sediment bypassing (Fig. 4).
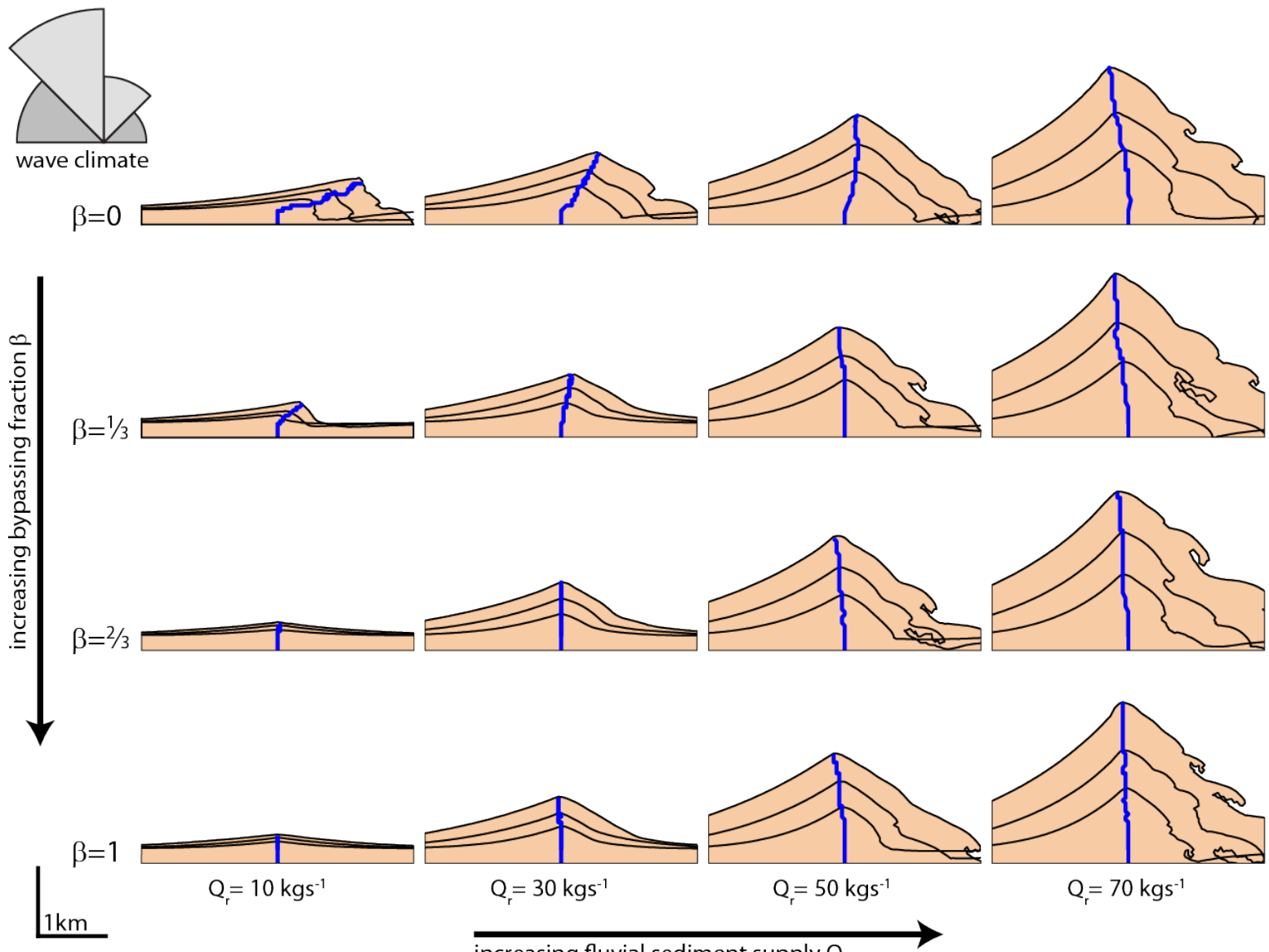

increasing fluvial sediment supply $Q_{r}$

Figure 4. Examples of wave-influenced deltas for different fluvial sediment supply rates and different bypassing fractions, $\beta$. The black lines indicate the shoreline position every 20 model years. All results here have the same wave climate, with $1 \mathrm{~m}$ waves, $\mathrm{A}=0.8$, and $\mathrm{U}=0.3$, as represented by rose of the angular distribution of incoming wave energy.

\subsection{Analysis Framework of Wave-influenced Deltas}

To better understand the controls on channel orientation, we next sought to identify the alongshore sediment transport fluxes driving morphologic change. Three key sediment fluxes 
affect the morphology of the modeled wave-influenced deltas. $Q_{r}$ is the fluvial sediment flux that is retained nearshore and therefore contributes to the cuspate shape of the delta. $Q_{s, \text { regional }}$ is the regional, "strike-feeding" [Dominguez, 1996] net alongshore sediment flux $\left(\mathrm{kgs}^{-1}\right)$. This flux is generated because of asymmetry in the wave climate and is therefore independent of the river's influence on the delta shoreline. The alongshore sediment transport tends towards $Q_{s, \text { regional }}$ far away from both left and right delta flanks (Fig. 5a, Fig. 5d). The third important sediment flux is the maximum potential gross alongshore sediment flux $Q_{s, \max }$, the sum of the maxima in sediment transport to the left, $Q_{s, l, \max }$, and to the right, $Q_{s, l, \max }$. The maximum potential flux occurs when all waves approach the shoreline at approximately $45^{\circ}$ (Fig. 2a), but can occur at other orientations for a distribution of wave approach angles [Ashton and Giosan, 2011; Nienhuis et al., 2015c].

The three fluxes $Q_{r}, Q_{s, r e g i o n a l}$, and $Q_{s, \text { max }}$ are known a priori and can therefore be used in a predictive framework of delta morphology. Based on $Q_{r}, Q_{s, \text { regional }}$, and $Q_{s, \text { max }}$, we define two non-dimensional numbers. The River Dominance ratio:

$$
R=\frac{Q_{r}}{Q_{s, \max }}
$$

which defines how wave-influenced a river delta is. If $R>1$, fluvial sediment supply $\left(Q_{r}\right)$ is larger than what waves can maximally transport away along the left and right delta flank, resulting in a river-dominated delta (Nienhuis et al. 2015).

The Sediment Source ratio:

$$
S=\frac{Q_{s, \text { regional }}}{Q_{r}},
$$

which defines the relative littoral flux asymmetry of a delta. For $S=0$, the wave climate is symmetrical and there is no net regional alongshore sediment transport. At $S>1$, the long term, net alongshore transport of sediment to the delta from the coastline updrift exceeds the fluvial sediment supply independently of river mouth dynamics. However, even in this case, the role of the river is critical in establishing the delta as a discontinuity in the alongshore transport system at its mouth. 


\subsection{Littoral Transport along Wave-influenced Deltas}

Because our modeled deltas reach a dynamic equilibrium shape, associated alongshore sediment transport fluxes correspondingly attain a long-term steady state and we can use the sediment fluxes defined in section 4.2 to characterize and predict their channel orientation. We calculate the net littoral flux by summing the alongshore sediment transport contributions from each wave angle weighted by the wave climate and based the modeled shoreline orientation. We take into account shadowing of certain wave directions due to the coast orientation.

Approaching the river mouth from updrift (the left side for our model experiments), the alongshore sediment transport decreases, and can reverse, due to the reorientation of the shoreline caused by the fluvial sediment supply (Fig. 5d). The long-term steady state behavior of the delta is evident in the alongshore sediment transport becoming linear near the river mouth, which corresponds to a constant divergence of the flux and a constant shoreline accretion rate alongshore.

At the river mouth, wave-dominated deltas display an abrupt reorientation of the shoreline to accommodate the fluvial sediment flux, $Q_{r}$ (Fig. 5d). $Q_{s, l}$ and $Q_{s, r}$ are the alongshore sediment transport left and right of the river mouth respectively. For deltas with large fluvial sediment supply, their flanks can reach the angle at which alongshore sediment transport is maximized. If this occurs, $Q_{s, l}=Q_{s, l, \max }$ and/or $Q_{s, r}=Q_{s, r, \max }$, the left and right maximum alongshore sediment transport rates. Note that if sediment is transported along the updrift flank towards the river mouth, $Q_{s, l}$ is positive, whereas a reversal in the transport direction leads to a negative $Q_{s, l}$.

\subsection{Controls on channel orientation}

\subsubsection{Symmetric Growth}

We have analyzed the conditions for symmetric growth (no channel reorientation) of modeled wave-influenced deltas using the framework established in section 4.r (Fig. 5d). For small symmetric deltas with straight channels, shoreline reorientation occurs symmetrically on both flanks, leading to $Q_{s, l}=Q_{s, \text { regional }}-1 / 2 Q_{r}$, and $Q_{s, r}=Q_{s, \text { regional }}+1 / 2 Q_{r}$ (Fig. 5d, marker I). The reorientation of the coastline remains symmetric as long as alongshore sediment transport along the downdrift flank of the delta $\left(Q_{s, r}\right)$ is less than the maximum potential alongshore sediment transport along the downdrift flank $\left(Q_{s, r, \text { max }}\right)$ (Fig. 5e). 


\subsubsection{Downdrift Migration}

Model results indicate that downdrift migration occurs when the downdrift shoreline orientation is maintained at a higher angle than the updrift shoreline orientation. Interestingly, bypassing does not affect the shoreline angle updrift of the river mouth: $Q_{s, l}$ is the same for no bypassing (case I) and bypassing (case II) scenarios at identical $Q_{r}$ (Fig. 5e). Downdrift of the river mouth however, the shoreline angle is steeper because of the reduced sediment transport from updrift. Downdrift migration therefore occurs when river mouth bypassing is limited $(\beta<$ 1) and fluvial sediment supply is low such that alongshore sediment transport on the updrift flank is oriented towards the river mouth $\left(Q_{s, l}>0\right.$, Fig. $\left.5 \mathrm{~d}\right)$. Because bypassing does not affect the updrift shoreline orientation, we can write: $Q_{s, l}=Q_{s, r e{ }^{-}} 1 / 2 Q_{r}>0$, or the delta Sediment Source ratio $S>1 / 2$ (Fig. 5). Recognizing that the volume of updrift sediment being blocked by the river mouth scales with the relative alongshore sediment flux $(S)$ that cannot bypass the channel (1- $\beta)$, we estimate downdrift migration by the Downdrift Migration Index D:

$$
D=(1-\beta) \cdot S
$$

where channels are increasingly migrating downdrift for increasing $D$.

\subsubsection{Updrift migration}

For small cuspate deltas that do not significantly reorient their shorelines and alongshore sediment transport is linearly dependent on wave approach angle, the channel remains straight because the shoreline orientation is symmetrical updrift and downdrift of the river mouth, resulting in $Q_{s, l}=Q_{s, \text { regional }}-1 / 2 Q_{r}$ and $Q_{s, r}=Q_{s, \text { regional }}+1 / 2 Q_{r}$. This symmetry is disturbed if, because of large fluvial sediment supply (high $\left.Q_{r}\right)$ or a very asymmetric wave climate $\left(Q_{s, \text { regional }}\right.$ approaching $Q_{s, r, \max }$ ), the downdrift shoreline angle reaches the angle at which alongshore transport is maximized $\left(Q_{s, r, \max }\right)$. If $Q_{r}$ is higher than what the downdrift flank can accommodate through shoreline reorientation $\left(Q_{s, \text { regional }}+1 / 2 Q_{r}>Q_{s, r \text { max }}\right)$, the additional fluvial sediment flux will be accommodated through reorientation of the updrift flank. Asymmetry in the shoreline angles around the river mouth associated with this reorientation cause updrift migration of the channel, regardless of the directional of updrift sediment transport ( $Q_{s, l}$ positive or negative). 
Mathematically defined, the channel will migrate updrift when the natural alongshore sediment transport along the downdrift flank $\left(1 / 2 Q_{r}+\beta \cdot Q_{s, \text { regional }}\right)$ is larger than the maximum potential sediment transport $\left(Q_{s, r, \max }\right)$ :

$$
1 / 2 Q_{r}+\beta \cdot Q_{s, \text { regional }}>Q_{s, r, \max },
$$

or, rearranging using the fact that $Q_{s, r, \max }=1 / 2 Q_{s, \max }$,

$$
1+2 \beta \cdot \frac{Q_{s, \text { regional }}}{Q_{r}}>\frac{Q_{s, \text { max }}}{Q_{r}},
$$

and rewriting in terms of the fluvial dominance ratio $R$ and the delta sediment source ratio $S$,

$$
R(1+2 \beta S)>1
$$

Because of (6), we define the ability for updrift migration as the Updrift Migration index $U$

$$
U=R(1+2 \beta S)
$$

where channels migrate updrift if $U>1$. Note that the direction of updrift migration depends on the wave climate. If the wave climate is symmetrical, the channel will remain straight independently of $U$. When $R=1$ and the delta is fluvially dominated, both flanks are at the $Q_{s, \max }$ for their flank, and the delta is migrating updrift into the incoming wave direction.

Additionally, note that for high fluvial sediment flux, such that $S<<R$, and $\mathrm{U} \approx \mathrm{R}$ (eq. 7): updrift migration occurs regardless of the bypassing fraction $\beta$. Intuitively, this makes sense because for high fluvial sediment supply updrift and downdrift flank transport are directed away from the river mouth $\left(Q_{s, l}<0\right.$ and $\left.Q_{s, r}>0\right)$ such that littoral sediment is rarely transported across the river mouth and affected by $\beta$. 

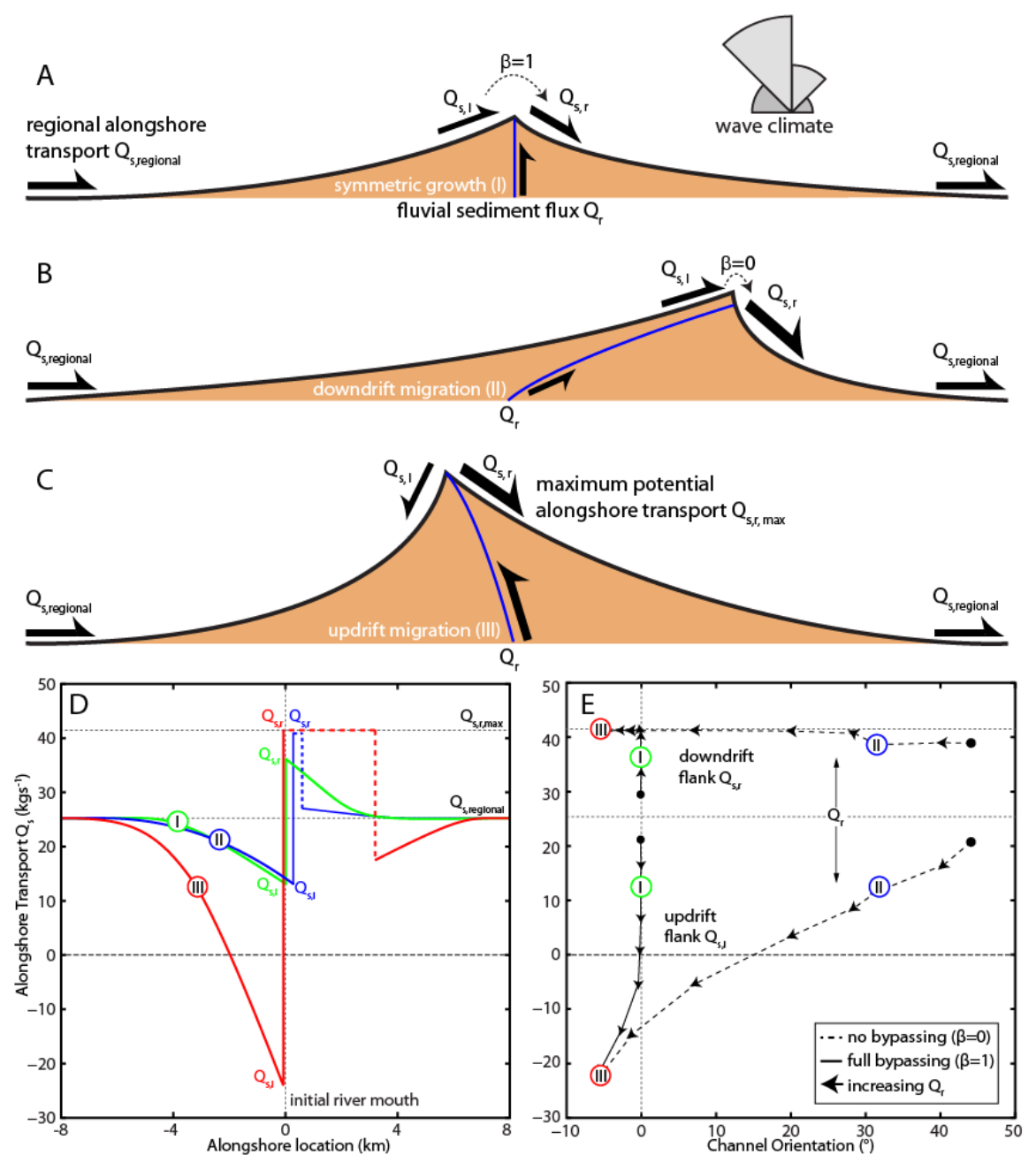

Figure 5. Flux definitions for three schematized model experiments showing (A) symmetric growth, (B) downdrift migration and (C) updrift migration. Arrows scale with the magnitude and direction of the littoral and fluvial sediment flux. The wave rose represents the angular distribution of incoming wave energy. $\mathrm{A}=0.8, \mathrm{U}=0.1$. (D) Long-term average alongshore sediment fluxes of three model runs (I-III) shown on top. Dashed portions of the lines represent when the deltaic shoreline has reached $Q_{s, r, \max }$. The instantaneous increase in alongshore sediment transport rate $Q_{s}$ at the river mouth equals to the fluvial sediment flux $Q_{r}$. (E) Average alongshore sediment fluxes to the left and right of the river mouth $\left(Q_{s, l}\right.$ and $Q_{s, r}$, the peaks in panel D) plotted against the channel orientation for modeled deltas with differing fluvial sediment fluxes ranging from $10 \mathrm{kgs}^{-1}$ to $80 \mathrm{kgs}^{-1}$, with arrows indicating the direction of increasing fluvial sediment flux. 


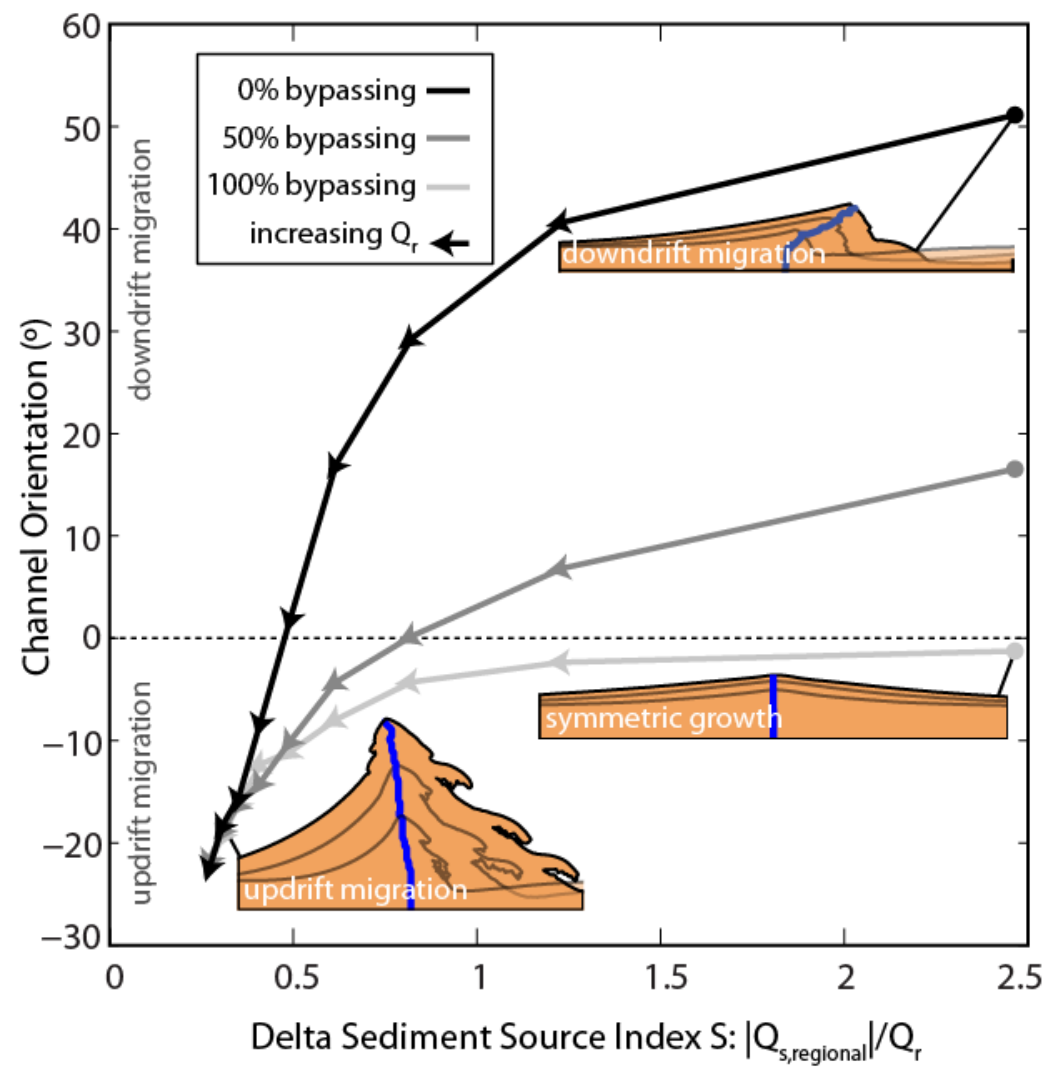

Figure 6. Channel orientation for different values of the delta flux asymmetry index $F$ for varying fluvial sediment supply $Q_{r}\left(10\right.$ to $\left.80 \mathrm{kgs}^{-1}\right)$ for the same wave climate $(\mathrm{A}=0.8, \mathrm{U}=0.1)$. Arrows point in the direction of increasing $Q_{r}$. Three model runs provide examples of delta morphology for different channel orientations.

\subsection{Comparison to natural examples}

Model investigations of channel orientation of wave-influenced deltas have enabled us to explore the mechanisms behind symmetric growth, downdrift migration and updrift migration (Fig. 5). The Updrift Migration index $U$ (eq. 7) and the Downdrift Migration index $D$ (eq. 3), via the river dominance ratio $R$ (eq. 1) and the delta flux asymmetry ratio $S$ (eq. 2), can be determined a priori (i.e. before observing delta morphology) and do not change as deltas grow.

Using all our model experiments combined with these two new indices, we can successfully forecast the channel orientation under a variety of modeled conditions (Fig. 7). Additionally, $R$ and $S$ can also be obtained for natural deltas, allowing us to test this framework of channel orientation for scenarios where we know the alongshore sediment bypassing fraction. 
Alternatively, we can use this framework as diagnostic for alongshore sediment bypassing, i.e. investigating how much alongshore sediment bypassing would result in the observed channel orientation.

Using the NOAA WaveWatch [Chawla et al., 2011] data and published fluvial sediment fluxes (see Supplemental Table 1), we calculate $R$ and $S$ for 10 natural deltas (or delta lobes). Assuming no bypassing $(\beta=0)$, the tendency of deltaic channels to either grow into (blue shades) or away from (red shades) the dominant wave direction is well predicted by our model. While these natural examples serve as a general test of our model of channel orientation on wave-influenced deltas, it also allows us to make some conjecture about $\beta$. For the Danube and the Sao Francisco, we show how a different $\beta$ would alter the predicted channel orientation.

The St. George lobe of the Danube delta shows a symmetrically growing channel (Fig. 1d). For $\beta=0$, the framework predicts a downdrift migration of about $10^{\circ}$. Following the trajectory for increasing $\beta$ (dashed line in Fig. 7), we find that an efficient bypassing regime ( $\beta$ approaching 1) compares best to the observed channel orientation. Although quantitative measurements have yet to be performed for alongshore sediment bypassing around the Danube, the possibility of an efficient bypassing regime has been suggested by Giosan [2007] based upon the existence of a large subaqueous platform downdrift of the river mouth increasing littoral transport.

The Sao Francisco River delta channel has migrated downdrift to a smaller extent $\left(15^{\circ}\right)$ than what the $\beta=0$ scenario would predict $\left(45^{\circ}\right)$. Using our framework of deltaic channel orientation, we predict that the river mouth of the Sao Francisco would be bypassing about $1 / 3$ of the alongshore sediment transport (dashed line in Fig. 7). Based on this long-term bypassing prediction and the delta sediment source ratio $S$ [1 for the Sao Francisco, see Dominguez, 1996], we can estimate the relative proportion of updrift, littoral sourced coarse-grained sediment versus fluvially sourced coarse-grained sediment in the downdrift delta flank. Using $Q_{s, l}=Q_{\text {regional }}-$ $1 / 2 Q_{r}$, we estimate that $\beta Q_{s, l}=1 / 3\left(Q_{\text {regional }}-1 / 2 Q_{r}\right)=1 / 6 Q_{r}$ of the downdrift flux is littoral material sourced from the updrift flank. Compared to $1 Q_{r}$ that is sourced from the river, we estimate that $6 / 7$ of the downdrift coarse-grained flux is fluvially derived. Analyses of the Sao Francisco beach median grain size indicate that the downdrift flank is composed of less mature sands of about 
$0.23 \mathrm{~mm}$ whereas the updrift flank is composed of $0.125 \mathrm{~mm}$ sands [Barbosa and Dominguez, 2004], indicating (a greater proportion of) fluvial sediment [Dominguez, 1996]. We are however not aware of any quantitative analyses of downdrift sediment provenance that could confirm our hypothesis. 


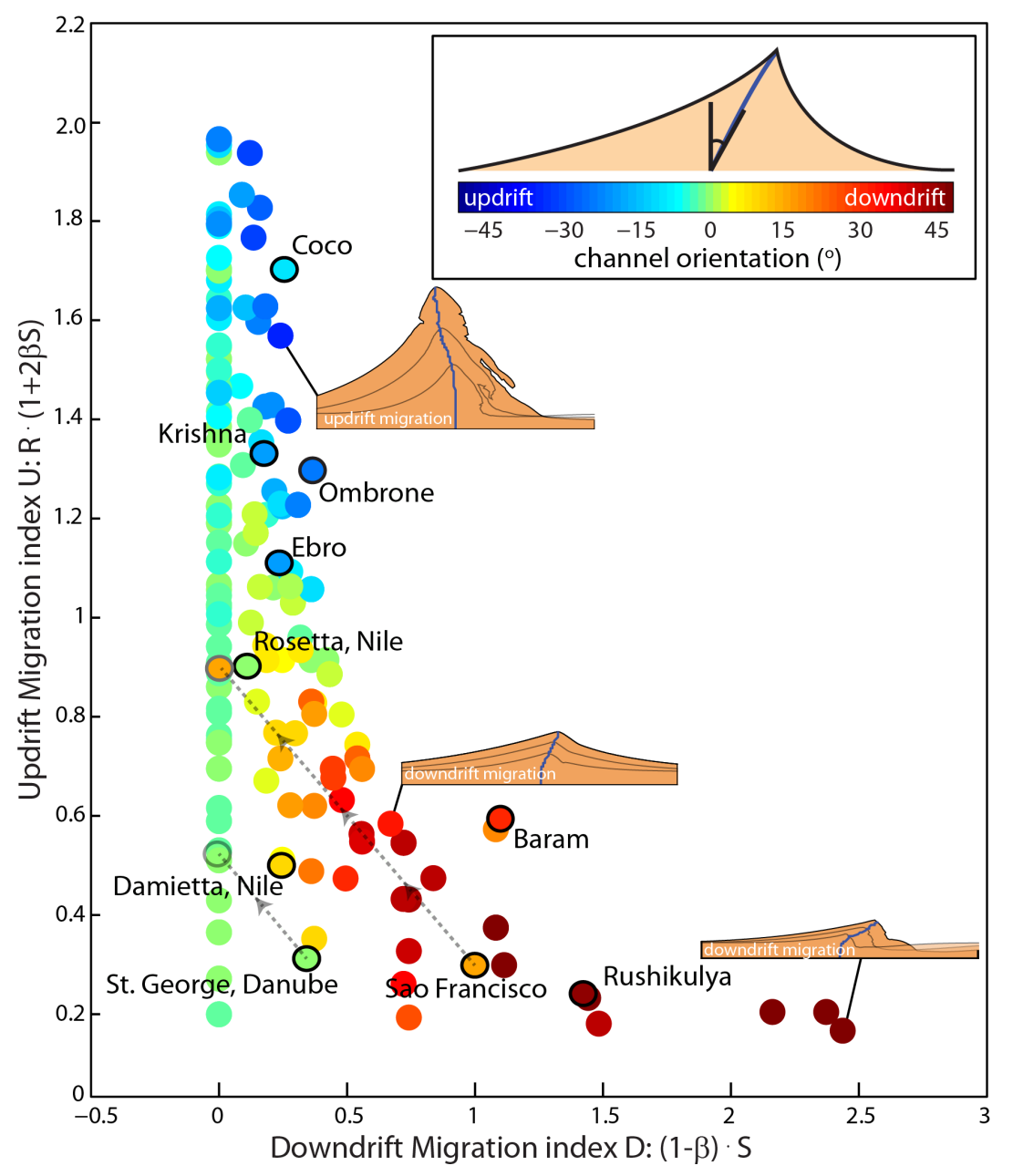

Figure 7. Channel orientation (color-coded, inset shows angle definition, positive in the direction of regional littoral drift.) for different values of $D$ (eq. 3) and $U$ (eq. 7) for both modeled and natural examples. Markers with black edge are natural examples of waveinfluenced deltas, plotted assuming $\beta=0$. The dashed lines show the trajectory of the Sao Francisco and the Danube delta for increasing bypassing.

\subsection{Change in sediment supply}

Apart from predicting the equilibrium channel orientation for deltas under constant environmental conditions (Fig. 7), our new framework also suggests that deltas experiencing changes in wave climate or fluvial sediment supply should see a corresponding shift in the channel orientation. As an example of longer term (decadal, centennial) fluctuations that affect deltaic areas, we investigated how an increase in fluvial sediment supply can be recorded in the delta channel orientation, under a constant wave climate and alongshore sediment bypassing $(\beta=$ 
0). Results indicate a rapid adjustment to a higher fluvial sediment flux, increasing the river mouth progradation rate and changing the channel orientation from downdrift to updrift migration (Fig. 8a, Fig. 8c).

Noting the channel orientation of the Arno and Ombrone deltas in Italy, Pranzini [2001] suggested that the change from downdrift to updrift migration occurred as a response to upstream land-use changes and an associated increase in fluvial sediment supply. Furthermore, the author hypothesized that updrift channel migration was due to a reversal of the updrift sediment transport direction. Here, we present a mechanism of updrift migration independent of the direction of updrift transport. Rather, updrift migration occurs when the fluvial sediment supply causes the downdrift coast to reorient to the angle at which alongshore sediment transport is maximized (Fig. 5).

Another example of long-term change in delta morphology occurs when fluvial sediment supply decreases and waves rework the coastline [Roberts, 1997; Nienhuis et al., 2013]. To investigate the effect of a decrease in fluvial sediment supply on channel orientation, we added a period of low ( $40 \mathrm{kgs}^{-1}$ ) fluvial sediment supply after the previously modeled increase (to $80 \mathrm{kgs}^{-}$ ${ }^{1}$ ) that was associated with updrift migration (Fig. 8b). Interestingly, because the decrease initiated partial abandonment and retreat of the river mouth, we find a significant delay before the channel reaches its original orientation (Fig. 8c). Note that for a $100 \%$ reduction in sediment supply, there is no net progradation that can set a channel orientation. However, in a scenario where alongshore sediment bypassing is still limited, reworking can lead to the construction of short-lived spits that extend across the river mouth from the updrift coast (e.g., Pranzini, 2001). 

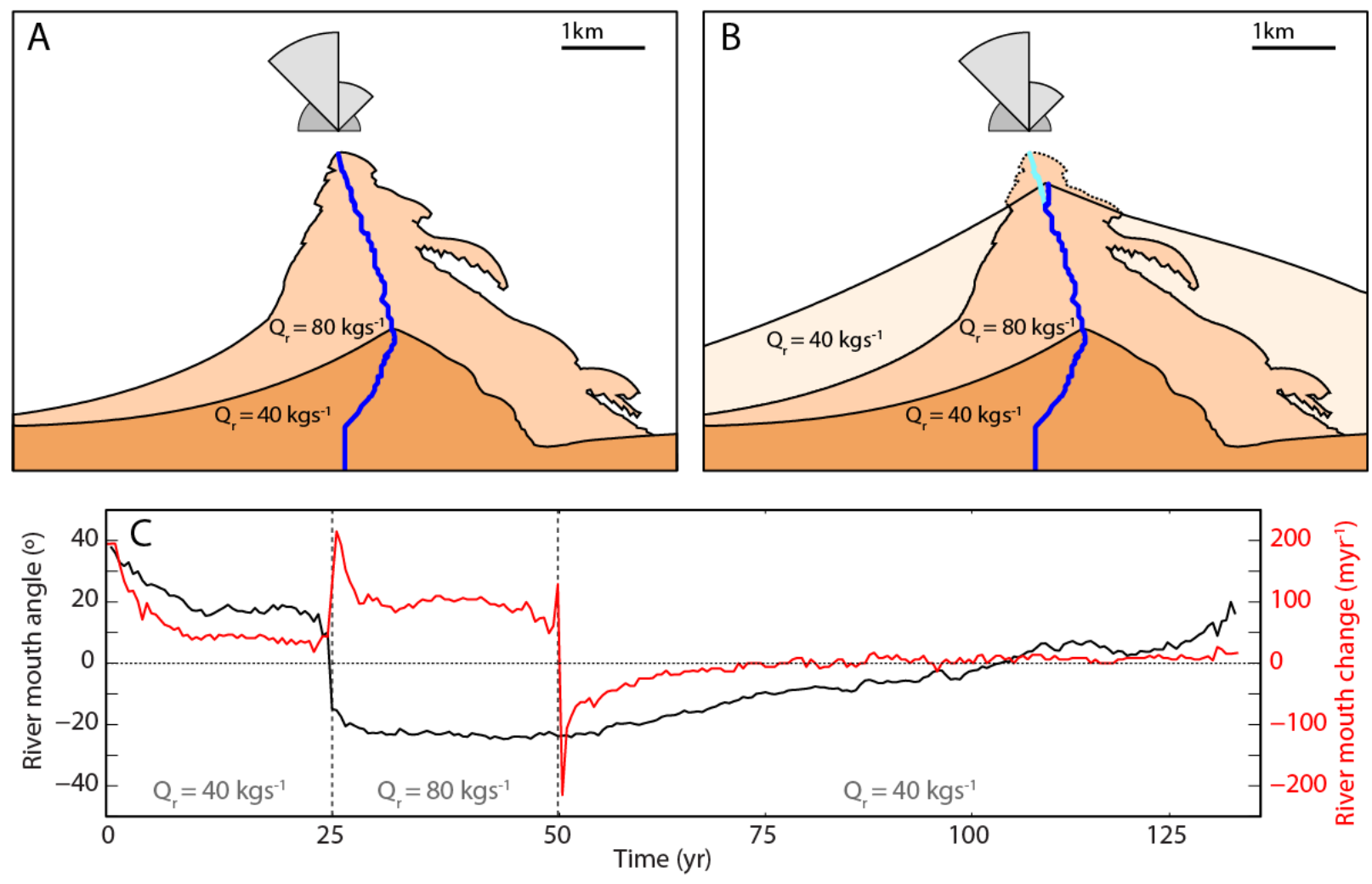

Figure 8. (A) Channel orientation response to an increase in fluvial sediment supply (40 $\mathrm{kgs}^{-1}$ to $80 \mathrm{kgs}^{-1}$ ), changing the delta sediment source ratio $S$ from 0.6 to 0.3 , and increasing the fluvial dominance ratio $R$ from 0.6 to 1.2. (B) Channel orientation response to a subsequent decrease in fluvial sediment supply $\left(80 \mathrm{kgs}^{-1}\right.$ to $\left.40 \mathrm{kgs}^{-1}\right)$. Initially a river mouth retreat (light shaded blue channel) before progradation can set a new orientation (dark shaded blue channel). Inset shows distribution of incoming wave energy. (C) River mouth angle (black) and river mouth progradation rate (red) of the delta in panels A and B. Dotted lines indicate when fluvial sediment supply changed.

\section{Discussion}

\subsection{Implications for delta predictions and paleoclimatology}

Model explorations performed here show how the deltaic channel orientation responds to long-term environmental conditions via alongshore sediment transport dynamics (Fig. 5), allowing us to use our newly developed framework (Fig. 7) as a predictive model of deltaic channel orientation. Predicted directional wave climate, fluvial sediment supply, and alongshore 
sediment bypassing allow us to calculate $R, S$ (eq. 1 and 2) and determine the resulting steadystate channel orientation.

Following the same approach, our framework (Fig. 7) also offers new possibilities for paleo-environmental reconstructions. From an observed channel orientation and an alongshore sediment bypassing fraction we can determine both the fluvial dominance ratio $R$ and the delta flux asymmetry index $S$. $R$ offers insight into the gross morphology of the river delta [Nienhuis et $a l ., 2015 \mathrm{c}]$, and $S$ can be used to characterize the delta's sedimentological asymmetry [Dominguez, 1996; Giosan, 1998]. Additionally, the product of $R$ and $S$ (equal to $Q_{s, \text { regional }}\left(Q_{s, \text { max }}\right)$, determined from just the channel orientation, provides a novel measure of wave climate directionality. For $R S=0$, the wave climate is fully symmetrical $(\mathrm{A}=0.5)$, and delta channels should be perpendicular to the wave climate and the regional coastline. At $R: S=1 / 2$ $\left(Q_{s, \text { regional }}=1 / 2 Q_{s, \max }=Q_{s, r, \max }\right)$, the wave climate is fully asymmetrical $(\mathrm{A}=1.0)$ and the regional coastline itself is oriented at $Q_{s, \max }$.

\subsection{Effect of fluvial water discharge}

Our model explorations of wave-influenced deltas suggest that the channel orientation of wave-influenced deltas generally becomes increasingly updrift for increasing fluvial sediment supply. High fluvial water discharge on the other hand is associated with low alongshore sediment bypassing [Bruun and Gerritsen, 1959; Kirk, 1991; Nienhuis et al., 2015a], and downdrift migrating channels. Combined, the fact that fluvial sediment supply and fluvial discharge lead to a different channel orientation response suggests that fluvial sediment concentration (fluvial coarse grained sediment supply divided by discharge) is an important property controlling delta morphology. Deltas with low fluvial sediment concentration (i.e., low coarse grained sediment supply but high water discharge) do not carry sufficient sediment to make up for the low bypassing fraction caused by the high discharge and thus, the channel will deflect. In contrast, deltas with high fluvial sediment concentration will carry sufficient fluvial sediment, or allow for sufficient sediment bypassing, to limit downdrift migration.

\subsection{Channel orientation for low fluvial sediment supply}

For low fluvial sediment flux or very high wave energy, river mouths are not able to reorient the coastline [Nienhuis et al., 2015c]. These small deltas however are often 'deflected' [Bhattacharya and Giosan, 2003] and show downdrift migrating channels along an otherwise 
straight coastline. River mouth processes dictate at this scale, such that dynamics that set channel orientation are not determined by fluvial sediment supply, but rather by alongshore sediment bypassing [Kirk, 1991; Nienhuis et al., 2015a]. When downdrift migration occurs without the net progradation typical of river deltas, channel orientation is generally very variable, with events such as spit breaching resetting the channel orientation on yearly timescales [Zenkovich, 1967]. Because our model sets the channel direction by the local shoreline orientation, downdrift migration requires coastline reorientation. The smallest-scale downdrift migrating delta our model can resolve therefore must extend on the order of a few river mouth widths offshore. (e.g., Fig. 1c).

\subsection{Short-term fluctuations}

Here we have modeled deltas on decadal and centennial timescales, where we assumed that short-term (seasonal) changes can be averaged into a long term equilibrium. Model experiments showed that the channel orientation can respond quickly to fluvial sediment supply increases. In contrast, decreases in fluvial sediment supply, associated with wave reworking, have a much slower channel orientation response (Fig. 8). Regardless, the one-contour-line approach of modeling wave-influenced deltas assumes that plan-view shoreline rotation by littoral transport is a long term process integrating over the effects of storms and seasonal fluctuations [Ashton and Murray, 2006a]. However, this assumption is less tested on other aspects parameterized here such as river mouth dynamics, which generally show signs of shortterm fluctuations [Wright, 1976]. Alongshore sediment bypassing for example could be strongly seasonal and related to flood frequency: alongshore transport can freely bypassing during droughts, and is restricted during flood events [Kirk, 1991; Cooper, 1994]. Bypassing could also vary daily based on the wave approach angle or tidal conditions. In future research we will investigate the effects of varying the alongshore bypassing fraction $\beta$ and associated delta morphology.

\subsection{Coarse-grained assumption}

We assume that fluvially-derived fine-grained sediment does not significantly contribute to the processes controlling the plan-view delta shape. Even though this is generally a good assumption for deltas shaped by alongshore sediment transport [Limber et al., 2008], river mouths on asymmetric deltas sometimes act as efficient traps of fine-grained material on the 
downdrift delta flank, resulting in series of shoreface sands separated by finer grained deposits [Bhattacharya and Giosan, 2003]. Further research is needed to investigate how much finegrained sediment contributes to the overall mass balance (and shoreline orientations) of waveinfluenced deltas.

\subsection{Shoreline-parallel bathymetry contours}

The delta evolution model assumes that waves refract across shoreline-parallel contours and that alongshore sediment flux divergence is linearly related to shoreline change [Ashton and Murray, 2006a]. With this assumption the model can collapse all vertical delta dynamics down to a single contour line, allowing a direct comparison of the model results to the surface expression of natural deltas. A drawback is that the parallel contour line assumption neglects the complex bathymetry that characterizes many wave-influenced deltas. In particular, deltas that develop in an asymmetric wave climate often show large subaqueous shoals downdrift that affect the downdrift coastline by refraction and reduction in wave energy [Giosan, 2007]. In a tidal inlet model, de Vriend et al. [1994], represented the coast by two separate contour lines to allow for a variable shoreface slope and a more accurate representation of ebb-tidal delta bathymetry. For a future model of wave-influenced deltas, we envision a similar 2-line approach to study the effects of non-shoreline parallel contours on delta asymmetry, channel orientation and alongshore sediment bypassing.

\section{Conclusion}

In this study we have modeled wave-influenced deltas by investigating feedbacks between the plan-view channel orientation, directional wave climate, fluvial sediment supply and alongshore sediment bypassing. The modeled results enabled us to formulate key criteria for updrift and downdrift channel migration. In particular, we found that limiting alongshore sediment bypassing of river mouths appears to be a necessary condition for downdrift channel migration. Deltaic channels migrate updrift when the magnitude of the fluvial sediment supply causes the downdrift flank to reach the angle of maximum alongshore transport.

Detailed investigation of alongshore sediment transport dynamics along wave-influenced deltas led us to a predictive framework of channel orientation, showing good agreement with natural examples and providing an approach to estimate the long-term alongshore sediment bypassing of river mouths. Given a fraction of alongshore sediment bypassing, our approach 
shows that paleo-environmental reconstructions of whole delta morphology, asymmetry and wave climate directionality are possible based upon an observed channel orientation.

Additionally, we find that deltaic channel orientation responds dynamically to fluvial sediment supply changes, highlighting its novel potential to backtrack anthropogenic and climate effects on deltaic environments.

\section{$7 \quad$ References}

Aibulatov, N.A., Shadrin, I.F., 1961. Some data on the long-shore drift of sand near natural obstacles. Tr. Inst. Okeanol. Akad. Nauk. SSSR 53.

Ashton, A.D., Giosan, L., 2011. Wave-angle control of delta evolution. Geophys. Res. Lett. 38, L13405. doi:10.1029/2011GL047630

Ashton, A.D., Hutton, E.W.H.H., Kettner, A.J., Xing, F., Kallumadikal, J., Nienhuis, J., Giosan, L., 2013. Progress in coupling models of coastline and fluvial dynamics. Comput. Geosci. 53, 21-29. doi:10.1016/j.cageo.2012.04.004

Ashton, A.D., Murray, A.B., 2006. High-angle wave instability and emergent shoreline shapes: 1. Modeling of sand waves, flying spits, and capes. J. Geophys. Res. 111, F04011. doi:10.1029/2005JF000422

Bakker, W.T.J.N.P., Edelman, T., 1964. The Coastline of River-deltas, in: Proc. of the 9th Conf. on Coastal Engineering. Rijkswaterstaat, Lisbon.

Balouin, Y., Ciavola, P., Michel, D., 2006. Support of Subtidal Tracer Studies to Quantify the Complex Morphodynamics of a River Outlet: the Bevano, NE Italy. J. Coast. Res. 1, 602606.

Barbosa, L.M., Dominguez, J.M.L., 2004. Coastal dune fields at the São Francisco River strandplain, northeastern Brazil: morphology and environmental controls. Earth Surf. Process. Landforms 29, 443-456. doi:10.1002/esp.1040

Bates, C.C., 1953. Rational theory of delta formation. Am. Assoc. Pet. Geol. Bull. 37, 2119 2162.

Bhattacharya, J.P., Giosan, L., 2003. Wave-influenced deltas: geomorphological implications for facies reconstuction. Sedimentology 50, 187-210. doi:10.1046/j.1365-3091.2003.00545.x

Bruun, P., Gerritsen, F., 1959. Natural By-Passing of Sand at Coastal Inlets. J. Waterw. Harb. Div. 85, 75-107.

Bruun, P., Gerritsen, F., 1961. By-Passing of Sand by Natural Action at Coastal Inlets and Passes. Trans. Am. Soc. Civ. Eng. 126, 823-850.

Chawla, A., Spindler, D., Tolman, H.L., 2011. A Thirty Year Wave Hindcast Using The Latest NCEP Climate Forecast System Reanalysis Winds, in: Proceedings of the 12th International Workshop on Wave Hindcasting and Forecasting. Kohala Coast, Hawaii.

Cooper, J.A.G., 1994. Sedimentary processes in the river-dominated Mvoti estuary, South Africa. Geomorphology 9, 271-300. doi:10.1016/0169-555X(94)90050-7 
de Vriend, H.J., Bakker, W.T., Bilse, D.P., 1994. A morphological behaviour model for the outer delta of mixed-energy tidal inlets. Coast. Eng. doi:10.1016/0378-3839(94)90008-6

Dominguez, J.M.L., 1996. The Sao Francisco strandplain: a paradigm for wave-dominated deltas? Geol. Soc. London, Spec. Publ. 117, 217-231. doi:10.1144/GSL.SP.1996.117.01.13

Fitzgerald, D.M., 1982. Sediment Bypassing at Mixed Energy Tidal Inlets, in: Edge, B.L. (Ed.), Proceedings of 18th Conference of Coastal Engineering. ASCE, Cape Town, South Africa, pp. 1094-1118. doi:10.9753/icce.v18

Giosan, L., 1998. Long term sediment dynamics of Danube delta coast, in: Dronkers, J., Scheffers, M. (Eds.), Physics of Estuaries and Coastal Seas. Balkema, Rotterdam, pp. 365376.

Giosan, L., 2007. Morphdynamic Feedbacks on Deltaic Coasts: lessons from the wavedominated Danube Delta, in: Kraus, N.C., Rosati, J.D. (Eds.), Coastal Sediments. New Orleans, LA. doi:10.1061/40926(239)63

Giosan, L., Donnelly, J.P., Vespremeanu, E., Bhattacharya, J.P., Olariu, C., Buonaiuto, F.S., 2005. River delta morphodynamics: examples from the Danube delta, SEPM Special Publication. SEPM (Society for Sedimentary Geology). doi:10.2110/pec.05.83

Grijm, W., 1960. Theoretical forms of shorelines, in: IXth Conference on Coastal Engineering. Lisbon, pp. 197-202.

Gulliver, F.P., 1896. Cuspate forelands. Bull. Geol. Soc. Am. 7, 399-422.

Hudson, P.F., Kesel, R.H., 2000. Channel migration and meander-bend curvature in the lower Mississippi River prior to major human modification. Geology 28, 531. doi:10.1130/00917613(2000)28<531:CMAMCI $>2.0 . \mathrm{CO} ; 2$

Jerolmack, D.J., Mohrig, D., 2007. Conditions for branching in depositional rivers. Geology 35, 463-466. doi:Doi 10.1130/G23308a.1

Kirk, R.M., 1991. River-beach interaction on mixed sand and gravel coasts: a geomorphic model for water resource planning. Appl. Geogr. 11, 267-287. doi:10.1016/0143-6228(91)90018-5

Kolb, C.R., 1963. Sediments Forming the Bed and Banks of the Lower Mississippi River and their Effect on River Migration. Sedimentology 2, 227-234. doi:10.1111/j.13653091.1963.tb01216.x

Komar, P.D., 1971. Mechanics of Sand Transport on Beaches. J. Geophys. Res. 76, 713-721. doi:10.1029/Jc076i003p00713

Komar, P.D., 1973. Computer models of delta growth due to sediment input from rivers and longshore transport. Bull. Geol. Soc. Am. 84, 2217-2226. doi:10.1130/00167606(1973)84<2217:CMODGD>2.0.CO;2

Lamb, M.P., Nittrouer, J. a., Mohrig, D., Shaw, J., 2012. Backwater and river plume controls on scour upstream of river mouths: Implications for fluvio-deltaic morphodynamics. J. Geophys. Res. Earth Surf. 117, 1-15. doi:10.1029/2011JF002079

Larson, M., Hanson, H., Kraus, N.C., 1987. Analytical solutions of the one-line model of shoreline change. US Army Waterw. Exp. Stn., Vicksburg. 
Limber, P.W., Patsch, K.B., Griggs, G.B., 2008. Coastal Sediment Budgets and the Littoral Cutoff Diameter: A Grain Size Threshold for Quantifying Active Sediment Inputs. J. Coast. Res. 2, 122-133. doi:10.2112/06-0675.1

Murray, A.B., 2003. Contrasting the goals, strategies and predictions associated with simplified numerical models and detailed simulations, in: Wilcock, P.R., Iverson, R.M. (Eds.), Prediction in Geomorphology. American Geophysical Union, Washington DC, USA, pp. 151-165. doi:10.1029/135GM11

Nienhuis, J.H., Ashton, A.D., Giosan, L., 2015a. What makes a delta wave-dominated? Geology 43, 511-514. doi:10.1130/G36518.1

Nienhuis, J.H., Ashton, A.D., Nardin, W., Fagherazzi, S., Giosan, L., 2015b. Breaking-wave driven sediment bypassing of river mouths: mechanisms and effects on delta evolution, in: Wang, P., Rosati, J., Cheng, J. (Eds.), The Proceedings of the Coastal Sediments 2015. World Scientific Pub Co Inc, San Diego, USA. doi:10.1142/9789814689977_0158

Nienhuis, J.H., Ashton, A.D., Roos, P.C., Hulscher, S.J.M.H., Giosan, L., 2013. Wave reworking of abandoned deltas. Geophys. Res. Lett. 40, 5899-5903. doi:10.1002/2013GL058231

Pranzini, E., 2001. Updrift river mouth migration on cuspate deltas: two examples from the coast of Tuscany (Italy). Geomorphology 38, 125-132. doi:10.1016/S0169-555x(00)00076-3

Roberts, H.H., 1997. Dynamic changes of the Holocene Mississippi River delta plain: The delta cycle. J. Coast. Res. 13, 605-627.

Roelvink, J.A., Boutmy, A., Stam, J., 1998. A simple method to predict long-term morphological changes, in: Edge, B.L. (Ed.), Coastal Engineering 1998. ASCE, Copenhagen, Denmark, pp. 3224-3237.

Tanner, W.F., 1958. The equilibrium beach. Trans. Am. Geophys. Union 39, 889. doi:10.1029/TR039i005p00889

Wright, L.D., 1976. Morphodynamics of a wave-dominated river mouth, in: Coastal Engineering Proceedings 1976. pp. 622-626.e2. doi:10.9753/icce.v15.\%25p

Wright, L.D., Coleman, J.M., 1973. Variations in morphology of major river deltas as functions on ocean wave and river discharge regimes. Am. Assoc. Pet. Geol. Bull. 57, 370-398.

Zenkovich, V.P., 1967. Processes of Coastal Development, 1st ed. Oliver \& Boyd, Edinburgh. 


\section{Alongshore sediment bypassing as a control on river mouth morphodynamics}

Jaap H. Nienhuis ${ }^{1,2^{*}}$, Andrew D. Ashton ${ }^{1}$, William Nardin $^{3}$, Sergio Fagherazzi ${ }^{3}$, Liviu Giosan ${ }^{1}$

${ }^{1}$ Department of Geology and Geophysics, Woods Hole Oceanographic Institution, Woods Hole, MA

${ }^{2}$ Earth, Atmospheric and Planetary Sciences, Massachusetts Institute of Technology, Cambridge, MA

${ }^{3}$ Department of Earth and Environment, Boston University, Boston, MA

* Corresponding author: 266 Woods Hole Road, MS 22, Woods Hole Oceanographic Institution, Woods Hole, MA, jnienhuis@whoi.edu 


\begin{abstract}
River mouths, dynamic shoreline features responsible for partitioning fluvial and coastal sediments via erosion, trapping, or redistribution, are responsible for the ultimate sedimentary architecture of deltas and, because of their dynamic nature, also pose great management and engineering challenges. To investigate the interaction between river mouths and littoral processes, we modeled the morphologic evolution of wave-dominated river mouths using the coupled hydrodynamic and morphodynamic model Delft3D-SWAN. Model experiments replicate alongshore migration of river mouths, river mouth spit development, and eventual spit breaching, suggesting that these are emergent phenomena that can develop even under constant fluvial and wave conditions. Furthermore, we find that sediment bypassing of a river mouth arises though feedbacks between waves and river mouth morphology, resulting in either continuous bypassing pathways or episodic bar bypassing pathways. Model results demonstrate that waves refracting into the river jet create a zone of low sediment transport updrift of the river mouth, which reduces sediment bypassing. Sediment bypassing, in turn, controls river mouth migration rates and the size of the river mouth spit. As a result, river mouth migration is maximized for an intermediate size of the river discharge. The fraction of alongshore sediment bypassing can also be predicted from the balance between the jet and the wave momentum flux, even for different river mouth morphologies. Quantitative comparisons shows a match between our modeled predictions of river mouth bypassing and migration rates observed at natural examples of river mouths with river mouth spits.
\end{abstract}




\section{$1 \quad$ Introduction}

As the majority of global sediment eroded from the continents is transported through them, river mouths carry out a pivotal role in Earth-surface dynamics [Hay, 1998]. Sediment delivered to river mouths steadily shapes our densely populated coastlines and deltaic coasts [Boyd et al., 1992]. As such, river mouths are the nexus of delta formation, representing the location of first response to fluvial sediment fluctuations as river mouth morphology rapidly adapts to anthropogenic sediment reductions and climate change [Syvitski and Saito, 2007; Nienhuis et al., 2013]. For example, as a result of the Aswan dam construction in 1964, the Nile river mouth at Rosetta is retreating at an average rate of 58 myr $^{-1}$ [Stanley and Warne, 1998]. The importance of ocean wave action on river mouth morphology has long been recognized [Wright, 1977]; however, the effect of waves on river mouth morphodynamics remains poorly quantified [Giosan, 2007; Fagherazzi et al., 2015]. Quantifying the drivers of river mouth morphology in various environments is important not only for forecasting upcoming changes to our deltaic shorelines, it also will allow us to better understand the longer-term coupling of terrestrial and marine processes.

Here we study how waves and associated alongshore sediment transport affect river mouth morphology, and how river mouth dynamics can be quantified in a framework of alongshore sediment bypassing, alongshore river mouth migration, and river mouth spit breaching. We test this framework with model experiments of river mouth morphology in idealized environments on yearly to decadal timescales using the numerical model Delft3DSWAN [Deltares, 2014].

\section{$2 \quad$ Background}

\subsection{River mouths in the absence of waves}

When a river enters a standing body of water, its water and sediment, previously confined to the channel, form a river mouth jet that gradually slows down and expands [Bates, 1953; Wright, 1977; Fagherazzi et al., 2015]. Hydrodynamically, river mouth jets are turbulent and bounded above and below by the free surface and bed friction, respectively [Rowland et al., 2009]. Dynamics of river mouths and their sedimentary deposits depend on the relative densities of the river and basin waters, the inertia of the river flow, and bed friction [Bates, 1953]. Depending on these environmental factors, river mouth jets can be unstable and meandering 
[Jirka, 1994; Mariotti et al., 2013; Canestrelli et al., 2014], can plunge below the basin water (hyperpycnal flow conditions), or be buoyant (hypopycnal flow conditions) [Bates, 1953; Wright, 1977].

The hydrodynamics of river mouths are strongly coupled to their morphology and morphodynamics. River mouth width and depth are a function of the fluvial discharge, sediment characteristics, and bank cohesion [Wright, 1977; Parker, 1978; Andren, 1994]. Sediment from the decelerating river mouth jet can be preferentially deposited as a mouth bar in the jet centerline or as levees along the sides of the jet depending on jet stability and bed friction [Rowland et al., 2010; Mariotti et al., 2013; Canestrelli et al., 2014; Falcini et al., 2014].

\subsection{Wave effect of river mouths}

Most often, river mouths are shaped not only by fluvial factors but also by marine processes such as waves and tides. Waves affect the river mouth jet by increasing bed friction, which enhances jet spreading [Ismail and Wiegel, 1983] and jet stability [Jirka, 2001]. Ismail and Wiegel [1983], using theory and laboratory experiments, demonstrated that jet spreading is controlled by the ratio between waves momentum of jet momentum. Waves make river mouth bars form closer to the river mouth and impede the growth of lateral levees [Wright, 1977; Nardin et al., 2013]. River mouth bars often form during floods, but channel bifurcations around river mouth bars are often short-lived when waves are present [Giosan et al., 2005; Gelfenbaum et al., 2015], resulting in the formation of one major channel [Jerolmack and Swenson, 2007].Wave-dominated river mouths display depositional patterns very similar to ebb-tidal deltas offshore of tidal inlets [Fitzgerald, 1982] but also generate unique features such as large submarine platforms [Giosan et al., 2005; Giosan, 2007]. The most obvious effect of waves on river mouths is expressed in the large-scale plan-view morphology of wave- vs. river-dominated deltas: breaking-wave-driven alongshore sediment transport spreads sediment from the river mouth alongcoast to produce cuspate deltas with smooth shorelines [Nienhuis et al., 2015c].

When waves approach the river mouth obliquely, they set up an alongshore current. This alongshore current and the associated transport of sediment interacts with the jet, with shoals and subaqueous levees mostly forming on the updrift side [Wright, 1977; Giosan, 2007] and extensive deltaic submarine platforms on the downdrift side [Correggiari et al., 2005; Giosan et al., 2005]. Waves can also deflect the river mouth jet even in the absence of an established 
alongshore current [Nardin and Fagherazzi, 2012]. Tanaka et al. [1996] show that the balance between river mouth sediment deposition by littoral processes and sediment erosion by fluvial discharge controls the width and depth of river mouths in wave-dominated environments. In some cases, when the discharge of individual streams is too small to maintain a permanent river mouth, rivers can amalgamate alongshore until the outlet has sufficient discharge to maintain a permanent river mouth [Zenkovich, 1967].

The morphology and sediment composition of river mouths on coasts with a net direction of littoral transport are often asymmetrical (different on the updrift and downdrift coasts) because delta mouths are fed by two sediment sources: fluvial and littoral. The dynamics of wave-dominated river mouths thus depend on how the fluvial sediment interfaces with sediment sourced from the updrift coastline [Hicks and Inman, 1987]. Waves are an efficient sediment sorter and move fine-grained fluvial material offshore, coarsening the nearshore environment [Friedman, 1967]. The morphological implication of sediment sorting by waves is that the total fluvial sediment flux is less important that the proportion of the fluvial sediment flux sufficiently coarse to sustain the coast [Zenkovich, 1967; Bhattacharya and Giosan, 2003].

\subsection{Sediment bypassing and river mouth migration}

Important in the interaction between alongshore sediment transport and a river is how sediment is potentially able to bypass the river mouth [Zenkovich, 1967]. Using sediment tracers to study alongshore sediment bypassing around river mouths, Aibulatov and Shadrin [1961] found that littoral sediment was transported around the river mouth bar. In another study, Balouin et al [2006] identified bypass pathways of littoral sediment through the inlet channel. Littoral bypassing around river mouths bears many similarities with bypassing around tidal inlets. Bruun and Gerritsen [1959] found that for high ratios of littoral transport to tidal discharge, strong waves will force bypassing around the ebb tidal delta. If littoral transport is low relative to the tidal discharge, waves are weak and tidal currents will transport littoral sediment via the channel and the ebb-tidal delta to the downdrift coast.

Alongshore sediment bypassing is related to the longer-term morphology of the river mouth through alongshore migration [Fig. 1, see also Zenkovich, 1967; Dominguez, 1996]. If the river mouth acts as an obstacle to the alongshore transport and no sediment is able to bypass, a river mouth spit tends to form that can cause the channel to migrate alongshore (Fig. 1b). For 
example, the river mouth spit on the Senegal river is $26 \mathrm{~km}$ long, and migrated an average of 200 myr $^{-1}$ between 1850 and 1917 [Guilchar and Nicholas, 1954]. As river mouth processes and alongshore sediment bypassing control the formation of river mouth spits, onshore sand transport, wind and vegetation allow for subsequent subaerial accretion [Sedrati et al., 2011; Heathfield and Walker, 2015].

There are limits, however, to the distance river mouths can migrate alongshore. In cases where the river mouth spit is coarse-grained such that groundwater flow is significant, discharge through the mouth decreases as the barrier elongates. A small river mouth discharge can then lead to either river mouth closure or significant bypassing of sediment around the mouth, which would stop migration [Kirk, 1991; Balouin et al., 2006]. Another natural limit to migration is spit breaching caused by storms or floods. Breaching events "reset" the river mouth updrift; this rapid change of the river outlet can be seen as a large instantaneous bypassing event [Cooper, 1990; Kirk, 1991; Hart, 2007]. A spit breach leaves behind a lagoon: a depression where once the channel flowed through [Hart, 2007]. Kelk [1974] demonstrated that the Ashburton river in New Zealand, exhibits cycles of alongshore migration and subsequent spit breaching of about 12-19 months.

When river mouths carry significantly larger fluvial sediment supply that they can reorient the coastline into a cuspate wave-dominated delta [Nienhuis et al., 2015c], the dynamics of alongshore sediment bypassing and river mouth migration are more complicated [Giosan, 2007; Nienhuis et al., 2015b]. In this case, different shoreline orientations on either side of the river mouth result in different quantities of alongshore sediment transport to and from the river mouth [Bakker and Edelman, 1964; Ashton and Giosan, 2011]. A balance between fluvial sediment supply, the shoreline, and the directional wave climate develops such that alongshore sediment bypassing affects the channel orientation, and can control updrift vs. downdrift flank growth [Nienhuis et al., 2015b]. One example is the undeflected St. George lobe of the Danube delta. Here, Giosan et al. [2005] show that an efficient bypassing mechanism exists where littoral sediment is initially trapped in front of the river mouth, but in time is transported downdrift when a barrier island emerges. 


\subsection{Models of river mouth morphodynamics}

Several numerical models of river mouth dynamics have been developed to estimate future river mouth geometries [Tanaka, 2003] or to explain the physics behind observed river mouth morphologies [Edmonds and Slingerland, 2007; Gelfenbaum et al., 2015]. Gelfenbaum et al. [2015] modeled the hydrodynamics and sediment transport of the Elwha river delta to match real-time measurements. In their study, they were able to simulate 2 months of morphologic change of the delta following the removal of a dam in the river watershed. Simpler, predictive models of river mouths can incorporate only a few processes [e.g. Tanaka, 2003] and allow the implementation of more realistic boundary conditions and longer timescales.

Here instead we choose an intermediate approach, similar to that of Edmonds and Slingerland [2007] and Nardin et al. [2013], where we use a detailed simulation model [Delft3DSWAN, see Deltares, 2014] to simulate idealized river mouth morphodynamics over interannual timescales. We model the morphologic development of river mouths under the influence of waves, where the river interacts with a sandy shoreline and a fully developed littoral current. A critical aspect of our simulations is that the river mouth morphology is an emergent characteristic of the underlying physics. Although the model complexity limits us to the use of only simple boundary conditions, it does allow a detailed exploration of the physics of river mouths. We then draw on our model experiments to parameterize a simple conceptual model of sediment bypassing and river mouth spit evolution that is subsequently tested against natural examples.

\section{Conceptual model of sediment bypassing}

To analyze our model experiments and to explore the effect of wave and fluvial dynamics on alongshore sediment bypassing and channel migration, we propose a conceptual model of river mouths in wave-dominated environments (Fig. 1). In this conceptual model, we quantify sediment bypassing as the fraction $\beta$ of the net alongshore sediment transport $\left(Q_{s}\right)$ that is transported downdrift past the river mouth [Nienhuis et al., 2015a].

If there is a net direction of alongshore sediment transport, for a river mouth to remain undeflected (Fig. 1a), 100\% of the littoral sediment must be able to bypass the river mouth $(\beta=1)$. If, on the other hand, a river mouth is deflected (Fig. 1b), $\beta$ is necessarily less than 1 because some sediment must build the spit deflecting the mouth. River mouth migration and 
river mouth spit formation are therefore closely coupled: river mouths migrate by building a river mouth spit, and the river mouth spit forms because the river mouth itself migrates alongshore.

When fluvial sediment supply is small relative to the alongshore sediment transport [Nienhuis et al., 2015c], the river is not able to reorient the shoreline (Fig. 1a, 1b). For small fluvial sediment supply, we can infer the alongshore sediment bypassing fraction $\beta$ from the migration rate of the river mouth, invoking the conservation of mass:

$$
v=\frac{Q_{s} \cdot(1-\beta)}{A_{b}},
$$

where $v$ is the migration rate $\left(\mathrm{ms}^{-1}\right), Q_{s}$ is the volumetric alongshore sediment transport rate $\left(\mathrm{m}^{3} \mathrm{~s}^{-}\right.$ ${ }^{1}$ ), $\beta$ is the fraction of alongshore sediment transport that is able to bypass the river mouth, and $A_{b}$ is the representative cross-sectional area of the river mouth spit $\left(\mathrm{m}^{2}\right)$ composed of blocked littoral sediment from the updrift coast.

The view of bypassing proposed here is Lagrangian: moving with the migrating river mouth. In this case, a breaching event would entail a large sudden increase in the volume of sediment bypassed only because the location of the river mouth has changed. We prefer the Lagrangian view on alongshore sediment bypassing over an Eulerian approach. The latter would measure the updrift sediment flux as a fraction of the total alongshore sediment flux at a fixed position alongshore. Updrift of the river mouth, all littoral sediment would originate from the updrift coast, yielding an Eulerian bypassing ratio of 1 . Immediately downdrift of the river mouth, only a fraction $\beta$ of the littoral flux would be sourced from the updrift coast, with the remaining fraction $1-\beta$ sourced from the eroded downdrift coast. However, measuring the Eulerian bypassing fraction and relating it to a particular morphology is very difficult for natural river mouths.

For deltaic systems where relative fluvial sediment supply is larger, a break in the shoreline orientation develops across the river mouth (Fig. 1c) [Grijm, 1960; Bakker and Edelman, 1964; Ashton and Giosan, 2011]. In this case, bypassing is expected to play an important role in controlling the channel orientation due to feedbacks between fluvial sediment supply, the bypassing fraction $\beta$, and the offshore wave climate. For example, Nienhuis et al. 
[2015b] prescribed delta mouth bypassing rate in a simplified model of shoreline evolution, and found that bypassing plays an important role in large-scale delta dynamics; however, as arbitrary values of $\beta$ were used, they did not explore the processes controlling alongshore sediment bypassing. Here we formulate and test a quantitative framework of river mouth bypassing that can be parameterized for large-scale delta simulations in wave-dominated environments. 

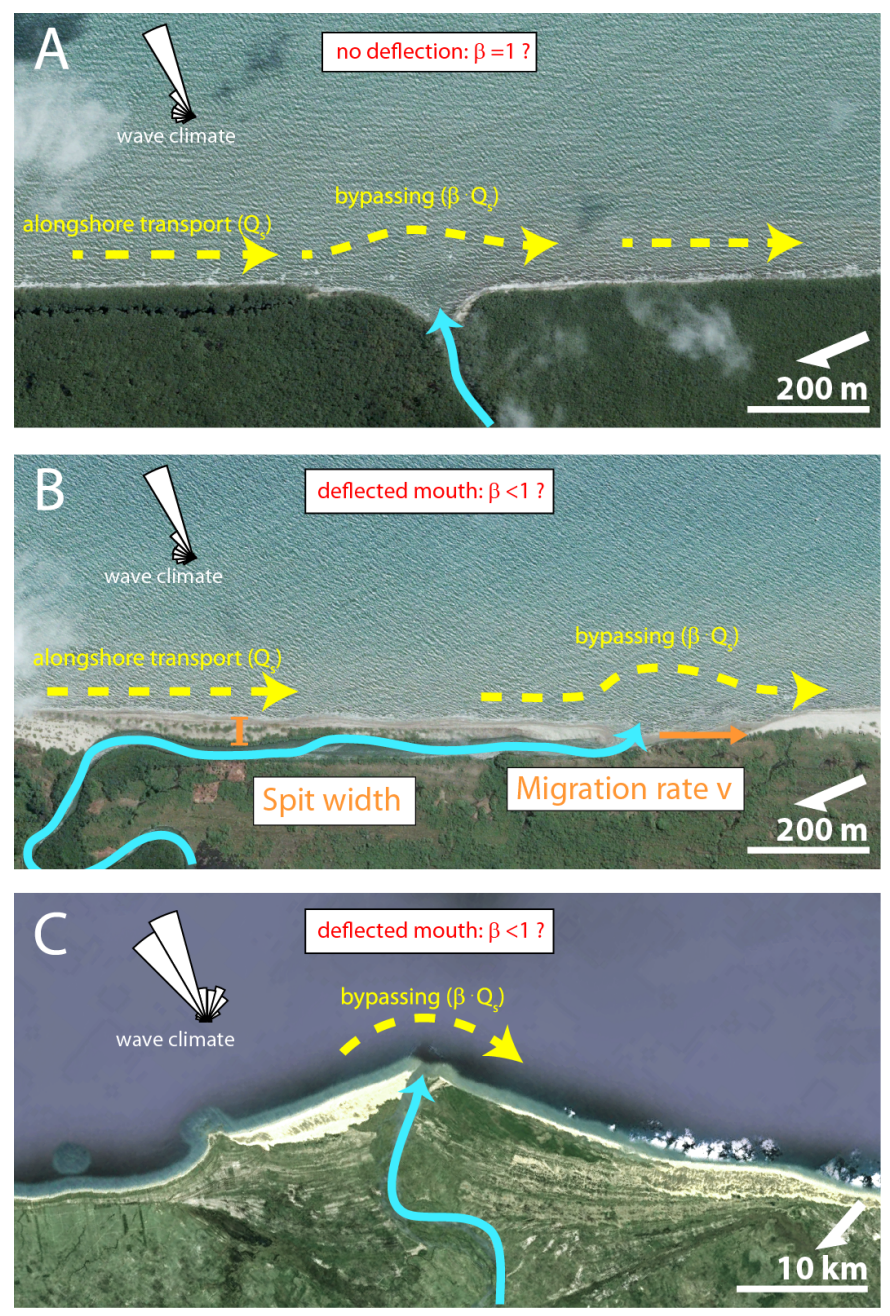

Figure 1. Examples of three wave-dominated river mouths. (A) An undeflected mouth of the Sikia Pakia Bila river and (B) a deflected mouth of the Dakura Tingni river, both along the coast of Nicaragua and experiencing a similar wave climate. (C) The wave-dominated Sao Francisco delta in Brazil, showing how fluvial sediment affects the shoreline orientation. In all panels, the blue arrows denote the channels. Yellow arrows show the inferred direction of alongshore sediment transport across the river mouth. The wave roses display the angular distribution of wave energy using data from WaveWatch III ${ }^{\circledR}$ [Chawla et al., 2011]. 


\section{Methods}

\subsection{Delft3D-SWAN}

To explore the morphodynamics of wave-dominated river mouths, we use the coupled hydrodynamic and morphodynamic model Delft3D-SWAN [Lesser et al., 2004]. Delft3D solves the shallow-water equations for unsteady, incompressible, and turbulent flow. We use Delft3D in 2 dimensions, solving the depth-averaged flow. The Delft3D flow model is embedded in the SWAN phase-averaged spectral wave model which solves the wave action equation to simulate wave propagation and dissipation as well as wave-wave and wave-current interactions [Booij et al., 1999]. The formulations of van Rijn [1993] are used to calculate suspended and bedload sediment transport due to the waves and currents. In this depth-average model, we set the waverelated suspended and bedload transport factors to 0.15 to model an appropriate balance of crossshore wave-driven suspended and bedload transport that stabilized the shoreface [Brocatus, 2008].

\subsection{Model setup}

We explore river mouth morphodynamics with an initially idealized shoreface and river mouth (Fig. 2). The Delft3D flow domain is $6 \mathrm{~km}$ alongshore and $5 \mathrm{~km}$ offshore, and includes a $750 \mathrm{~m}$ wide subaerial beach elevated $3 \mathrm{~m}$ above mean sea level to prevent overland flow. The grid resolution is $40 \mathrm{~m}$ in the along shore direction, and $25 \mathrm{~m}, 50 \mathrm{~m}$, and $100 \mathrm{~m}$ in the crossshore direction depending on the depth. We set grid resolution to ensure that the alongshore current is at least 7 grid cells wide. The entire flow domain is $150 \times 116$ cells, with an offshore water-level boundary condition and an alongshore Neumann boundary condition that allows the alongshore current and associated sediment transport to freely flow into and out of the domain [Deltares, 2014]. The channel is forced with a discharge boundary condition, with water that has equal density as the basin water. Fluvial sediment is supplied as a constant sediment concentration condition at the same boundary. The flow domain is embedded in a slightly larger "Small" SWAN wave domain that extends alongshore for $30 \mathrm{~km}$ within a "Large" SWAN wave domain that encompasses $186 \mathrm{~km}$ alongshore by $90 \mathrm{~km}$ offshore (Fig. 2b). A wave domain of this size allows for a fully developed alongshore current without boundary artifacts [List and Ashton, 2007]. 
The initial shoreface follows a Dean-type profile of $h(x)=a x^{2 / 3}$, where $h$ is the water depth (m) at a distance $\mathrm{x}(\mathrm{m})$ from shore and $a$ is 0.1 , the recommended value for $200 \mu \mathrm{m}$ sand [Dean, 1991]. We extend this shape offshore to $200 \mathrm{~m}$ depth in the wave domain (Fig 2c), an extension well beyond the shallow closure depths $(<10 \mathrm{~m})$ used to develop this shape; however, the deeper profile is nearly linear and does not affect model behavior, particularly as waves at the offshore boundary are well within deep water. The initial river mouth is straight and shore perpendicular, shallowing towards the beach to limit the river mouths offshore expression (Fig. 2a). We use simple hydraulic geometry relations [Parker, 1978] to initialize the river channel dimensions for the given discharge condition at the boundary to limit spin-up effects. The river banks are fully erodible.

The initial bed composition of the model domain consists of $200.01 \mu \mathrm{m}$ "updrift sediment", located updrift of the initial river mouth, and $200.00 \mu \mathrm{m}$ “downdrift sediment", located downdrift of the initial river mouth (Fig. 2a). Supplied fluvial sediment consists of $199.99 \mu \mathrm{m}$ sand. With this minimal but detectable grain size variation, and by tracking the bed composition using 25 vertical cells of $0.2 \mathrm{~m}$ each, sediment acts as a tracer. This allows us to track the movement of the updrift, downdrift, and fluvial sediment "fractions" as the delta mouth morphology evolves while making sure that each fraction has nearly equal sediment transport properties. Supplemental table S1 provides an overview of all the settings and parameters.

All model experiments have long period deep-water swell waves approaching $40^{\circ}$ from shore normal (Fig. 2), with a wave period of $10 \mathrm{~s}$, and with wave heights varied between $0.7 \mathrm{~m}$ and $1.5 \mathrm{~m}$, setting up alongshore sediment transport rates $\left(Q_{s}\right)$ between 7 and $70 \mathrm{kgs}^{-1}$. Water discharge is varied between $50 \mathrm{~m}^{3} \mathrm{~s}^{-1}$ and $2000 \mathrm{~m}^{3} \mathrm{~s}^{-1}$, fluvial sediment supply is varied between 0 $\mathrm{kgs}^{-1}$ and $50 \mathrm{kgs}^{-1}$. Even though almost all natural river mouths carry some fluvial sediment, we include model experiments without fluvial sediment supply to simplify the long-term mass balance of the littoral system. See supplemental table S2 for an overview of the model experiments.

We run the model with 1 day of hydrodynamic spin-up time, and then do a fully coupled hydrodynamic and morphodynamic simulation of 13 days. We use a morphologic scaling factor [Lesser et al., 2004] to speed up the morphodynamics, multiplying bed erosion and deposition 
with a linear factor of 90 . Tests with morphologic factors of 22.5 and 45 show that a factor of 90 does not significantly affect the morphodynamics. Because of the morphologic factor, our 13 day hydrodynamic simulations correspond to approximately 3.2 years of morphologic change.

However, we model river mouth dynamics with constant boundary conditions such that 3.2 years of full river flow and wave energy could correspond to many years in natural systems influenced by intermittent waves and river discharge.

\subsection{Model analyses}

We use the model setup as described above to investigate wave effects on river mouth morphology, bypassing, and migration. The river mouth dimensions, the river mouth jet, and the alongshore sediment transport are emergent properties of the simulation that co-develop with the morphology. To compute bypassing in the Lagrangian framework, we track the position of the channel through time, from the upstream boundary to the location of minimum depth along the channel. We then sum the volume of the updrift sediment fraction that is located downdrift of the river mouth, including the updrift fraction that has left the domain. This bypassed volume divided by the total alongshore sediment flux represents the cumulative alongshore sediment bypassing fraction $\beta$. Each model time step, we differentiate the cumulative fraction with respect to time to obtain the instantaneous bypassing fraction $\beta$. With a hydrodynamic time step of 0.2 minutes and a morphologic scaling factor of 90 , this instantaneous bypassing fraction is an average over 18 minutes. Note that while the cumulative bypassing fraction $\beta$ for downdrift migrating river mouths is always between 0 and 1, the instantaneous fraction can be much greater than one, for example when a spit breaches and the river mouth relocates upcoast. The instantaneous fraction can also be negative when the river mouth migrates into updrift sediment that was previously bypassed. 


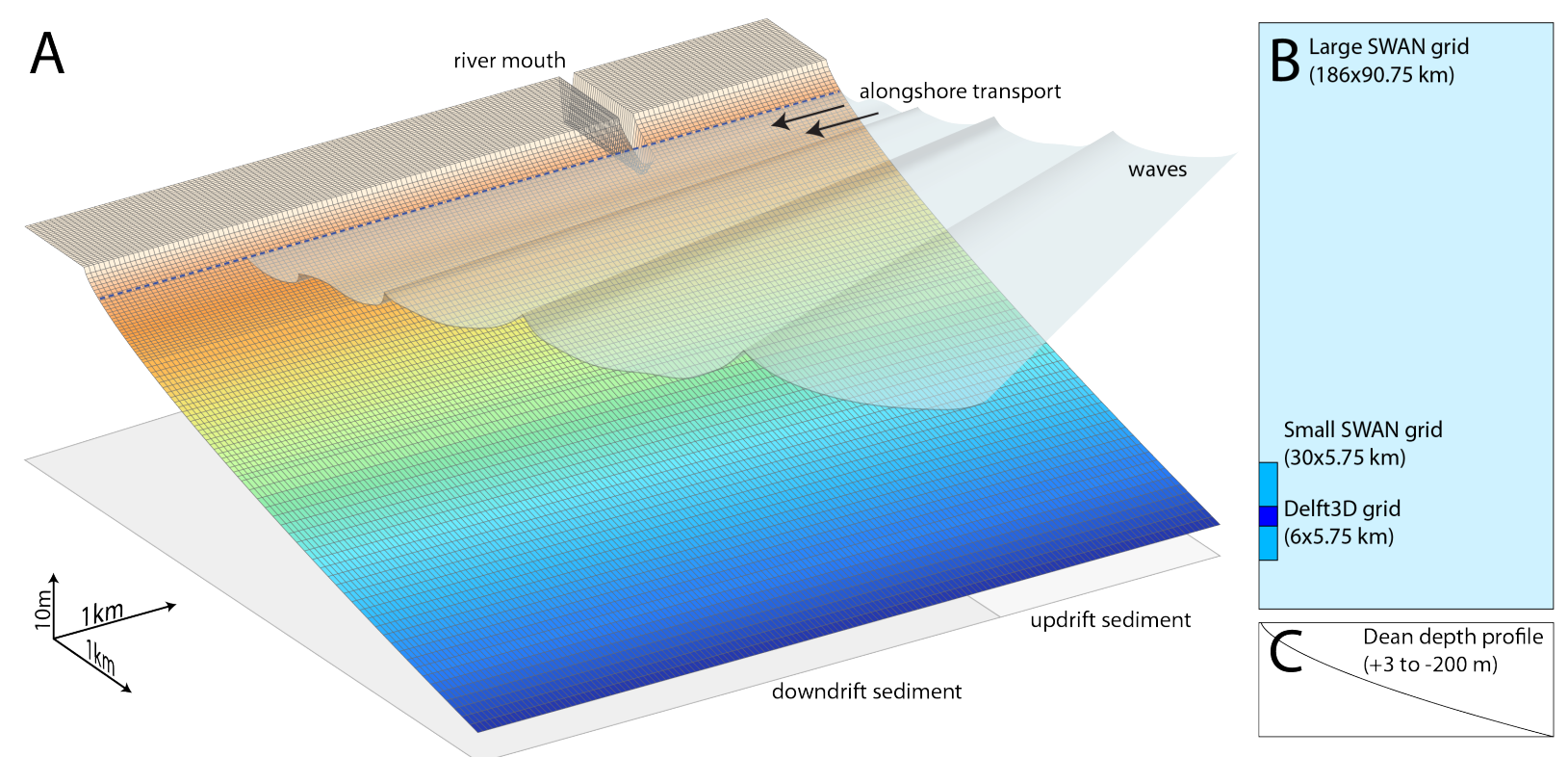

Figure 2. (A) The Delft3D flow domain and (B) the flow domain embedded into a two larger SWAN wave domains. The initial subaerial beach is $750 \mathrm{~m}$ wide and 3 meters above MSL. (C) Initial cross-shore profile.

\section{$5 \quad$ River mouth morphology}

We performed model experiments to explore river mouth morphodynamics and alongshore sediment bypassing. In each simulation, the river mouth quickly reaches a steadystate width and depth. The shoreface profile is stable (or quasi-stable) such that, updrift of the river mouth, cross-shore sediment transport is negligible and alongshore sediment transport remains nearly constant throughout the simulation. Both the equilibrium morphology and shoreface stability are essential in our study of river mouth morphodynamics, allowing us to investigate model behavior arising from emergent, developed morphodynamic feedbacks rather than transient changes developed from an initially out-of-equilibrium configuration.

Our results display a wide variety of river mouth morphologies depending on discharge and sediment supply (Fig 3). Broadly categorized, these morphologies include: undeflected (Fig. 3a), deflected (Fig. 3b), deflected with a river mouth oriented into the waves (Fig. 3c), and a prograding asymmetric delta (Fig 3d). For all simulations, by tracking the movement of updrift sediment, we can compute "updrift sediment" thickness and investigate its distribution across the river mouth (Fig. 3, middle panels). 
For the undeflected case (Fig. 3a), the river mouth bar is small and consists mostly of updrift sediment. As such, littoral sediment is transported very effectively along the shoreface by breaking waves, easily bypassing the river mouth.

For increasing discharge (Fig. 3b, 3c), the river mouth bar volume increases and is constituted of significant deposits of updrift sediment. The accumulated bypassing fraction is initially close to 1 , but lowers throughout the duration of the simulation, and dropping more rapidly for simulations with a higher discharge. Interestingly, the rate of river mouth migration is maximized for the intermediate discharge scenario while the alongshore sediment bypassing fraction continuously decreases for increasing discharge (Fig. 4). We find that the width of the river mouth spit increases for increasing discharge, lowering the migration rate even when bypassing is limited (eq. 1).

A wave-influenced delta develops in a scenario with high fluvial sediment supply (Fig. 3d), showing a difference in the shoreline orientation between the updrift and downdrift flank [Bhattacharya and Giosan, 2003; Ashton and Giosan, 2011], and a downdrift deflected channel [Nienhuis et al., 2015b]. Bypassing is on average high but intermittent because of an unstable channel that oscillates periodically from a downdrift to an updrift orientation (Fig. 3d, bottom panel). Apart from the oscillations, the river mouth migration rate is low compared to a river mouth without fluvial sediment supply. We attribute this difference in migration rate to the deposition of fluvial sediment downdrift of the river mouth. The growth of the downdrift delta flank leads to the initial low in alongshore sediment bypassing (compare Fig. 3b to Fig. 3d) and the subsequent formation of an updrift delta flank composed of updrift sediment. Eventually, as the downdrift flank prevents further downdrift migration of the channel, bypassing increases to be higher than the model experiment without fluvial sediment supply (Fig. 3b).

In general, the river mouth morphologies formed in the model arise from the interaction between fluvial discharge, the local wave field and the alongshore sediment flux (Fig. 5). Wavecurrent interactions and the presence of a river mouth bar steepen waves in the river mouth jet, and decrease the wave height updrift and downdrift of the river mouth (Fig. 5). The river mouth jet effect on wave height depends on the jet and wave momentum flux [Ismail and Wiegel, 1983]. 

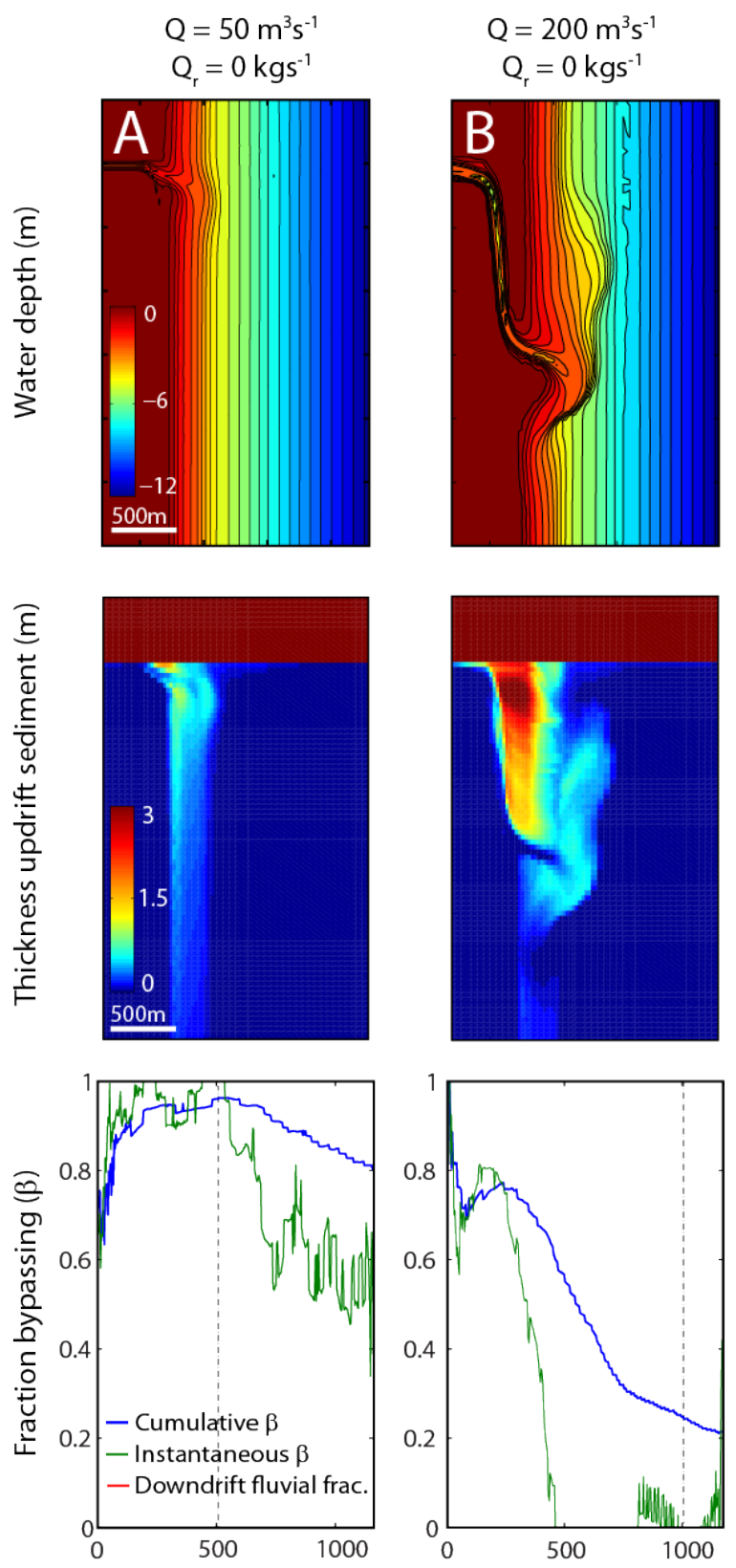
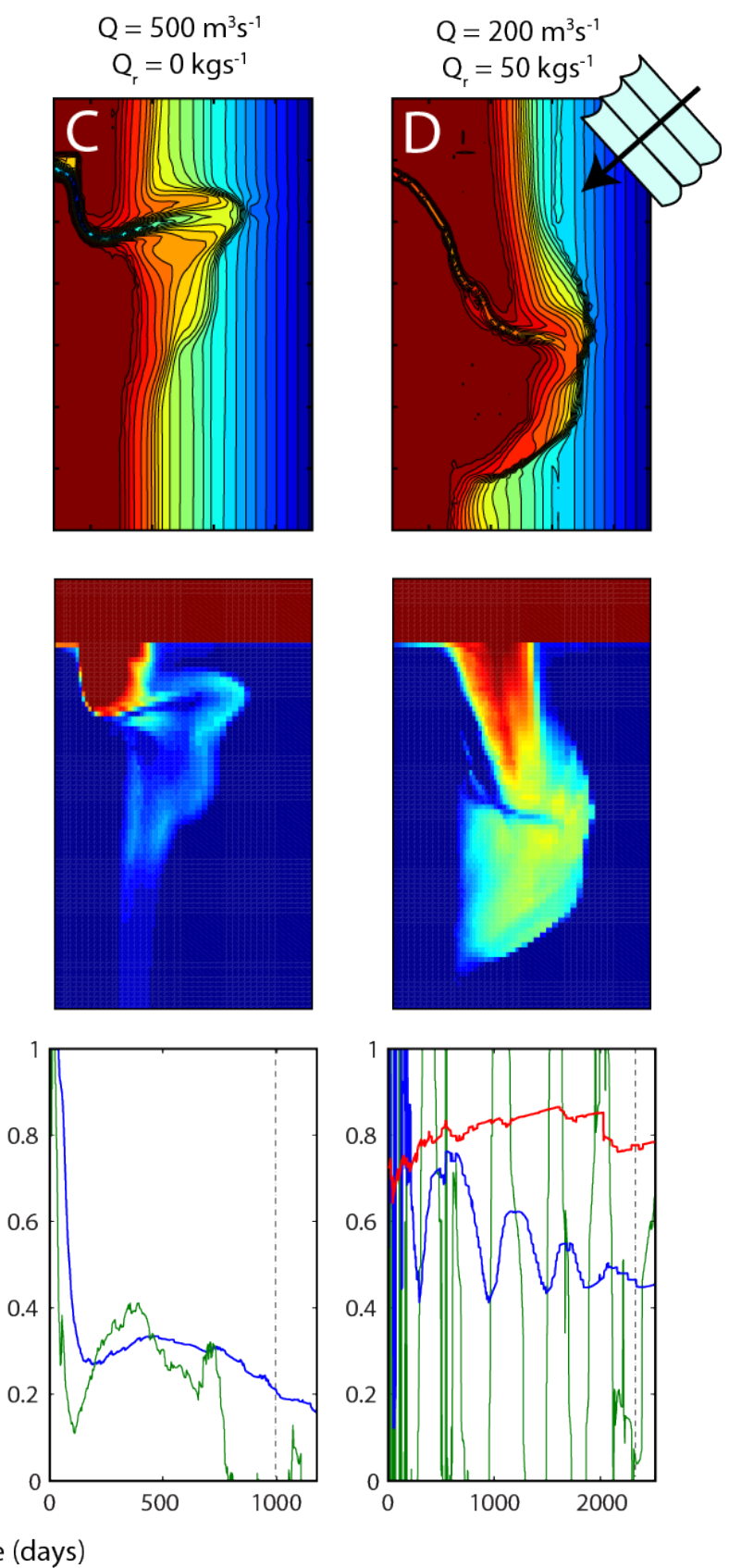

Figure 3. Examples of (top row) river mouth morphology and (middle row) updrift sediment deposits after (A) 500 days, (B, C) 1000 days, and (D) 2200 days of sediment transport. See supplemental videos S1 through S4 for the full morphologic simulation. (lower row). The cumulative (blue) and the instantaneous (green) bypassing fraction along with the downdrift fraction of the fluvial sediment flux (red) through time. Wave height is $1 \mathrm{~m}$, wave period is $10 \mathrm{~s}$, and waves approach at $-40^{\circ}$ from normal. 


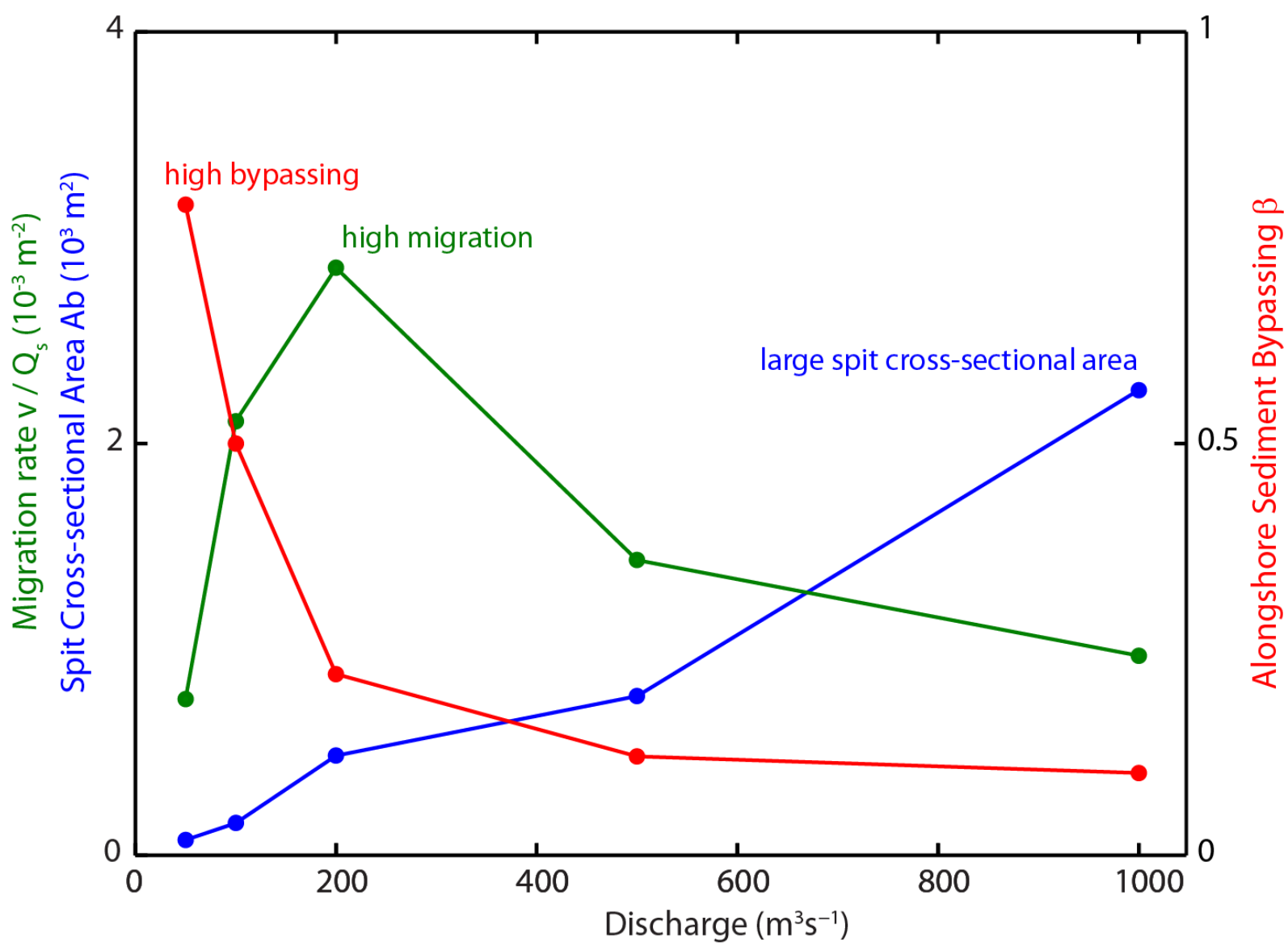

Figure 4. Average migration rate, spit cross-sectional area and alongshore sediment bypassing fraction for model runs with different discharge. The migration rate is normalized by $Q_{s}$.

\section{$6 \quad$ Alongshore Sediment Bypassing}

\subsection{Bypassing pathways}

Tracing the instantaneous pathways of updrift sediment, model experiments show three mechanisms of alongshore river mouth sediment bypassing (Fig. 5). One pathway, associated with low fluvial discharge and a weak river mouth jet that is highly deflected, arises when the channel depth is smaller than the breaking wave depth. In this case, the jet is easily deflected and it has little impact on the incoming waves that drive alongshore sediment transport. Most of the updrift sediment is bypassed around a small river mouth bar and there is minimal river mouth migration (Fig 3a, 5a). 
In the second scenario, with a stronger river mouth jet (Fig. 3b, 5b), alongshore sediment transport decreases close to the river mouth. A fraction $(\beta)$ of the updrift sediment is conveyed into the channel and continues its way downdrift. The blocked (1- $\beta)$ fraction of the updrift supply, however, is deposited at the river mouth spit, forcing the river mouth to migrate downdrift. Blocking occurs because the river mouth morphology and river mouth jet affect the incoming waves: waves refract into the river mouth bar and into the river mouth jet, creating a zone of relatively low wave heights and therefore low alongshore transport updrift of the river mouth (Fig. 5b). This favors updrift sediment deposition, driving spit formation and river mouth migration.

With even larger fluvial discharge (Fig. 3c, 5c), updrift sediment is sequestered via the channel in the river mouth bar at about $3 \mathrm{~m}$ water depth. In these simulations, the river mouth jet is unsteady, regularly changing its path around the river mouth bar. When the jet is directed updrift around the river mouth bar, continued sediment deposition tends to force the jet direction downdrift (and vice versa). The strong jet affects the incoming waves, limiting bypassing. Bypassing occurs via the channel through the formation and migration of river mouth bars (Fig. $3 c, 5 c)$. In this case, the river mouth bar consists of both sediment eroded by the channel from the downdrift bank of the river mouth and of updrift sediment transported along the spit and through the channel. As the river mouth migrates downdrift, part of the river mouth bar merges back onshore, updrift of the river mouth.

On the other hand, with a significant fluvial sediment flux, the river mouth is net progradational (Fig. 5d). Bypassing occurs via the channel, and the river mouth jet is strongly deflected to set up a regime where wave height does not vary alongshore (similar to Fig. 5a). There is no zone of low wave heights updrift of the river mouth that would point to sediment deposition. 

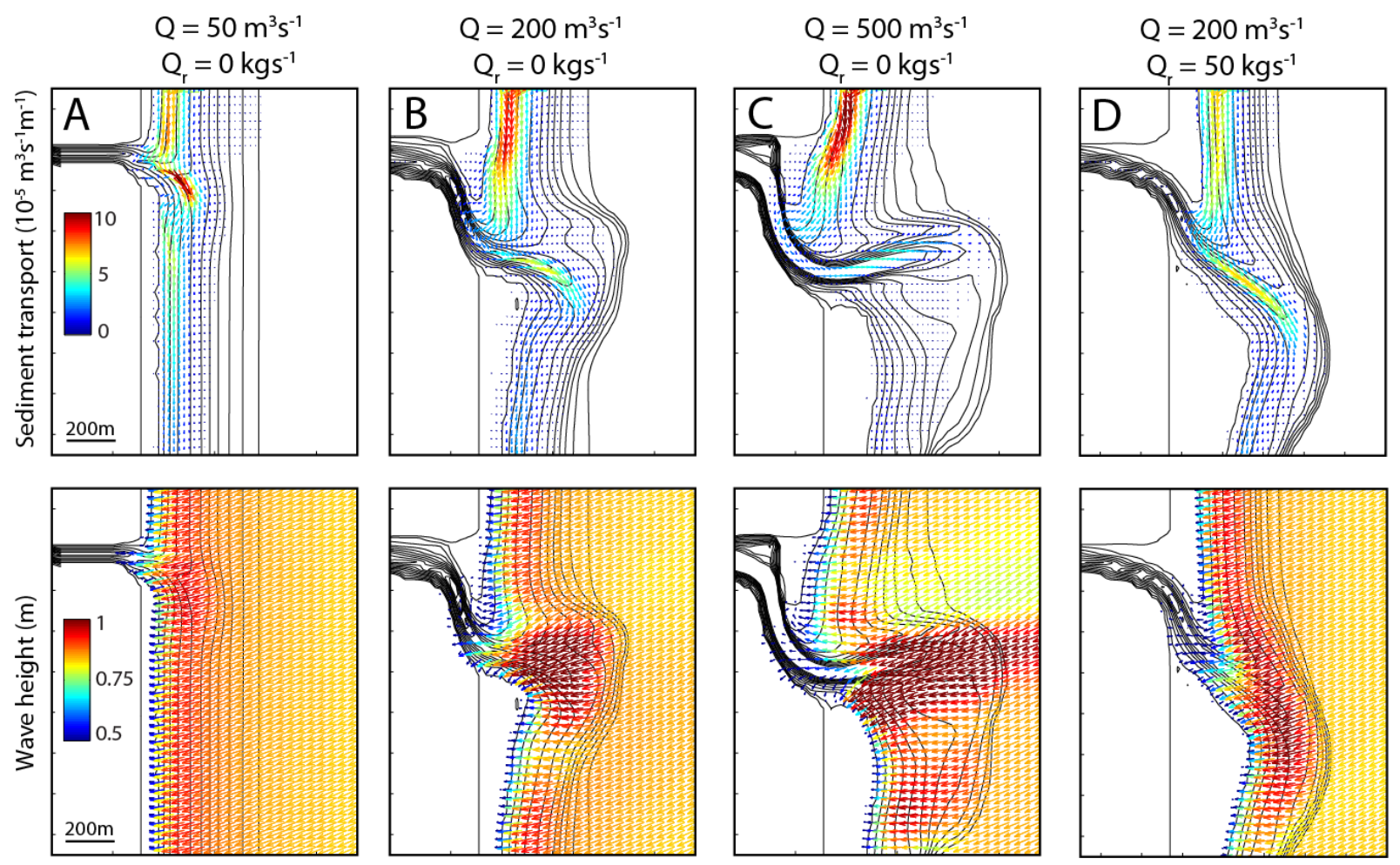

Figure 5. Sediment transport fluxes and wave height for the four cases also shown in figure 3. (top panels) Sediment transport direction and magnitude only of the updrift sediment. Black lines show the bathymetry contours up to $5 \mathrm{~m}$ of water depth. (bottom panels) Significant wave height and direction showing how the wave field interacts with the river mouth morphology and the river jet. Experiment snapshots are taken after (A) 190, (B) 550, (C) 790 and (D) 680 model days.

\subsection{Wave and river mouth jet controls on bypassing}

To expand on the descriptive findings above, we sought a non-dimensional parameter that would best predict alongshore sediment transport bypassing for river mouths. We ran model experiments with fluvial water discharge ranging from $50 \mathrm{~m}^{3} \mathrm{~s}^{-1}$ to $1000 \mathrm{~m}^{3} \mathrm{~s}^{-1}$ and wave heights ranging from $0.7 \mathrm{~m}$ to $1.5 \mathrm{~m}$. See supplementary table 2 for an overview of the model experiments. As shown in section 6.1, the pathways of alongshore sediment bypassing are highly influenced by interactions between the jet and the waves, and in particular the jet deflection by the waves. To characterize jet deflection, we look to the ratio of the jet momentum flux vs. the alongshore component of the wave momentum flux, 


$$
\frac{M_{J}}{M_{W}}=\frac{\rho_{w} \cdot Q \cdot u}{S_{x y}}=\frac{\rho_{w} \cdot Q \cdot u}{E \cdot n(\cos \theta \cdot \sin \theta) \cdot W},
$$

where $M_{J}$ is the momentum flux of the river mouth $\left(\mathrm{kg} \mathrm{m} \mathrm{s}^{-2}\right), \mathrm{M}_{W}$ is the wave momentum flux $\left(\mathrm{kg} \mathrm{m} \mathrm{s}^{-2}\right), \rho_{w}$ is the water density $\left(\mathrm{kg} \mathrm{m}^{3}\right), Q$ is the river discharge $\left(\mathrm{m}^{3} \mathrm{~s}^{-1}\right), u$ is the depth- and width-averaged river velocity $\left(\mathrm{m} \mathrm{s}^{-1}\right), S_{x y}$ is the alongshore directed component of the radiation stress $\left(\mathrm{N} \mathrm{m}^{-1}\right), W$ is the width of the river mouth $(\mathrm{m}), E$ is the wave energy density $\left(\mathrm{N} \mathrm{m}^{-1}\right)$ which equals $\frac{1}{16} \cdot \rho_{w} \cdot g \cdot H_{s}{ }^{2}$ [Dean and Dalrymple, 1991], $g$ is the vertical acceleration due to gravity $\left(\mathrm{m} \mathrm{s}^{-2}\right), \mathrm{H}_{s}$ is the significant wave height $(\mathrm{m}), n$ is the ratio of the group velocity, and the phase velocity of the incoming (deep-water) waves, and $\theta$ is the incoming wave angle.

To avoid complications arising from shoreline reorientation, we investigate experiments without fluvial sediment supply to determine whether this balance (eq. 2) can characterize jet deflection. Model results suggest that when the momentum flux balance exceeds approximately 0.5 (i.e. for relatively stronger fluvial momentum flux), the river mouth shifts from a stable deflected jet to a morphologically unstable jet (Fig. 6a). Note that the jet is not hydrodynamically unstable [as in Canestrelli et al., 2014], but morphologically unstable. The unstable river mouth jet switches its orientation between deflected away from the waves (positive angle) and into the waves (negative angle, Fig. 6a) because of the formation and migration of the river mouth bar (Fig. 3c).

\subsection{Fluvial sediment supply controls on bypassing}

As shown in section 6.1, fluvial sediment supply significantly affects alongshore sediment bypassing. To quantify this phenomenon, we ran 45 experiments with discharge varying between $50 \mathrm{~m}^{3} \mathrm{~s}^{-1}$ and $1000 \mathrm{~m}^{3} \mathrm{~s}^{-1}$ and fluvial sand supply ranging from $0 \mathrm{kgs}^{-1}$ to 100 $\mathrm{kgs}^{-1}$. For river mouths along a straight coastline, the capacity for alongshore sediment transport far updrift and far downdrift of the river mouth are approximately equal. By supplying fluvial sediment to the downdrift coastline, littoral sediment from updrift can no longer be transported there and will therefore not be bypassed. We conjecture that supplying the river mouth with an equal contribution of fluvial and littoral sediment, thereby doubling the littoral sediment budget, has a similar effect on the bypassing fraction as increasing the wave momentum flux $\left(M_{w}\right)$ by a factor of 2, which also doubles the littoral sediment flux. To account for fluvial sediment supply, we include in the momentum flux balance (eq. 2) a non-dimensional sediment flux balance 
$Q_{s} /\left(Q_{r}+Q_{s}\right)$, where $Q_{s}$ is the alongshore sediment transport flux $\left(\mathrm{m}^{3} \mathrm{~s}^{-1}\right)$ and $Q_{r}$ is the fluvial sediment flux $\left(\mathrm{m}^{3} \mathrm{~s}^{-1}\right)$. Combined, we formulate the non-dimensional river mouth balance $J$,

$$
J=\frac{M_{J}}{M_{W}} \cdot \frac{Q_{s}}{Q_{s}+Q_{r}}
$$

We find that the river mouth balance $J$ is able to explain the observed variability in longterm (cumulative) alongshore sediment bypassing fraction $\beta$. When the wave momentum flux exceeds the jet momentum flux, the river mouth is wave-dominated $(\mathrm{J}<1)$ and bypassing is high $(\beta>0.5)$. When, on the other hand, the jet momentum flux is high, the river mouth is jetdominated $(\mathrm{J}>1)$ and alongshore sediment is not able to bypass the river mouth (Fig. $6 \mathrm{~b}$ ) Interestingly, alongshore sediment bypassing appears bimodal, with the majority of model experiments tending towards either uninterrupted bypassing of littoral sediment $(\beta \rightarrow 1)$ or complete blocking $(\beta \rightarrow 0)$. 

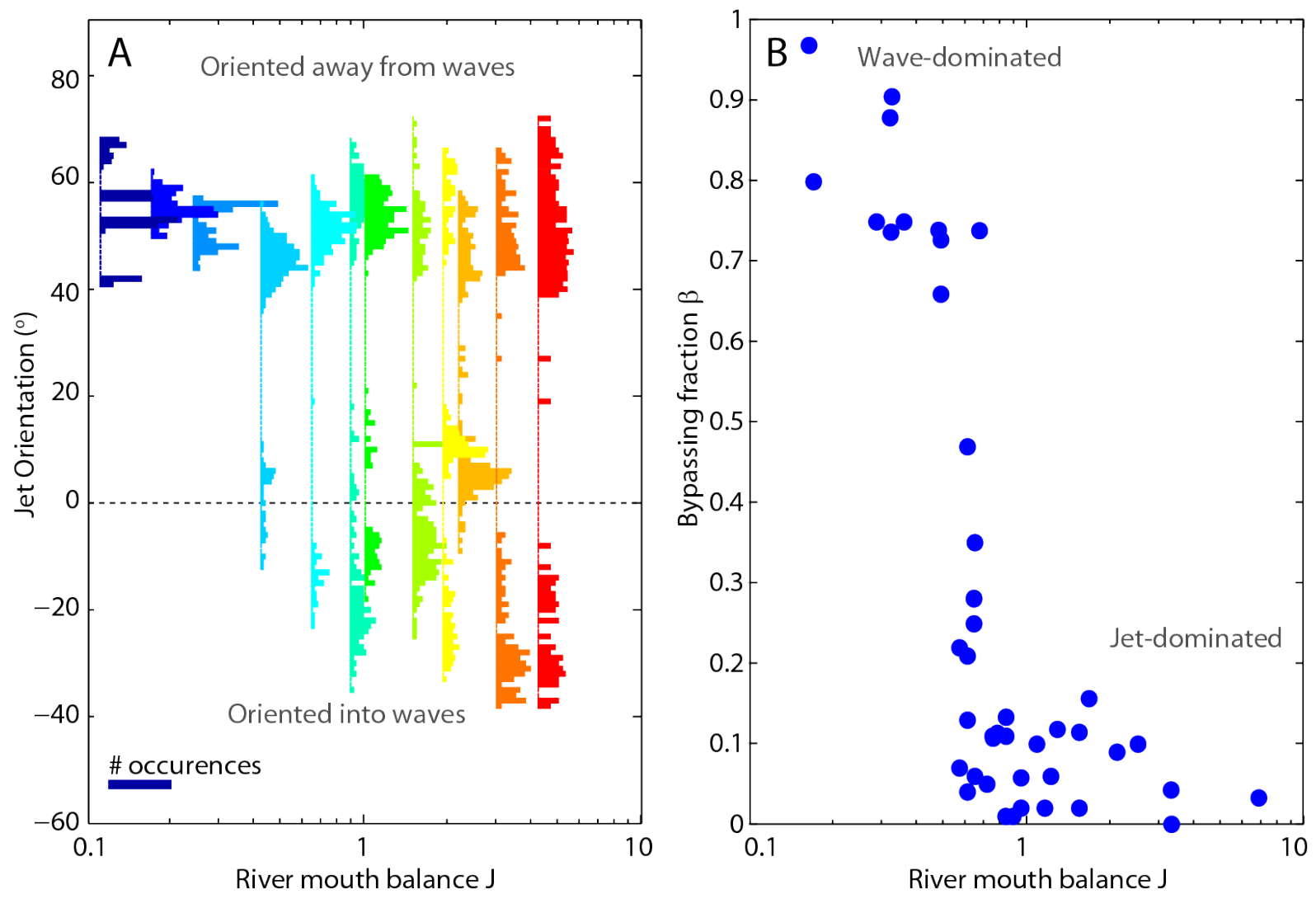

Figure 6. (A) Histograms of jet orientation for 12 model experiments with different momentum flux balances. Colors are used to visually distinguish the model experiments. $+90^{\circ}$ is shoreparallel away from the waves, $0^{\circ}$ is shore-normal, and $-90^{\circ}$ is shore-parallel into the wave approach direction. (B) Average alongshore sediment bypassing fraction $\beta$ for different river mouth balance ratios $\mathrm{J}$.

\section{$7 \quad$ River mouth migration}

\subsection{Dimensions of the river mouth spit}

Using our understanding of river mouth bypassing from our model experiments, we can estimate the alongshore migration rate of both simulated and natural river mouths. If bypassing is limited, the rate of river mouth migration should be controlled by the volume of blocked updrift sediment divided by the representative cross-sectional area of the river mouth spit (eq. 1). Thus, in order to successfully predict the river mouth migration rates, or to use observed migration rates to estimate bypassing for natural systems, we need to know the size of the river mouth spit $\left(A_{b}\right)$. 
Surprisingly, for the model experiments, calculating river mouth migration using the river mouth depth and spit width to calculate $A_{b}$ in equation (1) leads to a large underprediction of the migration rate when we use the computed bypassing fraction and the observed river mouth spit depth (Fig. 7c) and width (Fig. 7b). However, after investigating the origin of the deposited sediment with our tracking technique, we find that the river mouth spit is not solely composed of updrift sediment (Fig. 7c). Rather, a significant fraction of the deposited river mouth spit is composed of eroded sediment from the downdrift beach (Fig. 7). As the downdrift sediment is eroded and transported onto the river mouth bar, subsequent migration of the river mouth downdrift of the bar leads to onshore sediment movement and incorporation of the downdrift sediment into the river mouth spit (Fig. 7c). Using the model experiments for different fluvial discharges and different offshore wave heights, we find that approximately $1 / 2$ of the depth of the river mouth spit is composed of updrift sediment (Fig. 8a).

Additionally, our model experiments indicate that the channel width $\left(\mathrm{W}_{c}\right)$ is a good predictor of the width of the river mouth spit ( $\mathrm{W}_{b}$, Fig. $\left.7 \mathrm{~b}\right)$. Across two orders of magnitude in channel size, river mouth spit width is about $1 \frac{1}{2}$ times the channel width. We note here that the process of river mouth spit formation could be analogous to the processes that control the curvature in meandering rivers. As a migrating river mouth bends approximately $90^{\circ}$ to become perpendicular to the shoreface (e.g. Fig. 3c), the width of the river mouth spit plus half of the channel width is equal to its meander curvature. The observed scaling between river mouth spit width and channel width of $1 \frac{1}{2}$ (Fig. $8 \mathrm{~b}$ ) therefore corresponds to a ratio of meander curvature to channel width of 2, commonly found in river meanders [Leopold and Wolman, 1960] and associated with a maximum in meander bend migration rates [Hickin and Nanson, 1984]. 


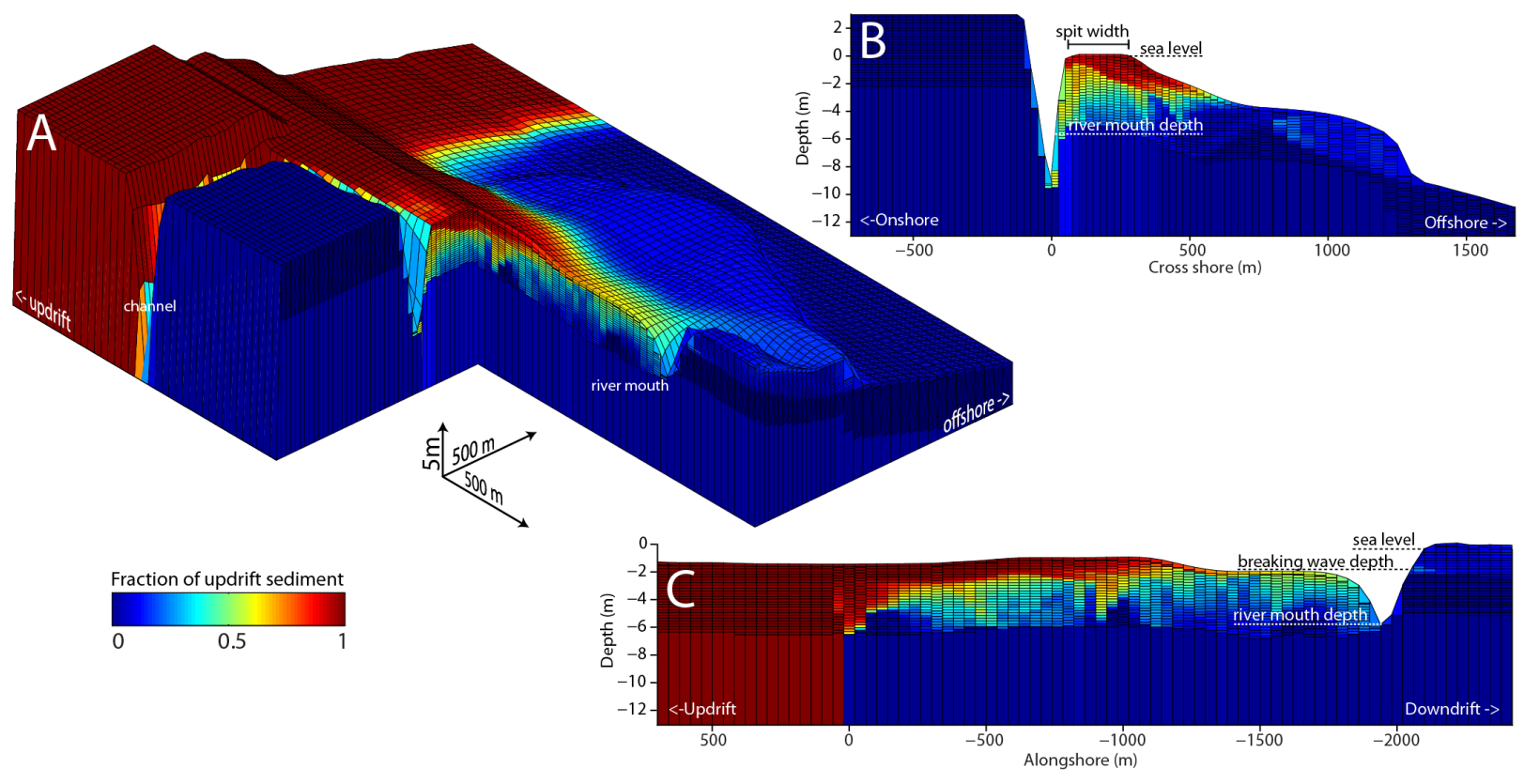

Figure 7.Morphology and depth slices of the river mouth spit colored by the fraction of updrift sediment. (A) View looking offshore and updrift, (B) cross-section of the river mouth spit, (C) long-section of the river mouth spit. Note that the lighter shaded blue bars extending below the channel depth arise from limited vertical resolution of the bed composition tracking at depth. 

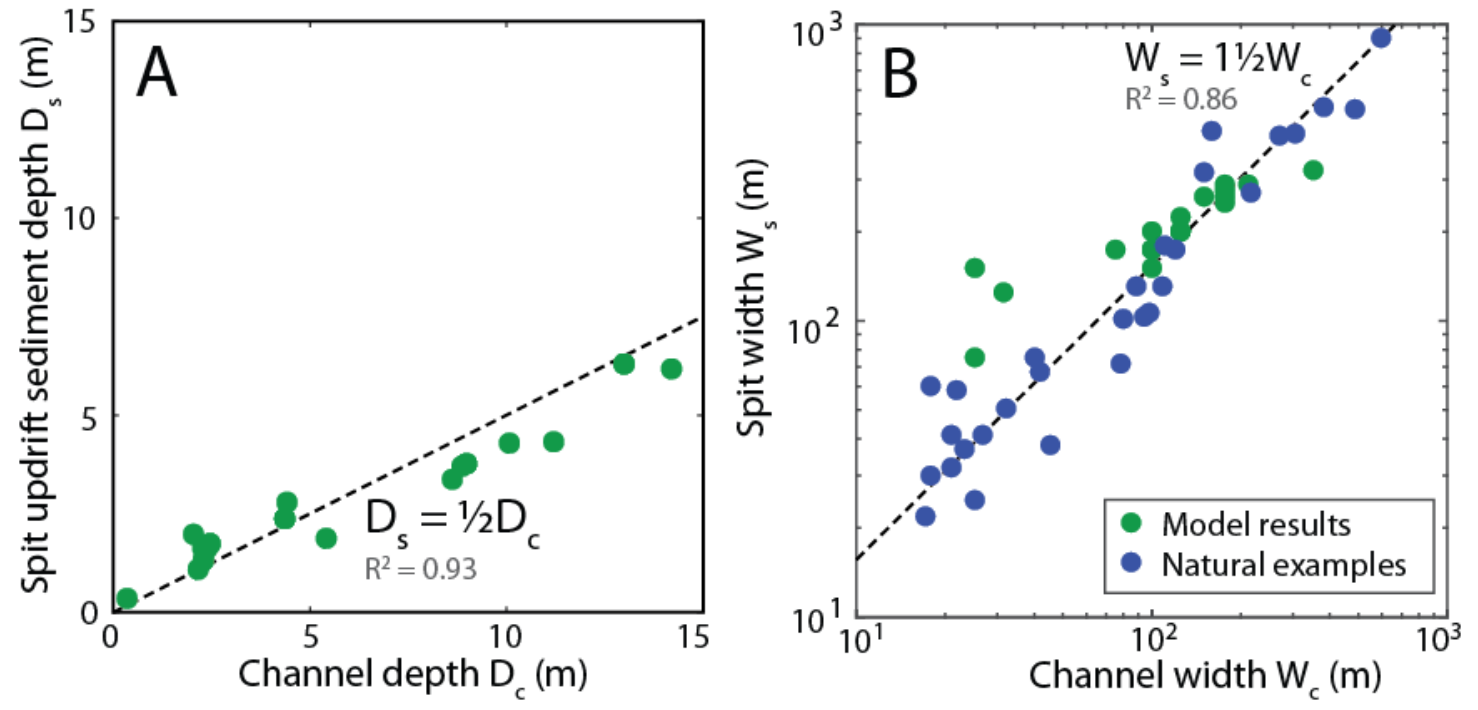

Figure 8. (A) Average thickness, $D_{s}$, of modeled updrift sediment in the river mouth spit for different channel depths $D_{c}$. (B) Average spit width, $W_{s}$, for different channel widths, $W_{c}$, for both model results (black) and natural examples (red). Dashed line indicate an approximate fit to model results and natural examples. See supplemental table S3 for a list of the natural examples.

\subsection{Predictive model of river mouth migration}

The combination of alongshore bypassing fractions $(\beta)$, spit depth $\left(D_{s}\right)$, and spit width $\left(W_{s}\right)$ allow us to develop a predictive model of river mouth migration, building on the mass balance proposed earlier (eq. 1). We estimate the cumulative alongshore sediment bypassing fraction $\beta$ as a function of the river mouth balance $J$ (eq. 3) by fitting a smooth sigmoid shape $\beta(J)$ to the bypassing data,

$$
\beta(J)=\frac{1}{1+a \cdot J^{b}}
$$

with fitted parameters $a=10$ and $b=3$. This functional form ensures that $\beta(J)$ is smooth and that bypassing in the wave-dominated limit $(J \rightarrow 0)$ approaches 1 , and bypassing for jetdominated river mouths $(J \rightarrow \infty)$ tends towards 0 .

Secondly, the representative spit cross-sectional area $A_{b}\left(\mathrm{~m}^{2}\right)$ is the product of spit width $W_{s}(\mathrm{~m})$ and the spit updrift sediment depth $D_{s}(\mathrm{~m})$. Following the dependence of spit width to channel width and spit updrift sediment thickness to channel depth established earlier (Fig. 8), we can formulate a predictive model for the river mouth migration rate $v$, as: 


$$
v=\frac{Q_{s} \cdot[1-\beta]}{A_{b}}=\frac{Q_{s} \cdot[1-\beta(J)]}{\frac{3}{2} W_{c} \cdot \frac{1}{2} D_{c}},
$$

that allows us to estimate the migration rate for a given river mouth depending on the river mouth balance $J$. Reorganized, this also allows us to estimate the bypassing fraction $\beta$ using the observed migration rate of a particular river mouth:

$$
\beta=1-\left(\frac{v \cdot \frac{3}{2} W_{c} \cdot \frac{1}{2} D_{c}}{Q_{s}}\right),
$$

\section{$8 \quad$ Application to natural examples}

One advantage of the simple boundary conditions and idealized domain used in our model runs is the ability to generalize the model findings and to apply them to wide range of natural systems. We analyzed 15 natural river mouths distributed across the world (i.e., in Georgia, Nicaragua, Honduras, Brazil, Senegal) to investigate their bypassing fractions and alongshore migration rates, limiting our analysis to cases without significant fluvial sediment supply and without significant tidal range. Migration rates for these river mouths were calculated using satellite imagery from Google Earth or NASA Landsat, tracking the river mouth location across multiple images spanning several years. For all river mouths except the Senegal River, we estimated discharge and channel depth based on hydraulic geometry [Andren, 1994] using the average channel width upstream of the river mouth. In all cases, alongshore sediment transport was estimated with the CERC formula assuming shore-parallel depth contours [Komar, 1971; Nienhuis et al., 2015c], and directional wave data from WaveWatch III [Chawla et al., 2011]. See supplementary table S3 for an overview of the natural examples.

The observed migration rates of the natural river mouths constrain the fraction of alongshore sediment transport that is able to bypass the river mouth. Given the approximations in the analysis, we observe a surprisingly good fit between inferred bypassing fraction (eq. 6) and the river mouth balance $J$ (Fig. 9a). Next, we use the bypassing function $\beta(J)$ (eq. 4) with the calculated river mouth balance $J$ to predict a migration rate for the model results (Fig. 9b, green markers) and the natural examples (Fig. 9b, blue markers). Note that the deviations of the model results away from the 1-1 agreement are due to the approximations in the bypassing function (eq. 4) and the representative river mouth spit cross-sectional area, $A_{b}$. Again, the natural examples 
show a surprisingly good fit in sign (migration with the alongshore transport direction), in magnitude, and in trend (Fig. 9b).
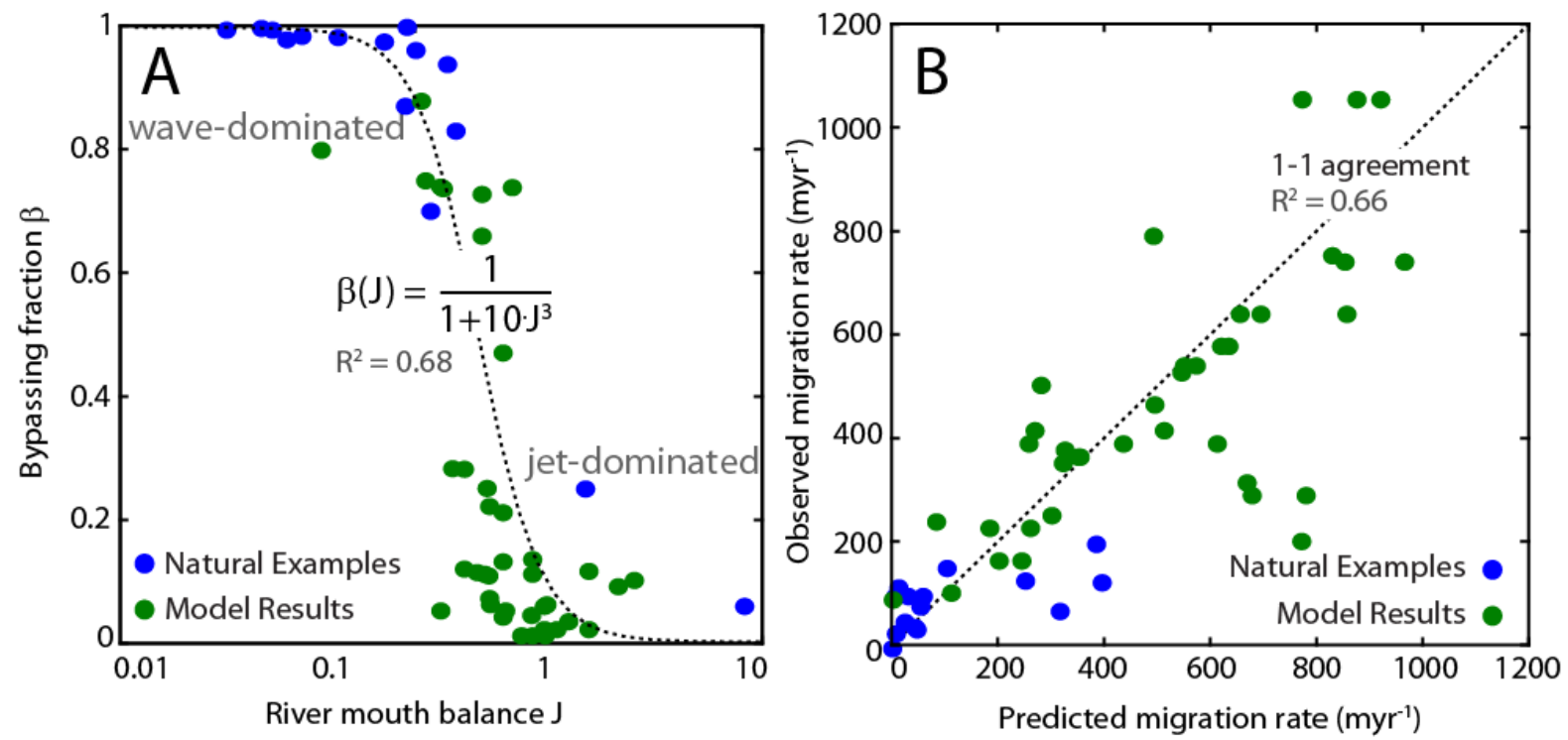

Figure 9. (A) Alongshore sediment bypassing for model results and natural examples. The dotted line shows the fit of a simple logistic function (eq. 4). (B) Predicted vs. observed migration rates for our model results and natural examples. Dotted line shows 1-1 agreement.

\section{$9 \quad$ River mouth spit breaching}

The alongshore migration of a river mouth is often stopped by a breach in the spit, typically thought to be initiated by either increased water level setup in the channel due to floods, or from the coast due to storms or tides [Cooper, 1990]. Investigating a model experiment over 14 morphological years, we find that, even under constant forcing conditions, the modeled system can undergo repeated cycles of river mouth spit elongation interrupted by distinct breaching events (Fig. 10a). In this model experiment (Table S2 \#46), breaches are initiated when the river mouth has migrated approximately $2500 \mathrm{~m}$ from the original river location, when the upstream water level reaches a critical threshold of approximately $30 \mathrm{~cm}$ (Fig. 10b). After about 5 years of morphological spin-up, breaches occur at a regular time interval and at a regular channel length (Fig. 10a). As the river mouth migrates and the channel maintains a constant water surface slope, the elevation of the water surface at the upstream boundary is directly 
related to the channel length. Therefore when the channel length reaches a critical length (corresponding to an elevated water level of $30 \mathrm{~cm}$ ) a breach is initiated.

We can use eq. (1) to evaluate the controls on river mouth spit breaching timescales. Here, $T_{\text {breach }}=L_{\text {breach }} / v$, where $T_{\text {breach }}$ is the breaching timescale (s), $L_{\text {breach }}$ is the breaching length scale $(\mathrm{m})$ and $v$ is the alongshore migration rate of the river mouth $\left(\mathrm{ms}^{-1}\right)$. Investigating bypassing through time, we find that each breaching event is associated with a peak in the instantaneous alongshore sediment bypassing fraction $\beta$ (Fig. 10c). Therefore, in order to successfully relate the breaching length scale to a breaching timescale, the key bypassing fraction is the cumulative bypassing fraction during the migration phase of the river mouth just before a breach occurs $(\beta \approx 0.7$, Fig. $10 \mathrm{c})$.

Combining the bypassing estimate with the breaching length scale to obtain the breaching time scale, we arrive at

$$
T_{\text {breach }}=\frac{L_{\text {breach }}}{v}=\frac{L_{\text {breach }} \cdot A_{b}}{Q_{s}(1-\beta)},
$$

which for $L_{\text {breach }}=2500 \mathrm{~m}, \beta=0.7, Q_{s}=0.012 \mathrm{~m}^{3} \mathrm{~s}^{-1}$, and $A_{b}=250 \mathrm{~m}^{2}$ (Table S2, \#46) leads to a breaching interval of 2.4 years, closely matching the modeled channel dynamics. This breaching experiment (Fig. 10) also indicates that migration does not continue perpetually, and that without the river mouth progradation associated with fluvial sediment supply, bypassing averaged over long timescales will always tend to 1 . However, it is the bypassing fraction on breaching timescales that controls the river mouth migration rate. 

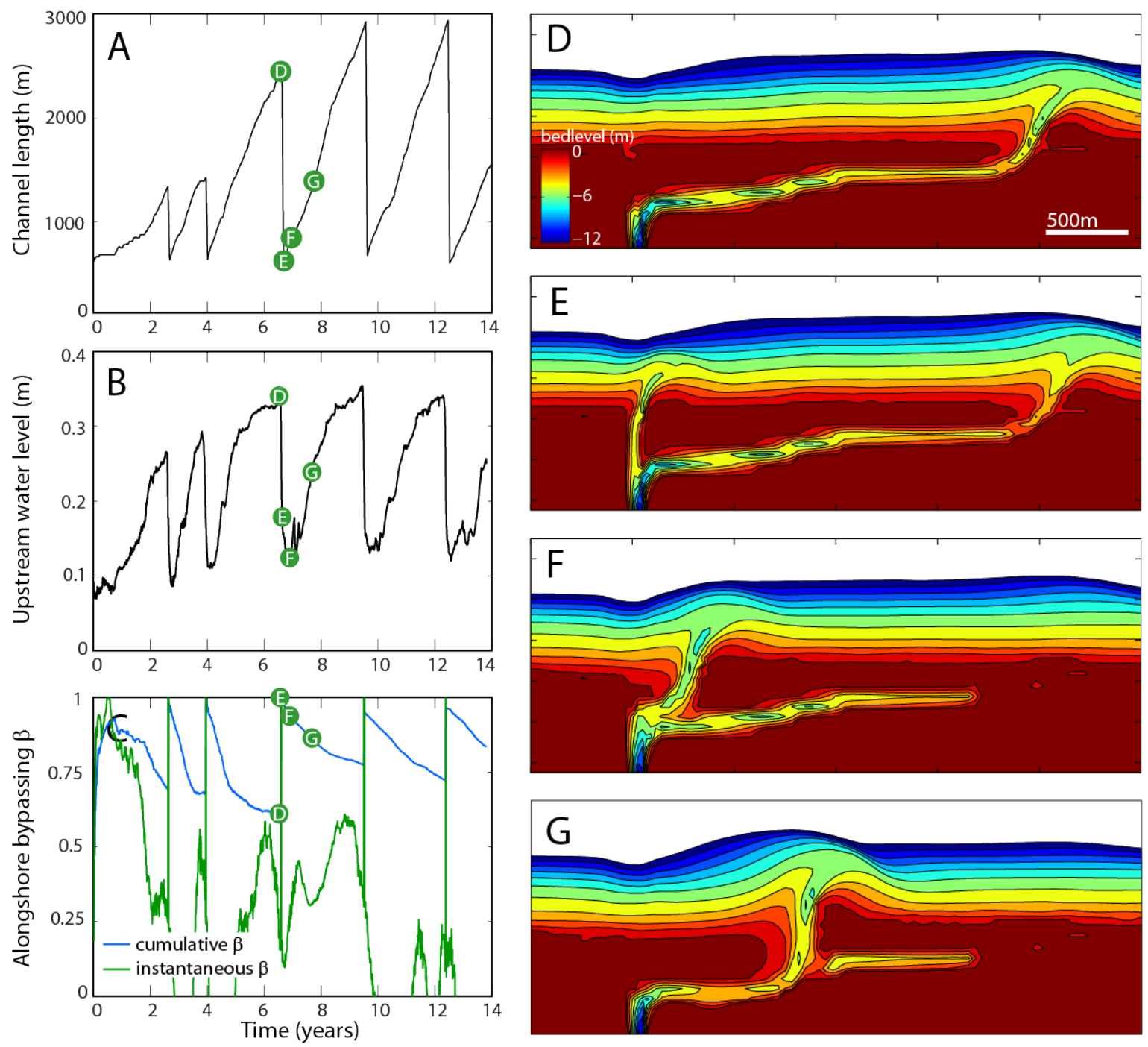

Figure 10. Example of a river mouth spit breach. (A) The channel length, (B) water level and (C) alongshore sediment bypassing over the course of 14 model years. Green markers show the times of the 4 model snapshots in panels D-G. (D-G) River mouth morphology. Colors indicate bed level relative to mean sea level (m). 


\section{Discussion}

\subsection{Alongshore migration rate}

In this study we have formulated a predictive relationship for the alongshore migration rate of river mouth spits. Migration is controlled by the volume of alongshore sediment transport that is not bypassed and by the cross-sectional area of the river mouth spit, and generally ranges between zero and several hundred meters per simulation year. Obliquely approaching waves that deflect the river mouth jet control the pathways and rates of alongshore sediment bypassing (Fig. 5). We estimate jet deflection, and therefore alongshore sediment bypassing, with the ratio of the jet momentum flux vs the alongshore directed component of the wave momentum flux (Fig. 6).

Investigating model experiments and natural examples, we found that the cross-sectional area of the spit increases with increasing channel size (Fig. 8). Because the fraction of alongshore sediment transport that is blocked also increases for increasing channel size, the combined effect is that the river mouth migration rate is maximized for intermediate sized river mouths (Fig. 4).

\subsection{Short-term and long-term fluctuations}

The model experiments shown here with constant boundary conditions are a significant simplification from the complicated marine and fluvial forcings that affect river mouths. River mouths change seasonally, and are influenced by extreme events, such as storms or floods [e.g., Cooper, 1990; Hart, 2007]. However, the results reported here hint that the dynamics of channel bypassing, migration, and breaching can be sustained even with constant forcing, i.e. in the absence of punctuated events of high intensity. Even though storms and floods most likely dictate the short-term dynamics of small river mouth systems, it is worthwhile to realize that extreme events are not necessary ingredients to gain process understanding of long-term river mouth morphodynamics.

The effect of fluvial and wave climate fluctuations on river mouth dynamics can be assessed by their formative timescales. For fluvial geomorphology, the formative timescale is typically the bank-full, 11/2-year flood [Wolman and Miller, 1960]. The analysis of Kirk [1991] showed that some river mouth spits breach at these timescales. Kraus et al. [2002] found that storm-induced breach timescales correlate with the 10-year storm surge height relative to the tidal range, a proxy for the subaerial elevation of the river mouth spit. Alongshore sediment 
transport, the main mechanism for bypassing and migration, acts on much shorter timescales [Hicks and Inman, 1987], leading to river mouth migration (low bypassing) or closure (high bypassing) to be associated with average day-to-day conditions [Hicks and Inman, 1987; Kirk, 1991]. However, while the formative timescale for alongshore sediment transport is short, the direction of alongshore sediment transport can be strongly seasonal. The multi-annual migration rate and direction of river mouths therefore can potentially be dependent not just on the annual average bypassing conditions but on the degree of temporal overlap of the directional wave climate with the average fluvial discharge.

Fluvial floods deliver coarse sediment and often lead to the formation of ephemeral mouth bars in wave-dominated environments. These mouth bars can decrease alongshore sediment transport on short timescales, but, on seasonal timescales, can feed the littoral system or be transported offshore [Warrick and Barnard, 2012]. Fluvial sediment can also form offshore platforms that increase alongshore sediment bypassing [Giosan, 2007; Giosan et al., 2013]. While the parameterizations presented here are useful for studies of deltaic and coastline evolution on larger scales [Nienhuis et al., 2015b], future work will be required to study the longer timescale effect of fluvial sediment on alongshore sediment bypassing. Similarly, the effect of tides on both the modulation of sediment discharge [e.g. Leonardi et al., 2013, 2015] and waves should be addressed in future studies.

\subsection{Erosion of the downdrift coast}

The link between river mouth migration, alongshore sediment transport, and river mouth bypassing established here relies in part on the ability of the river mouth to freely erode into the downdrift coastline. However, the migration of natural river mouths is in many cases limited by the strength of the downdrift bank [Izumi et al., 1999; Cooper, 2001]. In these cases, a decrease in channel migration rate is often paired with an increase in alongshore sediment bypassing. For future work, this effect could be studied by including a downdrift lithology factor such that not just the river mouth balance $J$ (eq. 3), but also sediment erodibility will influence bypassing.

\section{Conclusions}

This study has provided quantitative understanding of river mouth morphodynamics in wave-dominated environments. This understanding is not only relevant for the longer timescale evolution and storage of terrestrial signals in the marine environment, but, because river mouths 
and adjacent coasts experience changes of many kilometers on human timescales, a quantitative understanding of river mouth behavior is also essential for successful coastal planning and management. Furthermore, these predictions can be used to analyze how river mouths influence the dynamics of larger wave-influenced deltaic systems, and offer insight into the future evolution of river mouths under current anthropogenic modifications and climate change.

Using model experiments and natural examples, we found that the fraction of alongshore sediment that is bypassed and the size of the river mouths spit control the alongshore migration rate of river mouths. Alongshore bypassing pathways and bypassing fluxes are themselves controlled by river mouth jet deflection. For a downdrift-deflected jet, updrift alongshore sediment transport is not affected by the river mouth; the resulting sediment bypassing fraction is high and bypassing can occur close to the shoreline. If the jet is not deflected, wave-current interactions form a zone of low alongshore transport updrift of the river mouth, effectively disabling alongshore sediment bypassing. We found in our model experiments that bypassing can be predicted by the ratio of jet momentum flux vs. the alongshore component of the wave momentum flux.

The coupling between alongshore sediment bypassing and river mouth migration has enabled us to formulate a predictive framework of alongshore sediment bypassing that can be tested on natural examples. Furthermore, model experiments show that river mouth migration, bypassing, and spit breaching dynamics can appear even under constant discharge and wave climate conditions. These feedbacks can potentially set up an important autogenic clock for wave-dominated river mouths.

\section{Acknowledgements}

This research was supported by NSF grant EAR-0952146. We thank Jeff List for sharing his Delft3D setup. 


\section{References}

Aibulatov, N. A., and I. F. Shadrin (1961), Some data on the long-shore drift of sand near natural obstacles, Tr. Inst. Okeanol. Akad. Nauk. SSSR, 53.

Andren, H. (1994), Development of the Laitaure delta, Swedish Lapland: A study of growth, distributary forms, and processes, Uppsala University.

Ashton, A. D., and L. Giosan (2011), Wave-angle control of delta evolution, Geophys. Res. Lett., 38(13), L13405, doi:10.1029/2011GL047630.

Bakker, W. T. J. N. P., and T. Edelman (1964), The Coastline of River-deltas, in Proc. of the 9th Conf. on Coastal Engineering, Rijkswaterstaat, Lisbon.

Balouin, Y., P. Ciavola, and D. Michel (2006), Support of Subtidal Tracer Studies to Quantify the Complex Morphodynamics of a River Outlet: the Bevano, NE Italy, J. Coast. Res., 1(39), 602-606.

Bates, C. C. (1953), Rational theory of delta formation, Am. Assoc. Pet. Geol. Bull., 37(9), 2119-2162.

Bhattacharya, J. P., and L. Giosan (2003), Wave-influenced deltas: geomorphological implications for facies reconstuction, Sedimentology, 50(1), 187-210, doi:10.1046/j.13653091.2003.00545.x.

Booij, N., R. C. Ris, and L. H. Holthuijsen (1999), A third-generation wave model for coastal regions: 1. Model description and validation, J. Geophys. Res., 104(C4), 7649, doi:10.1029/98JC02622.

Boyd, R., R. Dalrymple, and B. A. Zaitlin (1992), Classification of clastic coastal depositional environments, Sediment. Geol., 80(3-4), 139-150, doi:10.1016/0037-0738(92)90037-R.

Brocatus, J. (2008), Sediment Budget Analysis of the Santa Barbara Littoral Cell, Delft University of Technology.

Bruun, P., and F. Gerritsen (1959), Natural By-Passing of Sand at Coastal Inlets, J. Waterw. Harb. Div., 85(4), 75-107.

Canestrelli, A., W. Nardin, D. Edmonds, S. Fagherazzi, and R. Slingerland (2014), Importance of frictional effects and jet instability on the morphodynamics of river mouth bars and levees, J. Geophys. Res. Ocean., 119(1), 509-522, doi:10.1002/2013JC009312.

Chawla, A., D. Spindler, and H. L. Tolman (2011), A Thirty Year Wave Hindcast Using The Latest NCEP Climate Forecast System Reanalysis Winds, in Proceedings of the 12th International Workshop on Wave Hindcasting and Forecasting, Kohala Coast, Hawaii.

Cooper, J. A. G. (1990), Ephemeral stream-mouth bars at flood-breach river mouths on a wavedominated coast: Comparison with ebb-tidal deltas at barrier inlets, Mar. Geol., 95(1), 5770, doi:10.1016/0025-3227(90)90021-B.

Cooper, J. A. G. (2001), Geomorphological variability among microtidal estuaries from the wave-dominated South African coast, Geomorphology, 40(1-2), 99-122, doi:10.1016/S0169-555X(01)00039-3. 
Correggiari, A., A. Cattaneo, and F. Trincardi (2005), The modern Po Delta system: Lobe switching and asymmetric prodelta growth, Mar. Geol., 222(October 2015), 49-74, doi:10.1016/j.margeo.2005.06.039.

Dean, R. G. (1991), Equilibrium Beach Profiles : Characteristics and Applications, J. Coast. Res., $7(1), 53-84$.

Dean, R. G., and R. A. Dalrymple (1991), Water wave mechanics for engineers and scientists, World Scientific Pub Co Inc, Hackensack, NJ.

Deltares (2014), User Manual Delft3D, Deltares, Delft, The Netherlands.

Dominguez, J. M. L. (1996), The Sao Francisco strandplain: a paradigm for wave-dominated deltas?, Geol. Soc. London, Spec. Publ., 117(1), 217-231, doi:10.1144/GSL.SP.1996.117.01.13.

Edmonds, D. A., and R. L. Slingerland (2007), Mechanics of river mouth bar formation: Implications for the morphodynamics of delta distributary networks, J. Geophys. Res., 112(F2), F02034, doi:10.1029/2006JF000574.

Fagherazzi, S., D. A. Edmonds, W. Nardin, N. Leonardi, A. Canestrelli, F. Falcini, D. J. Jerolmack, G. Mariotti, J. C. Rowland, and R. L. Slingerland (2015), Dynamics of river mouth deposits, Rev. Geophys., 69(37), 1-31, doi:10.1002/2014RG000451.

Falcini, F., A. Piliouras, R. Garra, A. Guerin, D. J. Jerolmack, J. Rowland, and C. Paola (2014), Hydrodynamic and suspended sediment transport controls on river mouth morphology, J. Geophys. Res. Earth Surf., 119(1), 1-11, doi:10.1002/2013JF002831.

Fitzgerald, D. M. (1982), Sediment Bypassing at Mixed Energy Tidal Inlets, in Proceedings of 18th Conference of Coastal Engineering, vol. 18, edited by B. L. Edge, pp. 1094-1118, ASCE, Cape Town, South Africa.

Friedman, G. M. (1967), Dynamic processes and statistical parameters compared for size frequency distribution of beach and river sands, J. Sediment. Res., 37(2), 327-354, doi:10.1306/74D716CC-2B21-11D7-8648000102C1865D.

Gelfenbaum, G., A. W. Stevens, I. Miller, J. A. Warrick, A. S. Ogston, and E. Eidam (2015), Large-scale dam removal on the Elwha River, Washington, USA: Coastal geomorphic change, Geomorphology, 246, 649-668, doi:10.1016/j.geomorph.2015.01.002.

Giosan, L. (2007), Morphdynamic Feedbacks on Deltaic Coasts: lessons from the wavedominated Danube Delta, in Coastal Sediments, edited by N. C. Kraus and J. D. Rosati, New Orleans, LA.

Giosan, L., J. P. Donnelly, E. Vespremeanu, J. P. Bhattacharya, C. Olariu, and F. S. Buonaiuto (2005), River delta morphodynamics: examples from the Danube delta, edited by L. Giosan and J. P. Bhattacharya, SEPM (Society for Sedimentary Geology).

Giosan, L., S. Constantinescu, F. Filip, and B. Deng (2013), Maintenance of large deltas through channelization: Nature vs. humans in the Danube delta, Anthropocene, 1, 35-45, doi:10.1016/j.ancene.2013.09.001. 
Grijm, W. (1960), Theoretical forms of shorelines, in IXth Conference on Coastal Engineering, vol. 2.13, pp. 197-202, Lisbon.

Guilchar, A., and J. P. Nicholas (1954), Observation sur la Langue de Barbarie et les bras du Senegal aux environs de Saint-Louis, Bull. Inf. C.O.E.C., 6, 227-242.

Hart, D. E. (2007), River-mouth lagoon dynamics on mixed sand and gravel barrier coasts, J. Coast. Res., 50(ICS2007), 927-931.

Hay, W. W. (1998), Detrital sediment fluxes from continents to oceans, Chem. Geol., 145(3-4), 287-323, doi:10.1016/S0009-2541(97)00149-6.

Heathfield, D. K., and I. J. Walker (2015), Evolution of a foredune and backshore river complex on a high-energy, drift-aligned beach, Geomorphology, doi:10.1016/j.geomorph.2015.08.006.

Hickin, E. J., and G. C. Nanson (1984), Lateral Migration Rates of River Bends, J. Hydraul. Eng., 110(11), 1557-1567, doi:10.1061/(ASCE)0733-9429(1984)110:11(1557).

Hicks, D. M., and D. L. Inman (1987), Sand dispersion from an ephemeral river delta on the Central California coast, Mar. Geol., 77(3-4), 305-318, doi:10.1016/0025-3227(87)901198.

Ismail, N. M., and R. L. Wiegel (1983), Opposing Wave Effect on Momentum Jets Spreading Rate, J. Waterw. Port, Coastal, Ocean Eng., 109(4), 465-483, doi:10.1061/(ASCE)0733950X(1983)109:4(465).

Izumi, N., N. Shuto, and H. Tanaka (1999), Instability of River Mouth Locations in Pocket Beaches, in Coastal Sediments '99, pp. 628-643.

Jerolmack, D. J., and J. B. Swenson (2007), Scaling relationships and evolution of distributary networks on wave-influenced deltas, Geophys. Res. Lett., 34(23), L23402, doi:10.1029/2007g1031823.

Jirka, G. H. (1994), Shallow jets, in Recent Research Advances in the Fluid Mechanics of Turbulent Jets and Plumes, edited by P. A. Davies and M. J. Valente Neves, pp. 155-175, Kluwer Academic Publishers, Dordrecht.

Jirka, G. H. (2001), Large scale flow structures and mixing processes in shallow flows, J. Hydraul. Res., 39(6), 567-573, doi:10.1080/00221686.2001.9628285.

Kelk, J. G. (1974), A morphological approach to process interaction on the mid Canterbury coastline, University of Canterbury.

Kirk, R. M. (1991), River-beach interaction on mixed sand and gravel coasts: a geomorphic model for water resource planning, Appl. Geogr., 11(4), 267-287, doi:10.1016/01436228(91)90018-5.

Komar, P. D. (1971), Mechanics of Sand Transport on Beaches, J. Geophys. Res., 76(3), 713721, doi:10.1029/Jc076i003p00713.

Kraus, N. C., A. Militello, and G. Todoroff (2002), Barrier Beaching Processes and Barrier Spit Breach, Stone Lagoon, California, Shore and Beach, 70(4), 21-28. 
Leonardi, N., A. Canestrelli, T. Sun, and S. Fagherazzi (2013), Effect of tides on mouth bar morphology and hydrodynamics, J. Geophys. Res. Ocean., 118(9), 4169-4183, doi:10.1002/jgrc.20302.

Leonardi, N., A. S. Kolker, and S. Fagherazzi (2015), Interplay between river discharge and tides in a delta distributary, Adv. Water Resour., 80, 69-78, doi:10.1016/j.advwatres.2015.03.005.

Leopold, L. B., and M. G. Wolman (1960), River Meanders, Geol. Soc. Am. Bull., 71(6), 769, doi:10.1130/0016-7606(1960)71[769:RM]2.0.CO;2.

Lesser, G. R., J. A. Roelvink, J. A. T. M. Kester, and G. S. Stelling (2004), Development and validation of a three-dimensional morphological model, Coast. Eng., 51, 883-915, doi:10.1016/j.coastaleng.2004.07.014.

List, J. H., and A. D. Ashton (2007), A circulation modeling approach for evaluating the conditions for shoreline instabilities, in Coastal Sediments '07, edited by N. C. Kraus and J. D. Rosati, New Orleans, LA.

Mariotti, G., F. Falcini, N. Geleynse, M. Guala, T. Sun, and S. Fagherazzi (2013), Sediment eddy diffusivity in meandering turbulent jets: Implications for levee formation at river mouths, J. Geophys. Res. Earth Surf., 118(3), 1908-1920, doi:10.1002/jgrf.20134.

Nardin, W., and S. Fagherazzi (2012), The effect of wind waves on the development of river mouth bars, Geophys. Res. Lett., 39(12), L12607, doi:10.1029/2012g1051788.

Nardin, W., G. Mariotti, D. A. Edmonds, R. Guercio, and S. Fagherazzi (2013), Growth of river mouth bars in sheltered bays in the presence of frontal waves, J. Geophys. Res. Earth Surf., 118(2), 872-886, doi:10.1002/jgrf.20057.

Nienhuis, J. H., A. D. Ashton, P. C. Roos, S. J. M. H. Hulscher, and L. Giosan (2013), Wave reworking of abandoned deltas, Geophys. Res. Lett., 40(22), 5899-5903, doi:10.1002/2013GL058231.

Nienhuis, J. H., A. D. Ashton, W. Nardin, S. Fagherazzi, and L. Giosan (2015a), Breaking-wave driven sediment bypassing of river mouths: mechanisms and effects on delta evolution, in The Proceedings of the Coastal Sediments 2015, edited by P. Wang, J. Rosati, and J. Cheng, World Scientific Pub Co Inc, San Diego, USA.

Nienhuis, J. H., A. D. Ashton, and L. Giosan (2015b), Steering of deltaic channels through river mouth bypassing and alongshore sediment transport, Prep.

Nienhuis, J. H., A. D. Ashton, and L. Giosan (2015c), What makes a delta wave-dominated?, Geology, 43(6), 511-514, doi:10.1130/G36518.1.

Parker, G. (1978), Self-formed straight rivers with equilibrium banks and mobile bed. Part 1. The sand-silt river, J. Fluid Mech., 89(01), 109-125, doi:10.1017/S0022112078002505.

van Rijn, L. C. (1993), Principles of Sediment Transport in Rivers, Estuaries and Coastal Seas, 1st ed., Aqua Publications, Amsterdam. 
Rowland, J. C., M. T. Stacey, and W. E. Dietrich (2009), Turbulent characteristics of a shallow wall-bounded plane jet: experimental implications for river mouth hydrodynamics, J. Fluid Mech., 627, 423, doi:10.1017/S0022112009006107.

Rowland, J. C., W. E. Dietrich, and M. T. Stacey (2010), Morphodynamics of subaqueous levee formation: Insights into river mouth morphologies arising from experiments, J. Geophys. Res., 115(F4), F04007, doi:10.1029/2010jf001684.

Sedrati, M., P. Ciavola, and C. Armaroli (2011), Morphodynamic evolution of a microtidal barrier, the role of overwash: Bevano, Northern Adriatic Sea, J. Coast. Res., SI 64(ICS2011), 696-700.

Stanley, D. J., and A. G. Warne (1998), Nile Delta in Its Destruction Phase, J. Coast. Res., 14(3), 795-825.

Syvitski, J. P. M. M., and Y. Saito (2007), Morphodynamics of deltas under the influence of humans, Glob. Planet. Change, 57(3-4), 261-282, doi:10.1016/j.gloplacha.2006.12.001.

Tanaka, H. (2003), Mathematical modelling of morphological change at a river mouth, in International conference on estuaries and coasts, pp. 87-98, Hangzhou, China, China.

Tanaka, H., F. Takahashi, and A. Takahashi (1996), Complete closure of the Nanakita River mouth in 1994, in Coastal Engineering Proceedings, vol. 25, edited by B. L. Edge, pp. 4545-4556, ASCE, Orlando, USA.

Warrick, J. A., and P. L. Barnard (2012), The offshore export of sand during exceptional discharge from California rivers, Geology, 40(9), 787-790, doi:10.1130/G33115.1.

Wolman, M. G., and J. P. Miller (1960), Magnitude and frequency of forces in geomorphic processes, J. Geol., 68(1), 54-74.

Wright, L. D. (1977), Sediment Transport and Deposition at River Mouths - Synthesis, Geol. Soc. Am. Bull., 88(6), 857-868, doi:10.1130/0016-7606(1977)88<857.

Zenkovich, V. P. (1967), Processes of Coastal Development, 1st ed., edited by J. A. Steers, Oliver \& Boyd, Edinburgh. 


\section{Wave reworking of abandoned deltas}

Jaap H. Nienhuis ${ }^{1,2, c}$, Andrew D. Ashton ${ }^{1}$, Pieter C. Roos ${ }^{2}$, Suzanne J.M.H. Hulscher ${ }^{2}$, Liviu Giosan $^{1}$

${ }^{1}$ Geology and Geophysics department, Woods Hole Oceanographic Institution, 266 Woods Hole Road, MS \#22, Woods Hole, MA 02543

${ }^{2}$ Water Engineering and Management department, University of Twente, PO Box 217, 7500 AE Enschede

${ }^{\mathrm{c}}$ Corresponding author: Jaap H. Nienhuis, Geology and Geophysics Department, Woods Hole Oceanographic Institution, 266 Woods Hole Road, MS \#22, Woods Hole, MA 02543, +1774-444-5167,jnienhuis@whoi.edu

Reprinted with permission of John Wiley \& Sons Inc.

Citation: Nienhuis, J. H., A. D. Ashton, P. C. Roos, S. J. M. H. Hulscher, and L. Giosan (2013), Wave reworking of abandoned deltas, Geophys. Res. Lett., 40(22), 5899-5903, doi:10.1002/2013GL058231. 


\begin{abstract}
River deltas and individual delta lobes frequently face reduction of sediment supply, either from the geologic process of river avulsion or, more recently, due to human activities such as river damming. Using a process-based shoreline evolution model, we investigate wave reworking of delta shorelines after fluvial input elimination. Model results suggest littoral sediment transport can result in four characteristic modes of delta abandonment, ranging from diffusional smoothing of the delta (or delta lobe) to the development of recurved spits. A straightforward analysis of delta shape and wave characteristics provides a framework for predicting the mode of delta abandonment. The observed morphologies of historically abandoned delta lobes, including those of the Nile, Ebro, and Rhone rivers, fit within this framework. Our results provide quantitative insight into the potential evolution of active delta environments in light of future extreme reduction of fluvial sediment input.
\end{abstract}




\section{Introduction}

River deltas are dynamic and complex depositional landforms, shaped by the competition between marine and fluvial processes [Wright and Coleman, 1973]. Fluvial sediment delivery to deltas or individual delta lobes varies over time, with the potential for elimination or drastic reduction of fluvial sediment by (i) delta channel avulsion, which causes sediment to be routed through a new channel [Roberts, 1997], (ii) redistribution of discharge among distributaries [Giosan et al., 2006], or, over the last decades, (iii) river damming and water use [Milliman et al., 2008]. The reduction in sediment supply often tips the balance between marine and fluvial processes, as reworking by waves changes the abandoned delta's morphology (Fig. 1). Despite the importance of marine reworking [Roberts, 1997] in the preservation of deltaic stratigraphy [Geleynse et al., 2011], there have been few quantitative studies of reworking after abandonment [e.g. Hillen et al., 2009]. Here, we apply a process-based model of plan-view shoreline evolution to characterize the long-term (centennial to millennial) plan-view response of a delta to wave reworking after elimination of fluvial sediment load. We then investigate how wave characteristics combined with the morphology of the delta plain created during growth affect the morphologic style of post-abandonment reworking, using both modeled and natural examples.

\section{Background: Marine Reworking of Deltas}

The balance between incoming wave energy, tides, and river discharge operates as a firstorder morphologic control on delta shape [Wright and Coleman, 1973; Galloway, 1975]. Wave influence sculpts characteristic plan-view landforms and morphologies indicative of marine reworking, including beach ridges and recurved spits; these features may be coeval with delta formation or develop after abandonment. Waves also suppress mouth bar formation [Wright, 1977; Geleynse et al., 2011; Nardin and Fagherazzi, 2012], thereby limiting the amount of distributary channels on the delta plain [Bhattacharya and Giosan, 2003; Jerolmack and Swenson, 2007]. Obliquely approaching waves can deflect the river mouth itself [Bhattacharya and Giosan, 2003; Nardin and Fagherazzi, 2012].

Over decadal to millennial timescales, river avulsions [Jerolmack and Mohrig, 2007] and discharge redistribution [Giosan et al., 2005] can result in drastic reduction of sediment delivery to the coast. River damming presents a new mechanism for severe decline or even elimination of fluvial sediment discharge for the entire delta system [Syvitski et al., 2009]. Sediment discharge 
reduction initiates a "destructive" period of the so-called "Delta Cycle"[Roberts, 1997], where subsidence and marine reworking control the morphology of the abandoned coast (Fig. 1). Although this cycle is typically applied to river-dominated deltas, reworking of abandoned wavedominated deltas similarly reorients the coast, resulting in truncated beach ridges and other features generally indicative of changes in driving forces [Curray et al., 1969; Giosan et al., 2006].

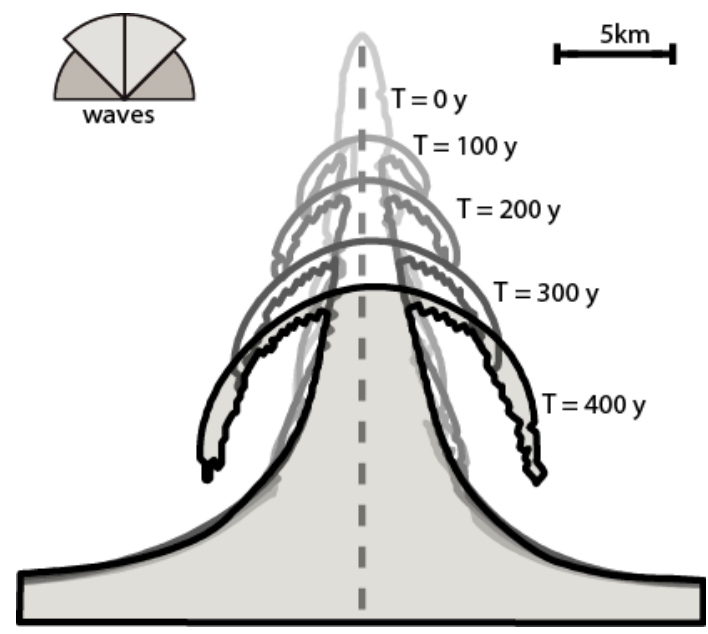

Figure 1. Demonstration of the destructive stage of the 'delta cycle' [Roberts, 1997] using an example model run. Reworking by littoral sediment transport of a delta that is river-dominated during growth results in two distinct recurved spits. Successive shorelines are shown at 100-year intervals, from grey to black. Simulations use a symmetric wave climate (inset rose represents the angular distribution of wave energy, of which the darker portions are unstable, high-angle waves).

\section{Background: Modeling Coastline Evolution}

Alongshore transport of littoral sediment by breaking waves is an efficacious sediment transport mechanism. The alongshore flux of sediment depends on the angle between wave crests (at the toe of the shoreface) and the shoreline, and displays a maximum at approximately $45^{\circ}$ (Fig. 2) [Ashton et al., 2001]. Waves from beyond the maximizing angle drive an antidiffusional shoreline instability, with increasing instability for more oblique waves (Fig. 2) [Ashton and Murray, 2006a]. Just as every set of wave conditions drives a given quantity of sediment alongshore, each set of wave conditions contributes to the stability of the coastline, either diffusively $\left(<45^{\circ}\right)$ or antidiffusively $\left(>45^{\circ}\right)$ [Ashton and Murray, 2006b]. The net littoral 
transport $Q \mathrm{~S}\left(\mathrm{kgs}^{-1}\right.$, positive to the right, looking offshore) and the net diffusivity $\Gamma$ (a dimensionless number varying between -1 and 1) can be computed by summing over a long-term series of waves (a "wave climate"). For a given shoreline, the value of $\Gamma$ is the relative rate at which plan-view shoreline perturbations will decay (stable shoreline, $\Gamma>0$ ) or amplify (unstable shoreline, $\Gamma<0$ ). Unstable shorelines tend to develop capes, flying spits, and alongshore sandwaves [Ashton et al., 2001; Falqués and Calvete, 2005].

Plan-view delta evolution has been previously modeled both analytically [Larson et al., 1987] and numerically [Komar, 1973] for the case of a river with constant sediment input and exclusively low-angle waves, i.e. waves approaching relatively straight to the shoreline. More recent investigations by Ashton and Giosan [2011] emphasize the role of wave angle climate on delta morphologies during growth. If there is asymmetry in the wave climate, downdrift shorelines will experience higher angle waves, with an increased probability of downdrift spit formation and shoreline instability. These results can explain certain features observed on asymmetric wave-influenced deltas [Bhattacharya and Giosan, 2003], such as shore parallel barriers or spits. However, none of the simulations by Ashton and Giosan [2011] show the formation of distinct recurved spits, observed, for example, on the Ebro and Krishna Deltas [Canicio and Ibanez, 1999; Rao et al., 2006]. 


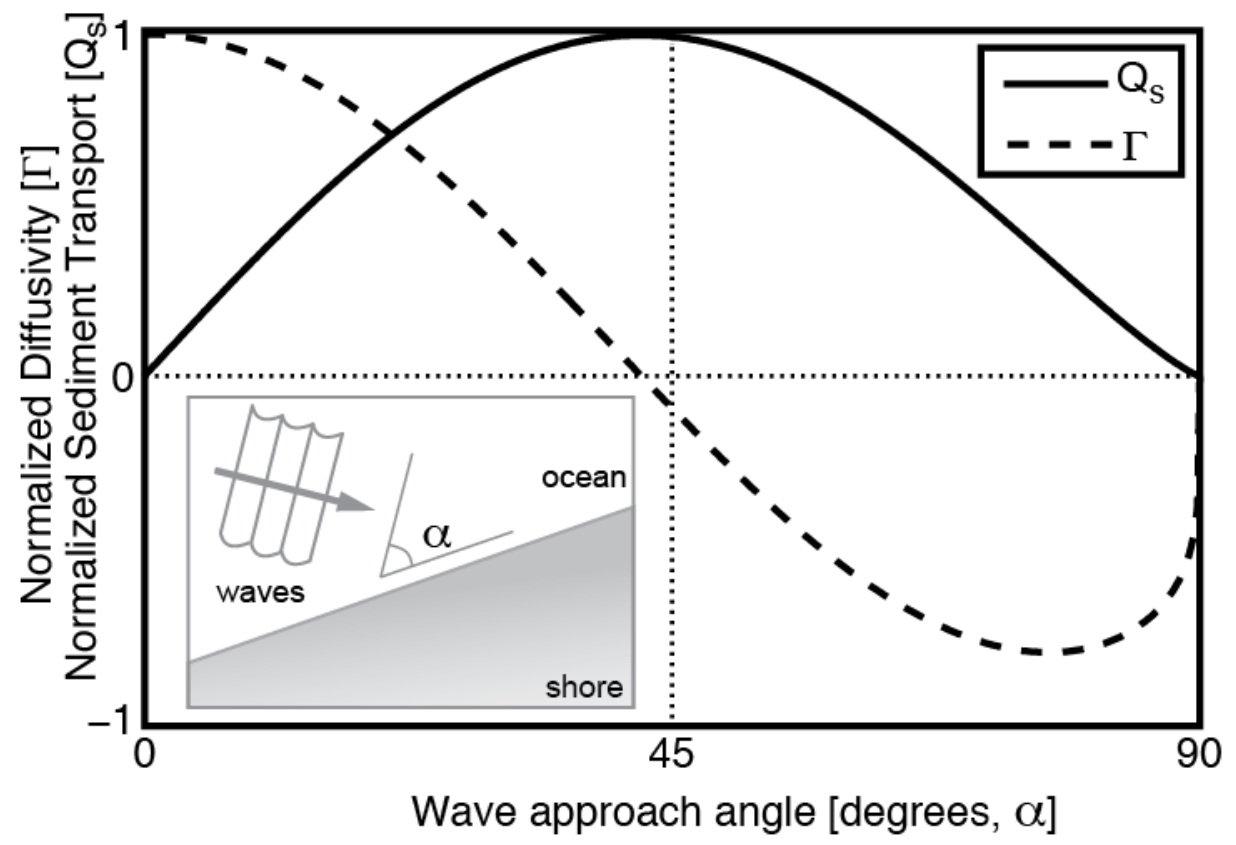

Figure 2. Plot of normalized wave-sustained littoral sediment transport (Qs, solid line) and normalized diffusivity ( $\Gamma$, dashed line) versus deep-water wave approach angle, $\alpha$, defined at the toe of the shoreface. Following Ashton and Murray [2006b], littoral transport is described by the CERC formula: $Q_{s}=K_{2} H_{0}^{\frac{12}{5}} T^{\frac{1}{5}} \cos ^{\frac{6}{5}}(\alpha) \sin (\alpha)$, where $\mathrm{K}_{2}$ is an empirical constant (m s-2), relating wave energy to sediment volume; H0 and T are respectively the significant deepwater wave height and period. Normalized diffusivity (in this case for waves approaching from a single angle) is described by: $\Gamma=\cos ^{\frac{1}{5}}(\alpha)\left[\cos ^{2}(\alpha)-\frac{6}{5} \sin ^{2}(\alpha)\right]$. Inset depicts the wave approach angle definition.

\section{Methods: Coastline Evolution Model}

We study the effect of fluvial sediment elimination on delta morphology using an exploratory [Murray, 2007] process-based one-contour-line model of shoreline evolution [for a full description see Ashton and Murray, 2006a]. In short, the plan-view coastal zone is discretized into square $(200 \mathrm{~m})$ cells whose geometry defines the shoreline. Littoral transport, $\mathrm{Q}_{s}$, is calculated with the CERC formula using breaking wave angle and height [Komar, 1971, 1973] assuming refraction over shore-parallel shoreface contours (Fig. 2). To simulate long-term fluvial sediment influx, we add sediment to the model coastline at a predefined alongshore 
position ("river mouth") at a constant rate $\left(\mathrm{Q}_{r}\right)$. There are no feedbacks between waves and $\mathrm{Q}_{r}$, and littoral sediment is allowed to bypass the river mouth moving alongshore.

Each model day, a wave direction is picked from a probability distribution defined by two variables: asymmetry $(A)$, the fraction of waves coming from the left, and the proportion of unstable, high-angle waves $(U)$, where larger $U$ results in decreased overall diffusivity (see Supplementary Table 2 for model run parameters).

\section{$5 \quad$ Results: Modes of Delta Reworking}

We model delta formation over 500 years, then eliminate the fluvial sediment supply while keeping wave conditions constant. During growth, feedbacks between alongshore sediment transport, shoreline orientation, and sediment input control the delta's plan-form shape. Larger sediment delivery rates, greater wave asymmetry, and higher-angle waves result in more steeply pointed delta shapes [Ashton and Giosan, 2011]. The delta shape during growth is important at it sets a template for post-abandonment wave reworking.

We identify four distinct modes of delta abandonment by their dominant morphologic expression (Fig. 3): (i) smooth diffusive shoreline, (ii) discontinuous shoreline (iii) growing spit, and (iv) decaying shoreline sandwaves. Shoreline instability, and therefore more complex responses, are favored on the downdrift delta coast [Ashton and Giosan, 2011]; here we identify abandonment modes based on this downdrift behavior. Note, however, complex behavior is also possible on the updrift coasts or along both coasts if the wave climate is symmetric (Fig. 1) or nearly so.

The smooth diffusive shoreline mode occurs when the pre-abandonment delta has a cuspate shape, and both the updrift and downdrift shorelines are stable (Fig. 3a). The abandoned delta maintains its general shape, which is diffused by alongshore transport gradients, with erosion around the river mouth and deposition on the updrift and downdrift flanks. This is the expected response given by the traditional diffusion equation for shoreline evolution [Larson et al., 1987]. 
Alternatively, abandonment can spur the growth of shoreline features if, during delta growth, the shoreline passed the orientation for which maximum transport occurs. A discontinuous shoreline mode (Fig. 3b) arises when the shoreline is marginally unstable, with $\Gamma$ below, but close to 0 . After abandonment, removal of the riverine sediment source results in rapid rearrangement of the delta tip while sediment flux remains positive (i.e. $Q_{s}>0$ along the entire downdrift coast) (Fig. 3b, dotted ellipse). The mouth 'collapse' propagates as a downdriftmigrating erosion/accretion couplet (Fig. 3b, inside the dotted ellipse), much like the expected downdrift migration of the upcoast inflection points for the case of a single growing flying spit [Ashton and Murray, 2006a]. This shoreline discontinuity, where $\Gamma$ becomes negative, migrates away from the river mouth, initially preserving the downdrift-skewed form of the delta. The discontinuity eventually dissipates as the shoreline flattens.

A delta extending further offshore (i.e. with a larger offshore to alongshore aspect ratio), either due to a relatively large fluvial sediment input or small effective shoreline diffusivity during growth, exhibits a different abandonment mode marked by the development of a recurved spit. In contrast with the shoreline discontinuity case, delta tip collapse creates a zero flux location $\left(Q_{s}=0\right)$ which persists as the delta decays (Fig. 3c, dashed ellipse). The zero flux point then translates downdrift with a plan-view trajectory gentler than that of the shoreline angle itself, forming a spit. Eventually, the spit reconnects with the shoreline and dissipates, at this point behaving analogously to the shoreline discontinuity mode with $Q_{s}>0$ and $\Gamma<0$ (Fig. 3c, dotted ellipse).

Finally, strongly asymmetric wave climates result in highly unstable downdrift coasts, triggering the formation of shoreline sandwaves before abandonment (Fig. 3d). During growth, increased sediment transport downdrift from the river mouth decreases the overall plan-view extent (for the same fluvial input). In this case, post-abandonment behavior is complex, with formation of a spit that collapses near the river mouth and continued formation of shoreline sandwaves as the delta is reworked. As wave conditions favor downdrift instability, the subtle shoreline discontinuity persists longer than in the other modes. 

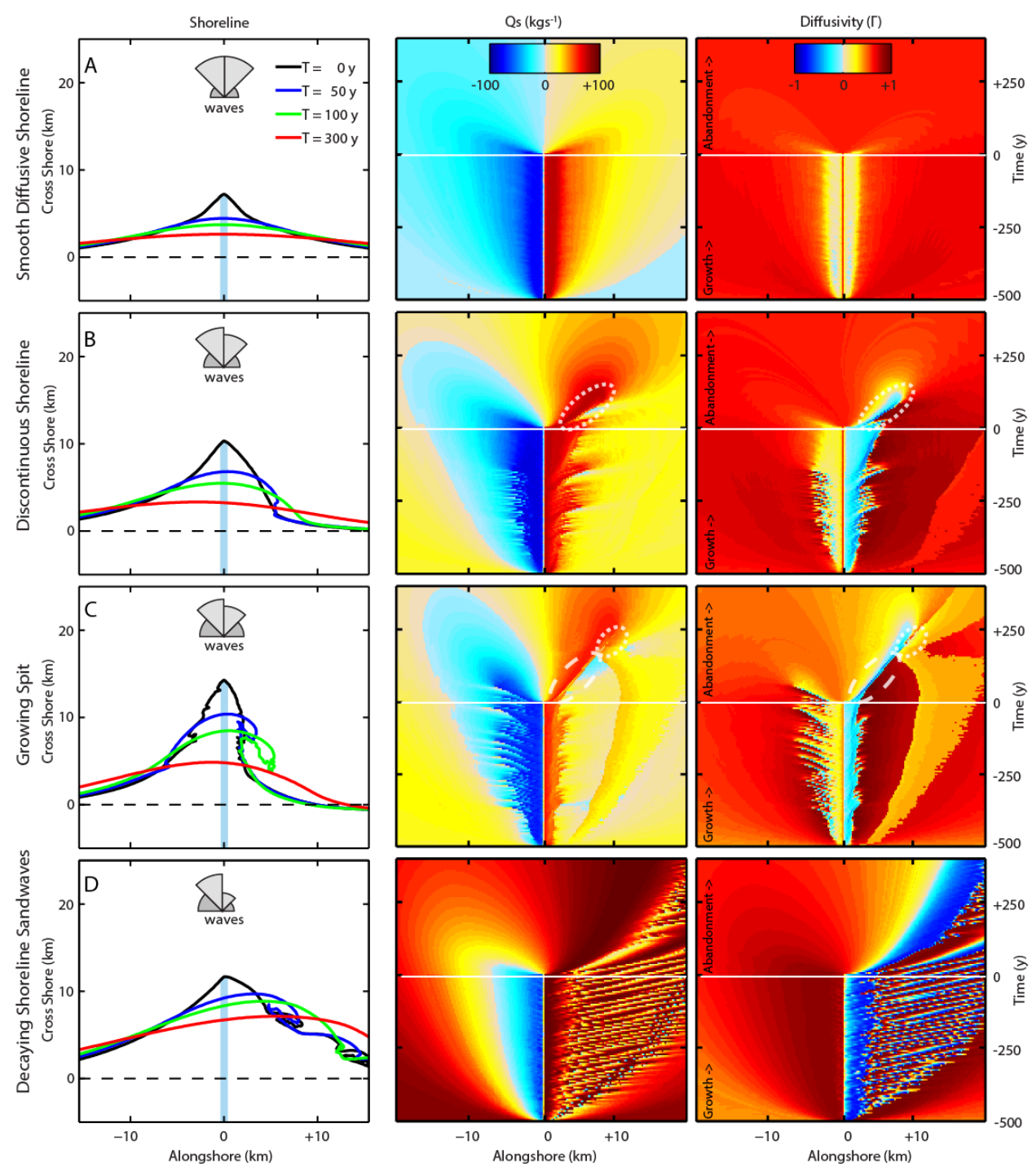

Figure 3. Sample model results of the four identified delta abandonment modes, A through D, plotting shoreline configuration (left column) at abandonment $(\mathrm{T}=0 \mathrm{y})$ and afterwards. Inset roses display the angular distribution of incoming wave energy. Plotted time stacks show net alongshore sediment transport $\left(Q_{s}\right)$ (middle column, sediment transport is positive to the right) and normalized shoreline diffusivity $(I)$ (right column). Note that wave height $(1 \mathrm{~m})$, period (5 s), and fluvial bedload flux $\left(Q_{r}=200 \mathrm{~kg} \mathrm{~s}^{-1}\right)$ are left unchanged among these runs - these different behaviors are solely due to differences in the angular distribution of waves. Dashed and dotted ellipses indicate regions discussed in the text. 


\section{Results: Controls on Abandonment Mode}

To better understand the controls on deltas after abandonment, we ran simulations for a range of fluvial and marine conditions (162 runs, see Supplemental Information for parameter ranges) and characterized the abandonment mode based on the plan-view morphology. After investigating a wide array of parameters, including fluvial discharge rate and wave height, we found two characteristics of the delta at abandonment that best predict post-abandonment evolution: plan-view aspect ratio and the diffusivity for the flank-averaged coastal orientation (Fig. 4a). These two quantities are emergent properties of delta evolution that arise during growth and can be measured from delta geometry (using either the shoreline or beach ridges) and modern driving forces (with knowledge of the directional wave climate). Our approach therefore does not require quantification of fluvial sediment discharge, which is notoriously difficult to measure [Turowski et al., 2010].

Interestingly, the spit mode occurs almost exclusively when the aspect ratio of the coast is greater than one (i.e. the coast is beyond $45^{\circ}$; Fig. $4 \mathrm{a}$ ). This suggests that when well-formed, spatially extensive recurved spits (which are generally diagnostic of wave reworking of sediment promontories) are found on a delta plain, they likely arose from abrupt abandonment after a previous stage of intense progradation. Note that our investigations here studied complete elimination of fluvial sediment supply on deltas in a low-tide environment; less drastic sediment reductions makes shoreline reorientation more gradual, decreasing the possibility of recurved spit growth. Overall, our results also emphasize the ephemeral nature of promontories to wave attack.

For natural examples, we determine pre-abandonment geometry from satellite images and wave climate characteristics from wave hindcast data (see Supplementary Table 1) (Fig. 4b and Fig. 4c). Lobes of the Ebro, Po and Rhone deltas experienced drastic reductions of sediment supply due to river avulsion (Ebro, Rhone) or geoengineering (Po) [Canicio and Ibanez, 1999; Vella et al., 2005; Sabatier et al., 2006; Simeoni et al., 2007], with subsequent spit development (La Banya Spit on the Ebro, the Goro Spit on the Po and the Beaudoc spit on the Rhone). The observed spit formation after avulsion is consistent with their location in our parameter space (Fig. 4a). Significant reductions of fluvial input due to human impact in their drainage basins have affected the Ombrone [Innocenti and Pranzini, 1993] and Arno [Pranzini, 2001] deltas as well as the two modern lobes of the Nile [Stanley and Warne, 1998]. Whereas the Ombrone and 
Arno Deltas, with their diffusive wave climates and subtle shape [Bellotti et al., 2004], exhibit a diffusive shoreline mode (Fig. 4c), the Rosetta lobe of the Nile delta, with the formation of undulating spits extending downdrift as the delta recedes, demonstrates behavior spanning the spit and alongshore sand wave modes (Fig. 4b). In other cases where deltas or delta lobes are not yet abandoned per se (Nestos, Coco, Danube, Sao Francisco), the parameter space suggests possible future delta abandonment styles if fluvial supply were to (or were to continue to) decrease dramatically (Fig. 4a).

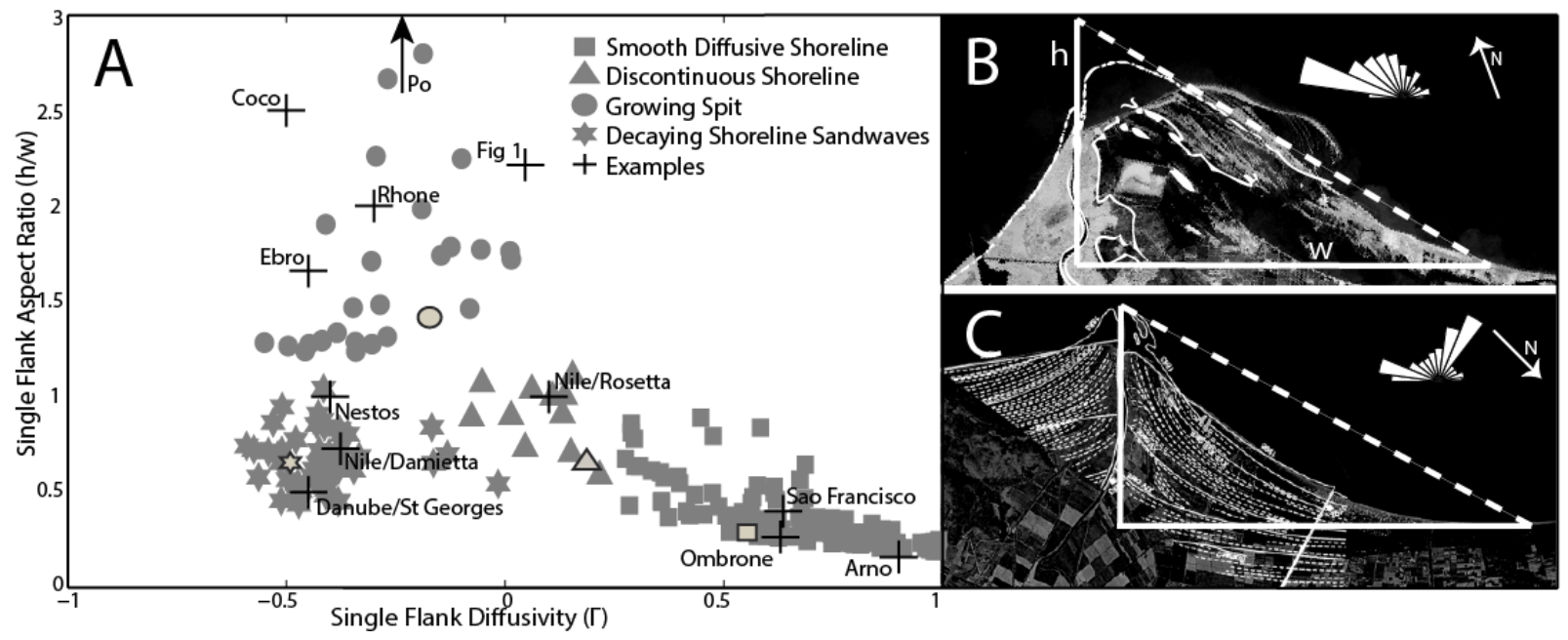

Figure 4. (A) Abandonment modes plotted in terms of pre-abandonment aspect ratio $(\mathrm{h} / \mathrm{w})$ versus normalized diffusivity of the delta flank (for model parameters see Supplementary Table 2). The markers with solid outlines show examples from Fig. 3. The aspect ratio of the Po Delta (di Goro Lobe) is 6. (B) The Rosetta lobe of the Nile Delta, Egypt, and (C) the Ombrone Delta, Italy, demonstrating the calculation method for aspect ratio and wave climate characteristics. Images copyright NASA, overlays from Pranzini [2001] and Stanley and Warne [Stanley and Warne, 1998].

\section{$7 \quad$ Conclusions}

We identify four distinct modes of marine working of delta planforms after abrupt reduction of sediment supply, providing, for the first time, a quantitative framework to understand the morphologic evolution of an abandoned wave-influenced delta. Model results and comparison with natural examples show that delta shoreline geometry and wave climate at the 
time of abandonment can be a good predictor of the abandonment mode. Overall, development of alongshore-extending spits tends to occur on abandoned deltas with initially high ratios of offshore versus alongshore extent - i.e., sharply protruding spits tend to form when a delta is close to fluvial dominance before sediment supply is eliminated.

Understanding the controls upon the style of delta reworking is important for interpreting immediate and long term paleo-environmental conditions that may be recorded in delta plain geometries [Giosan et al., 2006]. Not only may this knowledge help guide interpretation of the rock record, but the more immediate application pertains to interpretation of the geometries of Holocene delta forms, for instance providing insight into the mechanistic origin of features such as recurved spits found on some deltas. Looking towards the future, as sediment supply to deltas continues to wane due to human influence, understanding the likely style and form of wave reworking will play an important role in management of deltaic coastlines.

\section{Acknowledgements}

This research was supported by NSF Grant EAR-0952146. We wish to thank Ad van der Spek for feedback and two anonymous reviewers of this submittal.

\section{References}

Ashton, A. D., and L. Giosan (2011), Wave-angle control of delta evolution, Geophys. Res. Lett., 38(13), L13405, doi:10.1029/2011GL047630.

Ashton, A. D., and A. B. Murray (2006a), High-angle wave instability and emergent shoreline shapes: 1. Modeling of sand waves, flying spits, and capes, J. Geophys. Res., 111(F4), F04011, doi:10.1029/2005JF000422.

Ashton, A. D., and A. B. Murray (2006b), High-angle wave instability and emergent shoreline shapes: 2. Wave climate analysis and comparisons to nature, J. Geophys. Res., 111(F4), F04012, doi:10.1029/2005JF000423.

Ashton, A. D., A. B. Murray, and O. Arnoult (2001), Formation of coastline features by largescale instabilities induced by high-angle waves, Nature, 414(6861), 296-300, doi: $10.1038 / 35104541$.

Bellotti, P., C. Caputo, L. Davoli, S. Evangelista, E. Garzanti, F. Pugliese, and P. Valeri (2004), Morpho-sedimentary characteristics and Holocene evolution of the emergent part of the Ombrone River delta (southern Tuscany), Geomorphology, 61(1-2), 71-90, doi:Doi 10.1016/J.Geomorph.2003.11.007. 
Bhattacharya, J. P., and L. Giosan (2003), Wave-influenced deltas: geomorphological implications for facies reconstuction, Sedimentology, 50(1), 187-210, doi:10.1046/j.13653091.2003.00545.x.

Canicio, A., and C. Ibanez (1999), The Holocene Evolution of the Ebro Delta Catalonia, Spain, Acta Geogr. Sin., 54(5), 462-469.

Curray, J. R., F. J. Emmel, and P. J. S. Crampton (1969), Holocene history of a strand plain, lagoonal coast, Nayarit, Mexico, in Lagunas Costeras, Un Simposio. Mem. Simp. Intern. Lagunas Costeras, edited by A. A. Castanares and F. B. Phleger, pp. 63-100, UNAMUNESCO, Mexico City, Mexico.

Falqués, a., and D. Calvete (2005), Large-scale dynamics of sandy coastlines: Diffusivity and instability, J. Geophys. Res., 110(C3), C03007, doi:10.1029/2004JC002587.

Galloway, W. D. (1975), Process Framework for describing the morphologic and stratigraphic evolution of deltaic depositional systems, in Deltas, Models for Exploration, edited by M. L. Broussard, pp. 86-98, Houston Geological Society, Houston, TX.

Geleynse, N., J. E. A. Storms, D.-J. R. Walstra, H. R. A. Jagers, Z. B. Wang, and M. J. F. Stive (2011), Controls on river delta formation; insights from numerical modelling, Earth Planet. Sci. Lett., 302(1-2), 217-226, doi:10.1016/j.epsl.2010.12.013.

Giosan, L., J. P. Donnelly, E. Vespremeanu, J. P. Bhattacharya, C. Olariu, and F. S. Buonaiuto (2005), River delta morphodynamics: examples from the Danube delta, edited by L. Giosan and J. P. Bhattacharya, SEPM (Society for Sedimentary Geology).

Giosan, L., J. P. Donnelly, S. Constantinescu, F. Filip, I. Ovejanu, A. Vespremeanu-Stroe, E. Vespremeanu, and G. A. T. Duller (2006), Young Danube delta documents stable Black Sea level since the middle Holocene: Morphodynamic, paleogeographic, and archaeological implications, Geology, 34(9), 757-760, doi:Doi 10.1130/G22587.1.

Hillen, M. M., N. Geleynse, J. E. A. Storms, D. R. Walstra, and M. J. F. Stive (2009), Morphology and stratigraphy of a degrading delta, in Proceedings of Coastal Dynamics 2009. Impacts of human activities on dynamics coastal processes, edited by M. Mizuguchi and S. Sato, pp. 1-12, World scientific Publishing Co. Pte. Ltd., Tokyo, Japan.

Innocenti, L., and E. Pranzini (1993), Geomorphological Evolution and Sedimentology of the Ombrone River Delta, Italy, J. Coast. Res., 9(2), 481-493.

Jerolmack, D. J., and D. Mohrig (2007), Conditions for branching in depositional rivers, Geology, 35(5), 463-466, doi:Doi 10.1130/G23308a.1.

Jerolmack, D. J., and J. B. Swenson (2007), Scaling relationships and evolution of distributary networks on wave-influenced deltas, Geophys. Res. Lett., 34(23), L23402, doi:10.1029/2007g1031823.

Komar, P. D. (1971), Mechanics of Sand Transport on Beaches, J. Geophys. Res., 76(3), 713721, doi:10.1029/Jc076i003p00713.

Komar, P. D. (1973), Computer models of delta growth due to sediment input from rivers and longshore transport, Bull. Geol. Soc. Am., 84(7), 2217-2226, doi:10.1130/00167606(1973)84<2217:CMODGD>2.0.CO;2. 
Larson, M., H. Hanson, and N. C. Kraus (1987), Analytical solutions of the one-line model of shoreline change, US Army Waterw. Exp. Stn., Vicksburg.

Milliman, J. D., K. L. Farnsworth, P. D. Jones, K. H. Xu, and L. C. Smith (2008), Climatic and anthropogenic factors affecting river discharge to the global ocean, 1951-2000, Glob. Planet. Change, 62(3-4), 187-194, doi:Doi 10.1016/J.Gloplacha.2008.03.001.

Murray, A. B. (2007), Reducing model complexity for explanation and prediction, Geomorphology, 90(3-4), 178-191, doi:10.1016/j.geomorph.2006.10.020.

Nardin, W., and S. Fagherazzi (2012), The effect of wind waves on the development of river mouth bars, Geophys. Res. Lett., 39(12), L12607, doi:10.1029/2012g1051788.

Pranzini, E. (2001), Updrift river mouth migration on cuspate deltas: two examples from the coast of Tuscany (Italy), Geomorphology, 38(1-2), 125-132, doi:10.1016/S0169$555 x(00) 00076-3$.

Rao, M. A., S. Ramamurthy, B. M. Shah, and V. H. Rao (2006), Recent morphological changes along the Krishna Delta shoreline, J. Geol. Soc. india, 67(5), 629-635.

Roberts, H. H. (1997), Dynamic changes of the Holocene Mississippi River delta plain: The delta cycle, J. Coast. Res., 13(3), 605-627.

Sabatier, F., G. Maillet, M. Provansal, T.-J. Fleury, S. Suanez, and C. Vella (2006), Sediment budget of the Rhône delta shoreface since the middle of the 19th century, Mar. Geol., 234(1-4), 143-157, doi:http://dx.doi.org/10.1016/j.margeo.2006.09.022.

Simeoni, U., G. Fontolan, U. Tessari, and C. Corbau (2007), Domains of spit evolution in the Goro area, Po Delta, Italy, Geomorphology, 86(3-4), 332-348, doi:http://dx.doi.org/10.1016/j.geomorph.2006.09.006.

Stanley, D. J., and A. G. Warne (1998), Nile Delta in Its Destruction Phase, J. Coast. Res., 14(3), $795-825$.

Syvitski, J. P. M. et al. (2009), Sinking deltas due to human activities, Nat. Geosci., 2(10), 681686, doi:10.1038/Ngeo629.

Turowski, J. M., D. Rickenmann, and S. J. Dadson (2010), The partitioning of the total sediment load of a river into suspended load and bedload: a review of empirical data, Sedimentology, 57(4), 1126-1146, doi:10.1111/j.1365-3091.2009.01140.x.

Vella, C., T. J. Fleury, G. Raccasi, M. Provansal, F. Sabatier, and M. Bourcier (2005), Evolution of the Rhone delta plain in the Holocene, Mar. Geol., 222, 235-265, doi:Doi 10.1016/J.Margeo.2005.06.028.

Wright, L. D. (1977), Sediment Transport and Deposition at River Mouths - Synthesis, Geol. Soc. Am. Bull., 88(6), 857-868, doi:10.1130/0016-7606(1977)88<857.

Wright, L. D., and J. M. Coleman (1973), Variations in morphology of major river deltas as functions on ocean wave and river discharge regimes, Am. Assoc. Pet. Geol. Bull., 57(2), 370-398. 


\section{Using simple models to constrain the evolution of Ebro delta}

Jaap H. Nienhuis ${ }^{1,2}$, Andrew D. Ashton ${ }^{2}$, Albert J. Kettner ${ }^{3}$, Liviu Giosan ${ }^{2}$

${ }^{1}$ Earth, Atmospheric and Planetary Science, Massachusetts Institute of Technology, Cambridge, MA

${ }^{2}$ Geology and Geophysics, Woods Hole Oceanographic Institution, Woods Hole, MA

${ }^{3}$ Institute of Arctic and Alpine Research, University of Colorado, Boulder, CO 


\begin{abstract}
The rich morphologic history of the Ebro delta is evident in its distinctive plan-view shape. Although autogenic dynamics have generated some aspects of the Ebro delta shape, other aspects are allogenic, and allow us to study the effects of human- and climate-induced changes on delta morphology. Here we have used simple coastal and fluvial morphodynamic models to quantify paleo-environmental changes that affected the Ebro delta over the late Holocene. Based on simulations and the modern Ebro delta shape, we estimate that a period of rapid progradation started around 2000 years BP and was probably caused by a doubling in coarse-grained sediment supply to the delta. Delta expansion was possibly aided by a strongly positive North Atlantic Oscillation (NAO) and associated weakened wave energy. Using river profile models to backtrack our delta model derived estimates of fluvial sediment supply back to the drainage basin we find a combination of flood discharge increase and upstream drainage basin erosion possibly starting thousands of years earlier. The persistence of progradation throughout the last 2000 years likely points at human influence on sediment supply and flooding intensity. These findings highlight how scenario-based investigations of deltaic systems using simple models allows for a more quantitative reconstruction of the paleo-environment, essential not only to address the effects of past human influence and climate change, but also to better understand the future of deltaic landforms.
\end{abstract}




\section{$1 \quad$ Introduction}

The Ebro Delta, Spain, with its distinctive plan-view shape, has experienced significant morphologic changes over the last millennia (Fig. 1) [Canicio and Ibanez, 1999]. While some of these morphological changes might be caused by autogenic processes such as avulsions, others aspects could be attributable to climate change or anthropogenic activities in the drainage basin. Many different scenarios leading to the observed modern morphology have been proposed, including high-frequency (centennial scale) sea level fluctuations [Somoza et al., 1998], human induced sediment load changes in the Ebro river [Guillén and Palanques, 1997], and an added significant effect of climate fluctuations resulting in increased fluvial discharge [Xing et al., 2014].

Like the Ebro, many deltas around the world have experienced substantial morphologic changes over the last millennia [Syvitski and Saito, 2007; Giosan et al., 2012; Maselli and Trincardi, 2013; Anthony et al., 2014], due to among others river damming and land-use change [Syvitski and Saito, 2007] and climate change [Ericson et al., 2006]. The Ebro delta lends itself particularly well to a quantitative reconstruction because it is morphologically constrained [Nelson, 1990], displays a distinctive information rich plan-view shape (Fig. 1), and its environment is well-studied [Maldonado, 1975]. To quantitatively constrain the style, timing and rate of Ebro delta morphologic change and the associated fluvial transport conditions of the Ebro delta during the Holocene we use a delta evolution model and a river profile evolution model.

Our goal in this paper is to investigate the general evolution of the Ebro delta-river system using "scenario-based" model experiments. We do not attempt to capture the precise morphology or geochronology, but rather approximate the Ebro delta paleo-morphodynamics and demonstrate the potential physical mechanisms behind it. This exercise allows us to test existing hypotheses of Ebro delta change, and quantify first-order sediment fluxes and timescales. To test the suitability of the delta and the river models, we compare their predictions to observed deltaic change [Jiménez and Sánchez-Arcilla, 1993] and observed fluvial change [Vericat and Batalla, 2006] of the last century. 


\section{Background}

\subsection{Ebro River}

The Ebro River formed about 5 million years ago flowing into the Mediterranean since the Pliocene, after the Messinian Salinity Crisis [Babault et al., 2006]. Its drainage basin extends over $85530 \mathrm{~km}^{2}$ and has been stable throughout the Quaternary covering a large portion of the Pyrenees and the Iberian massif [Mikeš, 2010]. The erosion rate during the Holocene highstand was estimated to ca. $200 \mathrm{kgs}^{-1}\left(6.3 \mathrm{MTyr}^{-1}\right)$ [Nelson, 1990], whereas the fluvial water discharge records from the early $20^{\text {th }}$ century average about $450 \mathrm{~m}^{3} \mathrm{~s}^{-1}$ [Batalla et al., 2004].

The average channel width in the lower course of the river is $\sim 150 \mathrm{~m}$, with a bankfull flow depth of $\sim 5 \mathrm{~m}$ [Guillén and Palanques, 1997]. Jimenez [1990] estimated the modern sand load to the delta at $1.6 \mathrm{kgs}^{-1}\left(0.05 \mathrm{MTyr}^{-1}\right)$ using predictive sediment transport formulae combined with discharge measurements. Later measurements, $50 \mathrm{~km}$ upstream of the delta, estimated the modern sediment load delivered to the delta at about $28 \mathrm{kgs}^{-1}\left(0.9 \mathrm{MT} \mathrm{yr}^{-1}\right)$, of which $40 \%$ is transported as bedload [Vericat and Batalla, 2006]. The suspended load consists mostly of clay and silt [Muñoz and Prat, 1989], while the bedload is predominantly sand and gravel [Vericat and Batalla, 2006]. The channel bed of the lower course of the Ebro consists of mixed sand and gravel, with a median grain size of $17 \mathrm{~mm}$ [Vericat and Batalla, 2006].

The modern Ebro is highly regulated by 187 dams that impound 57\% of the mean annual runoff [Batalla et al., 2004]. Prior to the construction of the major dams in the Ebro, peak discharge was about 50\% higher [Batalla et al., 2004]. While bedload transporting flows ( $>860$ $\mathrm{m}^{3} \mathrm{~s}^{-1}$ ) were previously exceeded $15 \%$ of the time, dams reduced the exceedance frequency of these floods to just $5 \%$ of the year [Vericat and Batalla, 2006]. Dams not only modify the Ebro's hydrograph, but also trap about $90 \%$ of the upstream suspended sediment load and $100 \%$ of the upstream bedload [Vericat and Batalla, 2006]. The estimated pre-dam (1913-1962) suspended and bedload sediment transport rates are $576 \mathrm{kgs}^{-1}\left(18 \mathrm{MT} \mathrm{yr}^{-1}\right)$ and $71 \mathrm{kgs}^{-1}\left(2.2 \mathrm{MT} \mathrm{yr}^{-1}\right)$ respectively [Syvitski and Saito, 2007]. This modern sediment deficit leads to scouring of the lower course of the channel bed and favors the formation of armour layers. Downstream of the dams, the channel bed surface consists of coarse gravel $\left(D_{50}=38 \mathrm{~mm}\right)$ while the subsurface consists of mixed sand and gravel $\left(\mathrm{D}_{50}=17 \mathrm{~mm}\right)$ [Vericat et al., 2006]. 


\subsection{Ebro Delta}

At the Ebro River outlet to the Mediterranean Sea, fluvial sediment deposition over the course of millions of years has formed the Ebro continental shelf and the Ebro delta [Nelson, 1990; Babault et al., 2006]. Strong waves and limited coarse-grained sediment input have shaped the Ebro coast into in a wave-dominated delta [Jimenez et al., 1997] with smooth shoreline and single thread distributary network [Galloway, 1975; Jerolmack and Swenson, 2007; Nienhuis et al., 2015c]. The Ebro nearshore zone consists mostly of sand size sediment [Maldonado, 1975; Somoza et al., 1998] down to $\sim 12 \mathrm{~m}$, and transitioning into muds farther offshore [Guillén et al., 2005]. Two distinctive features on the Ebro delta are the spits to the north (El Fangar) and south (La Banya) of the current river mouth, formed by the wave reworking of abandoned delta lobes [Maldonado, 1975].

\subsection{Delta Evolution}

Holocene sea level rise led to the transgression of the last Pleistocene Ebro delta [Maldonado, 1975], like for many other deltas around the world [Stanley and Warne, 1994]. The maximum flooding surface of the Ebro delta resulting from Holocene sea level rise is dated to about 6900 years BP, with its landward extent near the town of Amposta [Lario et al., 1995; Somoza et al., 1998]. From historical references, the Ebro was still an estuary 2000 years ago [Guillén and Palanques, 1997; Maselli and Trincardi, 2013], although this has been debated. Radiocarbon dating of relict beach ridges indicate that the modern Ebro delta was already formed $\sim 6000$ years BP [Canicio and Ibanez, 1999].

Dated beach ridges show that the Ebro delta was a small cuspate and wave-dominated at least until 3000 years BP. Progradation rates, at least 2 to 3 times faster than before, formed the Riet Vell delta lobe extending around $20 \mathrm{~km}$ into the Mediterranean probably around 1100 years BP [Canicio and Ibanez, 1999] although no dates to confirm that are yet available. This increase in progradation rate, occurring sometime between 3000 and 1100 years BP, is commonly ascribed to land use changes and climatic variability causing an increase in fluvial sediment supply [Thorndycraft and Benito, 2006]. Benito et al. [2008], dating floodplain alluviation on Spanish rivers, estimated three periods of intense flooding: 2710-2320 years BP, 2000-1830 years BP, and 910-500 years BP. Floodplain aggradation during the two later periods was attributed to anthropogenic modifications such as deforestation, because only the first of these 
periods is associated with slack water deposition (palaeoflood records) and climate variability [Benito et al., 2008]. Other deltas around the Mediterranean, which have observed similar landuse histories, show contemporaneous changes [Giosan et al., 2012; Maselli and Trincardi, 2013; Anthony et al., 2014].

To quantitatively study the effect of anthropogenic and climate change on fluvial sediment supply to the Ebro delta, Xing et al. [2014] used the long-term fluvial discharge and sediment supply model Hydrotrend [Kettner and Syvitski, 2008]. Their model results suggested that discharge variation was mostly a result of precipitation variability, whereas forest clearing contributed to changes in sediment load. Overall, Xing et al. [2014] estimated a smaller increase in the fluvial suspended sediment load ( $+40 \%)$ compared to other studies, which reconstructed a sediment budget from delta plain progradation rates and estimated an increase of 350\% [Nelson, 1990; Guillén and Palanques, 1997].

Two relict channel deposits on the delta plain [Maldonado, 1975] combined with published maps [Canicio and Ibanez, 1999] indicate that the progradation of the Riet Vell lobe stopped prior to 600 years BP. The avulsion of the main channel started a new lobe, the Sol de Riu. Subsequently Riet Vell was into reworked into the La Banya spit [Canicio and Ibanez, 1999]. After a second avulsion about 300 years ago, the Sol de Riu lobe was also abandoned and reworked into the northern, El Fangar spit [Canicio and Ibanez, 1999]. The modern MitjornBuda lobe has started to be reworked recently (Fig. 1) [Jiménez and Sánchez-Arcilla, 1993].

\subsection{Recent Changes}

The long period of rapid progradation of the Ebro delta stopped dramatically after the construction of hydropower dams, mostly constructed between 1950 and 1975 [Maldonado, 1975]. Coarse-grained sediment supply to the delta has decreased from about $70 \mathrm{kgs}^{-1}$ (2.2 MT

$\left.\mathrm{yr}^{-1}\right)$ to about $12 \mathrm{kgs}^{-1}\left(0.4 \mathrm{MT} \mathrm{yr}^{-1}\right)$ [Nelson, 1990; Vericat and Batalla, 2006; Syvitski and Saito, 2007]. While for much of the last millennia, the Ebro delta was at least periodically close to a river-dominated morphology [Jimenez et al., 1997], this sharp reduction has created a more wave-dominated delta that is expected to be further reworked by waves in the near future [Jimenez et al., 1997]. Large scale coastal change is not only caused by river damming, it is also estimated that subsidence and sea level rise will effectively submerge $45 \%$ of the delta surface by 2100 [Rovira and Ibànez, 2007]. However, in projections of coastal evolution up to 2050, sea- 
level rise is negligible compared to alongshore sediment transport gradients [Sánchez-Arcilla et al., 2008], which have caused retreat rates of $50 \mathrm{myr}^{-1}$ near the river mouth, and have resulted in spit accretion at approximately $10 \mathrm{myr}^{-1}$ [Jiménez and Sánchez-Arcilla, 1993].

\subsection{Modeling Wave-Influenced Deltas}

Many numerical models have been developed over the last decades to quantitatively reproduce, predict, and to understand the dynamics of deltaic systems. Complex 'simulation models' typically are used to reproduce a particular well-constrained natural environment or to parameterize poorly understood physical processes. Simple 'exploratory models' of 'reduced complexity' on the other hand are designed to capture the essential feedbacks leading to an observed phenomenon [Murray, 2003].

Because the long-term, millennial-scale, the development of Ebro delta is poorly constrained, we choose an exploratory model in a scenario-based approach; we aim to capture the essential physical mechanisms using an exploratory model of wave-influenced delta dynamics applied specifically to the Ebro delta.

The plan-view shape of the Ebro delta, like other wave-dominated deltas, is governed by wave-driven alongshore sediment transport [Bakker and Edelman, 1964; Jiménez and SánchezArcilla, 1993]. Modeling of wave-dominated delta shape is therefore usually performed with coastline models [Bakker and Edelman, 1964; Komar, 1973; Larson et al., 1987; e.g., Ashton and Giosan, 2011], where gradients in alongshore transport are linearly related to accretion or erosion of the coastline using the one-contour line assumption [Pelnard-Considère, 1956]. Onecontour-line models calculate alongshore sediment transport based on formulas such as the CERC formula [Komar, 1971], which relates the relative wave angle and wave energy to a sediment transport flux. The cuspate coastline shape typical of wave-influenced deltas arises by adding a point-source of (fluvial) sediment alongshore [Grijm, 1960]. However, Ashton and Giosan [2011] showed that for very obliquely approaching waves, wave-dominated deltas can become asymmetrical and develop shoreline instabilities on the downdrift flank. Large recurved spits can form if these downdrift shoreline instabilities are accompanied by a rapid reduction in sediment supply [Nienhuis et al., 2013]. 
Using an one-contour-line approach, Nienhuis et al [2015c] showed how alongshore sediment transport dynamics define the large scale planview morphology of wave-dominated deltas. If the fluvial sediment supply is larger than the maximum potential alongshore sediment transport away from both delta flanks, waves cannot transport all the fluvial sediment alongshore and the delta will be river-dominated. Following this idea, Nienhuis et al [2015c] defined the ratio $R$ as the fluvial sediment flux divided by the maximum alongshore sediment transport flux. For $R>1$, the delta is river-dominated.

\subsection{Modeling the Fluvial Sediment Supply}

The sand-sized sediment feeding the Ebro delta is supplied as bedload and suspended load through the Ebro river, interacting with the alluvial river bed [Jimenez et al., 1990]. In alluvial rivers, channel-bed interaction sets up an equilibrium between the along-stream slope, its discharge, and its sediment supply [Lane, 1955]. One of the first attempts to numerically model fluvial sediment transport was by Hirano [1971], who combined the depth averaged, onedimensional Saint-Venant equations for fluid flow with a simple formulation for sediment transport. Their model resulted in a typical concave up longitudinal river profile for a scenario of gradually increasing water discharge downstream [Hirano, 1971; Snow and Slingerland, 1987]. A more recent study using the Saint-Venant equations was done by van der Wegen et al. [2011], who applied Delft3D to study how an increased sediment supply due to mining was transported through the San Pablo Bay in California.

For normal flow conditions, the Saint-Venant equations can be simplified substantially by formulating an alongstream momentum balance that relates bed shear stress to water depth and bed slope. Models that assume normal flow are usually combined with an Exner equation for sediment conservations and a Chezy or Manning coefficient for form drag and produce a simple analytical expression for longitudinal river profiles and equilibrium sediment transport rates [Parker, 1978]. Later studies expanded this concept to account for non-steady flow conditions such as backwater zones [Hotchkiss and Parker, 1991] and the downstream migration of a sediment pulse [Cui and Parker, 2005]. In dealing with the complexity of multiple grain sizes, Ribberink [1987] modeled the effect of non-uniform sediment on fluvial morphodynamics, and Parker [1991] modeled the effects of selective transport. Paola et al. [1992] and Viparelli et al. 
[2010] combined selective transport with long term aggradation and degradation of the channel bed to investigate the resulting stratigraphic signatures of rivers.

A simpler approach to model long term fluvial sediment transport is by applying HydroTrend [Kettner and Syvitski, 2008], which uses empirical relations between among others basin area, land-cover, drainage basin relief, temperature and precipitation and is calibrated on modern sediment transport records to predict river sediment load. In HydroTrend there is no feedback with the channel form, and the fluvial sediment flux is only weakly dependent on discharge (to the 0.3 power), making the model more appropriate for simulating finer grained, wash and suspended load sediment. An advantage of HydroTrend is the ease with which spatial heterogeneities in the drainage basin like land cover, discharge and lithology can be implemented to investigate sediment yield through time.

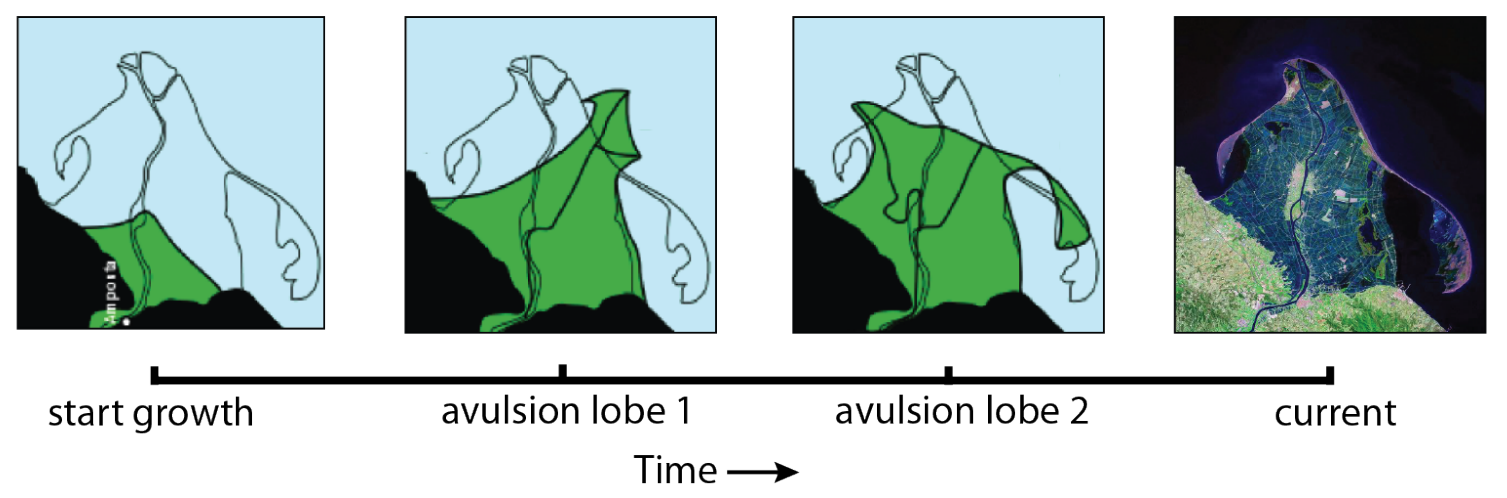

Figure 1. Reconstructed morphologic development of the Ebro delta, after Canicio and Ibanez [1999].

\section{Methods}

\subsection{Delta Evolution Model}

We study the morphologic evolution of the Ebro delta using the Coastline Evolution Model (CEM), an exploratory, process-based one-contour-line model [for a full description see Ashton and Murray, 2006a]. In this model, the plan-view coastal zone is discretized into 50m square cells that follow the shoreline. Incoming deep-water waves are refracted and shoaled assuming parallel shoreline contours from the toe of the shoreface up to the breaking wave depth. We calculate alongshore sediment transport with the CERC formula [Komar, 1971], using the 
wave height and the relative wave approach angle to determine the sediment flux across different shoreline cells. Following the one-contour-line approach, the divergence of alongshore sediment transport is then related to shoreline accretion or erosion up to the shoreface depth (which we model at $10 \mathrm{~m}$ water depth, approximately $1000 \mathrm{~m}$ offshore). We use a littoral transport coefficient $k$ of 0.15 as the littoral transport constant following studies of Jimenez and SanchezArcilla [1993].

An advantage of CEM is the ability to produce arbitrarily sinuous shoreline shapes such as spits. When the spit narrows to a critical width, overwash occurs and sediment is transported from the shoreface to the backbarrier [Jiménez and Sánchez-Arcilla, 2004]. This routine allows spits and barriers to retreat without disconnecting from the rest of the coastline [Ashton and Murray, 2006a]. Following observations of Jimenez and Sanchez-Arcilla [2004], we set the critical barrier width to $250 \mathrm{~m}$. In the past, this model has been successful at modeling deltas [Ashton and Giosan, 2011], spits [Ashton et al., 2015] and wave reworking of abandoned deltas [Nienhuis et al., 2013].

In CEM, the channel is highly simplified and is only represented as the location alongshore where the littoral grade portion of the fluvial sediment is deposited. By modeling the mass balance this way, we assume the fine-grained fluvial sediment is deposited largely offshore beyond $12 \mathrm{~m}$ depth [Guillén and Jiménez, 2009]. The characteristic shoreface slope (0.01) and shelf slope (0.002) are set based on work from Guillen and Jimenez [1995] and Jimenez and Sanchez-Arcilla [1993]. As the delta progrades or retreats, the channel location follows a predefined trajectory. To apply the delta evolution model to the Ebro, we implemented channel avulsion by forcing the channel in a new direction at a predefined point in time. Each channel builds out at a specified orientation from the coastline based upon the Ebro delta's history. The Riet Vell lobe and the Sol de Riu lobe build out at $5^{\circ}$ and $-45^{\circ}$ from shore normal, following old channel deposits [Maldonado, 1975], and the modern Mitjorn-Buda lobe is orientated at $-20^{\circ}$. A second modification to the original model is disabling alongshore sediment transport out of a cell that is part of the initial coastline. This modification accounts for the fact that the rocky coastline of Mediterranean Spain limits updrift sediment supply to the Ebro delta (Fig. 2).

Note that we are not explicitly simulating the history of the Ebro River delta, rather we use simple models to constrain fluvial sediment fluxes and delta growth in a broadly 
representative environment. We run scenarios to investigate timing of lobes, the morphology of the spits for different fluvial sediment supply rates.

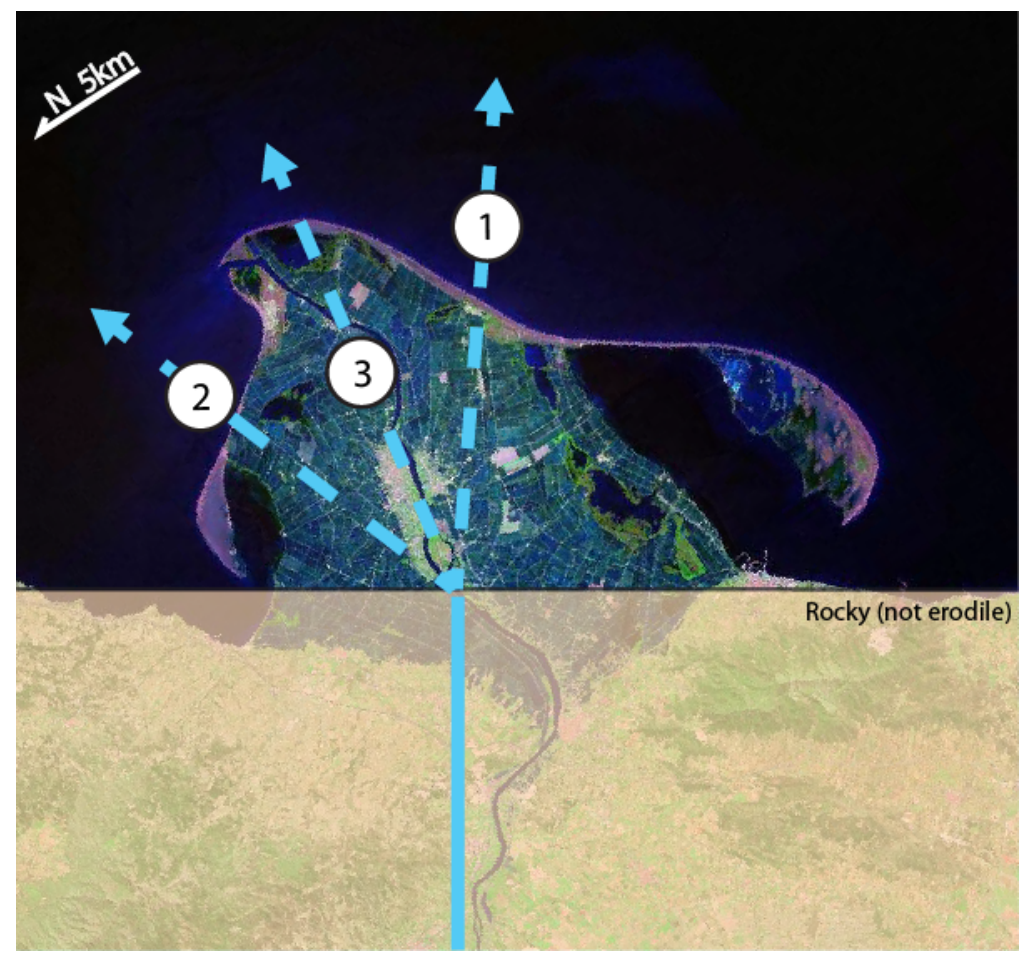

Figure 2. Modeling methodology, shown on top of the modern Ebro delta morphology (NASA Landsat image), highlighting the succession and orientation of Ebro delta lobes. The straight reference coastline is assumed to be non-erodible.

\subsection{Wave Climate}

Because wave-influenced deltas are not only controlled by wave energy but also by the angular distribution of wave energy [Ashton and Giosan, 2011], we analyzed the wave climate close to the Ebro delta. Two sources of wave climates are derived from directional wave buoys, and three are extracted from hindcasted wave models (Fig. 3 and Table 1). The wave energy and the distribution of wave energies across approach angles are comparable, but differ particularly in the relative strength of the peak of wave energy approaching from the south.

To use these distributions in the delta evolution model, we rotate the wave climates and extract the window of wave approach angles that affect alongshore sediment transport on the Ebro, correcting the long term average wave energy for the fact that waves are only directed onshore part of the year (Fig. 4 shows this process for the Cap Tortosa buoy data). All the 
sources are located in sufficiently deep water such that the waves can be treated as deep-water waves.

Table 1. Overview of 5 different sources of wave climate data close to the Ebro delta. See figure 3 for an overview of the angular distribution of wave energy.

$\begin{array}{lllllllll}\text { Name } & \text { Type } & \text { Lat } & \text { Lon } & \begin{array}{l}\text { Depth } \\ \mathbf{( m )}\end{array} & \begin{array}{l}\text { Wave } \\ \text { height (m) }\end{array} & \begin{array}{l}\text { Wave } \\ \text { period (s) }\end{array} & \begin{array}{l}\text { Period (yr) } \\ \text { Reference }\end{array} \\ \text { Cap Tortosa } & \text { buoy } & 40.7 & 1.0 & 60 & 0.8 & 4.1 & 1990-2011 & \text { Bolanos et al., 2009 } \\ \text { Tarragona } & \text { buoy } & 41.1 & 1.2 & 35 & 1.0 & 5.5 & 2004-2011 & \text { Puertos del Estado, 2015 } \\ \text { MedAtlas } & \text { model } & 40.0 & 1.0 & 222 & 0.9 & 4.0 & 1992-2002 & \text { Gaillard et al., 2004 } \\ \text { Hipocas } & \text { model } & 40.8 & 1.0 & 68 & 1.1 & 4.9 & 1958-2001 & \text { Sotillo et al., 2005 } \\ \text { Wavewatch III }{ }^{\circ} & \text { model } & 40.8 & 0.8 & 63 & 0.7 & 4.9 & 1979-2009 & \text { Chawla et al., 2011 }\end{array}$

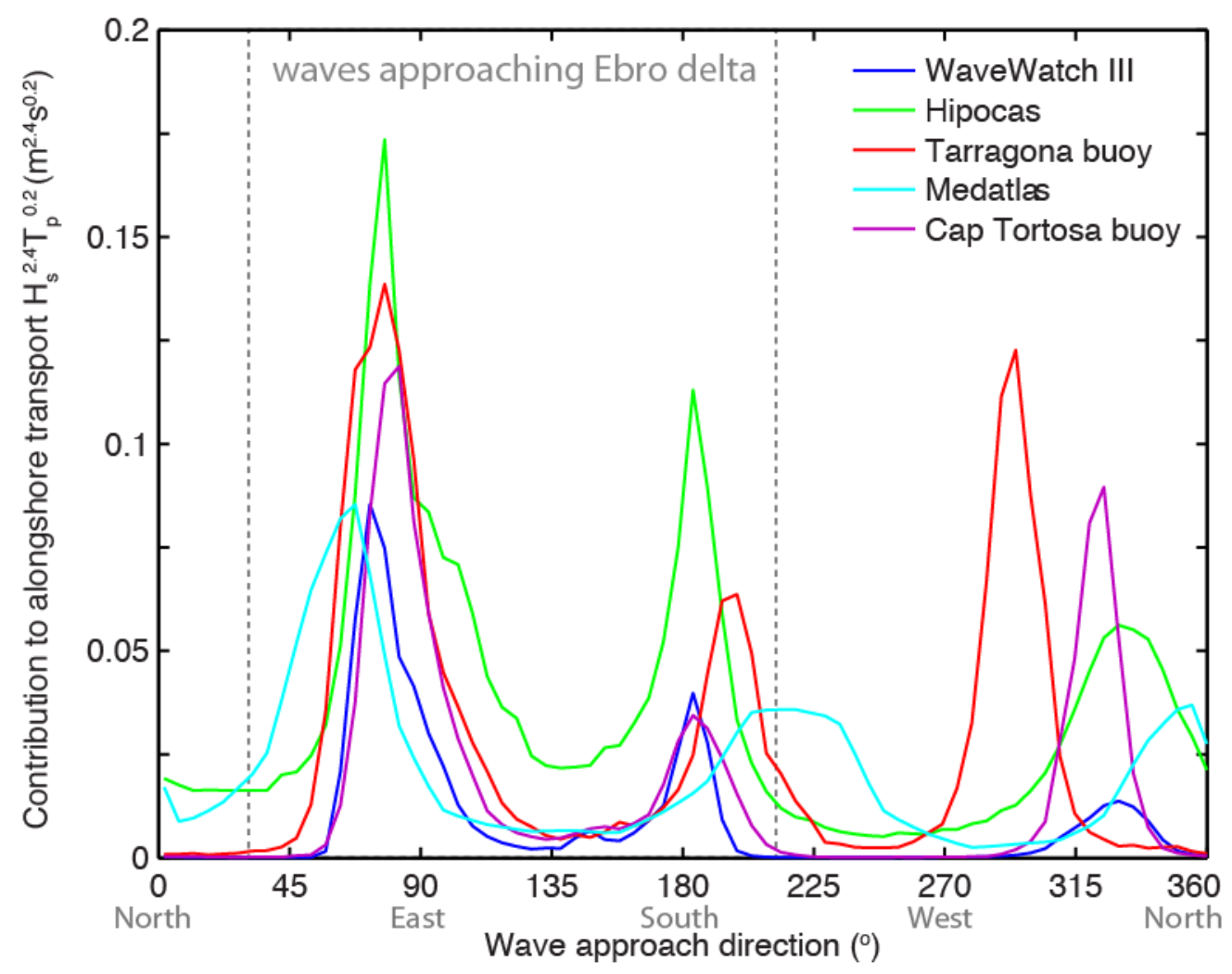

Figure 3. Angular distribution of wave energy weighted by their capacity for alongshore sediment transport for five different wave sources located close to the Ebro delta. All sources show peaks of wave energy from the East and from the South that affect Ebro delta alongshore transport, and one offshore directed peak from the North-West, see table 1 for an overview of the five sources. 


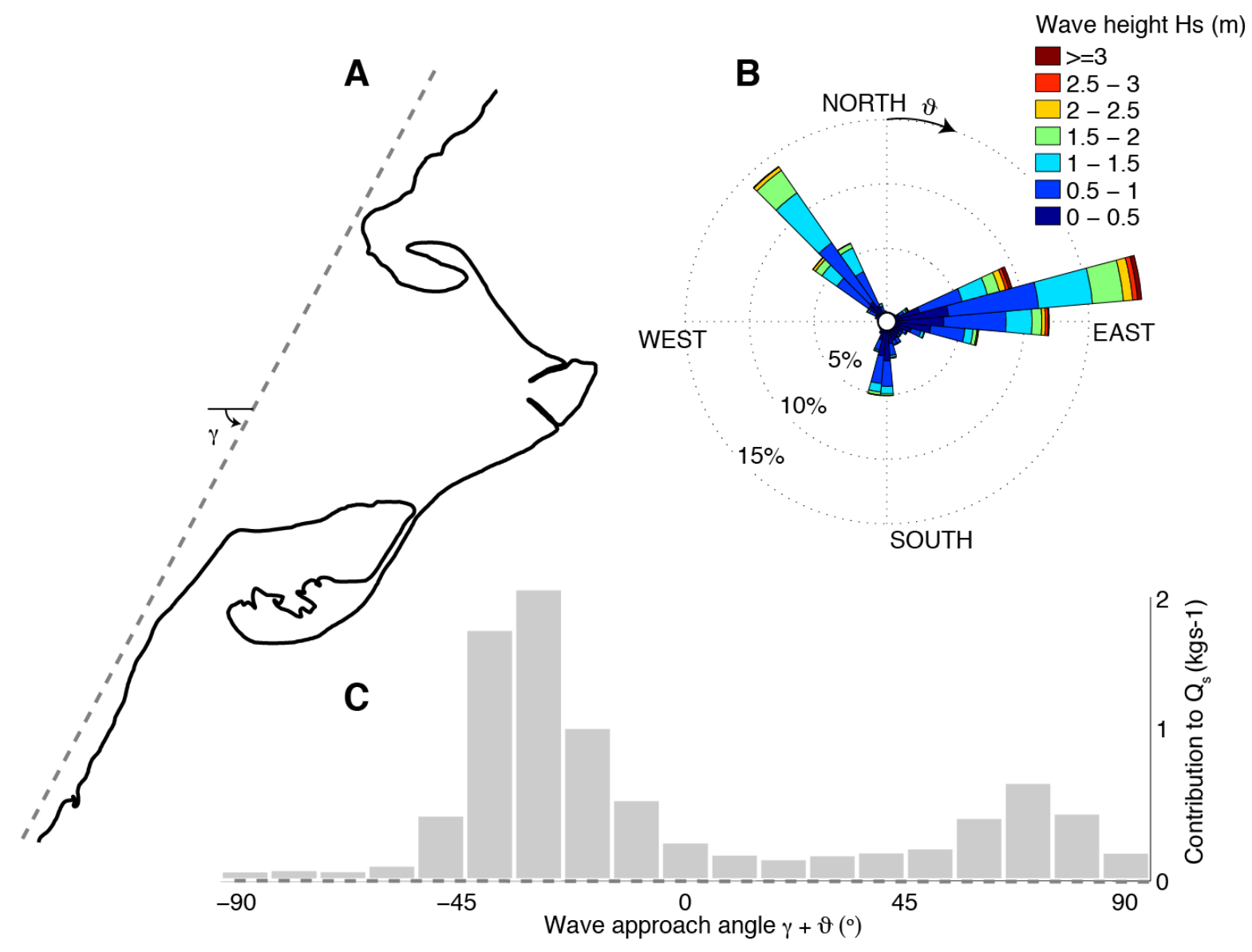

Figure 4. Wave climate transformation for the Cap Tortosa wave buoy data for the delta evolution model. (A) The modern Ebro delta shoreline retrieved from NOAA [2015]. (B) The Cap Tortosa wave buoy wave rose data. (C) The projection of the directional wave climate $H_{s}(\vartheta)$ onto the reference shoreline orientation $\gamma$ weighted by its capacity to move sediment alongshore.

\subsection{Testing the Delta Model}

To test the applicability of the delta evolution model to Ebro delta change, we compared its predictions of alongshore sediment transport to field measurements estimates of Jimenez and Sanchez-Arcilla [1993]. Their study used aerial photographs from 1957 to 1989 and beach profile measurements between 1988 and 1992 to calculate the average rate of change along the Ebro coastline. With the CERC formula [Komar, 1971], and using the 5 wave sources (Table 1 and Fig. 3), we computed alongshore sediment transport along the modern Ebro delta shoreline extracted from the NOAA shoreline database [NOAA, 2015], taking into account shadowing of certain wave approach angles by other portions of the coastline. 
The calculated littoral sediment transport trends along the Ebro delta coastline are similar between the 5 wave climates (Fig. 5), showing high sediment transport along both spits and close to the modern river mouth. The actual magnitude however between the wave climate sources differs by almost a factor of 3 . The magnitude of alongshore sediment transport flux that varies the least with the patterns estimated by Jimenez and Sanchez-Arcilla [1993] is from the Cap Tortosa buoy [described in Bolanos et al., 2009], which we therefore use in the delta evolution model (Fig. 5b, black markers).

From these alongshore sediment transport trends, we predict shoreline accretion and erosion using the one-contour-line approach. In general, both the shoreline trend and the shoreline rate of change are well predicted by the one-contour-line model and the wave climate from the Cap Tortosa buoy (Fig. 5). Around the river mouth, there is a nodal point with rapid coastal retreat to the south, and deposition further to the north of the river mouth. This good general agreement around the river mouth, without including a fluvial sediment contribution, provides further evidence of the state of rapid retreat and reworking around the coast as a result of dwindling fluvial sediment supply [Jiménez and Sánchez-Arcilla, 1993].

The difference between the alongshore sediment transport budget and the coastline change along the barrier portions of the Ebro delta are indicative of overwash that is independent of the alongshore transport-driven shoreline change. Both the northern and the southern spit are prograding at approximately $10 \mathrm{myr}^{-1}$, with coastal retreat occurring on their headland. These trends in coastal change also point to the existence of a fulcrum point on both spits, the location of maximum alongshore sediment transport where erosion of the neck of the spit changes into deposition associated with decreasing alongshore transport [Fig. 5, see also Ashton et al., 2015]. 

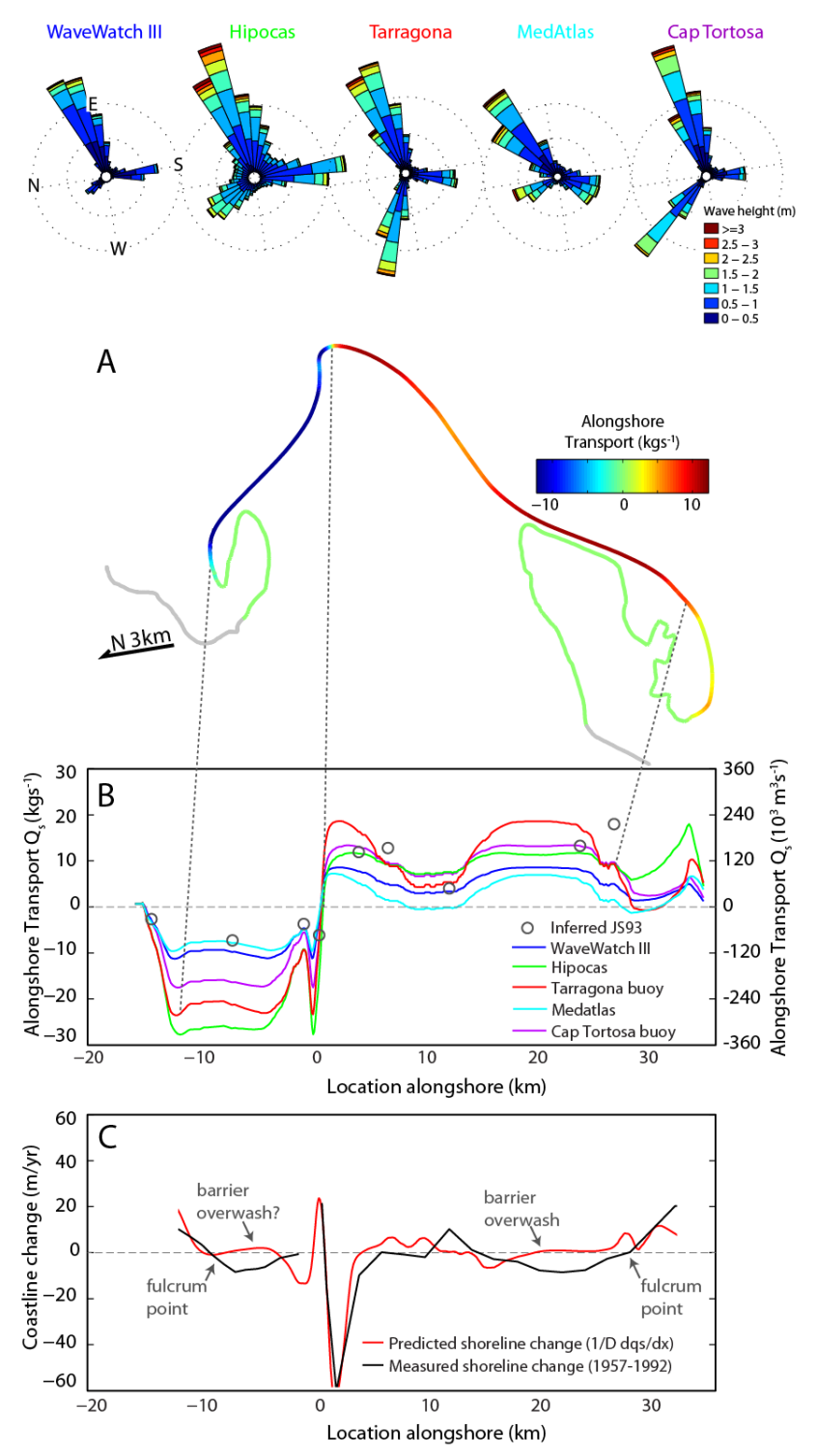

Figure 5. Comparison of the five different wave roses (see also table 1 and figure 3). (A) The Ebro delta coastline, colored by the predicted alongshore sediment transport flux from the Cap Tortosa data. (B) Alongshore sediment transport along the Ebro delta coastline from all five sources (and assuming no sediment was supplied by the Ebro River). Alongshore transport is positive to the right when looking offshore. Black markers indicate alongshore sediment transport estimates from Jimenez and Sachez-Arcilla [1993]. (C) The Cap Tortosa buoy data recasted into shoreline change rates using the one-contour-line approach compared to the measured shoreline change rates from Jimenez and Sachez-Arcilla [1993]. 


\subsection{River Modeling}

We investigate the response timescales of the river basin to climate and land-use changes using an exploratory 1-D river profile model [Parker, 2004]. In this model, sediment is not a passive tracer, but interacts with the bed elevation to reach a longitudinal profile in morphodynamic equilibrium [Carling and Cao, 2002]. Even though including the interaction between flow and topography complicates the dynamics - rivers are not treated as static pipes this model allows us to use the sequential longitudinal profiles to investigate past and present sediment transport conditions. Additionally, by focusing on the interaction of the flow with the channel bed, we can model the bed material load - sediment that makes up most of the delta - and ignore the finer grained material that is largely deposited farther offshore. The channel bed in the model is freely erodible and is therefore strictly applicable to alluvial, transport-limited systems [Parker, 2004]. This 1-D river profile model was recently applied to study timescales of sediment supply decreases in the Mississippi River [Nittrouer and Viparelli, 2014].

The 1-D river profile model assumes normal flow conditions, such that a width-averaged momentum balance connects bed slope and flow depth to bed shear stress. Flow in the channel is determined by applying a Chezy formulation for the flow resistance [Parker, 2004]. We use the Meyer-Peter and Muller [Meyer-Peter and Müller, 1948] equation to calculate sediment transport with a uniform grain size, which we choose to be the littoral grain size of $200 \mu \mathrm{m}$ [Jiménez and Sánchez-Arcilla, 1993]. This coarse grain sediment fraction is mostly transported during floods of $900 \mathrm{~m}^{3} \mathrm{~s}^{-1}$, which during pre-dam conditions were exceeded $15 \%$ of the time [Batalla et al., 2004].

We can compare the predictions from the model to the observed modern river profile and see how close the modern profile is to equilibrium. The modern Ebro River profile (Fig. 6) shows a constant slope up to $450 \mathrm{~km}$ upstream, where the channel bed steepens in response to the Arga River joining the Ebro. Applying the model based on the pre-dam fluvial and discharge conditions, we find that the equilibrium slope is estimated surprisingly well $\left(5.8^{\cdot} 10^{-4}\right.$, Fig. $\left.6 \mathrm{~b}\right)$. Note that the channel slope remains constant downstream of the confluence with Cinca River even though the flood discharge changes significantly. The steep slope of the Cinca channel (grey profile in Fig. 6b) could indicate a large grain size difference with the main-stem Ebro River. 
To investigate the effect of climate or human interventions on fluvial sediment supply to the delta, we model three different scenarios: (1) an increase in fluvial sediment supply, (2) an increase in fluvial flood discharge, and (3) an increase in fluvial sediment supply and fluvial flood discharge. For each of these scenarios, we impose the present-day conditions to be the modern (pre-dam) discharge $\left(900 \mathrm{~m}^{3} \mathrm{~s}^{-1}\right)$ and sediment supply $\left(70 \mathrm{kgs}^{-1}\right)$ (Fig. 6b), with a $30 \%$ intermittency [Wright and Parker, 2005].

The 1-D river profile model requires the choice of an upstream boundary, representing the average location of the fluvial discharge or sediment supply change in the drainage basin. The distance between the upstream boundary and the delta acts as a first-order control on fluvial sediment transport timescales. Using hydrologic records published by Batalla et al. [2004], we tracked the pre-dam morphologic (2-year) flood discharge along the Ebro river, and calculated its magnitude relative to the discharge at the delta. We set the upstream boundary condition at 450 $\mathrm{km}$ upstream of the delta, where the Ebro river discharge is $50 \%$ of its final discharge and a clear discontinuity in the longitudinal profile occurs (Fig. 6). 


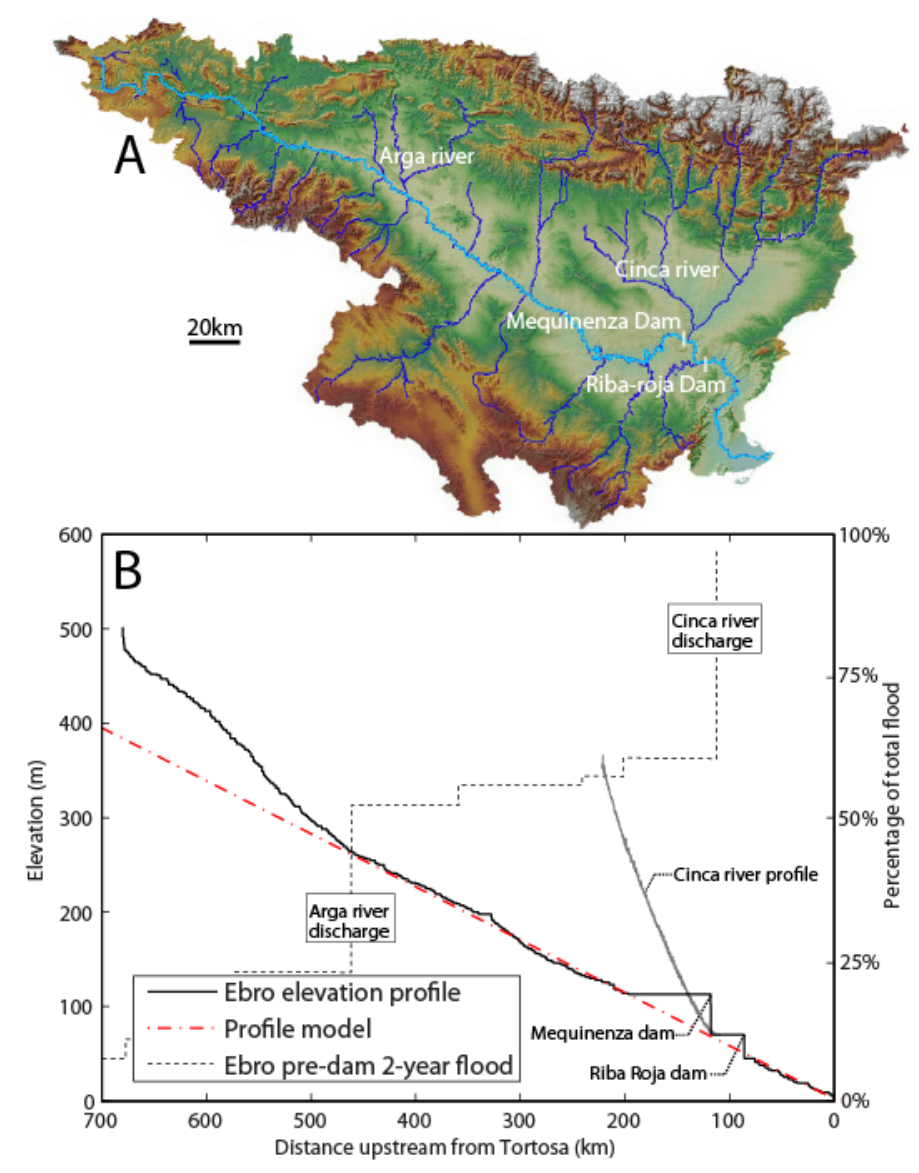

Figure 6. (A) The Ebro river basin showing the Ebro river in lightblue and its most important tributaries in darker blue, colored by elevation. (B) The elevation profile of the Ebro river, with the equilibrium profile model prediction in red dashed line. The black dashed line shows the cumulative fraction of the Ebro pre-dam discharge, increasing from $0 \%$ at the headwater to $100 \%$ at the mouth, with the Arga and the Cinca being the dominant tributaries. Data from Batalla et al. [2004].

\subsection{Testing the Fluvial Profile Model}

To test the applicability of the river profile model to estimate sediment supply changes and their corresponding timescales for the Ebro drainage basin, we compare model estimates of recent changes in the Ebro river to measured bed elevation and sediment transport changes 25 km downstream of the lowermost recent Flix Dam 55 years after its construction in 1948 (Fig. 7) [Vericat and Batalla, 2006]. 
Between 2002 and 2004, Vericat and Batalla [2006] observed an average bedload transport rate of $12 \mathrm{kgs}^{-1}$, down from pre-dam estimates of around $70 \mathrm{kgs}^{-1}$. They also observed downstream scour at a rate of about $0.03 \mathrm{myr}^{-1}$ in Mora d'Ebre (Fig. 7b). To model river profile response to dam construction, we applied a $100 \%$ reduction in sediment supply immediately downstream of the Flix Dam. Concomitantly, we decrease the upstream occurrence of bedload transporting floods $\left(900 \mathrm{~m}^{3} \mathrm{~s}^{-1}\right)$ from $30 \%$ to $8 \%$ to account for the changes in the hydrograph [Vericat and Batalla, 2006].

Even though the model does not capture processes like bed armouring and downstream fining [Vericat et al., 2006] results show reasonable agreement with the field measurements, estimating about $1 \mathrm{~m}$ of bed degradation 50 years after dam construction $\left(0.02 \mathrm{myr}^{-1}\right)$, and a sediment load of $16 \mathrm{kgs}^{-1}$. Furthermore, the model results show that the bed response to dam construction has not yet reached the Ebro delta and that, at Mora d'Ebre, about $95 \%$ of the coarse grained sediment flux reduction is due to changes in the flooding, whereas only $5 \%$ is due to a capturing of the sediment in the reservoirs (Fig. 7b).
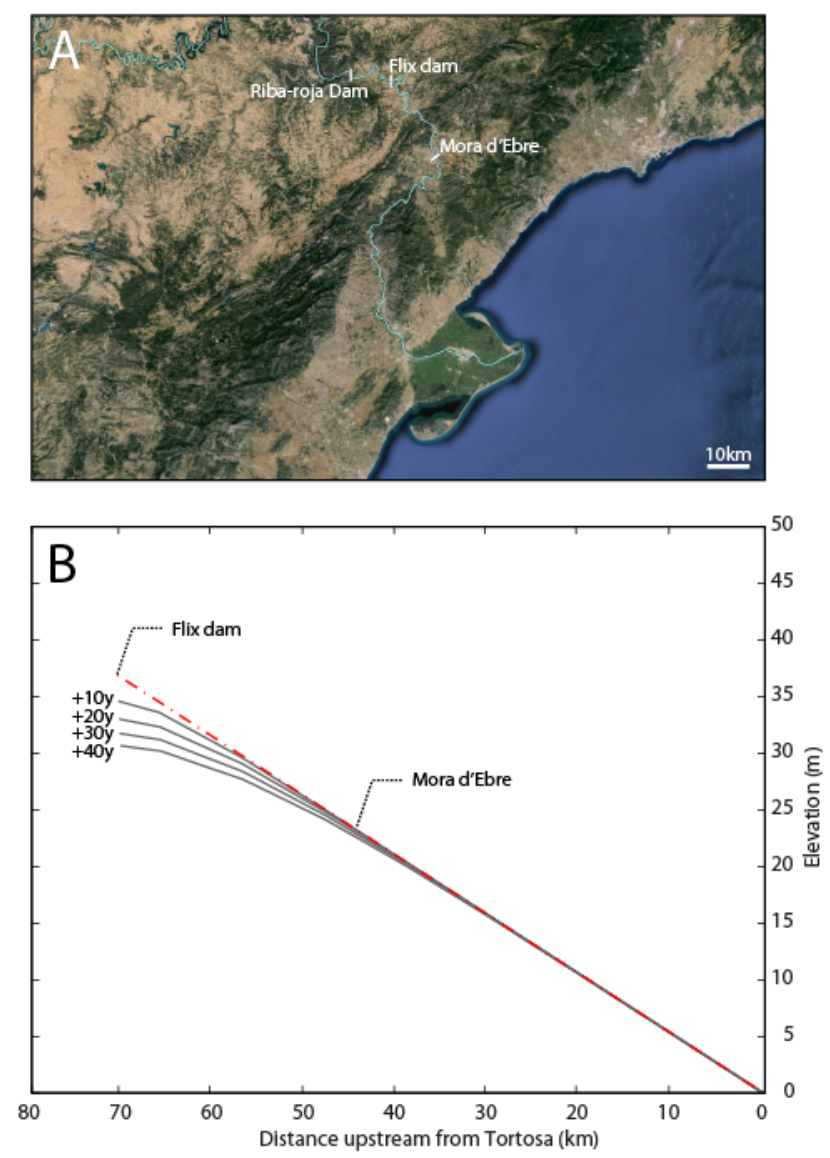
Figure 7. (A) A close-up of the Ebro drainage basin close to the delta (data from Google Earth, 2015). (B) Modeled response of the Ebro river downstream of the lowermost modern dam, the Flix dam. The bed degradation measurements from Vericat and Batalla [2006], are taken $25 \mathrm{~km}$ downstream of the Flix Dam, in Mora d'Ebre.

\section{Results}

\subsection{Delta Response to Increased Fluvial Sediment Supply}

Using our scenario-based approach, we investigated if changes in fluvial sediment supply could explain the rapid growth of the Riet Vell lobe that has be though to occur between 3000 and 1100 years BP [Canicio and Ibanez, 1999]. Our model experiments show that for bed load sediment fluxes up to about $35 \mathrm{kgs}^{-1}\left(1 \mathrm{MTyr}^{-1}\right)$, the delta morphology is cuspate (Fig. 8a), and progrades at about $5 \mathrm{myr}^{-1}$. Using a sediment flux of $70 \mathrm{kgs}^{-1}\left(2 \mathrm{MTyr}^{-1}\right)$, the delta grows at 20 myr $^{-1}$ [rates that are comparable with estimates from Maselli and Trincardi, 2013].

Wave climate analysis shows that the transition between a wave-dominated and a riverdominated morphology, with channel bifurcations and crenulated shoreline shapes, occurs at a fluvial sediment flux of about $80 \mathrm{kgs}^{-1}$. At a pre-dam estimate of $70 \mathrm{kgs}^{-1}$ [Nelson, 1990; Syvitski and Saito, 2007], this means that during the period of rapid growth [Canicio and Ibanez, 1999], the Ebro delta was close to a transition to river dominance, with a fluvial dominance ratio $R$ of 0.9 [see Nienhuis et al., 2015c]. Given the uncertainty in both alongshore sediment transport and historical estimates of fluvial sediment supply, it is possible that the Ebro delta was riverdominated throughout or repeatedly during its recent history.

In one set of model experiments, we study the effect of fluvial sediment supply on delta morphology and subsequent post-avulsion abandonment and wave reworking. Interestingly, we find very different morphologies at low fluvial sediment supply rates $\left(<40 \mathrm{kgs}^{-1}\right)$ than for high fluvial sediment supply $\left(>60 \mathrm{kgs}^{-1}\right)$. For low fluvial sediment supply, the delta remains strongly wave-dominated during growth, and no spit forms after abandonment. For high fluvial sediment supply, the delta sets up a pointy shape, with the downdrift delta flank experiencing shoreline instabilities (Fig. 2), and a spit forms after abandonment [Nienhuis et al., 2013] (Fig. 8b). Because the spit shape is largely controlled by updrift sediment supply [Ashton et al., 2015], the spits that develop after an avulsion (Fig. 8b) have a different morphology and are oriented more 
parallel to the non-deltaic coastline than the spits that form on the downdrift (right) coastline during delta growth (Fig. 8a). We speculate that the lagoons on the modern Ebro delta plain (e.g. the El Clot and La Tancada lagoons) are relics of these past growth spits that closed them from the sea.

Model experiments of delta growth and delta reworking have enabled us to constrain coarse-grained fluvial sediment supply rate leading to the cuspate morphology [around 3000 years BP, Canicio and Ibanez, 1999], and the sediment supply rate during the period of rapid growth that leads to spit reworking [around 1100 years BP, Canicio and Ibanez, 1999] to respectively less than $35 \mathrm{kgs}^{-1}$ and around $70 \mathrm{kgs}^{-1}$. Note that these values are sensitive to model parameters such as the effective shoreface depth, the littoral CERC formula constant and the basin depth [Ashton and Giosan, 2011].
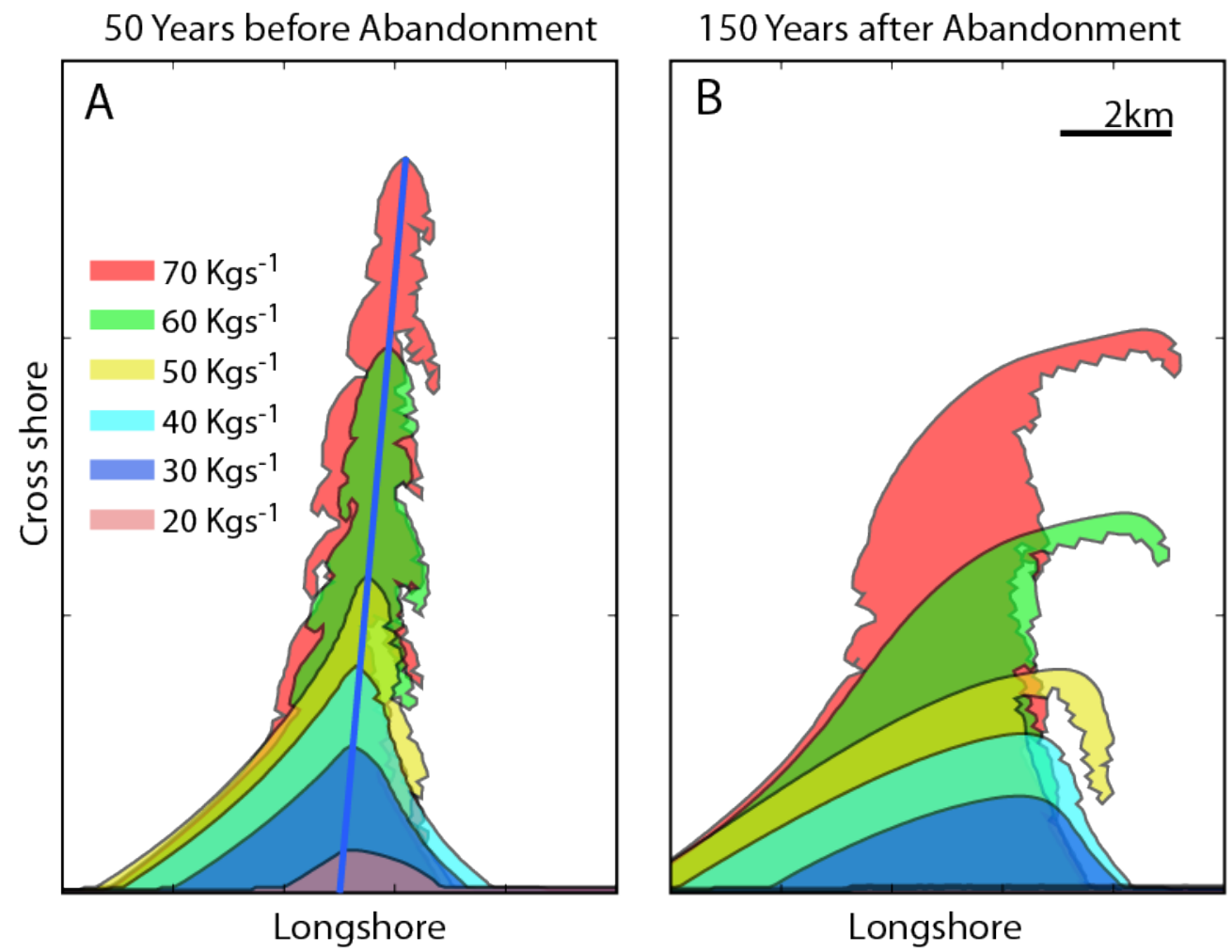

Figure 8. Modeled (A) growth and (B) reworking of the first lobe of the Ebro delta for various sediment supply rates. 


\subsection{Delta Response to Wave Climate Changes}

Investigating the effect of changes in sediment supply on the Ebro delta, we assumed the wave climate was constant. However, from previous studies [Goy et al., 2003; Sabatier et al., 2012] that focused on the western Mediterranean of the last millennia, there is compelling evidence of changes in wave climate as well. Goy et al. [2003] found that in the Gulf of Almeria in southern Spain, beach ridges were deposited during periods of negative North Atlantic Oscillation (NAO), which favor stronger winds from the southwest. Climate reconstructions show that the NAO index was more negative prior to 2000 years BP, then changed to become mostly positive up to about 600 years BP. Over the past 600 years, the NAO index has been fluctuating with short but strongly negative periods [Trouet et al., 2009].

With the Hipocas record, the longest wave climate hindcast record available spanning 44 years (Table 1), we analyzed the relationship between the wave conditions affecting the Ebro delta and the monthly NAO index. We observed a significant trend between the NAO and the directional wave climate, with higher wave energy from the south during periods of negative NAO (Fig. 9a). For more positive NAO values, waves are weaker and do not show a significant southern peak. Calculating the monthly $\mathrm{Q}_{s, \max }$, the maximum potential alongshore sediment transport rate, or how effective the wave climate is in distributing fluvial sediment alongshore, and comparing it to the NAO index, we find a trend from $140 \mathrm{kgs}^{-1}$ for strongly negative NAO, to $70 \mathrm{kgs}^{-1}$ for periods of strongly positive NAO (Fig. 9b).

Because wave-influenced delta morphology is controlled by the ratio of fluvial sediment flux to $\mathrm{Q}_{s, \max }$ [Nienhuis et al., 2015c], a significant increase in the NAO could, for equal fluvial sediment supply, significantly increase delta growth. For example, a fluvial sediment supply of $70 \mathrm{kgs}^{-1}$ would have resulted in a moderately wave-dominated delta at an NAO index of -2 , but would be significantly more fluvially-influenced at an NAO index of +2 . Wave climate change therefore offers a competing hypothesis for the rapid increase in delta growth, placing the change at about 2000 years BP. Note however that about 600 years BP, the North Atlantic Oscillation changed back to more negative conditions and higher waves. Because of observations of sustained (or even increased) delta growth after 600 years BP [Guillén and Palanques, 1997], changes in NAO were probably accompanied by an increase in fluvial sediment supply to the delta. 

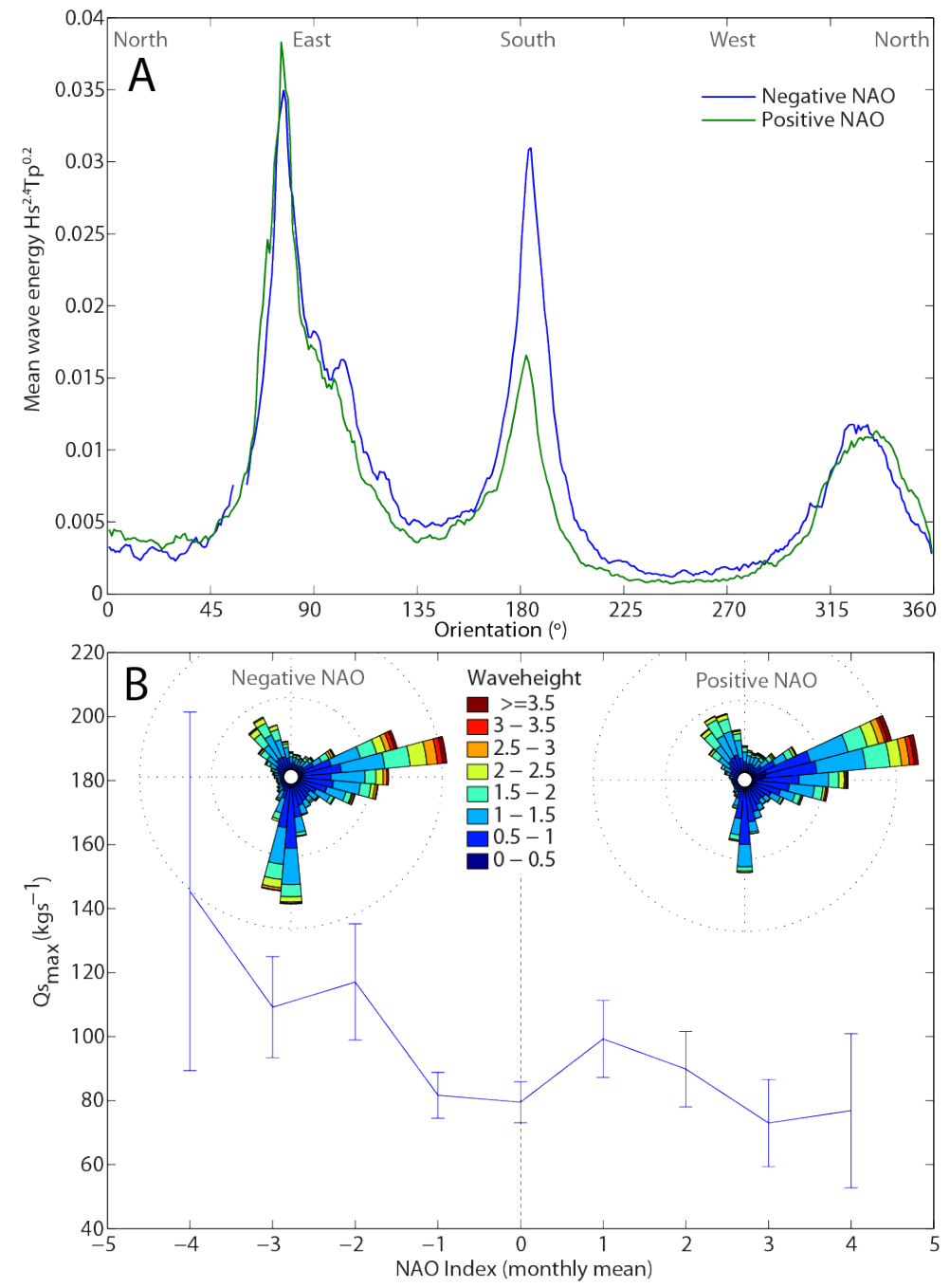

Figure 9. (A) The angular distribution of wave energy from Hipocas hindcast data [Sotillo et al., 2005], separated into periods of negative and positive North Atlantic Oscillation index [Chen and Van den Dool, 2003]. During negative NAO there is a clear enhanced peak of wave energy from the south. (B) The effect of the monthly NAO on the maximum potential alongshore sediment transport [see Nienhuis et al., 2015c]. Insets show wave roses weighted by wave energy for positive and negative NAO.

\subsection{Timescales of Deltaic Change}

The delta evolution model not only allows us to estimate the morphology of waveinfluenced deltas, it also allows us to assess the timescales associated with the growth and 
reworking of delta lobes. Analysis of the modern Ebro delta shows that both abandoned lobes, the Riet Vell lobe and the Sol de Riu lobe, extend about $10 \mathrm{~km}$ from the avulsion apex. The modern lobe, the Mitjorn, extends about $15 \mathrm{~km}$ from the apex (Fig. 2). With our estimates of fluvial sediment supply ( $70 \mathrm{kgs}^{-1}$ ), and the wave climate (the Cap Tortosa Buoy, Fig. 3), we have modeled the growth and reworking of all three lobes to match the current observed channel lengths (Fig. 10). Because the modern channel lengths are dependent on the rate of growth and reworking of the individual delta lobes, this approach yields a unique estimate for the avulsion times. Note that we do not model changes in NAO or fluvial sediment supply during our simulation to limit the number of independent variables and keep this strictly a scenario-based approach.

The best-match model scenario suggests that for the Riet Vell lobe and the Sol de Riu lobe to currently be $10 \mathrm{~km}$, the period of rapid growth must have initiated around 2000 years BP. Additionally, simulations reveal that the avulsion of the Riet Vell lobe occurred about 1100 years after rapid growth started, at 900 years BP, and that the second avulsion started about 300 years BP (Fig. 10).

Interestingly, our estimates of the start of rapid delta growth, made purely from the physical constraints set by alongshore sediment transport and fluvial sediment supply, coincide with changes in the North Atlantic Oscillation [Olsen et al., 2012], and with hydrologic changes observed in the drainage basin [Thorndycraft and Benito, 2006]. The avulsion times match closely the cartographic evidence compiled by Canicio and Ibanez [1999], at least for the second avulsion at $\sim 300$ years BP. Also the extent of the first lobe, about $20 \mathrm{~km}$, followed by an estimated $8 \mathrm{~km}$ retreat [Canicio and Ibanez, 1999], approximates the predictions from the delta evolution model. 


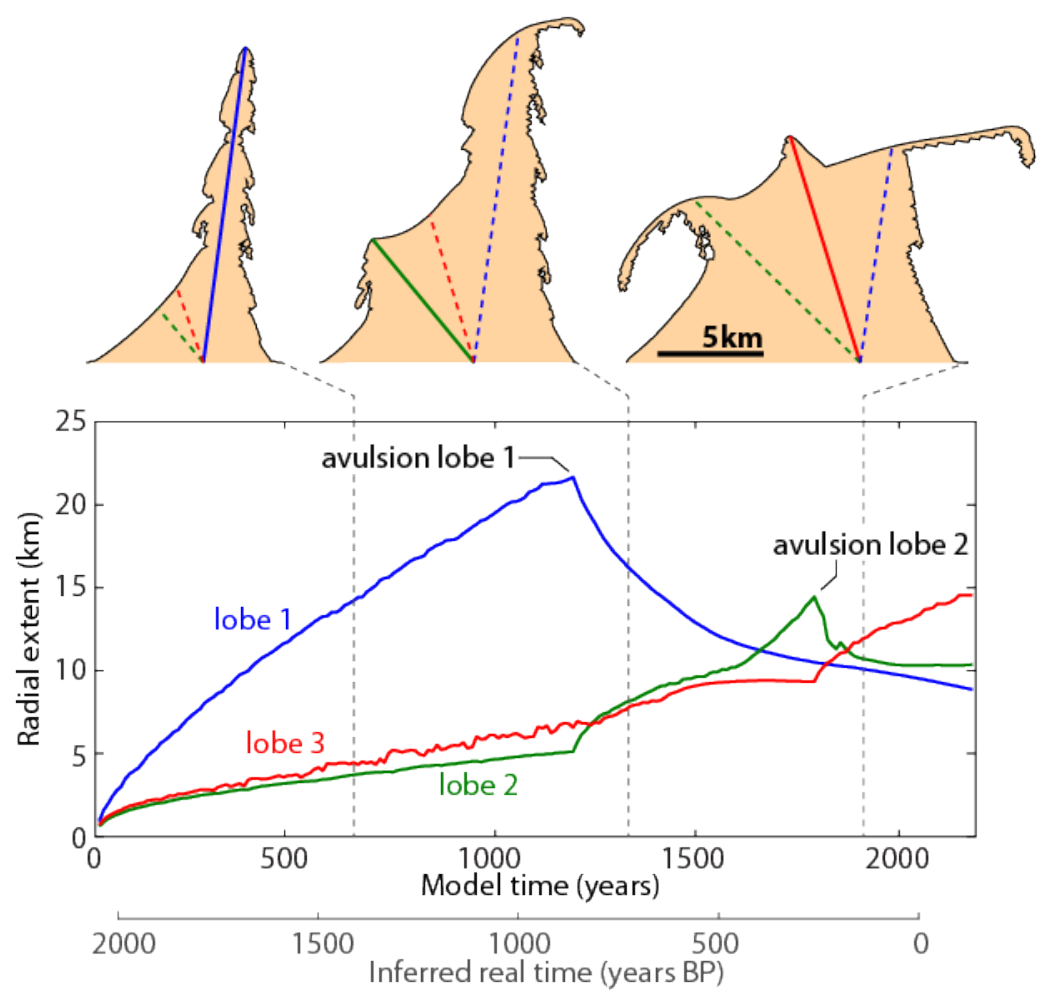

Figure 10. The radial extent of the three different Ebro delta lobes over 2200 model years, separated by color, from the delta evolution model. Note that the radial extent can increase without the lobe being active because of alongshore transport of littoral sediment building the delta. Three inset deltas show the model run after 700,1350 and 1900 years. The gray $2^{\text {nd }}$ horizontal axis indicates the real time inferred from the modern Ebro delta morphology, where lobe 1 and 2 are about $10 \mathrm{~km}$ long, and the active lobe is $15 \mathrm{~km}$ long.

\subsection{Timescales of Environmental Change}

Results from the delta evolution model, and indications from hydrologic and wave climate changes [Thorndycraft and Benito, 2006; Olsen et al., 2012], place the start of Ebro delta's rapid growth at about 2000 years BP. Using our river profile model, we can estimate when drainage basin changes occurred that would have resulted in an increase in fluvial sediment supply from around $35 \mathrm{kgs}^{-1}$ to $70 \mathrm{kgs}^{-1}$ at the delta during that time. Again, we constrain the final modeled modern river profile and hydrologic conditions to match the observed modern (pre-dam) environment. 
Table 2. Overview of the three model experiments and their final equilibrium slope and bed level change. $Q$ is the fluvial flood discharge, $I$ is the fluvial flood intermittency, $Q_{r}$ is the upstream fluvial sediment supply, $i$ is the initial antecedent fluvial environment, and $f$ is the final, modern fluvial environment.

\begin{tabular}{|c|c|c|c|c|c|c|c|}
\hline Description & $\begin{array}{l}Q_{i}\left(\mathrm{~m}^{3} \mathrm{~s}^{-1}\right), \\
\mathrm{I}(\%)\end{array}$ & $\begin{array}{l}Q_{f}\left(\mathrm{~m}^{3} \mathrm{~s}^{-1}\right), \\
\mathrm{I}(\%)\end{array}$ & $\begin{array}{l}Q_{r, i} \\
\left(\mathrm{kgs}^{-1}\right)\end{array}$ & $\begin{array}{l}Q_{r, f} \\
\left(\mathrm{kgs}^{-1}\right)\end{array}$ & $\begin{array}{l}\text { Slope } \\
\text { (i) }\end{array}$ & $\begin{array}{l}\text { Slope } \\
(f)\end{array}$ & $\begin{array}{l}\text { Upstream bed } \\
\text { level change }(\mathrm{m})\end{array}$ \\
\hline Sediment $\mathbf{x} 2$ & $900,30 \%$ & $900,30 \%$ & 35 & 70 & $2.9 \mathrm{e}-4$ & $5.8 \mathrm{e}-4$ & 130 \\
\hline Discharge $x 2$ & $900,15 \%$ & $900,30 \%$ & 35 & 35 & $5.8 \mathrm{e}-4$ & $2.9 \mathrm{e}-4$ & -130 \\
\hline Sediment and discharge $\times 2$ & $900,15 \%$ & $900,30 \%$ & 35 & 70 & $5.8 \mathrm{e}-4$ & $5.8 \mathrm{e}-4$ & 0 \\
\hline
\end{tabular}

In the scenario where we change upstream fluvial sediment supply from about $35 \mathrm{kgs}^{-1}$ to $70 \mathrm{kgs}^{-1}$, with the hydrology remaining constant, the model experiment shows that the sediment supply signal takes about 4000 years to significantly affect the Ebro delta (Fig. 11). This increase is associated with upstream aggradation of about $130 \mathrm{~m}$. While there are numerous field studies that show large alluvial deposits throughout the Ebro drainage basin that date between 6000 years BP up to 2000 years BP [Soriano, 1989; Gutiérrez-Elorza and Peña-Monné, 1998; González-Sampériz and Sopena Vicién, 2002; e.g. Benito et al., 2008; Constante and PenaMonne, 2009; Constante-Orrios et al., 2009; Constante et al., 2010], the majority of these deposits is on the order of $\sim 10 \mathrm{~m}$ in thickness. The lack of evidence for the predicted $130 \mathrm{~m}$ thick Holocene deposit makes it unlikely that exclusively a fluvial sediment supply increase occurred in the Ebro drainage basin. Even though subsequent erosion of some deposits is likely, a sustained increase in sediment supply should have been accompanied by a sustained high slope and preserved alluviation.

In contrast to fluvial sediment supply increases, changes in hydrology (flood magnitude or flood duration) propagate instantaneously across the basin (Fig. 11). A doubling in the flood duration results in a doubling of the fluvial sediment flux delivered to the delta, but would simultaneously cause the channel to start incising upstream. For about 8000 years, this incision process gradually lowers the fluvial sediment flux at the river mouth back to $35 \mathrm{kgs}^{-1}$ (Fig. 11). The current river profile is not concave down (Fig. 6b), which would be evidence of an upstream adjustment to a historical large increase in discharge. Therefore, we find it unlikely that an increase in flood discharge is the sole cause of increased Ebro delta growth. 
In a third scenario we investigated is a combination of both increased discharge and increased upstream sediment supply causing the fluvial sediment supply to the delta to change from $35 \mathrm{kgs}^{-1}$ to $70 \mathrm{kgs}^{-1}$. Interestingly, model results suggest that changing both flood discharge and sediment supply (e.g. deforestation) has a double peaked effect in deltaic sediment supply. The first peak due to upstream discharge increase is instantaneous, and the second peak due to upstream sediment supply is delayed by 4000 years (Fig. 11). Combined, these changes have a small effect on the river profile itself, with incision due to discharge increases being compensated by the aggradation caused by increased fluvial sediment supply.

Because floodplain aggradation is dependent on the elevation of the channel with respect to the surrounding floodplain [Schumm and Lichty, 1963; Heller and Paola, 1996], a scenario of increased floods leading to channel incision and increased sediment flux leading to channel aggradation has not only a double peaked response on the delta, but also a double peaked response in floodplain aggradation. Our model suggests that an increase in flood discharge would reflect an initial period of floodplain aggradation, and would decrease gradually as the channel starts to incise. The second period of floodplain aggradation would be related to the aggradation resulting from the increase in fluvial sediment supply. Interestingly, radiocarbon dating of floodplain aggradation across the entire Iberian Peninsula shows two periods of increased aggradation in the last 2000 years, one between 2000 and 1830 years BP, and one between 910500 years BP [Benito et al., 2008].

In general, model experiments of fluvial sediment transport indicate that a combination of increased flood discharge and increased fluvial sediment supply generates a response that best matches our understanding and previous findings of Ebro delta change. Unfortunately, both climate change and human impacts on landscapes such as deforestation can increase the fluvial flood discharge and the fluvial upstream sediment flux [Cosandey et al., 2005; Ferrier et al., 2013], making it difficult to use our model results to quantify the individual response of either climate or land-use changes. 

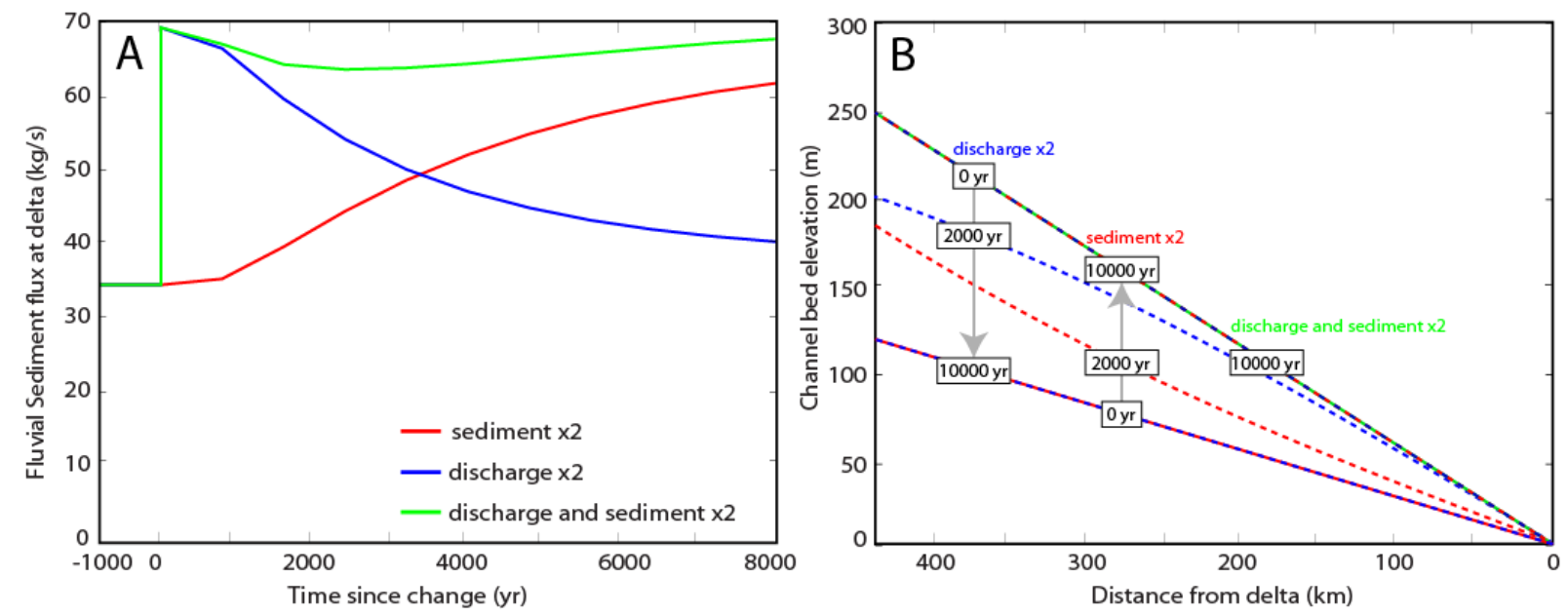

Figure 11. (A) Fluvial sediment flux at the mouth of the delta and (B) longitudinal river profile from three experiments of the river profile model: a doubling (x2) in sediment supply (red), flood discharge duration (blue) and a combination of sediment supply and flood discharge (green). See table 2 for an overview of the three experiments.

\section{$5 \quad$ Discussion and conclusions}

In this study we have used two reduced-complexity models to temporally and physically constrain the late Holocene evolution of the Ebro delta. Where possible, we have assumed the simplest possible scenario of environmental change and focused on the first-order effects on the Ebro River and its delta. We find that several independent observations of wave climate change [e.g. NAO: Olsen et al., 2012], increase in flood magnitude [Benito et al., 2008] and our delta evolution model based on the modern Ebro delta morphology all point to an increase in coarse fluvial sediment supply to the delta around 2000 years BP, allowing the delta to propagate around 2-3 times faster than before. Additionally, model experiments with the delta evolution model show that Ebro delta avulsions, resulting in the modern El Fangar and La Banya spit, likely occurred around 900 years BP and 300 years BP, consistent with other studies [Canicio and Ibanez, 1999]. Simulations also point to the formation of spits during delta growth, potentially responsible for delineating the El Clot and the La Tancada lagoons, which are distinct from large recurved El Fangar and La Banya spits.

Using constraints from the delta evolution model together with a river profile model, we find that a combination of fluvial flood discharge and fluvial sediment supply is the most likely cause of a rapid and sustained period of deltaic growth over the last 2000 years, with sediment 
supply changes occurring prior to 2000 years BP and increased floods around 2000 years BP. These estimates agree with many field studies of Holocene alluviation in the Ebro drainage basin dating between 6000 years BP and the present close to Zaragoza [Soriano, 1989; Constante et al., 2010] and further upstream in the Pyrenees [Gutiérrez-Elorza and Peña-Monné, 1998].

In this study we have highlighted a few factors that particularly influence the sensitivity of the results presented here. Fluvial sediment supply, shoreface characteristics and basin morphology all influence the morphologic predictions of the delta evolution model. Timescales of the river profile model are particularly sensitive to the upstream boundary location: the average distance between the delta and environmental change in the drainage basin. In all of the simulations presented here, we have chosen an average, representative model parameters frequently mentioned in the literature, with model results showing the broad first-order agreement with other studies of Ebro Holocene evolution.

In summary, we have shown how simple models that account for mass-balance and firstorder morphology allow for a more quantitative reconstruction of the Ebro delta paleoenvironment. This approach not only has allowed us to quantify potential effects of historical land-use and climate change on delta evolution but is also able to predict future deltaic responses and help alleviate negative effects [Giosan et al., 2014]. Simple models of coastal and fluvial dynamics used here can also be applied to other deltas around the world. Two examples are the Ombrone delta in Italy [Innocenti and Pranzini, 1993] and the Doce river delta in Brazil [Rossetti et al., 2015]. We envision using the modern plan-view shape, beach ridges, and channel orientation [Nienhuis et al., 2015b] to deltas like these to backtrack their paleo-morphology and make quantitative paleo-environmental reconstructions.

\section{References}

Anthony, E. J., N. Marriner, and C. Morhange (2014), Human influence and the changing geomorphology of Mediterranean deltas and coasts over the last 6000 years: From progradation to destruction phase?, Earth-Science Rev., 139, 336-361, doi:10.1016/j.earscirev.2014.10.003.

Ashton, A. D., and L. Giosan (2011), Wave-angle control of delta evolution, Geophys. Res. Lett., 38(13), L13405, doi:10.1029/2011GL047630.

Ashton, A. D., and A. B. Murray (2006), High-angle wave instability and emergent shoreline shapes: 1. Modeling of sand waves, flying spits, and capes, J. Geophys. Res., 111(F4), F04011, doi:10.1029/2005JF000422. 
Ashton, A. D., J. Nienhuis, and K. Ells (2015), On a neck, on a spit: controls on the shape of free spits, Earth Surf. Dyn. Discuss., 3(2), 515-560, doi:10.5194/esurfd-3-515-2015.

Babault, J., N. Loget, J. Van Den Driessche, S. Castelltort, S. Bonnet, and P. Davy (2006), Did the Ebro basin connect to the Mediterranean before the Messinian salinity crisis?, Geomorphology, 81(1-2), 155-165, doi:10.1016/j.geomorph.2006.04.004.

Bakker, W. T. J. N. P., and T. Edelman (1964), The Coastline of River-deltas, in Proc. of the 9th Conf. on Coastal Engineering, Rijkswaterstaat, Lisbon.

Batalla, R. J., C. M. Gómez, and G. M. Kondolf (2004), Reservoir-induced hydrological changes in the Ebro River basin (NE Spain), J. Hydrol., 290(1-2), 117-136, doi:10.1016/j.jhydrol.2003.12.002.

Benito, G., V. R. Thorndycraft, M. Rico, Y. Sánchez-Moya, and A. Sopeña (2008), Palaeoflood and floodplain records from Spain: Evidence for long-term climate variability and environmental changes, Geomorphology, 101(1-2), 68-77, doi:10.1016/j.geomorph.2008.05.020.

Bolanos, R., G. Jorda, J. Cateura, J. Lopez, J. Puigdefabregas, J. Gomez, M. Espino, and R. Bolaños (2009), The XIOM: 20 years of a regional coastal observatory in the Spanish Catalan coast, J. Mar. Syst., 77(3), 237-260, doi:10.1016/j.jmarsys.2007.12.018.

Canicio, A., and C. Ibanez (1999), The Holocene Evolution of the Ebro Delta Catalonia, Spain, Acta Geogr. Sin., 54(5), 462-469.

Carling, P. A., and Z. Cao (2002), Mathematical modelling of alluvial rivers: reality and myth. Part 1: General review, Proc. ICE - Water Marit. Eng., 154(4), 297-307, doi:10.1680/wame.2002.154.4.297.

Chawla, A., D. Spindler, and H. L. Tolman (2011), A Thirty Year Wave Hindcast Using The Latest NCEP Climate Forecast System Reanalysis Winds, in Proceedings of the 12th International Workshop on Wave Hindcasting and Forecasting, Kohala Coast, Hawaii.

Chen, W. Y., and H. Van den Dool (2003), Sensitivity of Teleconnection Patterns to the Sign of Their Primary Action Center, Mon. Weather Rev., 131(11), 2885-2899, doi:10.1175/15200493(2003)131<2885:SOTPTT>2.0.CO;2.

Constante, A., and J. L. Pena-Monne (2009), Human-induced erosion and sedimentation during the Holocene in the central Ebro depression, in International Conference on Desertification, pp. 207-210, University of Murcia, Murcia, Spain.

Constante, A., J. L. Peña-Monné, and A. Muñoz (2010), Alluvial geoarchaeology of an ephemeral stream: Implications for Holocene landscape change in the central part of the Ebro Depression, northeast Spain, Geoarchaeology, 25(4), 475-496, doi:10.1002/gea.20314.

Constante-Orrios, A., R. Dossche, J. L. Pena-Monne, C. Sancho-Marcen, and M. de Dapper (2009), Holocene evolution and geoarcheaology in the Ebro valley around Zaragoza (Northern Spain), in Ol' Man River: geo-archaeological aspects of rivers and river plains, edited by M. de Dapper, F. Vermeulen, S. Deprez, and D. Taelman, pp. 241-256, Academia Press, Ghent, Belgium. 
Cosandey, C., V. Andréassian, C. Martin, J. F. Didon-Lescot, J. Lavabre, N. Folton, N. Mathys, and D. Richard (2005), The hydrological impact of the mediterranean forest: a review of French research, J. Hydrol., 301(1-4), 235-249, doi:10.1016/j.jhydrol.2004.06.040.

Cui, Y., and G. Parker (2005), Numerical Model of Sediment Pulses and Sediment-Supply Disturbances in Mountain Rivers, J. Hydraul. Eng., 131(8), 646-656, doi:10.1061/(ASCE)0733-9429(2005)131:8(646).

Ericson, J., C. Vorosmarty, S. Dingman, L. Ward, and M. Meybeck (2006), Effective sea-level rise and deltas: Causes of change and human dimension implications, Glob. Planet. Change, 50(1-2), 63-82, doi:10.1016/j.gloplacha.2005.07.004.

Ferrier, K. L., J. T. Perron, S. Mukhopadhyay, M. Rosener, J. D. Stock, K. L. Huppert, and M. Slosberg (2013), Covariation of climate and long-term erosion rates across a steep rainfall gradient on the Hawaiian island of Kaua'i, Geol. Soc. Am. Bull., 125(7-8), 1146-1163, doi:10.1130/B30726.1.

Gaillard, P. et al. (2004), Wind and Wave Atlas of the Mediterranean Sea, edited by Western European Armaments Organisation Research Cell,

Galloway, W. D. (1975), Process Framework for describing the morphologic and stratigraphic evolution of deltaic depositional systems, in Deltas, Models for Exploration, edited by M. L. Broussard, pp. 86-98, Houston Geological Society, Houston, TX.

Giosan, L., M. J. L. Coolen, J. O. Kaplan, S. Constantinescu, F. Filip, M. Filipova-Marinova, A. J. Kettner, and N. Thom (2012), Early Anthropogenic Transformation of the Danube-Black Sea System, Sci. Rep., 2.

Giosan, L., J. Syvitski, S. Constantinescu, and J. Day (2014), Climate change: Protect the world's deltas, Nature, 516(7529), 31-33, doi:10.1038/516031a.

González-Sampériz, P., and M. . Sopena Vicién (2002), Recent Holocene palaeoenvironmental evolution in the central Ebro Basin (NE Spain), Quat. Int., 93-94, 177-190, doi:10.1016/S1040-6182(02)00016-2.

Goy, J. L., C. Zazo, and C. J. Dabrio (2003), A beach-ridge progradation complex reflecting periodical sea-level and climate variability during the Holocene (Gulf of Almería, Western Mediterranean), Geomorphology, 50(1-3), 251-268, doi:10.1016/S0169-555X(02)00217-9.

Grijm, W. (1960), Theoretical forms of shorelines, in IXth Conference on Coastal Engineering, vol. 2.13, pp. 197-202, Lisbon.

Guillén, A., and J. Palanques (1997), A historical perspective of the morphological evolution in the lower Ebro river, Environ. Geol., 30(3), 174-180.

Guillen, J., and J. Jimenez (1995), Processes behind the Longshore Variation of the Sediment Grain Size in the Ebro Delta Coast, J. Coast. Res., 11(1), 205-218.

Guillén, J., and J. A. Jiménez (2009), Comment on "Wave climate, sediment supply and the depth of the sand-mud transition: A global survey" by D.A. George and P.S. Hill [Marine Geology 254 (2008) 121-128], Mar. Geol., 264(3-4), 258-261, doi:10.1016/j.margeo.2009.04.004. 
Guillén, J., J. A. Jiménez, A. Palanques, P. Puig, and V. Gracia (2005), Bottom Sediment Variability in the Active Layer of the Inner Shelf off the Ebro Delta, J. Coast. Res., 213(3), 482-496, doi:10.2112/03-0056.1.

Gutiérrez-Elorza, M., and J. L. Peña-Monné (1998), Geomorphology and late Holocene climatic change in Northeastern Spain, Geomorphology, 23(2-4), 205-217, doi:10.1016/S0169$555 \mathrm{X}(98) 00004-\mathrm{X}$.

Heller, P. L., and C. Paola (1996), Downstream Changes in Alluvial Architecture: An Exploration of Controls on Channel-stacking Patterns, J. Sediment. Res., 66(2), 297-306.

Hirano, M. (1971), River bed degradation with armouring, Trans. Japanese Soc. Civ. Eng., 3, 194-195.

Hotchkiss, R. H., and G. Parker (1991), Shock Fitting of Aggradational Profiles Due to Backwater, J. Hydraul. Eng., 117(9), 1129-1144, doi:10.1061/(ASCE)07339429(1991)117:9(1129).

Innocenti, L., and E. Pranzini (1993), Geomorphological Evolution and Sedimentology of the Ombrone River Delta, Italy, J. Coast. Res., 9(2), 481-493.

Jerolmack, D. J., and J. B. Swenson (2007), Scaling relationships and evolution of distributary networks on wave-influenced deltas, Geophys. Res. Lett., 34(23), L23402, doi: $10.1029 / 2007 \mathrm{~g} 1031823$.

Jimenez, J. A., M. A. Garcia, and A. Sanchez-Arcilla (1990), Análisis y propuesta de soluciones para establizar el delta del Ebro: Estimatión del transporte de sedimentos en el río Ebro: Contributión a la evolución costera, Barcelona.

Jimenez, J. A., A. Sanchez-Arcilla, H. I. Valdemoro, V. Gracia, and F. Nieto (1997), Processes reshaping the Ebro delta, Mar. Geol., 144(1-3), 59-79.

Jiménez, J. A., and A. Sánchez-Arcilla (1993), Medium-term coastal response at the Ebro delta, Spain, Mar. Geol., 114(1-2), 105-118, doi:10.1016/0025-3227(93)90042-T.

Jiménez, J. A., and A. Sánchez-Arcilla (2004), A long-term (decadal scale) evolution model for microtidal barrier systems, Coast. Eng., 51(8-9), 749-764, doi:10.1016/j.coastaleng.2004.07.007.

Kettner, A. J., and J. P. M. Syvitski (2008), HydroTrend v.3.0: A climate-driven hydrological transport model that simulates discharge and sediment load leaving a river system, Comput. Geosci., 34(10), 1170-1183, doi:Doi 10.1016/J.Cageo.2008.02.008.

Komar, P. D. (1971), Mechanics of Sand Transport on Beaches, J. Geophys. Res., 76(3), $713-$ 721, doi:10.1029/Jc076i003p00713.

Komar, P. D. (1973), Computer models of delta growth due to sediment input from rivers and longshore transport, Bull. Geol. Soc. Am., 84(7), 2217-2226, doi:10.1130/00167606(1973)84<2217:CMODGD>2.0.CO;2.

Lane, E. W. (1955), The Importance of Fluvial Morphology in Hydraulic Engineering, Am. Soc. Civ. Eng. Proc., 81(745), 1-17. 
Lario, J., C. Zazo, C. J. Dabrio, L. Somoza, J. L. Goy, T. Bardaji, and P. G. Silva (1995), Recent Holocene Record on Spit Bars and Deltas Sediment of South Input Spain, J. Coast. Res., SI $17,241-245$.

Larson, M., H. Hanson, and N. C. Kraus (1987), Analytical solutions of the one-line model of shoreline change, US Army Waterw. Exp. Stn., Vicksburg.

Maldonado, A. (1975), Sedimentation, Stratigraphy, and Development of the Ebro Delta, Spain, in Deltas: Models for Exploration, edited by M. Lou Broussard, pp. 311-338, Houston Geological Society, Houston.

Maselli, V., and F. Trincardi (2013), Man made deltas., Sci. Rep., 3, 1926, doi:10.1038/srep01926.

Meyer-Peter, E., and R. Müller (1948), Formulas for Bed-Load Transport, in Proceedings of the 2nd Meeting of the International Association for Hydraulic Structures Research, pp. 39-64, Stockholm.

Mikeš, D. (2010), The upper cenozoic evolution of the Duero and Ebro fluvial systems (NSpain): part I. paleogeography; part II. geomorphology, Open Geosci., 2(3), 420-432, doi:10.2478/v10085-010-0017-4.

Muñoz, I., and N. Prat (1989), Effects of river regulation on the lower Ebro river (NE Spain), Regul. Rivers Res. Manag., 3(1), 345-354, doi:10.1002/rrr.3450030132.

Murray, A. B. (2003), Contrasting the goals, strategies and predictions associated with simplified numerical models and detailed simulations, in Prediction in geomorphology, edited by P. R. Wilcock and R. M. Iverson, pp. 151-165, American Geophysical Union, Washington DC, USA.

Nelson, C. H. (1990), Estimated post-Messinian sediment supply and sedimentation rates on the Ebro continental margin, Spain, Mar. Geol., 95(3-4), 395-418, doi:10.1016/00253227(90)90126-5.

Nienhuis, J. H., A. D. Ashton, P. C. Roos, S. J. M. H. Hulscher, and L. Giosan (2013), Wave reworking of abandoned deltas, Geophys. Res. Lett., 40(22), 5899-5903, doi:10.1002/2013GL058231.

Nienhuis, J. H., A. D. Ashton, and L. Giosan (2015a), Steering of deltaic channels through river mouth bypassing and alongshore sediment transport, Prep.

Nienhuis, J. H., A. D. Ashton, and L. Giosan (2015b), What makes a delta wave-dominated?, Geology, 43(6), 511-514, doi:10.1130/G36518.1.

Nittrouer, J. A., and E. Viparelli (2014), Sand as a stable and sustainable resource for nourishing the Mississippi River delta, Nat. Geosci., 7(5), 350-354, doi:10.1038/ngeo2142.

NOAA (2015), NOAA GSHHG Coastline, Natl. Geophys. Data Cent. Available from: http://www.ngdc.noaa.gov/mgg/shorelines/shorelines.html

Olsen, J., N. J. Anderson, and M. F. Knudsen (2012), Variability of the North Atlantic Oscillation over the past 5,200 years, Nat. Geosci., 5(11), 808-812, doi:10.1038/ngeo1589. 
Paola, C., P. L. Heller, and C. L. Angevine (1992), The large-scale dynamics of grain-size variation in alluvial basins, 1: Theory, Basin Res., 4(2), 73-90, doi:10.1111/j.13652117.1992.tb00145.x.

Parker, G. (1978), Self-formed straight rivers with equilibrium banks and mobile bed. Part 1. The sand-silt river, J. Fluid Mech., 89(01), 109-125, doi:10.1017/S0022112078002505.

Parker, G. (1991), Selective Sorting and Abrasion of River Gravel. I: Theory, J. Hydraul. Eng., 117(2), 131-147, doi:10.1061/(ASCE)0733-9429(1991)117:2(131).

Parker, G. (2004), 1D Sediment Transport Morphodynamics with Applications to Rivers and Turbidity Currents, ebook: hydrolab.illinois.edu/people/parkerg/morphodynamics_ebook.htm, Minneapolis.

Pelnard-Considère, R. (1956), Essai de theorie de l'Evolution des Formes de Rivage en Plages de Sable et de Galets, 4th Journees l'Hydraulique, Les Energies la Mer, Quest. III, vol. 1.

Puertos del Estado (2015), Wave Buoy data from Puertos del Estado, Available from: www.puertos.es

Ribberink, J. S. (1987), Mathematical modelling of one-dimensional morphological changes in rivers with non-uniform sediment, Delft University of Technology.

Rossetti, D. de F., S. P. Polizel, M. C. L. Cohen, and L. C. R. Pessenda (2015), Late PleistoceneHolocene evolution of the Doce River delta, southeastern Brazil: Implications for the understanding of wave-influenced deltas, Mar. Geol., 367, 171-190, doi:10.1016/j.margeo.2015.05.012.

Rovira, A., and C. Ibàñez (2007), Sediment management options for the lower Ebro River and its delta, J. Soils Sediments, 7(5), 285-295, doi:10.1065/jss2007.08.244.

Sabatier, P., L. Dezileau, C. Colin, L. Briqueu, F. Bouchette, P. Martinez, G. Siani, O. Raynal, and U. Von Grafenstein (2012), 7000years of paleostorm activity in the NW Mediterranean Sea in response to Holocene climate events, Quat. Res., 77(1), 1-11, doi:10.1016/j.yqres.2011.09.002.

Sánchez-Arcilla, A., J. a. Jiménez, H. I. Valdemoro, and V. Gracia (2008), Implications of Climatic Change on Spanish Mediterranean Low-Lying Coasts: The Ebro Delta Case, J. Coast. Res., 242(2), 306-316, doi:10.2112/07A-0005.1.

Schumm, S., and R. Lichty (1963), Channel widening and flood-plain construction along Cimarron River in southwestern Kansas, Geol. Surv. Prof. Pap., 352-D(D), 71-88.

Snow, R. S., and R. L. Slingerland (1987), Mathematical modeling of graded river profiles, J. Geol., 95(1), 15-33.

Somoza, L., A. Barnolas, A. Arasa, A. Maestro, J. G. Rees, and F. J. Hernandez-Molina (1998), Architectural stacking patterns of the Ebro delta controlled by Holocene high-frequency eustatic fluctuations, delta-lobe switching and subsidence processes, Sediment. Geol., 117(1-2), 11-32, doi:10.1016/S0037-0738(97)00121-8.

Soriano, M. A. (1989), Infilled valleys in the central Ebro Basin (Spain), CATENA, 16(4-5), 357-367, doi:10.1016/0341-8162(89)90020-9. 
Sotillo, M. G., A. W. Ratsimandresy, J. C. Carretero, A. Bentamy, F. Valero, and F. GonzálezRouco (2005), A high-resolution 44-year atmospheric hindcast for the Mediterranean Basin: contribution to the regional improvement of global reanalysis, Clim. Dyn., 25(2-3), 219236, doi:10.1007/s00382-005-0030-7.

Stanley, D. J., and A. G. Warne (1994), Worldwide Initiation of Holocene Marine Deltas by Deceleration of Sea-Level Rise, Science (80-. )., 265(5169), 228-231, doi:10.1126/science.265.5169.228.

Syvitski, J. P. M. M., and Y. Saito (2007), Morphodynamics of deltas under the influence of humans, Glob. Planet. Change, 57(3-4), 261-282, doi:10.1016/j.gloplacha.2006.12.001.

Thorndycraft, V. R., and G. Benito (2006), The Holocene fluvial chronology of Spain: evidence from a newly compiled radiocarbon database, Quat. Sci. Rev., 25(3-4), 223-234, doi:10.1016/j.quascirev.2005.07.003.

Vericat, D., and R. J. Batalla (2006), Sediment transport in a large impounded river: The lower Ebro, NE Iberian Peninsula, Geomorphology, 79(1-2), 72-92, doi:10.1016/j.geomorph.2005.09.017.

Vericat, D., R. J. Batalla, and C. Garcia (2006), Breakup and reestablishment of the armour layer in a large gravel-bed river below dams: The lower Ebro, Geomorphology, 76(1-2), 122136, doi:10.1016/j.geomorph.2005.10.005.

Viparelli, E., O. E. Sequeiros, A. Cantelli, P. R. Wilcock, and G. Parker (2010), River morphodynamics with creation/consumption of grain size stratigraphy 2: numerical model, J. Hydraul. Res., 48(6), 727-741, doi:10.1080/00221686.2010.526759.

van der Wegen, M., B. E. Jaffe, and J. A. Roelvink (2011), Process-based, morphodynamic hindcast of decadal deposition patterns in San Pablo Bay, California, 1856-1887, J. Geophys. Res., 116(F2), F02008, doi:10.1029/2009JF001614.

Wright, S., and G. Parker (2005), Modeling downstream fining in sand-bed rivers. I: formulation, J. Hydraul. Res., 43(6), 613-620, doi:10.1080/00221680509500381.

Xing, F., A. J. Kettner, A. Ashton, L. Giosan, C. Ibáñez, and J. O. Kaplan (2014), Fluvial response to climate variations and anthropogenic perturbations for the Ebro River, Spain in the last 4000years., Sci. Total Environ., 473-474, 20-31, doi:10.1016/j.scitotenv.2013.11.083. 


\section{Conclusions}

In this thesis I have studied wave-influenced deltas, focusing on predictive tools of delta plan-view shape (Ch. 1-3) as well as the application of these predictive tools to study how deltas might evolve into the coming century (Ch. 4), and to backtrack the modern observed morphology of river deltas for paleo-environmental reconstructions (Ch. 5)

In our first-order predictive model of delta morphology, we find that we can determine whether a delta is wave-dominated or river-dominated by quantifying the ratio between the coarse-grained fluvial sediment supply and the maximum potential ability of waves to spread sediments along the coast. A test on 25 deltas along the North shore of Java, Indonesia, and several other deltas worldwide, shows that this ratio is able to predict delta morphology and can be applied to estimate the vulnerability of deltas to environmental change.

The orientation of delta channels orientation is important because it greatly affects deltaic morphology and sedimentology both subaerially and in the deep-sea environment. In Chapter 2, a predictive framework linked fluvial sediment supply and wave characteristics to deltaic channel orientation, highlighting the importance of the previously largely overlooked effect of alongshore sediment bypassing of river mouths on delta morphology. Among others, alongshore sediment bypassing of river mouths is responsible for the downdrift migration of deltaic channels and the ultimate sedimentary asymmetry of deltas. Using detailed hydrodynamics and morphodynamic models, Chapter 3 then demonstrated how wave-current interactions around the river mouth leads to updrift trapping of sediment and a subsequent decrease in alongshore sediment bypassing.

Application of theories on delta morphology to two particular relevant scenarios, the deltaic response to river damming and palaeoenvironmental reconstruction using observed delta morphology, highlight the sensitivity of delta to fluvial sediment supply. Our results show how and how fast waves rework deltas following a rapid decrease in fluvial sediment supply. This thesis also highlights how scenario-based investigations of deltaic systems using simple models allows for a quantitative reconstruction of the paleo-environment, essential not only to address the impacts of past human influence and climate change, but also to better predict the future of modern deltaic landforms. 


\section{Appendices for chapter 1}

\section{Supplemental Methods}

Alongshore sediment transport is computed using the CERC or Komar (Komar, 1998) formula, reformulated into deep-water wave properties (Ashton and Murray, 2006) by backrefracting the waves over shore-parallel contours, which yields:

$$
Q_{s}=K_{1} \cdot \rho_{s} \cdot(1-p) \cdot H_{s}^{12 / 5} T^{1 / 5} \cos ^{6 / 5}\left(\phi_{0}-\theta\right) \sin \left(\phi_{0}-\theta\right),
$$

in units of $\mathrm{kgs}^{-1}$. Where

$$
K_{1}=5.3 \cdot 10^{-6} \cdot K\left(\frac{1}{2 n}\right)^{6 / 5}\left(\frac{\sqrt{g \gamma_{b}}}{2 \pi}\right)^{1 / 5}
$$

is an empirical constant that equals $\sim 0.06 \mathrm{~m}^{3 / 5} \mathrm{~s}^{-6 / 5} . K=0.46 \mathrm{rg}^{3 / 2}$ (Komar, 1998), $H_{s}$ is the offshore deep-water significant wave height $(\mathrm{m}), T$ is the wave period (s), $\phi O$ is the deep-water wave approach angle, and $\theta$ is the local shoreline orientation (Ashton and Murray, 2006) (Fig. 1c). The density of water and sediment are denoted by $\rho$ and $\rho_{s}\left(\mathrm{kgm}^{-3}\right), p$ is the dry mass void fraction, $g$ is the gravitational acceleration $\left(\mathrm{ms}^{-2}\right), g_{b}$ is the ratio of breaking wave height and water depth $\left(g_{b}=0.78\right)$, and $n$ is the ratio of group velocity to phase velocity of the breaking waves ( 1 in shallow water). With the angles defined as in figure $1 \mathrm{a}, Q_{s}$ is positive to the right looking offshore.

As waves approach the shore from different angles over time, they contribute to $Q_{s}$ either to the left or the right. Integrated over time, the relative contribution of each wave direction to the alongshore sediment transport is given by the wave energy probability density distribution (Fig. 1b),

$$
E\left(\phi_{0}\right)=\frac{H_{s}^{12 / 5}\left(\phi_{0}\right) \cdot T^{1 / 5}\left(\phi_{0}\right)}{\sum_{\phi_{0}} H_{s}^{12 / 5}\left(\phi_{0}\right) \cdot T^{1 / 5}\left(\phi_{0}\right)} .
$$


The net alongshore sediment transport for a shoreline orientation $q$ is therefore given by the convolution integral of the wave energy probability distribution $E$ and the alongshore sediment transport function $Q_{s}$,

$$
Q_{s, \text { net }}(\theta)=E\left(\phi_{0}\right) * Q_{s}\left(\phi_{0}-\theta\right)
$$

with $Q_{s}$ as defined in equation (1) (Fig. 1d). The deep-water significant wave height is

$$
H_{s, n e t}=\left(\frac{1}{N} \sum_{N} H_{s}^{12 / 5}\right)^{5 / 12} \text { and the wave period is } T_{n e t}=\left(\frac{1}{N} \sum_{N} T^{1 / 5}\right)^{5} \text {. }
$$

The maximum alongshore littoral transport away from the river mouth $Q_{s, \max }(q)$ is the sum of the maximum fluxes to the left and right delta flank,

$$
\begin{aligned}
& Q_{s, \text { max }}=Q_{s, \text { max }, r}-Q_{s, \text { max }, l}, \\
& Q_{s, \max }=\max _{-\pi \leq \theta \leq 0}\left[E\left(\phi_{0}\right) * Q_{s, r}\left(\phi_{0}-\theta\right)\right]-\min _{0 \leq \theta \leq \pi}\left[E\left(\phi_{0}\right) * Q_{s, l}\left(\phi_{0}-\theta\right) .\right.
\end{aligned}
$$

Note that the minus sign and the minimum function arise from the definition of $Q_{s}$, being positive to the right looking offshore.

For the drainage basins in Java, we compute sediment discharge using the BQART formula (Syvitski and Milliman, 2007), which estimates fluvial sediment flux based upon drainage area, basin climate, and relief,

$$
Q_{r}=\omega B Q^{0.31} A^{0.5} R T,
$$

where $\omega=0.02$ is a fitting parameter, $B=I L\left(1-T_{E}\right) E_{h}$ accounts for geologic and land use factors, $Q$ is the fluvial water discharge $\left(\mathrm{m}^{3} \mathrm{~s}^{-1}\right), A$ is the drainage basin area $\left(\mathrm{km}^{2}\right), R$ is the relief (elevation maximum, $\mathrm{km}$ ) and $T$ is the basin average temperature $\left({ }^{\circ} \mathrm{C}\right)$. For $B, I$ is a glacial erosion factor ( 1 in this case) and $L$ captures the soil erodibility. $T_{E}$ and $E_{h}$ account respectively for the anthropogenic trapping of sediment and increase in soil erosion, which we assume to cancel out (Syvitski and Milliman, 2007). Drainage basin areas and relief are retrieved from the USGS HydroSHEDS database (Lehner et al., 2008). Supplementary Tables 1 and 2 list the 
values used in this study. Based on estimates on the sand fraction in the Porong river in East-Java (Hoekstra, 1989), we assume that 10\% (the sand or littoral grade fraction) of the total fluvial sediment flux $\left(Q_{r, \text { total }}\right)$ directly amalgamates to the shoreline.

We measure shoreline orientation $q$ close to the river mouth of the left and right flanks of every delta, and the orientation of the non-deltaic coastline. As the Java deltas are generally symmetrical or close to it, we use an average of the two shoreline angles as a representative transport angle. To estimate wave climatology, we use the NOAA WaveWatch III hindcast reanalysis data of 1997 to 2010 (Chawla et al., 2011). 

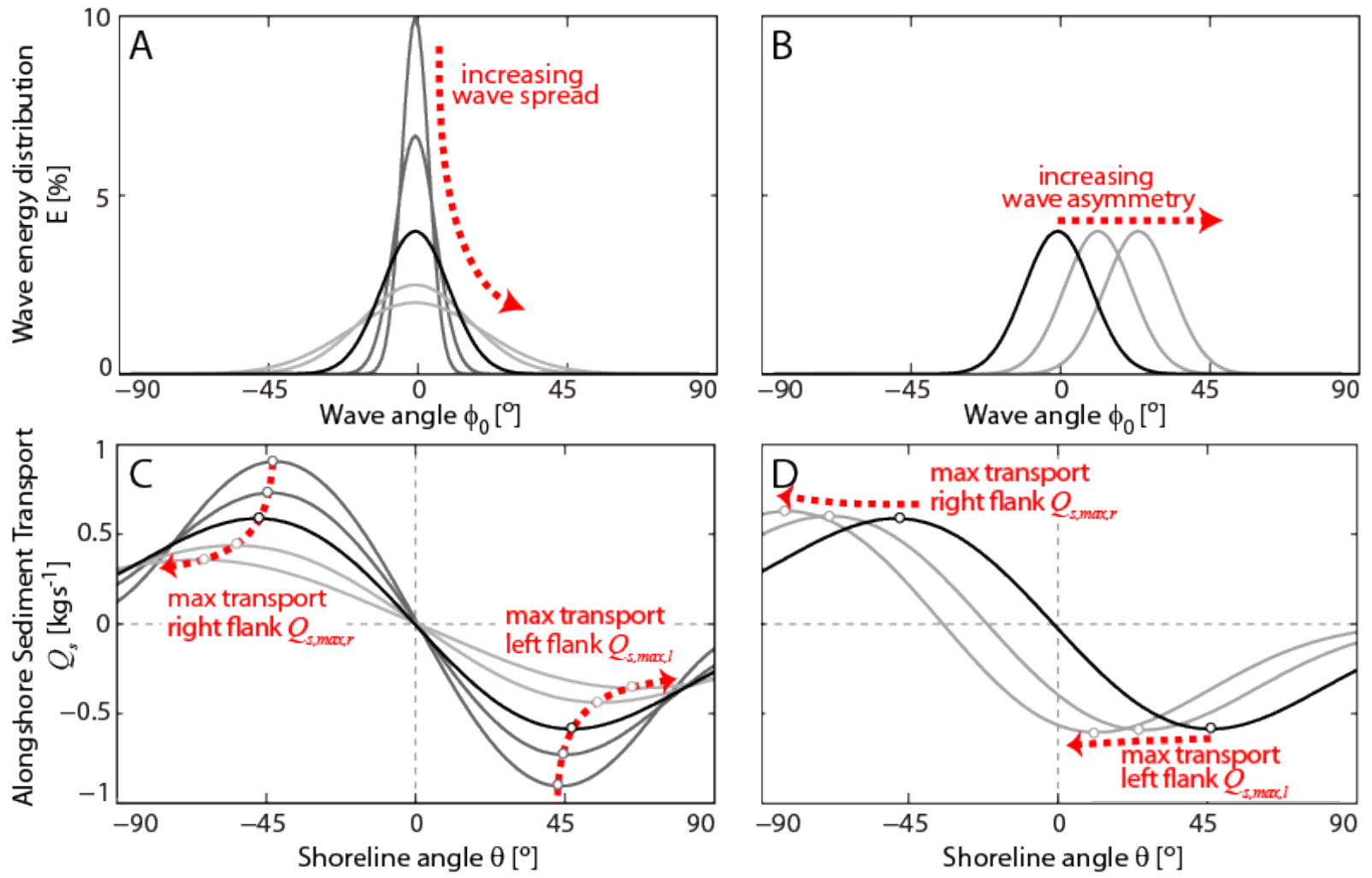

Supplementary Figure 1. Effect of wave climate distribution on $q_{\max }$ and $Q_{s, \max }$. Hypothetical wave distributions with varying (A) wave angle spread and (B) mean approach angle with (C, D) corresponding littoral transport as a function of shoreline orientation for the wave climates in the upper panels, normalized to $Q_{s}$ at zero standard deviation. Red dotted lines track the location of the maxima for changes in the wave distribution. 


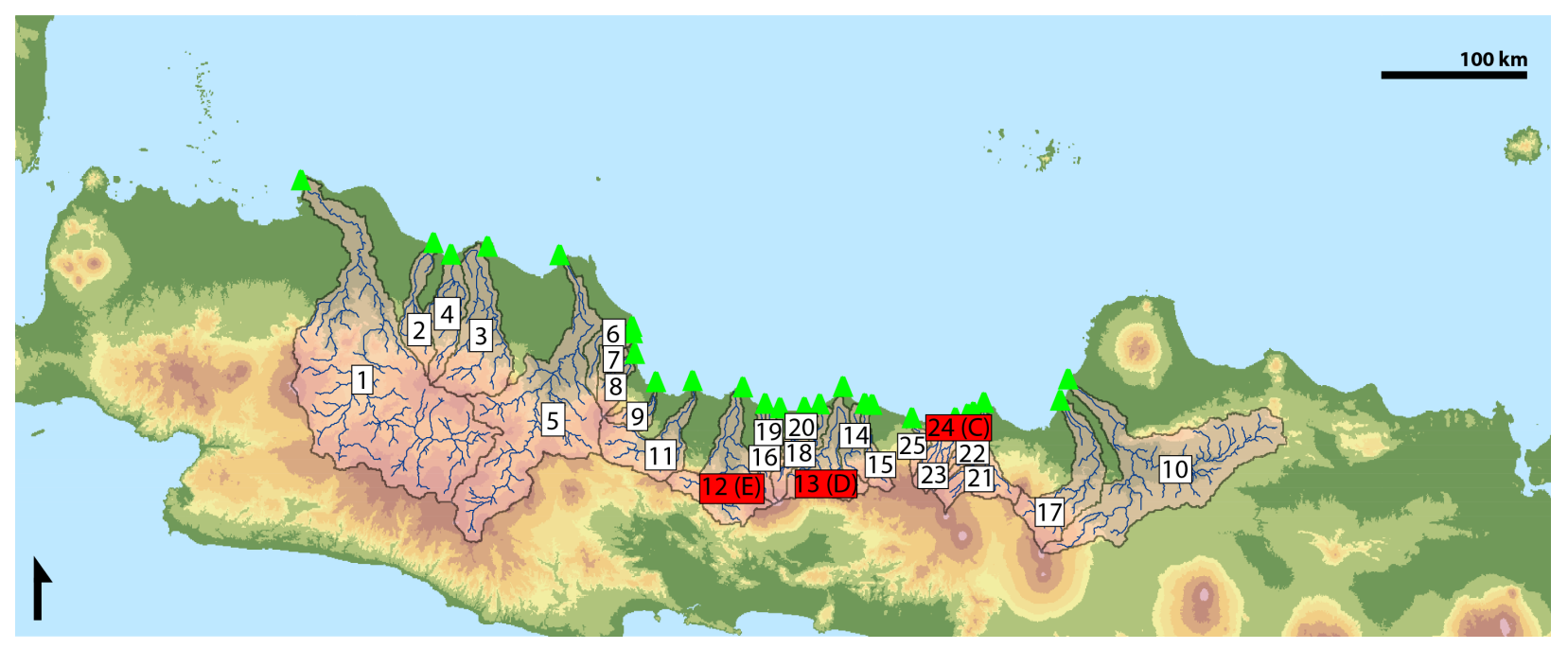

Supplementary Figure 2. Drainage basins of 25 deltas and the subaerial elevation from SRTM data (Farr and Kobrick, 2000). Red markers correspond to the examples displayed in Figure 2. See Supplementary Table 1. 
Supplementary Table 1: Morphologic and drainage basin properties of deltas along the Java, Indonesia, coastline. The index \# corresponds to the numbers in Supplementary Figure 2. The names of rivers 2, 9, 11, 19 and 22 are unknown to the authors. (*) indicates that the deltaic shoreline is visually river-dominated and therefore the shoreline orientation is unmeasurable.

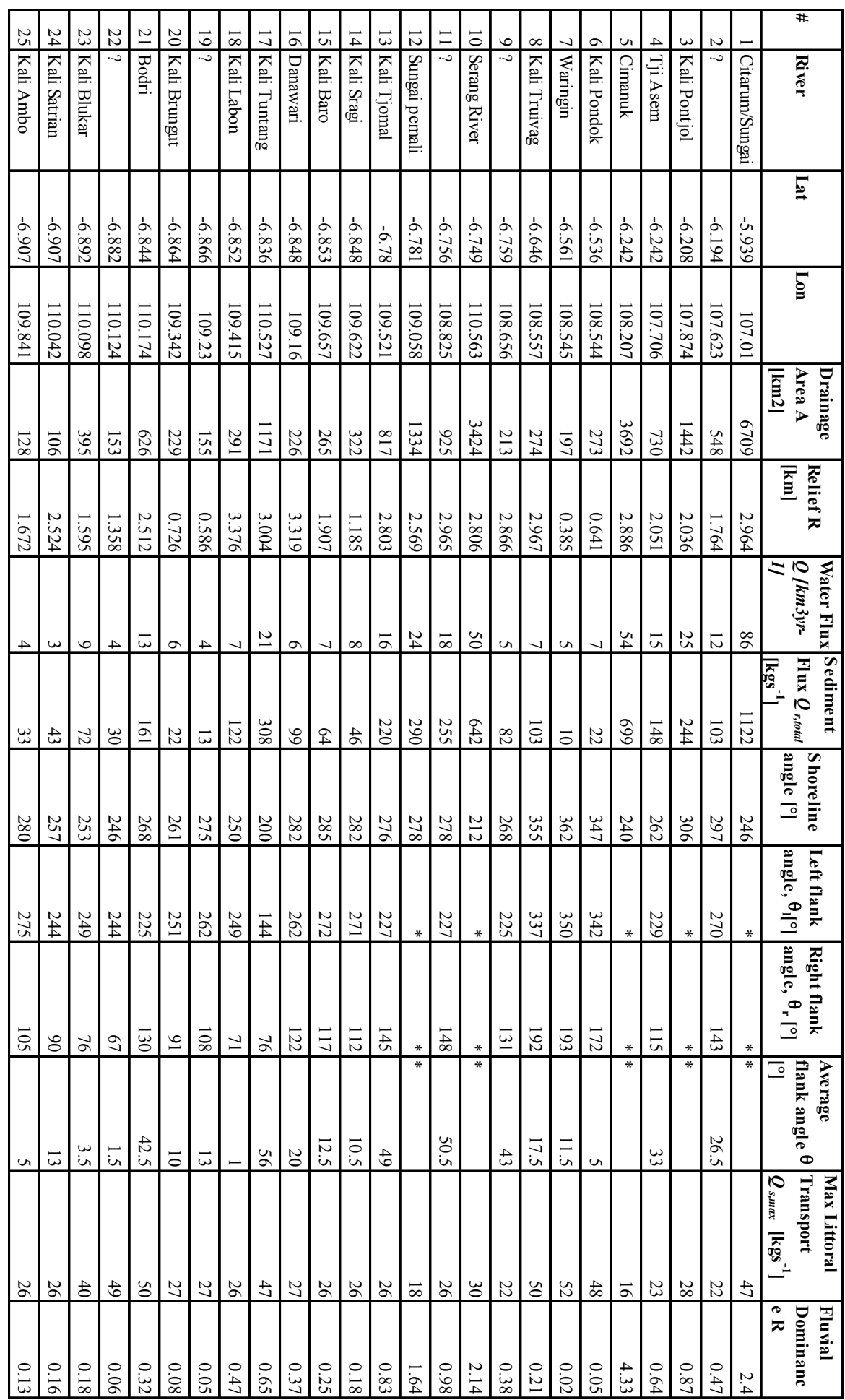


Supplementary Table 2: BQART factors and their values and references as used in this study.

$\begin{array}{ll}\text { Variable } & \text { Value } \\ Q_{r, \text { total }} & \\ w & \\ B & 0.02 \\ Q & 2 \\ A & \\ R & \\ T & \\ I & 28 \\ L & 1 \\ T_{E} & \\ & \\ E_{h} & \end{array}$

Note [units]

Estimated total fluvial sediment flux: $Q_{r, \text { total }}=$ $w B Q^{0.31} A^{0.5} R T\left[\mathrm{kgs}^{-1}\right]$

Fitting parameter $\left[\mathrm{kgs}^{-0.69} \mathrm{~km}^{-2 \circ} \mathrm{C}^{-1} \mathrm{~m}^{-0.93}\right]$

Accumulated geologic and land use factors: $B=I$ $L\left(1-T_{E}\right) E_{h}[-]$

Fluvial water discharge, $Q=0.075 A^{0.8}\left[\mathrm{~m}^{3} \mathrm{~s}^{-1}\right]$

Drainage basin area, retrieved from USGS

HydroSHEDS $\left[\mathrm{km}^{2}\right]$

Relief (maximum elevation) retrieved from SRTM $15 \mathrm{~s}$ DEM data $[\mathrm{km}]$

Basin-wide average temperature $\left[{ }^{\circ} \mathrm{C}\right]$

Glacial erosion factor [-]

Soil erodibility [-]

Anthropogenic trapping of sediment, we assume no net anthropogenic effect [-]

Anthropogenic increase in soil erosion, we assume no net anthropogenic effect [-]
Reference

(Syvitski and Milliman, 2007)

(Syvitski and Milliman, 2007)

(Syvitski and Milliman, 2007)

(Syvitski and Milliman, 2007)

(Lehner et al., 2008)

(Farr and Kobrick, 2000)

(World Meteorological Organization, 2014)

(Syvitski and Milliman, 2007)

Supplementary Table 3: Properties and flux estimates for 4 well-documented deltas. (*) indicates that the deltaic shoreline is river-dominated and therefore the shoreline orientation is unmeasurable. We assume a sand fraction of $10 \%$ for the Senegal and the Sao Francisco rivers.

\begin{tabular}{|c|c|c|c|c|c|c|c|c|c|c|}
\hline Delta & Lat & Lon & $\begin{array}{l}\text { Fluvial } \\
\text { sand } \\
\text { flux } Q_{r} \\
{\left[\mathbf{k g s}^{-1}\right]}\end{array}$ & $\begin{array}{l}\text { Shore } \\
\text { line } \\
\text { Angle } \\
{\left[^{\circ}\right]}\end{array}$ & $\begin{array}{l}\text { Left } \\
\text { Flank } \\
\text { Angle, } \\
\mathbf{q}_{l}\left[^{\circ}\right]\end{array}$ & $\begin{array}{l}\text { Right } \\
\text { Flank } \\
\text { Angle, } \\
\text { q } r^{\circ}\left[^{\circ}\right]\end{array}$ & $\begin{array}{l}\text { Aver } \\
\text { age } \\
\text { flank } \\
\text { angle } \\
\text { q }\left[^{\circ}\right]\end{array}$ & $\begin{array}{l}\text { Max } \\
\text { Littoral } \\
\text { Transp } \\
\text { ort } \\
Q_{s, \max } \\
{\left[\mathbf{k g s}^{-1}\right]}\end{array}$ & $\begin{array}{l}\text { Fluvial } \\
\text { Domin } \\
\text { ance } R\end{array}$ & Ref \\
\hline Senegal & 15.99 & -16.51 & 15 & 184 & 0 & 3 & 2 & 225 & 0.04 & $\begin{array}{l}\text { (Martins and } \\
\text { Probst, 1991; } \\
\text { Chawla et al., } \\
\text { 2011) }\end{array}$ \\
\hline $\begin{array}{l}\text { Sao } \\
\text { Francisco }\end{array}$ & -10.48 & -36.40 & 75 & 50 & 21 & 22 & 22 & 280 & 0.3 & $\begin{array}{l}\text { (Lima et al., } \\
\text { 2005; Chawla et } \\
\text { al., 2011) }\end{array}$ \\
\hline $\begin{array}{l}\text { Tinajones, } \\
\text { Sinu }\end{array}$ & 9.420 & -75.92 & 133 & 247 & $*$ & * & $*$ & 65 & 2 & $\begin{array}{l}\text { (Restrepo et al., } \\
\text { 2009; Chawla et } \\
\text { al., 2011) }\end{array}$ \\
\hline $\begin{array}{l}\text { Belize, } \\
\text { Mississipp } \\
\text { i }\end{array}$ & 29.20 & -89.30 & 919 & 82 & $*$ & $*$ & $*$ & 130 & 7 & $\begin{array}{l}\text { (Chawla et al., } \\
\text { 2011; Nittrouer } \\
\text { and Viparelli, } \\
\text { 2014) }\end{array}$ \\
\hline
\end{tabular}




\section{References}

Ashton, A.D., and Murray, A.B., 2006, High-angle wave instability and emergent shoreline shapes: 1. Modeling of sand waves, flying spits, and capes: Journal of Geophysical Research, v. 111, no. F4, p. F04011, doi: 10.1029/2005JF000422.

Chawla, A., Spindler, D., and Tolman, H.L., 2011, A Thirty Year Wave Hindcast Using The Latest NCEP Climate Forecast System Reanalysis Winds, in Proceedings of the 12th International Workshop on Wave Hindcasting and Forecasting, Kohala Coast, Hawaii.

Farr, T.G., and Kobrick, M., 2000, Shuttle radar topography mission produces a wealth of data: Eos, Transactions American Geophysical Union, v. 81, no. 48, p. 583, doi: 10.1029/EO081i048p00583.

Hoekstra, P., 1989, Hydrodynamics and depositional processes of the Solo and Porong Deltas, East Java, Indonesia, in Linden, W.J.M. van der, Cloetingh, S.A.P.L., Kaasschieter, J.P.., Graaff, W.J.. van de, Vandenberghe, J., and Gun, J.A.M. van der eds., Proceedings KNGMG Symposium "Coastal Lowlands, Geology and Geotechnology," Springer Science+Business Media, Dordrecht, p. 161-173.

Komar, P.D., 1998, Beach processes and sedimentation: Prentice Hall, Upper Saddle River, NJ. $544 \mathrm{p}$.

Lehner, B., Verdin, K., and Jarvis, A., 2008, New Global Hydrography Derived From Spaceborne Elevation Data: Eos, Transactions American Geophysical Union, v. 89, no. 10, p. 93, doi: 10.1029/2008EO100001.

Lima, J.E.F.W., Lopes, W.T.A., De Oliveira Carvalho, N., Vieira, M.R., and Da Silva, E.M., 2005, Suspended sediment fluxes in the large river basins of Brazil, in Walling, D.E. and Horowitz, A.J. eds., IAHS ICCE symposium: Sediments Budgets 1, IAHS Publications, p. 355-364.

Martins, O., and Probst, J.-L., 1991, Biogeochemistry of Major African Rivers: Carbon and Mineral Transport, in Degens, E.T., Kempe, S., and Richley, J.E. eds., Biogeochemistry of Major World Rivers, John Wiley \& Sons, Ltd., p. 127-155.

Nittrouer, J.A., and Viparelli, E., 2014, Sand as a stable and sustainable resource for nourishing the Mississippi River delta: Nature Geoscience, v. 7, no. 5, p. 350-354, doi: 10.1038/ngeo2142.

Restrepo, J.D., López, S.A., and Restrepo, J.C., 2009, The effects of geomorphic controls on sediment yield in the Andean rivers of Colombia: Latin American Journal of Sedimentology and Basin analysis, v. 16, no. 2, p. 79-92.

Syvitski, J.P.M., and Milliman, J.D., 2007, Geology, Geography, and Humans Battle for Dominance over the Delivery of Fluvial Sediment to the Coastal Ocean: The Journal of Geology, v. 115, no. 1, p. 1-19, doi: 10.1086/509246.

World Meteorological Organization, 2014, WMO Mean Annual Temperature: World Weather: Jakarta, Indonesia, p. http://worldweather.wmo.int/en/city.html?cityId=31. 


\section{Appendices for chapter 2}

Supplementary table 1. Channel orientation, asymmetry index (S) and fluvial dominance (R) for 10 deltas (or delta lobes).

\begin{tabular}{|c|c|c|c|c|c|c|c|c|c|c|}
\hline 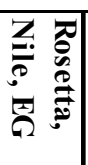 & 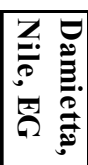 & 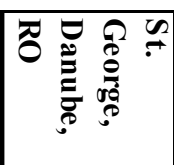 & 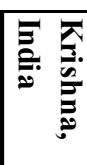 & ב & 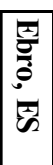 & 及 & 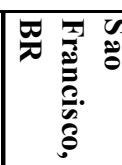 & $\begin{array}{l}2 \\
0 \\
0 \\
0 \\
z \\
z\end{array}$ & 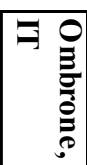 & $\frac{8}{20}$ \\
\hline$\frac{w}{i}$ & $\stackrel{\omega}{\leftrightarrows}$ & $\underset{f}{f}$ & $\vec{a}$ & $\begin{array}{l}\vec{b} \\
\dot{w} \\
\dot{v}\end{array}$ & \begin{tabular}{|l|}
$\overrightarrow{0}$ \\
$\dot{0}$ \\
$\dot{y}$
\end{tabular} & $\vec{i}$ & is & \begin{tabular}{|l|}
$\begin{array}{l}+ \\
0 \\
0 \\
0\end{array}$ \\
\end{tabular} & \begin{tabular}{|l|}
\multirow{2}{*}{} \\
a \\
\end{tabular} & 5 \\
\hline$\stackrel{\omega}{\infty}_{\infty}$ & $\underset{\stackrel{D}{D}}{\stackrel{D}{+}}$ & $\begin{array}{l}\text { N } \\
\text { in }\end{array}$ & $\infty$ & $\stackrel{\infty}{\leftrightarrow}$ & $\stackrel{1}{i}$ & $F$ & $\begin{array}{l}\dot{\omega} \\
\dot{\omega} \\
\dot{s}\end{array}$ & \begin{tabular}{|c|}
$\dot{\infty}$ \\
$\vdots$ \\
$\vdots$ \\
-
\end{tabular} & $=$ & 5 \\
\hline 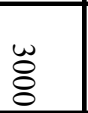 & प̆ & ठे & 芯 & $\ddot{\Xi}$ & ปุ & $\stackrel{\omega}{\leftrightarrow}$ & 岁 & $\vec{J}$ & 岕 & 10 \\
\hline $\begin{array}{l}8 \\
\text { i } \\
\end{array}$ & 家 & $\begin{array}{l}8 \\
\text { in } \\
\end{array}$ & $\dot{\Xi}$ & 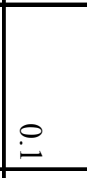 & $\dot{\mathrm{i}}$ & $\dot{\theta}$ & $\dot{0}$ & $\begin{array}{ll} \\
\dot{n} \\
\end{array}$ & $i$ & 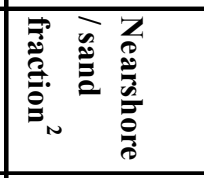 \\
\hline$\overline{\bar{y}}$ & $\vec{u}$ & $\infty$ & $\frac{N}{\infty}$ & $\omega$ & 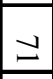 & $u$ & $\stackrel{\infty}{\infty}$ & 古 & $\alpha$ & 10 \\
\hline ్ㅗ & $\tilde{0}$ & $\omega$ & $\frac{1}{\infty}$ & $\ddot{\sigma}$ & $w$ & ì & $\stackrel{\circ}{\infty}$ & 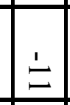 & & $\mid$ \\
\hline$\vec{\Phi}$ & $\vec{q}$ & ్ㅠㅇ & $\vec{\infty}$ & $\vec{\infty}$ & 2 & 8 & $\stackrel{N}{\infty}$ & 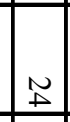 & 8 & \\
\hline 8 & in & $i$ & $i$ & i & $\dot{I}$ & ia & $i$ & $\dot{\square}$ & $\bar{\omega}$ & $\pi$ \\
\hline i & i & $\stackrel{\circ}{\perp}$ & i & $\bar{\perp}$ & i & $=$ & _ & is & $i$ & \\
\hline$\underset{w}{\sim}$ & $\underset{\infty}{\infty}$ & No & U. & us & $\omega$ & \begin{tabular}{|c} 
谂 \\
\end{tabular} & \begin{tabular}{|l}
$N$ \\
$N$ \\
$N$
\end{tabular} & 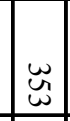 & $\frac{\omega}{6}$ & 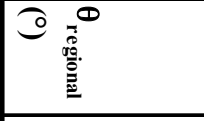 \\
\hline 点 & $\tilde{w}_{1}$ & $\underline{\underline{\omega}}$ & $\sqrt{\mathrm{N}}$ & 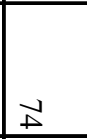 & $\stackrel{\infty}{\sim}$ & \begin{tabular}{|l}
$\tilde{a}$ \\
$\dot{p}$ \\
\end{tabular} & 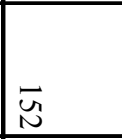 & 8 & 苫 & 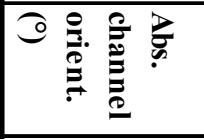 \\
\hline 0 & 6 & - & 心 & $\alpha$ & 总 & $\underline{\omega}$ & $\Xi$ & $\dot{\Delta}$ & 悹 & 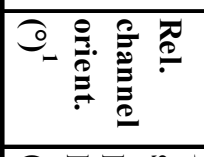 \\
\hline $\bar{u}_{r}$ & $\underset{\infty}{\sim}$ & 혼 & 芯 & $\vec{\infty}$ & \begin{tabular}{|l|} 
\\
$\infty$ \\
$i$ \\
\end{tabular} & $\begin{array}{l}\omega \\
0 \\
\end{array}$ & 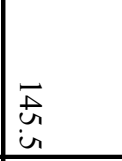 & \pm & $\mid \begin{array}{l}N \\
\bar{\omega} \\
i \\
\end{array}$ & 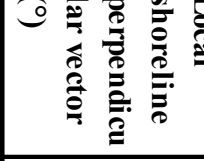 \\
\hline 0 & $\dot{\perp}$ & $a$ & $\dot{N}$ & i & in & i & is & + & $\begin{array}{l}\dot{b} \\
i \\
\end{array}$ & 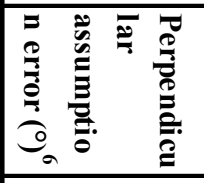 \\
\hline $\begin{array}{l}\bar{a} \\
\bar{u} \\
\bar{n}\end{array}$ & \begin{tabular}{|l|}
\multirow{E}{*}{} \\
\end{tabular} & $\hat{b}_{\mathrm{w}}$ & $a$ & $\infty$ & $a$ & ur & $D$ & $N$ & - & $10 \underset{0}{0}$ \\
\hline & ح & 흐 & $\omega$ & $\omega$ & $\checkmark$ & & $\omega$ & & & $10 \underset{0}{0}$ \\
\hline
\end{tabular}


1 Channel orientation relative to sign of $Q_{s, \text { regional }}$. Updrift channel migration has negative angles.

${ }^{2}$ Assuming $15 \%$ nearshore fraction if no other information is available.

${ }^{3}$ Bedload fraction from Syvitski and Saito (2007). Sediment flux from Giosan (2012)

${ }^{4}$ Bedload fraction from Syvitski and Saito (2007). Sediment flux from Sestini (1989), assuming $1 / 3$ of total Nile.

${ }^{5}$ Bedload fraction from Syvitski and Saito (2007). Sediment flux from Sestini (1989), assuming $2 / 3$ of total Nile.

${ }^{6}$ Difference between the true channel orientation and the local perpendicular vector extending from the average coastline orientation about the river mouth

\section{References}

1. Pranzini, E. Updrift river mouth migration on cuspate deltas: two examples from the coast of Tuscany (Italy). Geomorphology 38, 125-132 (2001).

2. Owens, E. H. \& Roberts, E. H. Variations of Wave-energy levels and Coastal Sedimentation, Eastern Nicaragua. in Coastal Engineering Proceeedings 16, 1195-1214 (Coastal Engineering Research Council, 1978).

3. Chawla, A., Spindler, D. \& Tolman, H. L. A Thirty Year Wave Hindcast Using The Latest NCEP Climate Forecast System Reanalysis Winds. in Proceedings of the 12th International Workshop on Wave Hindcasting and Forecasting (2011).

4. Dominguez, J. M. L. The Sao Francisco strandplain: a paradigm for wave-dominated deltas? Geol. Soc. London, Spec. Publ. 117, 217-231 (1996).

5. Hiscott, R. N., Geoscience, P., Tungku, J. \& Be, L. in Tropical Deltas of Southeast AsiaSedimentology, Stratigraphy, and Petroleum Geology Tropical D, 89-107 (SEPM Society for Sedimentary Geology, 2003).

6. Syvitski, J. P. M. M. \& Saito, Y. Morphodynamics of deltas under the influence of humans. Glob. Planet. Change 57, 261-282 (2007).

7. Gaillard, P. et al. Wind and Wave Atlas of the Mediterranean Sea. Software (2004). at $<$ http://users.ntua.gr/mathan/pdf/Pages_from _WIND_WAVE_ATLAS_MEDITERRANEAN_SEA_2004.pdf>

8. Syvitski, J. P. M. P. M. \& Milliman, J. D. D. Geology, Geography, and Humans Battle for Dominance over the Delivery of Fluvial Sediment to the Coastal Ocean. J. Geol. 115, 1-19 (2007). 
9. Giosan, L. et al. Early Anthropogenic Transformation of the Danube-Black Sea System. Sci. Rep. 2, (2012).

10. Dan, S., Stive, M. J. F., Walstra, D. R. \& Panin, N. Wave climate coastal sediment budget and shoreline changes for the danube delta. Mar. Geol. 39-49 (2009).

11. Sestini, G. Nile Delta: a review of depositional environments and geological history. Geol. Soc. London, Spec. Publ. 41, 99-127 (1989). 


\section{Appendices for chapter 3}

Supplementary Table 1. Overview of the Delft3D and SWAN model parameters.

\begin{tabular}{|c|c|c|c|}
\hline Parameter & Value & Units & Description \\
\hline \multicolumn{4}{|l|}{ General } \\
\hline Tstart & 0 & $\min$ & Start time \\
\hline Tstop & 41760 & $\min$ & Stop time \\
\hline $\mathrm{Dt}$ & 0.2 & $\min$ & Timestep \\
\hline $\mathrm{Ag}$ & 9.81 & $\mathrm{~ms}^{-2}$ & Gravitational Acceleration \\
\hline
\end{tabular}

Flow

\begin{tabular}{|l|l|l|l|}
\hline Rhow & 1025 & $\mathrm{kgm}^{-3}$ & Water Density \\
\hline Tempw & 15 & $\mathrm{C}$ & Water Temperature \\
\hline Salw & 31 & $\mathrm{ppt}$ & Salinity \\
\hline Rouwav & FR84 & & Bottom Stress formulation due to wave action \\
\hline Rhoa & 1 & $\mathrm{kgm}^{-3}$ & Air Density \\
\hline Ccofu & 65 & $\mathrm{~m}^{0.5} \mathrm{~s}^{-1}$ & Chezy roughness u \\
\hline Ccofv & 65 & $\mathrm{~m}^{0.5} \mathrm{~s}^{-1}$ & Chezy roughness v \\
\hline Vicouv & 2 & & Uniform horizontal eddy viscosity \\
\hline Dicouv & 10 & & Uniform vertical eddy diffusivity \\
\hline Z0v & 0.1 & $\mathrm{~m}$ & Roughness length vertical side walls \\
\hline Dryflc & 0.1 & $\mathrm{~m}$ & Threshold depth for drying and flooding \\
\hline Tlfsmo & 60 & $\mathrm{~s}$ & $\begin{array}{l}\text { Time interval to smooth hydrodynamic } \\
\text { boundary conditions }\end{array}$ \\
\hline North & $\begin{array}{l}\text { neuman } \\
\mathrm{n}\end{array}$ & & North boundary condition \\
\hline RettisNorth & -1 & $\mathrm{~s}$ & North Thatcher Harlemann return time \\
\hline East & $\begin{array}{l}\text { water } \\
\text { level }\end{array}$ & $\mathrm{m}$ & East boundary condition \\
\hline South & $\begin{array}{l}\text { neuman } \\
\mathrm{n}\end{array}$ & & South boundary condition \\
\hline RettisEast & -1 & $\mathrm{~s}$ & South Thatcher Harlemann return time \\
\hline Inlet & $\begin{array}{l}\text { discharg } \\
\mathrm{e}\end{array}$ & $\mathrm{m} \mathrm{s}^{-1}$ & Inlet boundary condition \\
\hline RettisInlet & 60 & $\mathrm{~s}$ & Inlet Thatcher Harlemann return time \\
\hline
\end{tabular}

Waves

\begin{tabular}{|l|l|l|l|}
\hline $\begin{array}{l}\text { MinimumDep } \\
\text { th }\end{array}$ & 0.05 & $\mathrm{~m}$ & Minimum depth \\
\hline $\begin{array}{l}\text { GenModePhy } \\
\text { sics }\end{array}$ & 3 & & Generation mode of physics \\
\hline Breaking & true & & Include wave breaking \\
\hline BreakAlpha & 1 & & Alpha coefficient for wave breaking \\
\hline BreakGamma & 0.73 & & Gamma coefficient for wave breaking \\
\hline BedFriction & jonswap & & Bed friction type \\
\hline BedFricCoef & 0.067 & & Bed friction coefficient \\
\hline Diffraction & false & & Include diffraction \\
\hline WindGrowth & false & & Include wind growth \\
\hline $\begin{array}{l}\text { WhiteCappin } \\
\text { g }\end{array}$ & Komen & & White capping formulation \\
\hline Quadruplts & false & & Include quadruplets \\
\hline Refraction & true & & Include refraction \\
\hline FreqShift & true & & Include frequency shifting in frequency space \\
\hline
\end{tabular}




\begin{tabular}{|c|c|c|c|}
\hline Parameter & Value & Units & Description \\
\hline WaveForces & \begin{tabular}{|l|l} 
rad \\
stress
\end{tabular} & & Method of wave force computation \\
\hline $\begin{array}{l}\text { FlowBedLeve } \\
11\end{array}$ & use & & $\begin{array}{l}\text { Use bed level from FLOW in WAVE domain } \\
\text { but do not extend }\end{array}$ \\
\hline $\begin{array}{l}\text { FlowWaterLe } \\
\text { vel } 1\end{array}$ & $\begin{array}{l}\text { use / } \\
\text { extend }\end{array}$ & & $\begin{array}{l}\text { Use water level from FLOW and extend across } \\
\text { WAVE domain }\end{array}$ \\
\hline $\begin{array}{l}\text { FlowVelocity } \\
1\end{array}$ & $\begin{array}{l}\text { use / } \\
\text { extend }\end{array}$ & & $\begin{array}{l}\text { Use water level from FLOW and extend across } \\
\text { WAVE domain }\end{array}$ \\
\hline $\begin{array}{l}\text { FlowBedLeve } \\
12\end{array}$ & $\begin{array}{l}\text { use / } \\
\text { extend }\end{array}$ & & $\begin{array}{l}\text { Use bed level from FLOW and extend across } \\
\text { WAVE domain }\end{array}$ \\
\hline $\begin{array}{l}\text { FlowWaterLe } \\
\text { vel } 2\end{array}$ & $\begin{array}{l}\text { use / } \\
\text { extend }\end{array}$ & & $\begin{array}{l}\text { Use water level from FLOW and extend across } \\
\text { WAVE domain }\end{array}$ \\
\hline $\begin{array}{l}\text { FlowVelocity } \\
2\end{array}$ & $\begin{array}{l}\text { use / } \\
\text { extend }\end{array}$ & & $\begin{array}{l}\text { Use flow velocity from FLOW and extend } \\
\text { across WAVE domain }\end{array}$ \\
\hline DirSpace & circle & & Default directional space \\
\hline Ndir & 36 & & Number of directional bins \\
\hline FreqMin & 0.05 & $\mathrm{~s}^{-1}$ & Minimum frequency \\
\hline FreqMax & 1 & $\mathrm{~s}^{-1}$ & Maximum frequency \\
\hline Nfreq & 24 & & Number of frequencies \\
\hline $\begin{array}{l}\text { SpectrumSpe } \\
\text { c }\end{array}$ & $\begin{array}{l}\text { paramet } \\
\text { ric }\end{array}$ & & Spectrum type \\
\hline SpShapeType & jonswap & & Spectrum shape \\
\hline PeriodType & peak & & Wave period type \\
\hline $\begin{array}{l}\text { DirSpreadTy } \\
\text { pe }\end{array}$ & degrees & & Directional spreading type \\
\hline $\begin{array}{l}\text { PeakEnhance } \\
\text { Fac }\end{array}$ & 3.3 & & Peak enhancement factor \\
\hline WaveHeight & var & $\mathrm{m}$ & Wave height at boundaries \\
\hline PeriodType & var & $\mathrm{s}$ & Wave period at boundaries \\
\hline Direction & var & deg & Wave direction at boundaries \\
\hline DirSpreading & 10 & $\operatorname{deg}$ & Directional spreading \\
\hline
\end{tabular}

Morphology
\begin{tabular}{|l|l|l|l|}
\hline EpsPar & false & & $\begin{array}{l}\text { Vertical mixing distribution according to van } \\
\text { Rijn }\end{array}$ \\
\hline MorFac & 90 & & Morphological scale factor \\
\hline MorStt & 1440 & min & $\begin{array}{l}\text { Spin-up interval from TStart to the start of } \\
\text { morphological changes }\end{array}$ \\
\hline Thresh & 0.05 & m & $\begin{array}{l}\text { Threshold sediment thickness for transport and } \\
\text { erosion reduction }\end{array}$ \\
\hline MorUpd & true & & Update bathymetry during FLOW simulation \\
\hline CMPUds & true & & Update bed composition during flow run \\
\hline EqmBc & false & & $\begin{array}{l}\text { Equilibrium sand concentration profile at } \\
\text { inflow boundaries }\end{array}$ \\
\hline DensIn & false & & $\begin{array}{l}\text { Include effect of sediment concentration on } \\
\text { fluid density }\end{array}$ \\
\hline AksFac & 0.5 & & van Rijn's reference height \\
\hline Rwave & 2 & & $\begin{array}{l}\text { Wave related roughness. Van Rijn recommends } \\
\text { range 1-3 }\end{array}$ \\
\hline AlfaBS & 1 & & $\begin{array}{l}\text { Streamwise bed gradient factor for bed load } \\
\text { transport }\end{array}$ \\
\hline AlfaBT & 20 & $\begin{array}{l}\text { Transverse bed gradient factor for bed load } \\
\text { transport }\end{array}$ \\
\hline Sus & 1 & Multiplication factor for suspended sediment \\
\hline
\end{tabular}




\begin{tabular}{|l|l|l|l|}
\hline Parameter & Value & Units & Description \\
\hline Bed & & & ref. concentration \\
\hline SusW & 1 & & $\begin{array}{l}\text { Multiplication factor for bed-load transport } \\
\text { vector magnitude }\end{array}$ \\
\hline BedW & 0.15 & & Wave-related suspended sed. transport factor \\
\hline SedThr & 0.15 & & Wave-related bed-load sed. transport factor \\
\hline ThetSD & 0.1 & $\mathrm{~m}$ & $\begin{array}{l}\text { Minimum water depth for sediment } \\
\text { computations }\end{array}$ \\
\hline HMaxTH & 0.9 & & Factor for erosion of adjacent dry cells \\
\hline FWFac & 1.5 & $\mathrm{~m}$ & Max depth for variable THETSD. \\
\hline UpdBaseLyr & 1 & & Tuning parameter for wave streaming \\
\hline UpdInf & true & & $\begin{array}{l}\text { Update option for composition and thickness of } \\
\text { base layer }\end{array}$ \\
\hline Islope & 2 & & Update bed levels at inflow boundaries \\
\hline IUnderLyr & 2 & & Flag for underlayer concept \\
\hline TTLForm & constant & & Transport layer thickness formulation \\
\hline ThTrLyr & 0.2 & $\mathrm{~m}$ & Thickness of the transport layer \\
\hline MxNULyr & 25 & & Underlayers (excl transp \& base lyrs) \\
\hline ThUnLyr & 0.2 & $\mathrm{~m}$ & Thickness of each underlayer \\
\hline Sediment & \multicolumn{3}{|l}{} \\
\hline Cref & 1600 & $\mathrm{kgm}{ }^{-3}$ & $\begin{array}{l}\text { CSoil Reference density for hindered settling } \\
\text { calculations }\end{array}$ \\
\hline
\end{tabular}

Sediment sand

\begin{tabular}{|l|l|l|l|}
\hline RhoSol & 2650 & $\mathrm{kgm}^{-3}$ & Specific density \\
\hline SedDia (1) & 0.0002 & $\mathrm{~m}$ & Median sediment diameter (D50), fraction 1 \\
\hline SedDia (2) & $\begin{array}{l}0.00019 \\
99\end{array}$ & $\mathrm{~m}$ & Median sediment diameter (D50), fraction 2 \\
\hline SedDia (3) & $\begin{array}{l}0.00020 \\
001\end{array}$ & $\mathrm{~m}$ & Median sediment diameter (D50), fraction 3 \\
\hline CdryB & 0.0016 & $\mathrm{kgm}^{-3}$ & Dry bed density \\
\hline $\begin{array}{l}\text { IniSedThick } \\
(1)\end{array}$ & $\begin{array}{l}\mathrm{sand1. \textrm {s }} \\
\mathrm{db}\end{array}$ & $\mathrm{m}$ & $\begin{array}{l}\text { Initial sediment sand 1 layer thickness at bed, } \\
\text { updrift sediments }\end{array}$ \\
\hline $\begin{array}{l}\text { IniSedThick } \\
(2)\end{array}$ & $\begin{array}{l}\mathrm{sand} . \mathrm{s} \\
\mathrm{db}\end{array}$ & $\mathrm{m}$ & $\begin{array}{l}\text { Initial sediment sand 2 layer thickness at bed, } \\
\text { downdrift sediments }\end{array}$ \\
\hline $\begin{array}{l}\text { IniSedThick } \\
(3)\end{array}$ & 0 & $\mathrm{~m}$ & $\begin{array}{l}\text { Initial sediment sand 3 layer thickness at bed, } \\
\text { fluvial sediments }\end{array}$ \\
\hline FacDSS & 1 & & $\begin{array}{l}\text { FacDss * SedDia = Initial suspended sediment } \\
\text { diameter. }\end{array}$ \\
\hline
\end{tabular}

Sediment mud

\begin{tabular}{|l|l|l|l|}
\hline RhoSol & 2650 & $\mathrm{kgm}^{-3}$ & Specific density \\
\hline SalMax & 0 & $\mathrm{ppt}$ & Salinity for saline settling velocity \\
\hline WS0 & 0.00025 & $\mathrm{~ms}^{-1}$ & Settling velocity fresh water \\
\hline WSM & 0.00025 & $\mathrm{~ms}^{-1}$ & Settling velocity saline water \\
\hline TcrSed & 1000 & $\mathrm{Nm}^{-2}$ & Critical bed shear stress for sedimentation \\
\hline TcrEro & 0.5 & $\mathrm{Nm}^{-2}$ & Critical bed shear stress for erosion \\
\hline EroPar & 0.0001 & $\begin{array}{l}\mathrm{kgm}^{-} \\
2 \mathrm{~s}^{-1}\end{array}$ & Erosion parameter \\
\hline CDryB & 500 & $\mathrm{kgm}^{-3}$ & Dry bed density \\
\hline IniSedThick & 0 & $\mathrm{~ms}^{-1}$ & Initial sediment layer thickness at bed \\
\hline FacDSS & 1 & & $\begin{array}{l}\text { FacDss } \text { SedDia }=\text { Initial suspended sediment } \\
\text { diameter. }\end{array}$ \\
\hline
\end{tabular}


Supplementary Table 2. Overview of the model experiments. $Q$ is the upstream river discharge, $Q_{r}$ is the upstream fluvial sediment supply, $H_{s}$ is the offshore waveheight, $T$ is the offshore wave period, $U$ is the average current velocity in the channel, $Q_{s}$ is the alongshore sediment transport updrift of the river mouth, $\mathrm{b}$ is the measured alongshore sediment bypassing fraction, $M_{j}$ is the river mouth jet momentum flux, $M_{w}$ is the wave momentum flux, $J$ is the river mouth balance, and $b_{\text {pred }}$ is the predicted bypassing fraction based on the river mouth balance $J$. Bathymetry of each of these model experiments is shown in figure S1 and S2.

\begin{tabular}{|c|c|c|c|c|c|c|c|c|c|c|c|c|c|c|c|c|c|c|c|}
\hline$\#$ & $\begin{array}{l}\mathbf{Q} \\
( \\
\mathbf{m} \\
{ }^{3} \mathbf{s} \\
{ }^{1} \\
\mathbf{y}\end{array}$ & \begin{tabular}{|l}
$\mathbf{Q}_{r}$ \\
$(\mathbf{k g}$ \\
$\left.\mathbf{s}^{-1}\right)$ \\
\end{tabular} & $\begin{array}{l}\text { Hs } \\
(\mathrm{m} \\
) \\
\end{array}$ & $\begin{array}{l}\mathbf{T} \\
(\mathbf{s} \\
) \\
\end{array}$ & \begin{tabular}{|l}
$\mathbf{U}$ \\
$(\mathbf{m}$ \\
$\left.\mathbf{s}^{-1}\right)$ \\
\end{tabular} & \begin{tabular}{|l|} 
Ch \\
an \\
nel \\
wi \\
dt \\
h \\
(m \\
\end{tabular} & $\begin{array}{l}\text { Cha } \\
\text { nnel } \\
\text { dept } \\
\text { h } \\
\text { (m) } \\
\end{array}$ & \begin{tabular}{|l|} 
Spi \\
t \\
wid \\
th \\
(m) \\
\end{tabular} & \begin{tabular}{|l} 
Migr. \\
dist \\
$(\mathrm{m})$
\end{tabular} & \begin{tabular}{|l} 
Mig \\
r. \\
time \\
(yr) \\
\end{tabular} & $\begin{array}{l}\text { Mig } \\
\text { r. } \\
\text { rate } \\
(\mathbf{m} / \mathbf{y} \\
\mathbf{r}) \\
\end{array}$ & $\begin{array}{l}\text { Qs } \\
(\mathbf{k g} \\
\left.\mathbf{s}^{-1}\right) \\
\end{array}$ & $\begin{array}{l}\text { Qs/( } \\
\text { Qs+ } \\
\text { Qr) }\end{array}$ & b & $\mathbf{M}_{j}$ & $\mathbf{M}_{w}$ & $\mathbf{J}$ & $\begin{array}{l}\mathbf{b}_{\text {pre }} \\
d\end{array}$ & $\begin{array}{l}\text { Mig } \\
\text { r. } \\
\text { rate } \\
\text { (pre } \\
\text { d., } \\
\text { myr } \\
\left.{ }^{1}\right) \\
\end{array}$ \\
\hline 1 & 50 & 0 & $\begin{array}{l}1 . \\
2\end{array}$ & $\begin{array}{l}1 \\
0\end{array}$ & \begin{tabular}{l|}
0.2 \\
6
\end{tabular} & $\begin{array}{l}22 \\
5\end{array}$ & 1.4 & 50 & 940 & 3.2 & 293 & 34 & 1.0 & 0.66 & $\begin{array}{l}1.3 \mathrm{E}+ \\
04\end{array}$ & $\begin{array}{l}5.2 \mathrm{E}+ \\
04\end{array}$ & \begin{tabular}{l|}
0.2 \\
5
\end{tabular} & \begin{tabular}{|l|}
0.8 \\
6
\end{tabular} & 679 \\
\hline 2 & \begin{tabular}{|l|}
10 \\
0
\end{tabular} & 0 & $\begin{array}{l}1 . \\
2\end{array}$ & $\begin{array}{l}1 \\
0\end{array}$ & \begin{tabular}{|l|}
0.3 \\
2
\end{tabular} & $\begin{array}{l}32 \\
5\end{array}$ & 3.5 & 80 & 2380 & 3.2 & 742 & 33 & 1.0 & 0.13 & $\begin{array}{l}3.2 \mathrm{E}+ \\
04\end{array}$ & $\begin{array}{l}8.3 \mathrm{E}+ \\
04\end{array}$ & \begin{tabular}{|l|}
0.3 \\
9
\end{tabular} & \begin{tabular}{|l|}
0.6 \\
3
\end{tabular} & 854 \\
\hline 3 & \begin{tabular}{|l|}
20 \\
0 \\
\end{tabular} & 0 & $\begin{array}{l}1 . \\
2\end{array}$ & $\begin{array}{l}1 \\
0 \\
\end{array}$ & 0.4 & \begin{tabular}{|l|}
37 \\
5 \\
\end{tabular} & 5.2 & 160 & 3380 & 3.2 & 1054 & 33 & 1.0 & 0.04 & \begin{tabular}{|l}
$8.0 \mathrm{E}+$ \\
04 \\
\end{tabular} & $\begin{array}{l}1.7 \mathrm{E}+ \\
05\end{array}$ & \begin{tabular}{|l|}
0.4 \\
8 \\
\end{tabular} & \begin{tabular}{|l|}
0.4 \\
7 \\
\end{tabular} & 877 \\
\hline 4 & \begin{tabular}{|l|}
50 \\
0 \\
\end{tabular} & 0 & $\begin{array}{l}1 . \\
2\end{array}$ & $\begin{array}{l}1 \\
0 \\
\end{array}$ & \begin{tabular}{|l|}
0.3 \\
7 \\
\end{tabular} & \begin{tabular}{|l|}
47 \\
5 \\
\end{tabular} & 10.7 & 160 & 1860 & 3.2 & 580 & 35 & 1.0 & 0.02 & $\begin{array}{l}1.9 \mathrm{E}+ \\
05\end{array}$ & $\begin{array}{l}1.6 \mathrm{E}+ \\
05\end{array}$ & \begin{tabular}{|l|}
1.1 \\
4 \\
\end{tabular} & \begin{tabular}{|l|}
0.0 \\
6 \\
\end{tabular} & 621 \\
\hline 5 & \begin{tabular}{|l|}
10 \\
00 \\
\end{tabular} & 0 & $\begin{array}{l}1 . \\
2\end{array}$ & $\begin{array}{l}1 \\
0 \\
\end{array}$ & \begin{tabular}{|l|}
0.4 \\
5 \\
\end{tabular} & \begin{tabular}{|l}
57 \\
5 \\
\end{tabular} & 16.7 & 520 & 1180 & 3.2 & 368 & 37 & 1.0 & 0.02 & \begin{tabular}{|l}
$4.5 \mathrm{E}+$ \\
05
\end{tabular} & \begin{tabular}{|l}
$5.3 \mathrm{E}+$ \\
05
\end{tabular} & \begin{tabular}{|l|}
0.8 \\
5 \\
\end{tabular} & \begin{tabular}{|l|}
0.1 \\
4 \\
\end{tabular} & 350 \\
\hline 6 & 50 & 5 & $\begin{array}{l}1 . \\
2\end{array}$ & $\begin{array}{l}1 \\
0\end{array}$ & \begin{tabular}{|l|}
0.4 \\
8
\end{tabular} & $\begin{array}{l}22 \\
5\end{array}$ & 1.1 & 80 & 540 & 3.2 & 168 & 34 & 0.9 & 0.75 & $\begin{array}{l}2.4 \mathrm{E}+ \\
04\end{array}$ & $\begin{array}{l}8.2 \mathrm{E}+ \\
04\end{array}$ & $\begin{array}{l}0.2 \\
5\end{array}$ & \begin{tabular}{|l|}
0.8 \\
6
\end{tabular} & 202 \\
\hline 7 & \begin{tabular}{|l|}
10 \\
0 \\
\end{tabular} & 5 & $\begin{array}{l}1 . \\
2 \\
\end{array}$ & $\begin{array}{l}1 \\
0 \\
\end{array}$ & \begin{tabular}{|l|}
0.5 \\
1 \\
\end{tabular} & \begin{tabular}{|l|}
25 \\
0 \\
\end{tabular} & 2.5 & 80 & 2420 & 3.2 & 755 & 33 & 0.9 & 0.22 & \begin{tabular}{|l|}
$5.1 \mathrm{E}+$ \\
04 \\
\end{tabular} & \begin{tabular}{|l}
$8.3 \mathrm{E}+$ \\
04 \\
\end{tabular} & \begin{tabular}{|l|}
0.5 \\
4 \\
\end{tabular} & \begin{tabular}{|l|}
0.3 \\
9 \\
\end{tabular} & 830 \\
\hline 8 & $\begin{array}{l}20 \\
0 \\
\end{array}$ & 5 & $\begin{array}{l}1 . \\
2\end{array}$ & $\begin{array}{l}1 \\
0\end{array}$ & \begin{tabular}{|l|}
0.5 \\
4
\end{tabular} & \begin{tabular}{|l|}
35 \\
0
\end{tabular} & 3.9 & 160 & 3380 & 3.2 & 1054 & 33 & 0.9 & 0.07 & $\begin{array}{l}1.1 \mathrm{E}+ \\
05\end{array}$ & $\begin{array}{l}1.6 \mathrm{E}+ \\
05\end{array}$ & $\begin{array}{l}0.5 \\
7 \\
\end{array}$ & \begin{tabular}{|l|}
0.3 \\
5 \\
\end{tabular} & 773 \\
\hline 9 & \begin{tabular}{|l|}
50 \\
0
\end{tabular} & 5 & $\begin{array}{l}1 . \\
2\end{array}$ & $\begin{array}{l}1 \\
0\end{array}$ & \begin{tabular}{|l}
0.6 \\
1
\end{tabular} & $\begin{array}{l}47 \\
5\end{array}$ & 8.8 & 200 & 1700 & 3.2 & 530 & 35 & 0.9 & & $\begin{array}{l}3.1 \mathrm{E}+ \\
05\end{array}$ & $\begin{array}{l}2.0 \mathrm{E}+ \\
05\end{array}$ & $\begin{array}{l}1.3 \\
2\end{array}$ & \begin{tabular}{|l|}
0.0 \\
4
\end{tabular} & 546 \\
\hline $\begin{array}{l}1 \\
0\end{array}$ & \begin{tabular}{|l|}
10 \\
00
\end{tabular} & 5 & $\begin{array}{l}1 . \\
2\end{array}$ & $\begin{array}{l}1 \\
0\end{array}$ & $\begin{array}{l}0.5 \\
7\end{array}$ & \begin{tabular}{|l|}
40 \\
0
\end{tabular} & 15.0 & 520 & 1140 & 3.2 & 356 & 36 & 0.9 & 0.01 & $\begin{array}{l}5.7 \mathrm{E}+ \\
05\end{array}$ & \begin{tabular}{|l|}
$5.3 \mathrm{E}+$ \\
05
\end{tabular} & \begin{tabular}{|l|}
0.9 \\
5
\end{tabular} & \begin{tabular}{|l|}
0.1 \\
0 \\
\end{tabular} & 323 \\
\hline $\begin{array}{l}1 \\
1\end{array}$ & $\begin{array}{ll}10 \\
0 \\
\end{array}$ & 10 & $\begin{array}{l}1 . \\
2\end{array}$ & $\begin{array}{l}1 \\
0 \\
\end{array}$ & $\begin{array}{l}0.5 \\
6 \\
\end{array}$ & $\begin{array}{l}27 \\
5\end{array}$ & 2.3 & 120 & 540 & 3.2 & 168 & 33 & 0.8 & 0.05 & \begin{tabular}{|l}
$5.6 \mathrm{E}+$ \\
04
\end{tabular} & $\begin{array}{l}1.2 \mathrm{E}+ \\
05\end{array}$ & \begin{tabular}{|l|}
0.3 \\
5 \\
\end{tabular} & \begin{tabular}{|l|}
0.7 \\
0 \\
\end{tabular} & 244 \\
\hline $\begin{array}{l}1 \\
2 \\
\end{array}$ & \begin{tabular}{|l|}
20 \\
0 \\
\end{tabular} & 10 & $\begin{array}{l}1 . \\
2 \\
\end{array}$ & $\begin{array}{l}1 \\
0 \\
\end{array}$ & \begin{tabular}{|l|}
0.5 \\
9 \\
\end{tabular} & $\begin{array}{l}37 \\
5 \\
\end{array}$ & 4.3 & 120 & 1500 & 3.2 & 468 & 33 & 0.8 & 0.05 & \begin{tabular}{|l}
$1.2 \mathrm{E}+$ \\
05 \\
\end{tabular} & \begin{tabular}{|l}
$1.2 \mathrm{E}+$ \\
05 \\
\end{tabular} & \begin{tabular}{|l|}
0.7 \\
4 \\
\end{tabular} & \begin{tabular}{|l|}
0.2 \\
0 \\
\end{tabular} & 495 \\
\hline $\begin{array}{l}1 \\
3\end{array}$ & \begin{tabular}{|l|}
50 \\
0
\end{tabular} & 10 & $\begin{array}{l}1 . \\
2\end{array}$ & $\begin{array}{l}1 \\
0\end{array}$ & \begin{tabular}{|l|}
0.6 \\
7
\end{tabular} & $\begin{array}{l}47 \\
5\end{array}$ & 8.8 & 200 & 1260 & 3.2 & 393 & 35 & 0.8 & 0.01 & $\begin{array}{l}3.4 \mathrm{E}+ \\
05\end{array}$ & $\begin{array}{l}2.0 \mathrm{E}+ \\
05\end{array}$ & $\begin{array}{l}1.2 \\
9\end{array}$ & $\begin{array}{l}0.0 \\
4\end{array}$ & 436 \\
\hline $\begin{array}{l}1 \\
4 \\
\end{array}$ & \begin{tabular}{|l|}
10 \\
00 \\
\end{tabular} & 10 & \begin{tabular}{|l}
1. \\
2
\end{tabular} & $\begin{array}{l}1 \\
0 \\
\end{array}$ & \begin{tabular}{|l|}
0.6 \\
6 \\
\end{tabular} & \begin{tabular}{|l|}
62 \\
5 \\
\end{tabular} & 14.2 & 520 & 1220 & 3.2 & 381 & 36 & 0.8 & 0.01 & \begin{tabular}{|l|}
$6.6 \mathrm{E}+$ \\
05 \\
\end{tabular} & \begin{tabular}{|l}
$5.3 \mathrm{E}+$ \\
05
\end{tabular} & $\begin{array}{l}0.9 \\
8 \\
\end{array}$ & \begin{tabular}{|l|}
0.1 \\
0 \\
\end{tabular} & 326 \\
\hline $\begin{array}{l}1 \\
5\end{array}$ & \begin{tabular}{|l|}
10 \\
0 \\
\end{tabular} & 20 & $\begin{array}{l}1 . \\
2\end{array}$ & $\begin{array}{l}1 \\
0 \\
\end{array}$ & \begin{tabular}{|l}
0.6 \\
2 \\
\end{tabular} & $\begin{array}{l}25 \\
0\end{array}$ & 1.9 & 120 & 340 & 3.2 & 106 & 33 & 0.6 & 0.88 & $\begin{array}{l}6.2 \mathrm{E}+ \\
04\end{array}$ & $\begin{array}{l}1.2 \mathrm{E}+ \\
05\end{array}$ & \begin{tabular}{|l|}
0.3 \\
1 \\
\end{tabular} & $\begin{array}{l}0.7 \\
7 \\
\end{array}$ & 111 \\
\hline $\begin{array}{l}1 \\
6\end{array}$ & \begin{tabular}{|l|}
20 \\
0
\end{tabular} & 20 & $\begin{array}{l}1 . \\
2\end{array}$ & $\begin{array}{l}1 \\
0\end{array}$ & $\begin{array}{l}0.6 \\
4\end{array}$ & $\begin{array}{l}32 \\
5\end{array}$ & 3.9 & 120 & 1020 & 3.2 & 318 & 33 & 0.6 & 0.25 & $\begin{array}{l}1.3 \mathrm{E}+ \\
05\end{array}$ & $\begin{array}{l}1.2 \mathrm{E}+ \\
05\end{array}$ & $\begin{array}{l}0.6 \\
5\end{array}$ & $\begin{array}{l}0.2 \\
7\end{array}$ & 669 \\
\hline $\begin{array}{l}1 \\
7\end{array}$ & $\begin{array}{l}50 \\
0 \\
\end{array}$ & 20 & $\begin{array}{l}1 . \\
2\end{array}$ & $\begin{array}{l}1 \\
0 \\
\end{array}$ & \begin{tabular}{|l|}
0.7 \\
5 \\
\end{tabular} & \begin{tabular}{|l}
47 \\
5 \\
\end{tabular} & 8.5 & 160 & 1740 & 3.2 & 543 & 35 & 0.6 & 0.06 & $\begin{array}{l}3.8 \mathrm{E}+ \\
05\end{array}$ & $\begin{array}{l}1.6 \mathrm{E}+ \\
05\end{array}$ & \begin{tabular}{|l}
1.4 \\
7
\end{tabular} & \begin{tabular}{|l|}
0.0 \\
3 \\
\end{tabular} & 551 \\
\hline
\end{tabular}




\begin{tabular}{|c|c|c|c|c|c|c|c|c|c|c|c|c|c|c|c|c|c|c|c|}
\hline & $\begin{array}{l}\mathbf{Q} \\
\mathbf{(} \\
\mathbf{m} \\
3^{3} \mathbf{s} \\
\left.1^{1}\right) \\
\end{array}$ & \begin{tabular}{|l}
$\mathbf{Q}_{r}$ \\
$(\mathbf{k g}$ \\
$\left.\mathbf{s}^{-1}\right)$ \\
\end{tabular} & $\begin{array}{l}\mathrm{Hs} \\
(\mathrm{m} \\
) \\
\end{array}$ & $\begin{array}{l}\mathrm{T} \\
(\mathrm{s} \\
) \\
\end{array}$ & \begin{tabular}{|l}
$\mathbf{U}$ \\
$(\mathbf{m}$ \\
$\left.\mathbf{s}^{-1}\right)$ \\
\end{tabular} & \begin{tabular}{|l|} 
Ch \\
an \\
nel \\
wi \\
dt \\
h \\
(m \\
) \\
\end{tabular} & $\begin{array}{l}\text { Cha } \\
\text { nnel } \\
\text { dept } \\
\text { h } \\
\text { (m) } \\
\end{array}$ & \begin{tabular}{|l|} 
Spi \\
t \\
wid \\
th \\
(m) \\
\end{tabular} & \begin{tabular}{|l} 
Migr. \\
dist \\
$(\mathrm{m})$
\end{tabular} & $\begin{array}{l}\text { Mig } \\
\text { r. } \\
\text { time } \\
(\mathrm{yr}) \\
\end{array}$ & $\begin{array}{l}\text { Mig } \\
\text { r. } \\
\text { rate } \\
(\mathbf{m} / \mathbf{y} \\
\mathbf{r}) \\
\end{array}$ & \begin{tabular}{|l} 
Qs \\
$(\mathbf{k g}$ \\
$\left.\mathbf{s}^{-1}\right)$ \\
\end{tabular} & $\begin{array}{l}\text { Qs/( } \\
\text { Qs+ } \\
\text { Qr) }\end{array}$ & b & $\mathbf{M}_{j}$ & $\mathbf{M}_{w}$ & $\mathbf{J}$ & $\begin{array}{l}\mathbf{b}_{\text {pre }} \\
d\end{array}$ & $\begin{array}{l}\text { Mig } \\
\text { r. } \\
\text { rate } \\
\text { (pre } \\
\text { d., } \\
\text { myr } \\
\left.1^{1}\right) \\
\end{array}$ \\
\hline 3 & $\begin{array}{l}10 \\
00\end{array}$ & 20 & $\begin{array}{l}1 . \\
2\end{array}$ & $\begin{array}{l}1 \\
0\end{array}$ & \begin{tabular}{|l|}
0.7 \\
2 \\
\end{tabular} & $\begin{array}{l}65 \\
0\end{array}$ & 13.5 & 600 & 1340 & 3.2 & 418 & 36 & 0.6 & 0.06 & $\begin{array}{l}7.2 \mathrm{E}+ \\
05\end{array}$ & $\begin{array}{l}6.1 \mathrm{E}+ \\
05\end{array}$ & $\begin{array}{l}0.7 \\
6 \\
\end{array}$ & \begin{tabular}{|l|}
0.1 \\
8 \\
\end{tabular} & 268 \\
\hline 9 & \begin{tabular}{|l|}
20 \\
0
\end{tabular} & 50 & 1. & $\begin{array}{l}1 \\
0\end{array}$ & \begin{tabular}{|l|}
0.7 \\
6
\end{tabular} & $\begin{array}{l}32 \\
5\end{array}$ & 3.1 & 120 & 740 & 3.2 & 231 & 31 & 0.4 & 0.74 & $\begin{array}{l}1.5 \mathrm{E}+ \\
05\end{array}$ & $\begin{array}{l}1.2 \mathrm{E}+ \\
05\end{array}$ & $\begin{array}{l}0.4 \\
7\end{array}$ & $\begin{array}{l}0.4 \\
9\end{array}$ & 183 \\
\hline 0 & \begin{tabular}{|l|}
50 \\
0 \\
\end{tabular} & 50 & $\begin{array}{l}1 . \\
2 . \\
\end{array}$ & $\begin{array}{l}1 \\
0 \\
\end{array}$ & \begin{tabular}{|l|}
0.8 \\
6 \\
\end{tabular} & \begin{tabular}{|l|}
50 \\
0 \\
\end{tabular} & 6.9 & 200 & 2540 & 3.2 & 792 & 33 & 0.4 & 0.11 & \begin{tabular}{|l}
$4.3 \mathrm{E}+$ \\
05
\end{tabular} & $\begin{array}{l}2.0 \mathrm{E}+ \\
05\end{array}$ & \begin{tabular}{|l|}
0.8 \\
6 \\
\end{tabular} & \begin{tabular}{|l|}
0.1 \\
4 \\
\end{tabular} & 493 \\
\hline $\begin{array}{l}2 \\
1\end{array}$ & $\begin{array}{l}10 \\
00 \\
\end{array}$ & 50 & $\begin{array}{l}1 . \\
2 .\end{array}$ & $\begin{array}{l}1 \\
0 \\
\end{array}$ & \begin{tabular}{|l|}
0.8 \\
5 \\
\end{tabular} & \begin{tabular}{|l|}
75 \\
0
\end{tabular} & 12.7 & 400 & 1260 & 3.2 & 393 & 35 & 0.4 & 0.11 & $\begin{array}{l}8.5 \mathrm{E}+ \\
05\end{array}$ & $\begin{array}{l}4.0 \mathrm{E}+ \\
05\end{array}$ & \begin{tabular}{|l|}
0.8 \\
8 \\
\end{tabular} & \begin{tabular}{|l|}
0.1 \\
3 \\
\end{tabular} & 258 \\
\hline $\begin{array}{l}2 \\
2 \\
\end{array}$ & \begin{tabular}{|l}
20 \\
0 \\
\end{tabular} & 100 & $\begin{array}{l}1 . \\
2 . \\
\end{array}$ & $\begin{array}{l}1 \\
0 \\
\end{array}$ & \begin{tabular}{|l|}
0.9 \\
1 \\
\end{tabular} & \begin{tabular}{|l}
45 \\
0 \\
\end{tabular} & 2.1 & 240 & 300 & 3.2 & 94 & 27 & 0.2 & 0.80 & \begin{tabular}{|l}
$1.8 \mathrm{E}+$ \\
05 \\
\end{tabular} & \begin{tabular}{|l}
$2.5 \mathrm{E}+$ \\
05 \\
\end{tabular} & \begin{tabular}{|l|}
0.1 \\
5 \\
\end{tabular} & \begin{tabular}{|l|}
0.9 \\
6 \\
\end{tabular} & 1 \\
\hline $\begin{array}{l}3 \\
3\end{array}$ & \begin{tabular}{|l|}
50 \\
0 \\
\end{tabular} & 100 & $\begin{array}{l}1 \\
2 \\
\end{array}$ & $\begin{array}{l}1 \\
0 \\
\end{array}$ & \begin{tabular}{|l|}
0.9 \\
8 \\
\end{tabular} & \begin{tabular}{|l|}
72 \\
5 \\
\end{tabular} & 5.8 & 160 & 780 & 3.2 & 243 & 30 & 0.2 & 0.28 & \begin{tabular}{|l|}
$4.9 \mathrm{E}+$ \\
05 \\
\end{tabular} & \begin{tabular}{|l|}
$1.6 \mathrm{E}+$ \\
05 \\
\end{tabular} & \begin{tabular}{|l|}
0.6 \\
9 \\
\end{tabular} & \begin{tabular}{|l|}
0.2 \\
4 \\
\end{tabular} & 82 \\
\hline 4 & $\begin{array}{l}10 \\
00 \\
\end{array}$ & 100 & $\begin{array}{l}1 \\
2\end{array}$ & $\begin{array}{l}1 \\
0 \\
\end{array}$ & \begin{tabular}{|l|}
0.9 \\
5 \\
\end{tabular} & \begin{tabular}{|l|}
80 \\
0
\end{tabular} & 10.7 & 280 & 1620 & 3.2 & 505 & 33 & & & $\begin{array}{l}9.5 \mathrm{E}+ \\
05\end{array}$ & $\begin{array}{l}2.7 \mathrm{E}+ \\
05\end{array}$ & $\begin{array}{l}0.8 \\
7 \\
\end{array}$ & \begin{tabular}{|l|}
0.1 \\
3 \\
\end{tabular} & 280 \\
\hline 5 & 50 & 0 & $\begin{array}{l}0 . \\
7 \\
\end{array}$ & $\begin{array}{l}1 \\
0 \\
\end{array}$ & \begin{tabular}{|l|}
0.4 \\
9 \\
\end{tabular} & \begin{tabular}{|l}
12 \\
0 \\
\end{tabular} & 2.5 & 150 & 100 & 32 & & 7 & & & \begin{tabular}{|l}
$2.5 \mathrm{E}+$ \\
04 \\
\end{tabular} & \begin{tabular}{|l}
$4.5 \mathrm{E}+$ \\
04 \\
\end{tabular} & \begin{tabular}{|l|}
0.5 \\
4 \\
\end{tabular} & \begin{tabular}{|l|}
0.3 \\
9 \\
\end{tabular} & 260 \\
\hline 6 & $\begin{array}{ll}10 \\
0\end{array}$ & 0 & $\begin{array}{l}0 . \\
7\end{array}$ & $\begin{array}{l}1 \\
0\end{array}$ & $\begin{array}{l}0.4 \\
6 \\
\end{array}$ & $\begin{array}{l}10 \\
0 \\
\end{array}$ & 2.4 & 175 & 140 & 32 & 44 & 7 & & & \begin{tabular}{|l|}
$4.6 \mathrm{E}+$ \\
04
\end{tabular} & $\begin{array}{l}6.1 \mathrm{E}+ \\
04\end{array}$ & \begin{tabular}{|l|}
0.7 \\
5 \\
\end{tabular} & \begin{tabular}{|l|}
0.1 \\
9 \\
\end{tabular} & 347 \\
\hline 2 & \begin{tabular}{|l|}
20 \\
0
\end{tabular} & 0 & $\begin{array}{l}0 \\
7\end{array}$ & $\begin{array}{l}1 \\
0 \\
\end{array}$ & \begin{tabular}{|l|}
0.4 \\
3 \\
\end{tabular} & $\begin{array}{l}16 \\
0\end{array}$ & 4.5 & 250 & & & & 0 & & & \begin{tabular}{|l|}
$8.6 \mathrm{E}+$ \\
04
\end{tabular} & $\begin{array}{l}6.2 \mathrm{E}+ \\
04\end{array}$ & $\begin{array}{l}1.3 \\
8 \\
\end{array}$ & \begin{tabular}{|l|}
0.0 \\
4 \\
\end{tabular} & 179 \\
\hline $\begin{array}{l}2 \\
8 \\
\end{array}$ & \begin{tabular}{|l|}
50 \\
0 \\
\end{tabular} & 0 & $\begin{array}{l}0 . \\
7 \\
\end{array}$ & $\begin{array}{l}1 \\
0 \\
\end{array}$ & \begin{tabular}{|l|}
0.5 \\
2 \\
\end{tabular} & \begin{tabular}{|l|}
16 \\
0 \\
\end{tabular} & 7.7 & 300 & 300 & 32 & 04 & 9 & 10 & 0.25 & \begin{tabular}{|l}
$2.6 \mathrm{E}+$ \\
05 \\
\end{tabular} & $\begin{array}{l}0 \mathrm{E}+ \\
4 \\
\end{array}$ & \begin{tabular}{|l|}
4.3 \\
4 \\
\end{tabular} & \begin{tabular}{|l|}
0.0 \\
0 \\
\end{tabular} & 93 \\
\hline $\begin{array}{l}2 \\
9 \\
\end{array}$ & $\begin{array}{l}10 \\
00 \\
\end{array}$ & 0 & $\begin{array}{l}0 . \\
7 \\
\end{array}$ & $\begin{array}{l}1 \\
0 \\
\end{array}$ & \begin{tabular}{|l|}
0.5 \\
4 \\
\end{tabular} & \begin{tabular}{|l|}
24 \\
0 \\
\end{tabular} & 10.7 & 350 & 250 & 32 & 78 & 9 & 10 & 0.20 & \begin{tabular}{|l}
$5.4 \mathrm{E}+$ \\
05 \\
\end{tabular} & \begin{tabular}{|l}
$9.0 \mathrm{E}+$ \\
04 \\
\end{tabular} & \begin{tabular}{|l|}
5.9 \\
8 \\
\end{tabular} & \begin{tabular}{|l|}
0.0 \\
0 \\
\end{tabular} & 59 \\
\hline $\begin{array}{l}3 \\
0\end{array}$ & 50 & 0 & 1 & $\begin{array}{l}1 \\
0 \\
\end{array}$ & \begin{tabular}{|l|}
0.2 \\
6 \\
\end{tabular} & $\begin{array}{l}22 \\
5 \\
\end{array}$ & 1.3 & 50 & 660 & 3.2 & 206 & 19 & 10 & 0.74 & \begin{tabular}{|l}
$1.3 \mathrm{E}+$ \\
04
\end{tabular} & \begin{tabular}{|l}
$3.7 \mathrm{E}+$ \\
04
\end{tabular} & $\begin{array}{l}0.3 \\
5 \\
\end{array}$ & \begin{tabular}{|l}
0.7 \\
0
\end{tabular} & 773 \\
\hline $\begin{array}{l}3 \\
1 \\
\end{array}$ & \begin{tabular}{|l}
10 \\
0 \\
\end{tabular} & 0 & 1 & $\begin{array}{l}1 \\
0 \\
\end{array}$ & \begin{tabular}{|l|}
0.3 \\
2 \\
\end{tabular} & \begin{tabular}{|l}
30 \\
0 \\
\end{tabular} & 3.1 & 80 & & 3.2 & 43 & 18 & & 0.13 & \begin{tabular}{|l}
$3.2 \mathrm{E}+$ \\
04 \\
\end{tabular} & \begin{tabular}{|l}
$6.0 \mathrm{E}+$ \\
04 \\
\end{tabular} & \begin{tabular}{|l|}
0.5 \\
4 \\
\end{tabular} & \begin{tabular}{|l|}
0.3 \\
9 \\
\end{tabular} & 857 \\
\hline 2 & \begin{tabular}{|l|}
20 \\
0 \\
\end{tabular} & 0 & 1 & $\begin{array}{l}1 \\
0 \\
\end{array}$ & 0.4 & \begin{tabular}{|l|}
37 \\
5 \\
\end{tabular} & & & & & & 18 & & & \begin{tabular}{|l|}
$8.0 \mathrm{E}+$ \\
04 \\
\end{tabular} & \begin{tabular}{|l}
$1.2 \mathrm{E}+$ \\
05 \\
\end{tabular} & \begin{tabular}{|l|}
0.6 \\
7 \\
\end{tabular} & \begin{tabular}{|l|}
0.2 \\
5 \\
\end{tabular} & 695 \\
\hline $\begin{array}{l}3 \\
3 \\
\end{array}$ & \begin{tabular}{|l}
50 \\
0 \\
\end{tabular} & 0 & 1 & $\begin{array}{l}1 \\
0 \\
\end{array}$ & $\begin{array}{l}0.3 \\
8\end{array}$ & $\begin{array}{l}52 \\
5 \\
\end{array}$ & & 160 & & & & 20 & & & $\begin{array}{l}1.9 \mathrm{E}+ \\
05\end{array}$ & \begin{tabular}{|l}
$1.2 \mathrm{E}+$ \\
05
\end{tabular} & \begin{tabular}{|l|}
1.6 \\
0
\end{tabular} & $\begin{array}{l}0.0 \\
2 \\
\end{array}$ & 301 \\
\hline $\begin{array}{l}3 \\
4\end{array}$ & $\begin{array}{l}10 \\
00\end{array}$ & 0 & 1 & $\begin{array}{l}1 \\
0\end{array}$ & \begin{tabular}{|l|}
0.4 \\
5
\end{tabular} & $\begin{array}{l}22 \\
5\end{array}$ & & & & & & & & & $\begin{array}{l}4.5 \mathrm{E}+ \\
05\end{array}$ & $\begin{array}{l}2.0 \mathrm{E}+ \\
05\end{array}$ & $\begin{array}{l}2.2 \\
6\end{array}$ & $\begin{array}{l}0.0 \\
1\end{array}$ & 261 \\
\hline \begin{tabular}{|l}
3 \\
5 \\
\end{tabular} & 50 & 0 & $\begin{array}{l}1 . \\
2 .\end{array}$ & $\begin{array}{l}1 \\
0 \\
\end{array}$ & \begin{tabular}{|l|}
0.2 \\
6 \\
\end{tabular} & $\begin{array}{l}22 \\
5 \\
\end{array}$ & & & & & & 37 & & & \begin{tabular}{|l|}
$1.3 \mathrm{E}+$ \\
04 \\
\end{tabular} & \begin{tabular}{|l|}
$5.2 \mathrm{E}+$ \\
04
\end{tabular} & \begin{tabular}{|l|}
0.2 \\
5 \\
\end{tabular} & \begin{tabular}{|l|}
0.8 \\
6 \\
\end{tabular} & 781 \\
\hline \begin{tabular}{|l}
3 \\
6 \\
\end{tabular} & \begin{tabular}{|l|}
10 \\
0 \\
\end{tabular} & 0 & \begin{tabular}{|l}
1. \\
2 \\
\end{tabular} & $\begin{array}{l}1 \\
0 \\
\end{array}$ & \begin{tabular}{|l|}
0.3 \\
2 \\
\end{tabular} & $\begin{array}{l}32 \\
5 \\
\end{array}$ & & 80 & 2380 & & 742 & 33 & 1.0 & 0.47 & \begin{tabular}{|l}
$3.2 \mathrm{E}+$ \\
04
\end{tabular} & \begin{tabular}{|l}
$8.3 \mathrm{E}+$ \\
04
\end{tabular} & \begin{tabular}{|l|}
0.3 \\
9 \\
\end{tabular} & \begin{tabular}{|l|}
0.6 \\
3 \\
\end{tabular} & 967 \\
\hline $\begin{array}{l}3 \\
7 \\
\end{array}$ & \begin{tabular}{|l}
20 \\
0 \\
\end{tabular} & 0 & 1. & $\begin{array}{l}1 \\
0 \\
\end{array}$ & 0.4 & \begin{tabular}{|l}
37 \\
5 \\
\end{tabular} & 5.2 & 160 & 3380 & 3.2 & 1054 & 33 & 1.0 & 0.21 & \begin{tabular}{|l}
$8.0 \mathrm{E}+$ \\
04 \\
\end{tabular} & \begin{tabular}{|l}
$1.7 \mathrm{E}+$ \\
05 \\
\end{tabular} & \begin{tabular}{|l|}
0.4 \\
8 \\
\end{tabular} & \begin{tabular}{|l|}
0.4 \\
7 \\
\end{tabular} & 921 \\
\hline $\begin{array}{l}3 \\
8 \\
\end{array}$ & \begin{tabular}{|l|}
50 \\
0 \\
\end{tabular} & 0 & \begin{tabular}{|l}
1. \\
2 \\
\end{tabular} & $\begin{array}{l}1 \\
0 \\
\end{array}$ & \begin{tabular}{|l|}
0.3 \\
7 \\
\end{tabular} & \begin{tabular}{|l|}
47 \\
5 \\
\end{tabular} & 10.7 & 160 & 1860 & .2 & 80 & \begin{tabular}{|l} 
\\
\end{tabular} & & 0.11 & \begin{tabular}{|l}
$1.9 \mathrm{E}+$ \\
05 \\
\end{tabular} & \begin{tabular}{|l}
$1.6 \mathrm{E}+$ \\
05 \\
\end{tabular} & \begin{tabular}{|l|}
1.1 \\
4 \\
\end{tabular} & \begin{tabular}{|l|}
0.0 \\
6 \\
\end{tabular} & 635 \\
\hline $\begin{array}{l}3 \\
9 \\
\end{array}$ & \begin{tabular}{|l}
10 \\
00 \\
\end{tabular} & 0 & $\begin{array}{l}1 . \\
2 \\
\end{array}$ & $\begin{array}{l}1 \\
0 \\
\end{array}$ & \begin{tabular}{|l|}
0.4 \\
5 \\
\end{tabular} & \begin{tabular}{|l|}
57 \\
5 \\
\end{tabular} & 16.7 & 520 & 1180 & . & 500 & 37 & 1.0 & 0.06 & \begin{tabular}{|l}
$4.5 \mathrm{E}+$ \\
05 \\
\end{tabular} & \begin{tabular}{|l|}
$5.3 \mathrm{E}+$ \\
05 \\
\end{tabular} & \begin{tabular}{|l|}
0.8 \\
5 \\
\end{tabular} & \begin{tabular}{|l|}
0.1 \\
4 \\
\end{tabular} & 354 \\
\hline 4 & 50 & 0 & $\begin{array}{l}1 . \\
5 \\
\end{array}$ & 1 & \begin{tabular}{|l|}
0.2 \\
5 \\
\end{tabular} & $\begin{array}{l}27 \\
5 \\
\end{array}$ & 1.7 & 50 & 1340 & 3.2 & 418 & 69 & 1.0 & 0.74 & $\begin{array}{l}1.3 \mathrm{E}+ \\
04\end{array}$ & \begin{tabular}{|l}
$7.8 \mathrm{E}+$ \\
04
\end{tabular} & \begin{tabular}{|l|}
0.1 \\
6 \\
\end{tabular} & \begin{tabular}{|l|}
0.9 \\
6 \\
\end{tabular} & 514 \\
\hline
\end{tabular}




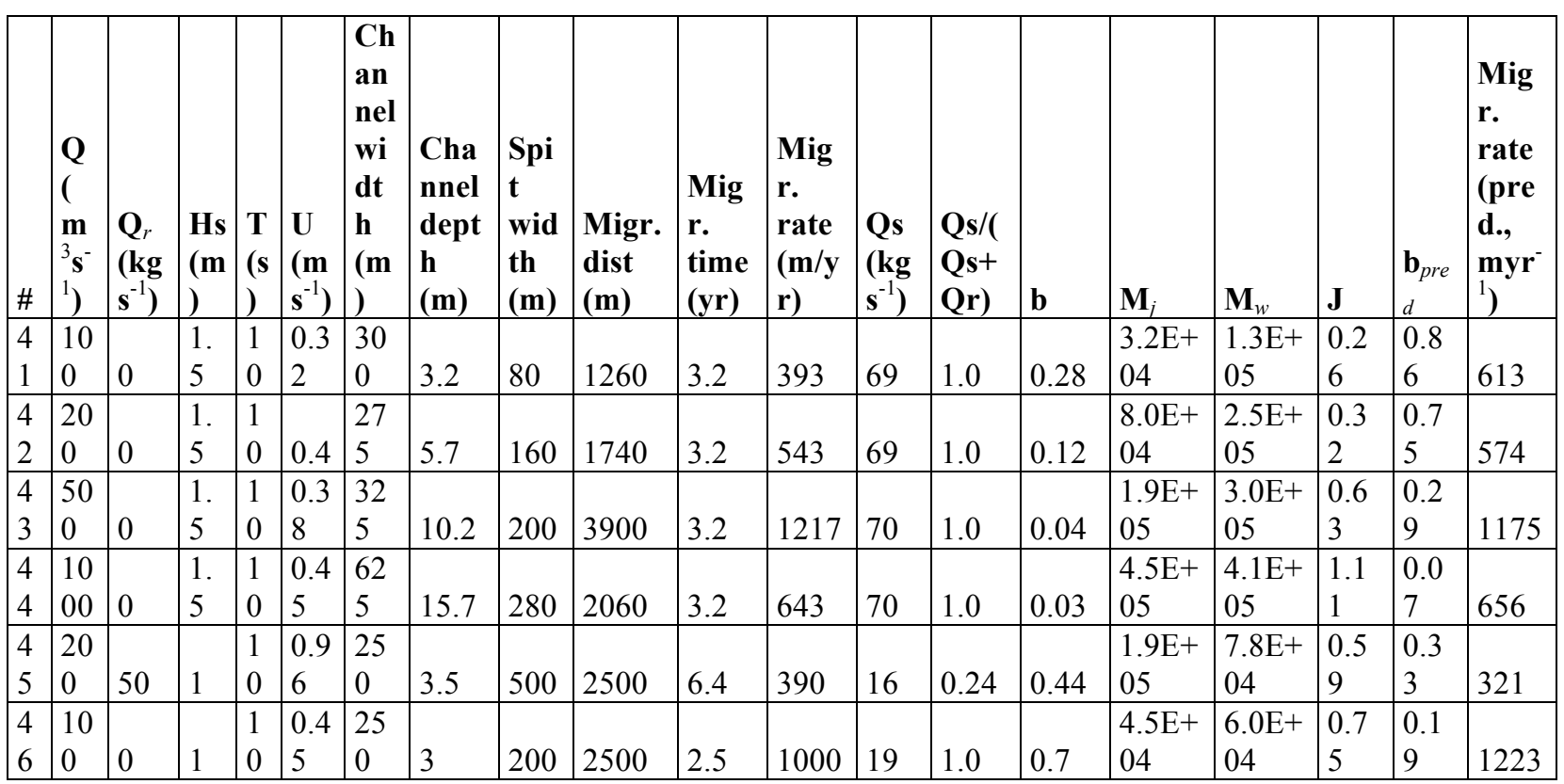

Table 3. Overview of the natural examples. $Q$ is the discharge, $U$ is the average current velocity in the channel, $Q_{s}$ is the alongshore sediment transport updrift of the river mouth, $H_{s}$ is the offshore waveheight, $Q_{r}$ is the upstream fluvial sediment supply, b is the hindcasted alongshore sediment bypassing fraction based on the observed migration rate, $M_{j}$ is the river mouth jet momentum flux, $M_{w}$ is the wave momentum flux, $J$ is the river mouth balance, and $\mathrm{b}_{\text {pred }}$ is the predicted bypassing fraction based on the river mouth balance $J$.

\begin{tabular}{|c|c|c|c|c|c|c|c|c|c|c|c|c|c|c|c|c|c|c|c|c|c|}
\hline Name & $\begin{array}{l}\text { Lo } \\
\text { n. }\end{array}$ & \begin{tabular}{|l|} 
La \\
t. \\
\end{tabular} & \begin{tabular}{|l} 
Ch \\
an \\
nel \\
wid \\
th \\
(m) \\
\end{tabular} & $\begin{array}{l}\mathbf{Q} \\
\mathbf{(} \\
\mathbf{m}^{3} \\
\mathbf{s}^{-} \\
1 \\
\left.{ }^{-}\right) \\
\end{array}$ & \begin{tabular}{|l|}
$\mathbf{U}$ \\
$\mathbf{(}$ \\
$\mathbf{m}$ \\
$\mathbf{s}$ \\
${ }^{-}$ \\
\end{tabular} & \begin{tabular}{|l} 
Spi \\
t \\
wid \\
th \\
(m) \\
\end{tabular} & \begin{tabular}{|l} 
Ch \\
ann \\
el \\
dep \\
th \\
$(\mathrm{m})$ \\
\end{tabular} & \begin{tabular}{|l} 
Spit \\
dept \\
h \\
$(\mathrm{m})$
\end{tabular} & \begin{tabular}{|l} 
Mi \\
gr. \\
dist \\
$\dot{(m)}$ \\
\end{tabular} & \begin{tabular}{|l} 
Mi \\
gr. \\
tim \\
e \\
(yr) \\
\end{tabular} & \begin{tabular}{|l|} 
Mig \\
r. \\
rate \\
$(\mathbf{m y r}$ \\
$\left.-{ }^{-1}\right)$ \\
\end{tabular} & \begin{tabular}{|l|}
$\mathbf{Q s}$ \\
$\mathbf{k}$ \\
$\mathbf{g s}$ \\
1 \\
\end{tabular} & $\begin{array}{l}\text { Hs } \\
(\mathrm{m} \\
) \\
\end{array}$ & \begin{tabular}{|l|} 
\\
Qr \\
(k \\
$\mathbf{g s}$ \\
$\mathbf{l}^{-}$ \\
\end{tabular} & $\begin{array}{l}\text { Qs } \\
/( \\
\text { Qr } \\
+ \\
\text { Qs } \\
\\
\end{array}$ & \begin{tabular}{|l} 
b \\
(hi \\
nd \\
ca \\
st) \\
\end{tabular} & $\mathbf{M}_{j}$ & $\mathbf{M}_{w}$ & $\mathbf{J}$ & $\begin{array}{l}\mathbf{b}_{p r} \\
e d\end{array}$ & $\begin{array}{l}\text { Mi } \\
\text { gr. } \\
\text { rat } \\
\text { e } \\
\text { (pr } \\
\text { ed, } \\
\text { my } \\
\left.\text { r }^{-1}\right)\end{array}$ \\
\hline $\begin{array}{l}\text { Psou, } \\
\text { Georgi } \\
\text { a }\end{array}$ & $\begin{array}{l}40 . \\
0\end{array}$ & $\begin{array}{l}43 \\
.4\end{array}$ & 45 & 21 & \begin{tabular}{|l|}
0. \\
5
\end{tabular} & 38 & 1.4 & 0.7 & 400 & 5 & 80 & $|-|$ & $\begin{array}{l}0.7 \\
8\end{array}$ & 0 & 1 & $\begin{array}{l}0.9 \\
8\end{array}$ & \begin{tabular}{|l}
9.8 \\
$E+0$ \\
3
\end{tabular} & \begin{tabular}{|l|}
9.5 \\
$\mathrm{E}+0$ \\
4
\end{tabular} & \begin{tabular}{|l|}
0.1 \\
0
\end{tabular} & \begin{tabular}{|l|}
0.9 \\
9
\end{tabular} & 53 \\
\hline $\begin{array}{l}\text { Bzipi, } \\
\text { Georgi } \\
\text { a }\end{array}$ & $\begin{array}{l}40 . \\
3\end{array}$ & $\begin{array}{l}43 \\
.2\end{array}$ & 80 & 65 & $\begin{array}{l}0 . \\
6\end{array}$ & 102 & 2.3 & 1.2 & 630 & 5 & 126 & \begin{tabular}{|l|}
20. \\
3 \\
\end{tabular} & $\begin{array}{l}0.7 \\
8\end{array}$ & 0 & 1 & $\begin{array}{l}0.9 \\
6\end{array}$ & \begin{tabular}{|l|}
4.0 \\
$E+0$ \\
4 \\
\end{tabular} & \begin{tabular}{|l|}
1.7 \\
$\mathrm{E}+0$ \\
5
\end{tabular} & $\begin{array}{l}0.2 \\
4\end{array}$ & \begin{tabular}{|l|}
0.8 \\
8
\end{tabular} & 396 \\
\hline $\begin{array}{l}\text { Gumist } \\
\text { a, } \\
\text { Georgi } \\
\text { a }\end{array}$ & $\begin{array}{l}40 . \\
5 \\
\end{array}$ & $\begin{array}{l}43 \\
.1 \\
\end{array}$ & 27 & 7 & $\begin{array}{l}0 . \\
4 \\
\end{array}$ & 41 & 0.9 & 0.4 & 300 & 3 & 100 & \begin{tabular}{|l|} 
\\
21. \\
3
\end{tabular} & $\begin{array}{l}0.7 \\
7 \\
\end{array}$ & 0 & 1 & \begin{tabular}{|l}
1.0 \\
0 \\
\end{tabular} & \begin{tabular}{|l}
2.8 \\
$E+0$ \\
3 \\
\end{tabular} & \begin{tabular}{|l|}
5.6 \\
$\mathrm{E}+0$ \\
4 \\
\end{tabular} & \begin{tabular}{|l|}
0.0 \\
5 \\
\end{tabular} & \begin{tabular}{|l|}
1.0 \\
0 \\
\end{tabular} & 29 \\
\hline $\begin{array}{l}\text { Eristsk } \\
\text { ali } \\
\text { Arkhi, } \\
\text { Georgi } \\
\text { a }\end{array}$ & $\begin{array}{l}41 . \\
5\end{array}$ & $\begin{array}{l}42 \\
.6 \\
\end{array}$ & 94 & 90 & $\begin{array}{l}0 . \\
7\end{array}$ & 104 & 2.7 & 1.4 & 500 & 7 & 71 & $\begin{array}{l}- \\
8.3\end{array}$ & \begin{tabular}{|l}
0.7 \\
4
\end{tabular} & 0 & 1 & $\begin{array}{l}0.9 \\
4 \\
\end{array}$ & \begin{tabular}{|l}
5.9 \\
$\mathrm{E}+0$ \\
4 \\
\end{tabular} & \begin{tabular}{|l|}
1.8 \\
$\mathrm{E}+0$ \\
5 \\
\end{tabular} & \begin{tabular}{|l|}
0.3 \\
3
\end{tabular} & \begin{tabular}{|l|}
0.7 \\
3 \\
\end{tabular} & 316 \\
\hline
\end{tabular}




\begin{tabular}{|c|c|c|c|c|c|c|c|c|c|c|c|c|c|c|c|c|c|c|c|c|c|}
\hline $\begin{array}{l}\text { Gagida } \\
\text { Georgi } \\
\text { a }\end{array}$ & $\begin{array}{l}41 . \\
5\end{array}$ & $\begin{array}{l}42 \\
.5\end{array}$ & 32 & 10 & $\begin{array}{l}0 . \\
4\end{array}$ & 51 & 1.0 & 0.5 & 200 & 7 & 29 & $\begin{array}{l}- \\
2.6\end{array}$ & $\begin{array}{l}0.7 \\
4\end{array}$ & 0 & 1 & $\begin{array}{l}0.9 \\
9\end{array}$ & \begin{tabular}{|l|}
4.2 \\
$\mathrm{E}+0$ \\
3 \\
\end{tabular} & \begin{tabular}{|l|}
6.1 \\
$\mathrm{E}+0$ \\
4 \\
\end{tabular} & \begin{tabular}{l|}
0.0 \\
7
\end{tabular} & $\begin{array}{l}1.0 \\
0\end{array}$ & 7 \\
\hline $\begin{array}{l}\text { Sandy, } \\
\text { Nicara } \\
\text { gua }\end{array}$ & $\begin{array}{l}- \\
83 . \\
5\end{array}$ & $\begin{array}{l}13 \\
.9 \\
\end{array}$ & 270 & $\begin{array}{l}74 \\
2 \\
\end{array}$ & $\begin{array}{l}1 . \\
1\end{array}$ & 350 & 7.0 & 3.5 & 80 & 2 & 40 & 2.6 & $\begin{array}{l}0.3 \\
2 \\
\end{array}$ & 0 & 1 & $\begin{array}{l}0.0 \\
6 \\
\end{array}$ & \begin{tabular}{|l|}
7.9 \\
$\mathrm{E}+0$ \\
5 \\
\end{tabular} & \begin{tabular}{|l|}
9.6 \\
$\mathrm{E}+0$ \\
4 \\
\end{tabular} & \begin{tabular}{|l|}
8.2 \\
6 \\
\end{tabular} & $\begin{array}{l}0.0 \\
0 \\
\end{array}$ & 42 \\
\hline $\begin{array}{l}\text { Patuca, } \\
\text { Hondu } \\
\text { ras }\end{array}$ & \begin{tabular}{|l} 
\\
84. \\
3 \\
\end{tabular} & $\begin{array}{l}15 \\
.8 \\
\end{array}$ & 110 & $\begin{array}{l}12 \\
3 \\
\end{array}$ & $\begin{array}{l}0 . \\
7 \\
\end{array}$ & 180 & 3.1 & 1.6 & 600 & 6 & 100 & \begin{tabular}{|l}
- \\
4.7 \\
\end{tabular} & $\begin{array}{l}0.9 \\
1 \\
\end{array}$ & 0 & 1 & \begin{tabular}{|l|}
0.7 \\
0 \\
\end{tabular} & \begin{tabular}{|l|}
8.7 \\
$\mathrm{E}+0$ \\
4 \\
\end{tabular} & \begin{tabular}{|l|}
3.2 \\
$\mathrm{E}+0$ \\
5 \\
\end{tabular} & \begin{tabular}{|l|}
0.2 \\
8 \\
\end{tabular} & \begin{tabular}{|l}
0.8 \\
3 \\
\end{tabular} & 58 \\
\hline $\begin{array}{l}\text { Sangre } \\
\text { laya, } \\
\text { Hondu } \\
\text { ras }\end{array}$ & $\begin{array}{l}- \\
85 . \\
1\end{array}$ & $\begin{array}{l}15 \\
.9\end{array}$ & 40 & 16 & 0. & 75 & 1.3 & 0.6 & 100 & 1 & 100 & \begin{tabular}{|l} 
\\
50. \\
4
\end{tabular} & $\begin{array}{l}1.3 \\
1\end{array}$ & 0 & 1 & $\begin{array}{l}1.0 \\
0\end{array}$ & \begin{tabular}{|l|}
7.3 \\
$E+0$ \\
3
\end{tabular} & \begin{tabular}{|l|}
2.4 \\
$\mathrm{E}+0$ \\
5
\end{tabular} & $\begin{array}{l}0.0 \\
3\end{array}$ & $\begin{array}{l}1.0 \\
0\end{array}$ & 6 \\
\hline $\begin{array}{l}\text { Salada, } \\
\text { Hondu } \\
\text { ras }\end{array}$ & \begin{tabular}{|l} 
\\
85. \\
5
\end{tabular} & $\begin{array}{l}15 \\
.9\end{array}$ & 78 & 62 & $\begin{array}{l}0 . \\
6\end{array}$ & 72 & 2.3 & 1.1 & 260 & 2 & 130 & \begin{tabular}{|l|}
- \\
23. \\
1
\end{tabular} & $\begin{array}{l}0.9 \\
1 \\
\end{array}$ & 0 & 1 & $\begin{array}{l}0.9 \\
8\end{array}$ & \begin{tabular}{|l|}
3.8 \\
$\mathrm{E}+0$ \\
4 \\
\end{tabular} & \begin{tabular}{|l|}
2.2 \\
$\mathrm{E}+0$ \\
5 \\
\end{tabular} & \begin{tabular}{l|}
0.1 \\
7
\end{tabular} & $\begin{array}{l}0.9 \\
5\end{array}$ & 251 \\
\hline $\begin{array}{l}\text { Quebra } \\
\text { da } \\
\text { Santa } \\
\text { Ines, } \\
\text { Hondu } \\
\text { ras }\end{array}$ & \begin{tabular}{|l}
- \\
86. \\
9
\end{tabular} & $\begin{array}{l}15 \\
.8\end{array}$ & 21 & 4 & $\begin{array}{l}0 . \\
3\end{array}$ & 32 & 0.7 & 0.4 & 300 & 6 & 50 & $\begin{array}{l}- \\
15 . \\
4\end{array}$ & $\begin{array}{l}0.6 \\
8\end{array}$ & 0 & 1 & $\begin{array}{l}1.0 \\
0\end{array}$ & \begin{tabular}{|l|}
1.5 \\
$\mathrm{E}+0$ \\
3 \\
\end{tabular} & \begin{tabular}{|l|}
3.4 \\
$\mathrm{E}+0$ \\
4 \\
\end{tabular} & \begin{tabular}{|l|}
0.0 \\
4 \\
\end{tabular} & $\begin{array}{l}1.0 \\
0\end{array}$ & 24 \\
\hline $\begin{array}{l}\text { Hicaqu } \\
\mathrm{d} \text {, } \\
\text { Hondu } \\
\text { ras }\end{array}$ & $\begin{array}{l}- \\
87 . \\
4\end{array}$ & $\begin{array}{l}15 \\
.8 \\
\end{array}$ & 42 & 18 & $\begin{array}{l}0 . \\
5 \\
\end{array}$ & 67 & 1.3 & 0.7 & 350 & 3 & 117 & \begin{tabular}{|l}
- \\
13. \\
0 \\
\end{tabular} & \begin{tabular}{|l|}
0.9 \\
8 \\
\end{tabular} & 0 & 1 & \begin{tabular}{|l|}
0.9 \\
8 \\
\end{tabular} & \begin{tabular}{|l|}
8.2 \\
$\mathrm{E}+0$ \\
3 \\
\end{tabular} & \begin{tabular}{|l|}
1.4 \\
$\mathrm{E}+0$ \\
5 \\
\end{tabular} & \begin{tabular}{|l|}
0.0 \\
6 \\
\end{tabular} & $\begin{array}{l}1.0 \\
0 \\
\end{array}$ & 12 \\
\hline $\begin{array}{l}\text { Ariri, } \\
\text { Brazil }\end{array}$ & \begin{tabular}{|l}
- \\
48. \\
1
\end{tabular} & $\begin{array}{l} \\
25 \\
.3 \\
\end{array}$ & 482 & $\begin{array}{l}23 \\
66 \\
\end{array}$ & 1. & 517 & $\begin{array}{l}11 . \\
8\end{array}$ & 5.9 & $\begin{array}{l}100 \\
0\end{array}$ & 28 & 36 & 7.3 & $\begin{array}{l}1.1 \\
5 \\
\end{array}$ & 0 & 1 & $\begin{array}{l}0.2 \\
5 \\
\end{array}$ & \begin{tabular}{|l|}
3.3 \\
$\mathrm{E}+0$ \\
6 \\
\end{tabular} & \begin{tabular}{|l|}
2.2 \\
$\mathrm{E}+0$ \\
6 \\
\end{tabular} & $\begin{array}{l}1.4 \\
9 \\
\end{array}$ & $\begin{array}{l}0.0 \\
3\end{array}$ & 46 \\
\hline $\begin{array}{l}\text { Araran } \\
\text { gua, } \\
\text { Brazil }\end{array}$ & \begin{tabular}{|l} 
\\
49. \\
3
\end{tabular} & $\begin{array}{l}- \\
28 \\
.9\end{array}$ & 216 & \begin{tabular}{|l|}
47 \\
5
\end{tabular} & 1. & 270 & 5.7 & 2.9 & \begin{tabular}{|l}
400 \\
0
\end{tabular} & 26 & 154 & \begin{tabular}{|l|} 
\\
46. \\
6
\end{tabular} & $\begin{array}{l}1.7 \\
0\end{array}$ & 0 & 1 & $\begin{array}{l}0.8 \\
7\end{array}$ & \begin{tabular}{|l|}
4.6 \\
$\mathrm{E}+0$ \\
5 \\
\end{tabular} & \begin{tabular}{|l|}
2.2 \\
$\mathrm{E}+0$ \\
6 \\
\end{tabular} & \begin{tabular}{|l|}
0.2 \\
1
\end{tabular} & $\begin{array}{l}0.9 \\
1\end{array}$ & 103 \\
\hline $\begin{array}{l}\text { Sikia } \\
\text { Pakia } \\
\text { Bila, } \\
\text { Nicara } \\
\text { gua }\end{array}$ & $\begin{array}{l}- \\
83 . \\
3\end{array}$ & $\begin{array}{l}14 \\
.7 \\
\end{array}$ & 22 & 5 & $\begin{array}{l}0 . \\
3 \\
\end{array}$ & 0 & 0.7 & 0.4 & 0 & 0 & 0 & 2.6 & \begin{tabular}{|l|}
0.3 \\
2 \\
\end{tabular} & 0 & 1 & \begin{tabular}{|l|}
1.0 \\
0 \\
\end{tabular} & \begin{tabular}{|l|}
1.7 \\
$\mathrm{E}+0$ \\
3 \\
\end{tabular} & \begin{tabular}{|l|}
7.8 \\
$\mathrm{E}+0$ \\
3 \\
\end{tabular} & \begin{tabular}{|l|}
0.2 \\
2 \\
\end{tabular} & \begin{tabular}{|l}
0.9 \\
1 \\
\end{tabular} & 0 \\
\hline $\begin{array}{l}\text { Senega } \\
1 \text {, } \\
\text { Senega } \\
1\end{array}$ & \begin{tabular}{|l}
- \\
16. \\
5
\end{tabular} & $\begin{array}{l}16 \\
.0\end{array}$ & 350 & $\begin{array}{l}12 \\
47 \\
\end{array}$ & $\begin{array}{l}1 . \\
2\end{array}$ & 500 & 8.9 & 4.4 & 400 & 2 & 200 & \begin{tabular}{|l|}
- \\
13 \\
2.0
\end{tabular} & $\begin{array}{l}1.8 \\
4 \\
\end{array}$ & 15 & $\begin{array}{l}0 . \\
9 \\
\end{array}$ & \begin{tabular}{|l|}
0.8 \\
3 \\
\end{tabular} & \begin{tabular}{|l|}
1.5 \\
$E+0$ \\
6 \\
\end{tabular} & \begin{tabular}{|l|}
4.1 \\
$\mathrm{E}+0$ \\
6 \\
\end{tabular} & \begin{tabular}{|l|}
0.3 \\
3 \\
\end{tabular} & \begin{tabular}{|l}
0.7 \\
4 \\
\end{tabular} & 307 \\
\hline
\end{tabular}




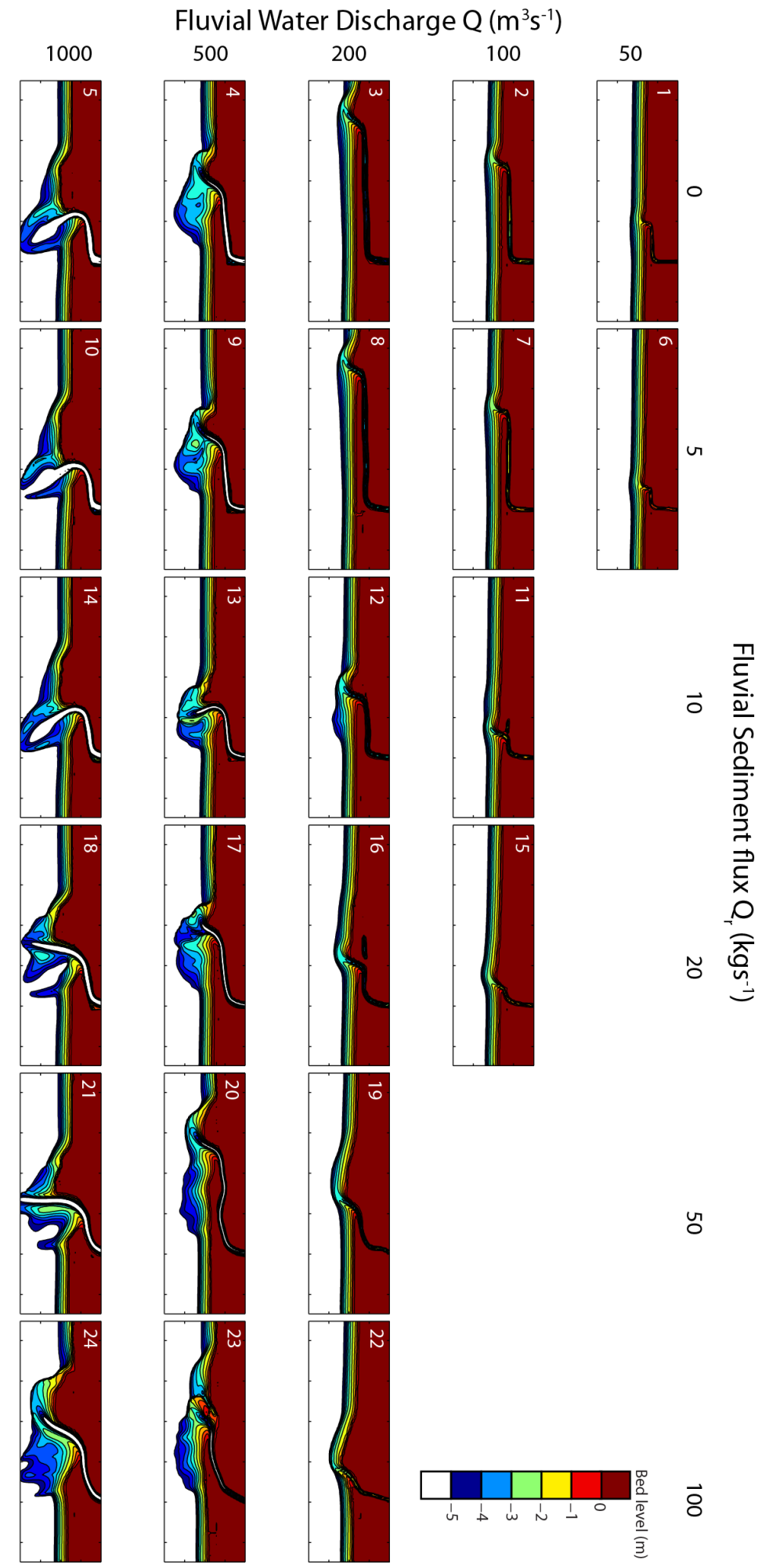

Figure S1. Final bathymetry of 24 model experiments (\#1-24 of supplementary table S2) varying the fluvial discharge $Q$ and the fluvial sediment flux $Q_{r}$. 


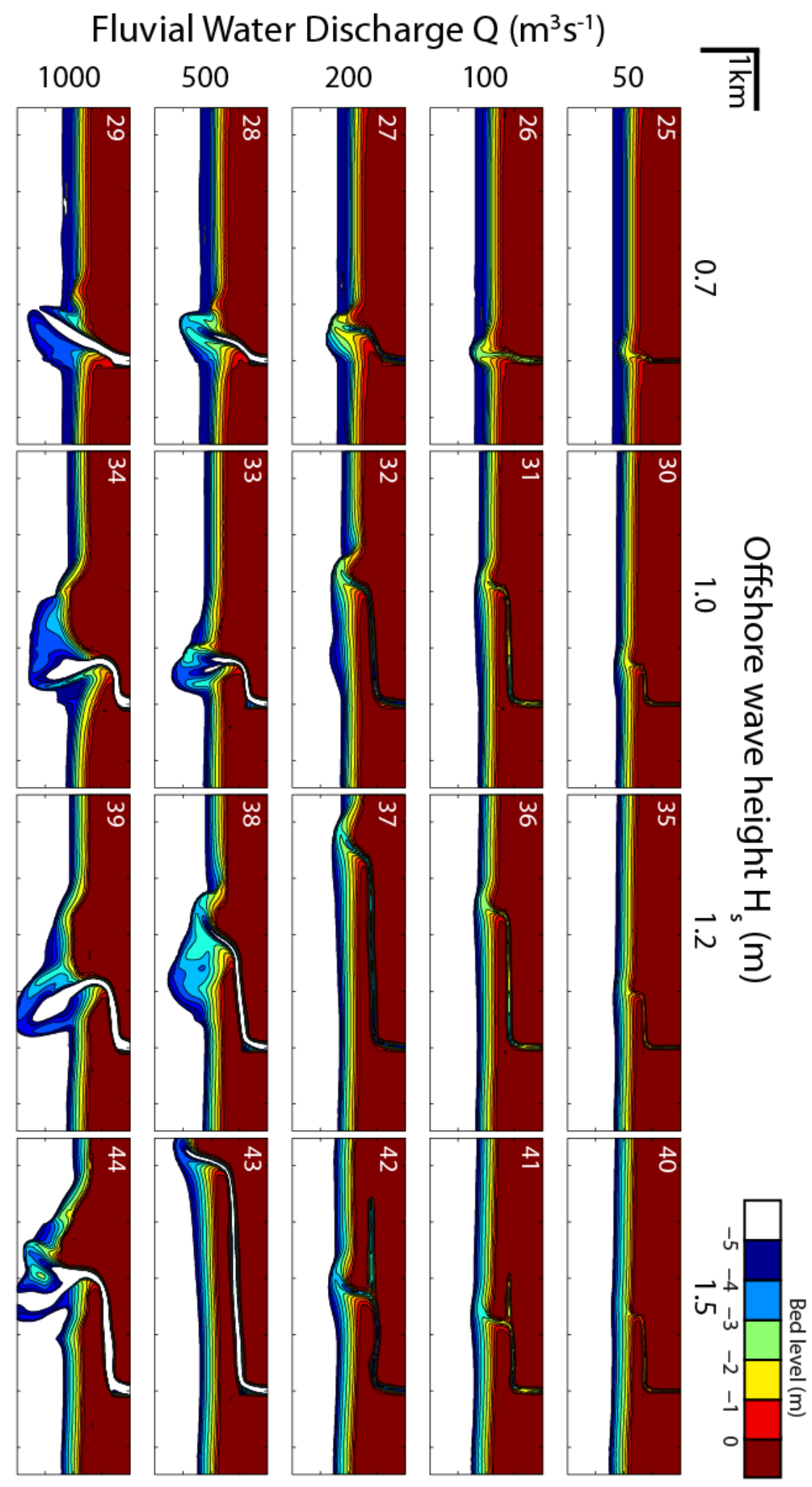

Figure S2. Final bathymetry of 20 model experiments (\#25-44 of supplementary table S2) varying the fluvial discharge $Q$ and the offshore wave height $H_{s}$. 


\section{Appendices for chapter 4}

Table 2: Natural examples, including data sources and extracted characteristics

\begin{tabular}{|c|c|c|c|c|}
\hline Delta & Wave source & Geometry source & $\Gamma$ & $\begin{array}{l}\text { Aspect R } \\
\text { (height/width) } \\
\text { (see Fig. 4b and 4c) }\end{array}$ \\
\hline Coco & $\begin{array}{l}\text { WAVEWATCH III }{ }^{\circledR} \text { version } \\
2.22 \text { [Tolman, 2009] } \\
\text { NWW3 Global Hindcast } \\
\text { reanalysis from Aug } 1999 \text { to } \\
\text { Feb } 2011\end{array}$ & NASA Landsat & -0.5 & 2.5 \\
\hline $\begin{array}{l}\text { Ebro (1kA bp, La } \\
\text { Banya Lobe) }\end{array}$ & $\begin{array}{l}\text { MedAtlas [Gaillard et al., } \\
\text { 2004] }\end{array}$ & Canicio and Ibanez [1999] & -0.45 & 1.6 \\
\hline Nile (Rosetta Lobe) & $\begin{array}{l}\text { MedAtlas [Gaillard et al., } \\
\text { 2004] }\end{array}$ & Stanley and Warne [1998] & 0.0 & 1.1 \\
\hline $\begin{array}{l}\text { Nile (Damietta } \\
\text { Lobe) }\end{array}$ & $\begin{array}{l}\text { MedAtlas [Gaillard et al., } \\
\text { 2004] }\end{array}$ & Stanley and Warne [1998] & -0.4 & 0.66 \\
\hline Nestos & $\begin{array}{l}\text { MedAtlas [Gaillard et al., } \\
\text { 2004] }\end{array}$ & NASA Landsat & -0.4 & 1 \\
\hline $\begin{array}{l}\text { Rhone }(0.3 \mathrm{kA} \mathrm{bp}, \\
\text { Bras de Fer Lobe) }\end{array}$ & $\begin{array}{l}\text { MedAtlas [Gaillard et al., } \\
\text { 2004] }\end{array}$ & Vella et al. [2005] & -0.3 & 2 \\
\hline Ombrone (0.1kA bp) & $\begin{array}{l}\text { MedAtlas [Gaillard et al., } \\
\text { 2004] }\end{array}$ & Pranzini [2001] & 0.63 & 0.3 \\
\hline Sao Francisco & $\begin{array}{l}\text { WAVEWATCH III }{ }^{\circledR} \text { version } \\
2.22[\text { Tolman, 2009]NWW3 } \\
\text { Global Hindcast reanalysis } \\
\text { from Aug } 1999 \text { to Feb } 2011\end{array}$ & NASA Landsat & 0.63 & 0.4 \\
\hline $\begin{array}{l}\text { Danube (St. George } \\
\text { Lobe) }\end{array}$ & Giosan [2007] & Giosan [2007] & -0.35 & 0.5 \\
\hline Arno & Pranzini [2001] & Pranzini [2001] & 0.9 & 0.16 \\
\hline Po (di Goro Lobe) & $\begin{array}{l}\text { MedAtlas [Gaillard et al., } \\
\text { 2004] }\end{array}$ & Simeoni et al. [2007] & -0.2 & 6 \\
\hline
\end{tabular}

Table 2: Delta Simulation Parameters

\begin{tabular}{|l|l|l|}
\hline Symbol & Description & Values \\
\hline $\mathrm{Q}_{r}$ & Fluvial sediment input $\left(\mathrm{kgs}^{-1}\right)$ & 150,200 \\
\hline $\mathrm{I}_{s}$ & Shelf Slope & 0.001 \\
\hline $\mathrm{I}_{s f}$ & Shoreface Slope & 0.01 \\
\hline $\mathrm{D}_{s f}$ & Shoreface Depth $(\mathrm{m})$ & 8 \\
\hline $\mathrm{A}$ & Proportion waves approaching from left & $0.5,0.55 \ldots, 0.9$ \\
\hline $\mathrm{U}$ & Proportion unstable waves & $0.0,0.05 \ldots, 0.4$ \\
\hline $\mathrm{H}$ & Wave height $(\mathrm{m})$ & 1 \\
\hline $\mathrm{T}$ & Wave period $(\mathrm{s})$ & 5 \\
\hline
\end{tabular}



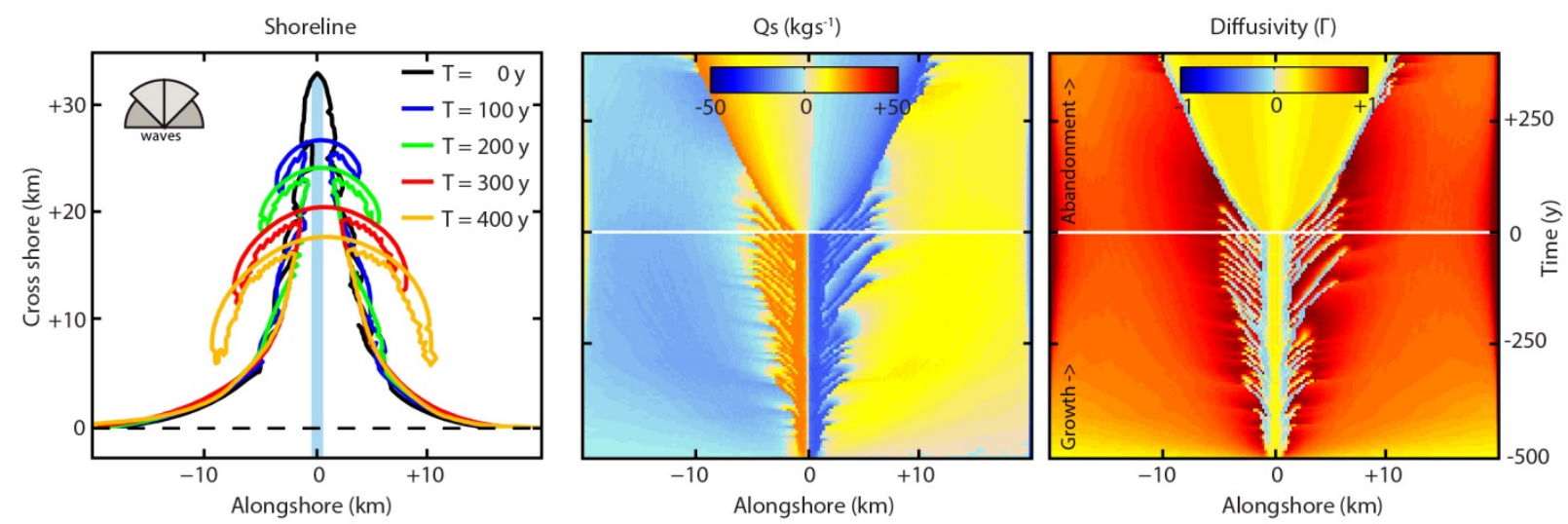

Figure S3: Shoreline configuration (left column), net alongshore sediment transport (Qs, middle column, sediment transport is positive to the right) and normalized shoreline diffusivity ( $\Gamma$, right column) for the example model run displayed in Figure 1. Inset roses display the angular distribution of incoming wave energy. Abandonment and spit formation starts at $\mathrm{T}=0 \mathrm{y}$.

\section{References}

Canicio, A., and C. Ibanez (1999), The Holocene Evolution of the Ebro Delta Catalonia, Spain, Acta Geographica Sinica, 54(5), 462-469.

Gaillard, P., P. Ravazzola, C. Kontolios, C. Arrivet, G. Athanassoulis, C. Stefanakos, T. Gerostathis, L. Cavaleri, L. Bertotti, and M. Sclavo (2004), Wind and Wave Atlas of the Mediterranean Sea, Western European Arnament Organization Research Cell, Athens, Greece.

Giosan, L. (2007), Morphodynamic Feedbacks on Deltaic Coasts: Lessons from the WaveDominated Danube Delta, in Coastal Sediments '07, edited by N. C. Kraus and J. D. Rosati, pp. 828-841, New Orleans, LA doi: 10.1061/40926(239)63.

Pranzini, E. (2001), Updrift river mouth migration on cuspate deltas: two examples from the coast of Tuscany (Italy), Geomorphology, 38(1-2), 125-132 doi: 10.1016/S0169$555 \mathrm{X}(00) 00076-3$.

Simeoni, U., G. Fontolan, U. Tessari, and C. Corbau (2007), Domains of spit evolution in the Goro area, Po Delta, Italy, Geomorphology, 86(3-4), 332-348, doi: 10.1016/j.geomorph.2006.09.006.

Stanley, D. J., and A. G. Warne (1998), Nile Delta in Its Destruction Phase, Journal of Coastal Research, 14(3), 795-825.

Tolman, H. (2009), User manual and system documentation of WAVEWATCH III TM version 3.14Rep., 194 pp, NOAA/NWS/NCEP/MMAB.

Vella, C., T. J. Fleury, G. Raccasi, M. Provansal, F. Sabatier, and M. Bourcier (2005), Evolution of the Rhone delta plain in the Holocene, Marine Geology, 222, 235-265 doi:

10.1016/J.Margeo.2005.06.028. 


\section{Bibliography}

Aibulatov, N. A., and I. F. Shadrin (1961), Some data on the long-shore drift of sand near natural obstacles, Tr. Inst. Okeanol. Akad. Nauk. SSSR, 53.

Andren, H. (1994), Development of the Laitaure delta, Swedish Lapland: A study of growth, distributary forms, and processes, Uppsala University.

Anthony, E. J., N. Marriner, and C. Morhange (2014), Human influence and the changing geomorphology of Mediterranean deltas and coasts over the last 6000 years: From progradation to destruction phase?, Earth-Science Rev., 139, 336-361, doi:10.1016/j.earscirev.2014.10.003.

Ashton, A. D., and L. Giosan (2011), Wave-angle control of delta evolution, Geophys. Res. Lett., 38(13), L13405, doi:10.1029/2011GL047630.

Ashton, A. D., and A. B. Murray (2006a), High-angle wave instability and emergent shoreline shapes: 1. Modeling of sand waves, flying spits, and capes, J. Geophys. Res., 111(F4), F04011, doi:10.1029/2005JF000422.

Ashton, A. D., and A. B. Murray (2006b), High-angle wave instability and emergent shoreline shapes: 2. Wave climate analysis and comparisons to nature, J. Geophys. Res., 111(F4), F04012, doi:10.1029/2005JF000423.

Ashton, A. D., A. B. Murray, and O. Arnoult (2001), Formation of coastline features by largescale instabilities induced by high-angle waves, Nature, 414(6861), 296-300, doi: $10.1038 / 35104541$.

Ashton, A. D., E. W. H. H. Hutton, A. J. Kettner, F. Xing, J. Kallumadikal, J. Nienhuis, and L. Giosan (2013), Progress in coupling models of coastline and fluvial dynamics, Comput. Geosci., 53, 21-29, doi:10.1016/j.cageo.2012.04.004.

Ashton, A. D., J. Nienhuis, and K. Ells (2015), On a neck, on a spit: controls on the shape of free spits, Earth Surf. Dyn. Discuss., 3(2), 515-560, doi:10.5194/esurfd-3-515-2015.

Babault, J., N. Loget, J. Van Den Driessche, S. Castelltort, S. Bonnet, and P. Davy (2006), Did the Ebro basin connect to the Mediterranean before the Messinian salinity crisis?, Geomorphology, 81(1-2), 155-165, doi:10.1016/j.geomorph.2006.04.004.

Bakker, W. T. J. N. P., and T. Edelman (1964), The Coastline of River-deltas, in Proc. of the 9th Conf. on Coastal Engineering, edited by B. Edge, pp. 199-218, ASCE, Lisbon.

Balouin, Y., P. Ciavola, and D. Michel (2006), Support of Subtidal Tracer Studies to Quantify the Complex Morphodynamics of a River Outlet: the Bevano, NE Italy, J. Coast. Res., 1(39), 602-606. 
Barbosa, L. M., and J. M. L. Dominguez (2004), Coastal dune fields at the São Francisco River strandplain, northeastern Brazil: morphology and environmental controls, Earth Surf. Process. Landforms, 29(4), 443-456, doi:10.1002/esp.1040.

Batalla, R. J., C. M. Gómez, and G. M. Kondolf (2004), Reservoir-induced hydrological changes in the Ebro River basin (NE Spain), J. Hydrol., 290(1-2), 117-136, doi:10.1016/j.jhydrol.2003.12.002.

Bates, C. C. (1953), Rational theory of delta formation, Am. Assoc. Pet. Geol. Bull., 37(9), 21192162.

Bellotti, P., C. Caputo, L. Davoli, S. Evangelista, E. Garzanti, F. Pugliese, and P. Valeri (2004), Morpho-sedimentary characteristics and Holocene evolution of the emergent part of the Ombrone River delta (southern Tuscany), Geomorphology, 61(1-2), 71-90, doi:Doi 10.1016/J.Geomorph.2003.11.007.

Benito, G., V. R. Thorndycraft, M. Rico, Y. Sánchez-Moya, and A. Sopeña (2008), Palaeoflood and floodplain records from Spain: Evidence for long-term climate variability and environmental changes, Geomorphology, 101(1-2), 68-77, doi:10.1016/j.geomorph.2008.05.020.

Bhattacharya, J. P., and L. Giosan (2003), Wave-influenced deltas: geomorphological implications for facies reconstuction, Sedimentology, 50(1), 187-210, doi:10.1046/j.13653091.2003.00545.x.

Bolanos, R., G. Jorda, J. Cateura, J. Lopez, J. Puigdefabregas, J. Gomez, M. Espino, and R. Bolaños (2009), The XIOM: 20 years of a regional coastal observatory in the Spanish Catalan coast, J. Mar. Syst., 77(3), 237-260, doi:10.1016/j.jmarsys.2007.12.018.

Booij, N., R. C. Ris, and L. H. Holthuijsen (1999), A third-generation wave model for coastal regions: 1. Model description and validation, J. Geophys. Res., 104(C4), 7649, doi:10.1029/98JC02622.

Boyd, R., R. Dalrymple, and B. A. Zaitlin (1992), Classification of clastic coastal depositional environments, Sediment. Geol., 80(3-4), 139-150, doi:10.1016/0037-0738(92)90037-R.

Brocatus, J. (2008), Sediment Budget Analysis of the Santa Barbara Littoral Cell, Delft University of Technology.

Bruun, P., and F. Gerritsen (1959), Natural By-Passing of Sand at Coastal Inlets, J. Waterw. Harb. Div., 85(4), 75-107.

Bruun, P., and F. Gerritsen (1961), By-Passing of Sand by Natural Action at Coastal Inlets and Passes, Trans. Am. Soc. Civ. Eng., 126(4), 823-850.

Caldwell, R. L., and D. A. Edmonds (2014), The effects of sediment properties on deltaic 
processes and morphologies: A numerical modeling study, J. Geophys. Res. Earth Surf., 119(5), 961-982, doi:10.1002/2013JF002965.

Canestrelli, A., W. Nardin, D. Edmonds, S. Fagherazzi, and R. Slingerland (2014), Importance of frictional effects and jet instability on the morphodynamics of river mouth bars and levees, J. Geophys. Res. Ocean., 119(1), 509-522, doi:10.1002/2013JC009312.

Canicio, A., and C. Ibanez (1999), The Holocene Evolution of the Ebro Delta Catalonia, Spain, Acta Geogr. Sin., 54(5), 462-469.

Carling, P. A., and Z. Cao (2002), Mathematical modelling of alluvial rivers: reality and myth. Part 1: General review, Proc. ICE - Water Marit. Eng., 154(4), 297-307, doi:10.1680/wame.2002.154.4.297.

Chawla, A., D. Spindler, and H. L. Tolman (2011), A Thirty Year Wave Hindcast Using The Latest NCEP Climate Forecast System Reanalysis Winds, in Proceedings of the 12th International Workshop on Wave Hindcasting and Forecasting, Kohala Coast, Hawaii.

Chen, W. Y., and H. Van den Dool (2003), Sensitivity of Teleconnection Patterns to the Sign of Their Primary Action Center, Mon. Weather Rev., 131(11), 2885-2899, doi:10.1175/15200493(2003) $131<2885$ :SOTPTT $>2.0$. CO;2.

Coleman, J. M., H. H. Roberts, and G. W. Stone (1998), Mississippi River Delta: an Overview, J. Coast. Res., 14(3), 698-716.

Constante, A., and J. L. Pena-Monne (2009), Human-induced erosion and sedimentation during the Holocene in the central Ebro depression, in International Conference on Desertification, pp. 207-210, University of Murcia, Murcia, Spain.

Constante, A., J. L. Peña-Monné, and A. Muñoz (2010), Alluvial geoarchaeology of an ephemeral stream: Implications for Holocene landscape change in the central part of the Ebro Depression, northeast Spain, Geoarchaeology, 25(4), 475-496, doi:10.1002/gea.20314.

Constante-Orrios, A., R. Dossche, J. L. Pena-Monne, C. Sancho-Marcen, and M. de Dapper (2009), Holocene evolution and geoarcheaology in the Ebro valley around Zaragoza (Northern Spain), in Ol' Man River: geo-archaeological aspects of rivers and river plains, edited by M. de Dapper, F. Vermeulen, S. Deprez, and D. Taelman, pp. 241-256, Academia Press, Ghent, Belgium.

Cooper, J. A. G. (1990), Ephemeral stream-mouth bars at flood-breach river mouths on a wavedominated coast: Comparison with ebb-tidal deltas at barrier inlets, Mar. Geol., 95(1), 5770, doi:10.1016/0025-3227(90)90021-B.

Cooper, J. A. G. (1994), Sedimentary processes in the river-dominated Mvoti estuary, South 
Africa, Geomorphology, 9(4), 271-300, doi:10.1016/0169-555X(94)90050-7.

Cooper, J. A. G. (2001), Geomorphological variability among microtidal estuaries from the wave-dominated South African coast, Geomorphology, 40(1-2), 99-122, doi:10.1016/S0169-555X(01)00039-3.

Correggiari, A., A. Cattaneo, and F. Trincardi (2005), The modern Po Delta system: Lobe switching and asymmetric prodelta growth, Mar. Geol., 222(October 2015), 49-74, doi:10.1016/j.margeo.2005.06.039.

Cosandey, C., V. Andréassian, C. Martin, J. F. Didon-Lescot, J. Lavabre, N. Folton, N. Mathys, and D. Richard (2005), The hydrological impact of the mediterranean forest: a review of French research, J. Hydrol., 301(1-4), 235-249, doi:10.1016/j.jhydrol.2004.06.040.

Credner, G. R. (1878), Die Deltas, edited by A. Peterman, Justus Perthes, Gotha.

Cui, Y., and G. Parker (2005), Numerical Model of Sediment Pulses and Sediment-Supply Disturbances in Mountain Rivers, J. Hydraul. Eng., 131(8), 646-656, doi:10.1061/(ASCE)0733-9429(2005)131:8(646).

Curray, J. R., F. J. Emmel, and P. J. S. Crampton (1969), Holocene history of a strand plain, lagoonal coast, Nayarit, Mexico, in Lagunas Costeras, Un Simposio. Mem. Simp. Intern. Lagunas Costeras, edited by A. A. Castanares and F. B. Phleger, pp. 63-100, UNAMUNESCO, Mexico City, Mexico.

Dean, R. G. (1991), Equilibrium Beach Profiles : Characteristics and Applications, J. Coast. Res., 7(1), 53-84.

Dean, R. G., and R. A. Dalrymple (1991), Water wave mechanics for engineers and scientists, World Scientific Pub Co Inc, Hackensack, NJ.

Deltares (2014), User Manual Delft3D, Deltares, Delft, The Netherlands.

Dominguez, J. M. L. (1996), The Sao Francisco strandplain: a paradigm for wave-dominated deltas?, Geol. Soc. London, Spec. Publ., 117(1), 217-231, doi:10.1144/GSL.SP.1996.117.01.13.

Edmonds, D. A., and R. L. Slingerland (2007), Mechanics of river mouth bar formation: Implications for the morphodynamics of delta distributary networks, J. Geophys. Res., 112(F2), F02034, doi:10.1029/2006JF000574.

Edmonds, D. A., and R. L. Slingerland (2009), Significant effect of sediment cohesion on delta morphology, Nat. Geosci., 3(2), 105-109, doi:10.1038/ngeo730.

Ericson, J., C. Vorosmarty, S. Dingman, L. Ward, and M. Meybeck (2006), Effective sea-level rise and deltas: Causes of change and human dimension implications, Glob. Planet. Change, 
50(1-2), 63-82, doi:10.1016/j.gloplacha.2005.07.004.

Fagherazzi, S. (2008), Self-organization of tidal deltas, PNAS, 105(48), 18692-18695.

Fagherazzi, S., D. A. Edmonds, W. Nardin, N. Leonardi, A. Canestrelli, F. Falcini, D. J. Jerolmack, G. Mariotti, J. C. Rowland, and R. L. Slingerland (2015), Dynamics of river mouth deposits, Rev. Geophys., 69(37), 1-31, doi:10.1002/2014RG000451.

Falcini, F., A. Piliouras, R. Garra, A. Guerin, D. J. Jerolmack, J. Rowland, and C. Paola (2014), Hydrodynamic and suspended sediment transport controls on river mouth morphology, $J$. Geophys. Res. Earth Surf., 119(1), 1-11, doi:10.1002/2013JF002831.

Falqués, a., and D. Calvete (2005), Large-scale dynamics of sandy coastlines: Diffusivity and instability, J. Geophys. Res., 110(C3), C03007, doi:10.1029/2004JC002587.

Ferrier, K. L., J. T. Perron, S. Mukhopadhyay, M. Rosener, J. D. Stock, K. L. Huppert, and M. Slosberg (2013), Covariation of climate and long-term erosion rates across a steep rainfall gradient on the Hawaiian island of Kaua'i, Geol. Soc. Am. Bull., 125(7-8), 1146-1163, doi:10.1130/B30726.1.

Filip, F., and L. Giosan (2014), Evolution of Chilia lobes of the Danube delta: Reorganization of deltaic processes under cultural pressures, Anthropocene, 5, 65-70, doi:10.1016/j.ancene.2014.07.003.

Fisher, W. L., and J. H. McGowen (1969), Depositional Systems in Wilcox Group (Eocene) of Texas and Their Relation to Occurrence of Oil and Gas, Am. Assoc. Pet. Geol. Bull., 53(1), $34-50$.

Fitzgerald, D. M. (1982), Sediment Bypassing at Mixed Energy Tidal Inlets, in Proceedings of 18th Conference of Coastal Engineering, vol. 18, edited by B. L. Edge, pp. 1094-1118, ASCE, Cape Town, South Africa.

Friedman, G. M. (1967), Dynamic processes and statistical parameters compared for size frequency distribution of beach and river sands, J. Sediment. Res., 37(2), 327-354, doi:10.1306/74D716CC-2B21-11D7-8648000102C1865D.

Gaillard, P. et al. (2004), Wind and Wave Atlas of the Mediterranean Sea, edited by Western European Armaments Organisation Research Cell,

Galloway, W. D. (1975), Process Framework for describing the morphologic and stratigraphic evolution of deltaic depositional systems, in Deltas, Models for Exploration, edited by M. L. Broussard, pp. 86-98, Houston Geological Society, Houston, TX.

Geleynse, N., J. E. A. Storms, D.-J. R. Walstra, H. R. A. Jagers, Z. B. Wang, and M. J. F. Stive (2011), Controls on river delta formation; insights from numerical modelling, Earth Planet. Sci. Lett., 302(1-2), 217-226, doi:10.1016/j.eps1.2010.12.013. 
Gelfenbaum, G., A. W. Stevens, I. Miller, J. A. Warrick, A. S. Ogston, and E. Eidam (2015), Large-scale dam removal on the Elwha River, Washington, USA: Coastal geomorphic change, Geomorphology, 246, 649-668, doi:10.1016/j.geomorph.2015.01.002.

Gilbert, G. K. (1885), The topographic features of lake shores, Washington DC, USA.

Giosan, L. (1998), Long term sediment dynamics of Danube delta coast, in Physics of Estuaries and Coastal Seas, edited by J. Dronkers and M. Scheffers, pp. 365-376, Balkema, Rotterdam.

Giosan, L. (2007), Morphodynamic Feedbacks on Deltaic Coasts: Lessons from the WaveDominated Danube Delta, edited by N. C. Kraus and J. D. Rosati, Coast. Sediments '07, 828-841, doi:10.1061/40926(239)63.

Giosan, L., J. P. Donnelly, E. Vespremeanu, J. P. Bhattacharya, C. Olariu, and F. S. Buonaiuto (2005), River delta morphodynamics: examples from the Danube delta, edited by L. Giosan and J. P. Bhattacharya, SEPM (Society for Sedimentary Geology).

Giosan, L., J. P. Donnelly, S. Constantinescu, F. Filip, I. Ovejanu, A. Vespremeanu-Stroe, E. Vespremeanu, and G. A. T. Duller (2006), Young Danube delta documents stable Black Sea level since the middle Holocene: Morphodynamic, paleogeographic, and archaeological implications, Geology, 34(9), 757-760, doi:Doi 10.1130/G22587.1.

Giosan, L., M. J. L. Coolen, J. O. Kaplan, S. Constantinescu, F. Filip, M. Filipova-Marinova, A. J. Kettner, and N. Thom (2012), Early Anthropogenic Transformation of the Danube-Black Sea System, Sci. Rep., 2.

Giosan, L., S. Constantinescu, F. Filip, and B. Deng (2013), Maintenance of large deltas through channelization: Nature vs. humans in the Danube delta, Anthropocene, 1, 35-45, doi:10.1016/j.ancene.2013.09.001.

Giosan, L., J. Syvitski, S. Constantinescu, and J. Day (2014), Climate change: Protect the world's deltas, Nature, 516(7529), 31-33, doi:10.1038/516031a.

González-Sampériz, P., and M. . Sopena Vicién (2002), Recent Holocene palaeoenvironmental evolution in the central Ebro Basin (NE Spain), Quat. Int., 93-94, 177-190, doi:10.1016/S1040-6182(02)00016-2.

Goy, J. L., C. Zazo, and C. J. Dabrio (2003), A beach-ridge progradation complex reflecting periodical sea-level and climate variability during the Holocene (Gulf of Almería, Western Mediterranean), Geomorphology, 50(1-3), 251-268, doi:10.1016/S0169-555X(02)00217-9.

Grijm, W. (1960), Theoretical forms of shorelines, in 7th Conference on Coastal Engineering, vol. 2, edited by B. Edge, pp. 197-202, ASCE, Lisbon.

Guilchar, A., and J. P. Nicholas (1954), Observation sur la Langue de Barbarie et les bras du 
Senegal aux environs de Saint-Louis, Bull. Inf. C.O.E.C., 6, 227-242.

Guillén, A., and J. Palanques (1997), A historical perspective of the morphological evolution in the lower Ebro river, Environ. Geol., 30(3), 174-180.

Guillen, J., and J. Jimenez (1995), Processes behind the Longshore Variation of the Sediment Grain Size in the Ebro Delta Coast, J. Coast. Res., 11(1), 205-218.

Guillén, J., and J. A. Jiménez (2009), Comment on "Wave climate, sediment supply and the depth of the sand-mud transition: A global survey" by D.A. George and P.S. Hill [Marine Geology 254 (2008) 121-128], Mar. Geol., 264(3-4), 258-261, doi:10.1016/j.margeo.2009.04.004.

Guillén, J., J. A. Jiménez, A. Palanques, P. Puig, and V. Gracia (2005), Bottom Sediment Variability in the Active Layer of the Inner Shelf off the Ebro Delta, J. Coast. Res., 213(3), 482-496, doi:10.2112/03-0056.1.

Gulliver, F. P. (1896), Cuspate forelands, Bull. Geol. Soc. Am., 7(18), 399-422.

Gutiérrez-Elorza, M., and J. L. Peña-Monné (1998), Geomorphology and late Holocene climatic change in Northeastern Spain, Geomorphology, 23(2-4), 205-217, doi:10.1016/S0169555X(98)00004-X.

Hart, D. E. (2007), River-mouth lagoon dynamics on mixed sand and gravel barrier coasts, $J$. Coast. Res., 50(ICS2007), 927-931.

Hay, W. W. (1998), Detrital sediment fluxes from continents to oceans, Chem. Geol., 145(3-4), 287-323, doi:10.1016/S0009-2541(97)00149-6.

Heathfield, D. K., and I. J. Walker (2015), Evolution of a foredune and backshore river complex on a high-energy, drift-aligned beach, Geomorphology, doi:10.1016/j.geomorph.2015.08.006.

Heller, P. L., and C. Paola (1996), Downstream Changes in Alluvial Architecture: An Exploration of Controls on Channel-stacking Patterns, J. Sediment. Res., 66(2), 297-306.

Hickin, E. J., and G. C. Nanson (1984), Lateral Migration Rates of River Bends, J. Hydraul. Eng., 110(11), 1557-1567, doi:10.1061/(ASCE)0733-9429(1984)110:11(1557).

Hicks, D. M., and D. L. Inman (1987), Sand dispersion from an ephemeral river delta on the Central California coast, Mar. Geol., 77(3-4), 305-318, doi:10.1016/0025-3227(87)901198.

Hillen, M. M., N. Geleynse, J. E. A. Storms, D. R. Walstra, and M. J. F. Stive (2009), Morphology and stratigraphy of a degrading delta, in Proceedings of Coastal Dynamics 2009. Impacts of human activities on dynamics coastal processes, edited by M. Mizuguchi 
and S. Sato, pp. 1-12, World scientific Publishing Co. Pte. Ltd., Tokyo, Japan.

Hirano, M. (1971), River bed degradation with armouring, Trans. Japanese Soc. Civ. Eng., 3, 194-195.

Hotchkiss, R. H., and G. Parker (1991), Shock Fitting of Aggradational Profiles Due to Backwater, J. Hydraul. Eng., 117(9), 1129-1144, doi:10.1061/(ASCE)07339429(1991)117:9(1129).

Hudson, P. F., and R. H. Kesel (2000), Channel migration and meander-bend curvature in the lower Mississippi River prior to major human modification, Geology, 28(6), 531, doi:10.1130/0091-7613(2000)28<531:CMAMCI>2.0.CO;2.

Innocenti, L., and E. Pranzini (1993), Geomorphological Evolution and Sedimentology of the Ombrone River Delta, Italy, J. Coast. Res., 9(2), 481-493.

Ismail, N. M., and R. L. Wiegel (1983), Opposing Wave Effect on Momentum Jets Spreading Rate, J. Waterw. Port, Coastal, Ocean Eng., 109(4), 465-483, doi:10.1061/(ASCE)0733950X(1983)109:4(465).

Izumi, N., N. Shuto, and H. Tanaka (1999), Instability of River Mouth Locations in Pocket Beaches, in Coastal Sediments '99, pp. 628-643.

Jerolmack, D. J., and D. Mohrig (2007), Conditions for branching in depositional rivers, Geology, 35(5), 463-466, doi:Doi 10.1130/G23308a.1.

Jerolmack, D. J., and J. B. Swenson (2007), Scaling relationships and evolution of distributary networks on wave-influenced deltas, Geophys. Res. Lett., 34(23), L23402, doi: $10.1029 / 2007 \mathrm{gl} 031823$.

Jimenez, J. A., M. A. Garcia, and A. Sanchez-Arcilla (1990), Análisis y propuesta de soluciones para establizar el delta del Ebro: Estimatión del transporte de sedimentos en el río Ebro: Contributión a la evolución costera, Barcelona.

Jimenez, J. A., A. Sanchez-Arcilla, H. I. Valdemoro, V. Gracia, and F. Nieto (1997), Processes reshaping the Ebro delta, Mar. Geol., 144(1-3), 59-79.

Jiménez, J. A., and A. Sánchez-Arcilla (1993), Medium-term coastal response at the Ebro delta, Spain, Mar. Geol., 114(1-2), 105-118, doi:10.1016/0025-3227(93)90042-T.

Jiménez, J. A., and A. Sánchez-Arcilla (2004), A long-term (decadal scale) evolution model for microtidal barrier systems, Coast. Eng., 51(8-9), 749-764, doi:10.1016/j.coastaleng.2004.07.007.

Jirka, G. H. (1994), Shallow jets, in Recent Research Advances in the Fluid Mechanics of Turbulent Jets and Plumes, edited by P. A. Davies and M. J. Valente Neves, pp. 155-175, 
Kluwer Academic Publishers, Dordrecht.

Jirka, G. H. (2001), Large scale flow structures and mixing processes in shallow flows, $J$. Hydraul. Res., 39(6), 567-573, doi:10.1080/00221686.2001.9628285.

Kelk, J. G. (1974), A morphological approach to process interaction on the mid Canterbury coastline, University of Canterbury.

Kettner, A. J., and J. P. M. Syvitski (2008), HydroTrend v.3.0: A climate-driven hydrological transport model that simulates discharge and sediment load leaving a river system, Comput. Geosci., 34(10), 1170-1183, doi:Doi 10.1016/J.Cageo.2008.02.008.

Kim, W., A. Dai, T. Muto, and G. Parker (2009a), Delta progradation driven by an advancing sediment source: Coupled theory and experiment describing the evolution of elongated deltas, Water Resour. Res., 45(6), W06428, doi:10.1029/2008WR007382.

Kim, W., D. Mohrig, R. Twilley, C. Paola, and G. Parker (2009b), Is It Feasible to Build New Land in the Mississippi River Delta?, Eos, Trans. Am. Geophys. Union, 90(42), 373-374, doi:10.1029/2009EO420001.

Kirk, R. M. (1991), River-beach interaction on mixed sand and gravel coasts: a geomorphic model for water resource planning, Appl. Geogr., 11(4), 267-287, doi:10.1016/01436228(91)90018-5.

Kolb, C. R. (1963), Sediments Forming the Bed and Banks of the Lower Mississippi River and their Effect on River Migration, Sedimentology, 2(3), 227-234, doi:10.1111/j.13653091.1963.tb01216.x.

Komar, P. D. (1971), Mechanics of Sand Transport on Beaches, J. Geophys. Res., 76(3), 713721, doi:10.1029/Jc076i003p00713.

Komar, P. D. (1973), Computer models of delta growth due to sediment input from rivers and longshore transport, Bull. Geol. Soc. Am., 84(7), 2217-2226, doi:10.1130/00167606(1973)84<2217:CMODGD>2.0.CO;2.

Komar, P. D. (1998), Beach processes and sedimentation, 2e ed., Prentice Hall, Upper Saddle River, NJ.

Kraus, N. C., A. Militello, and G. Todoroff (2002), Barrier Beaching Processes and Barrier Spit Breach, Stone Lagoon, California, Shore and Beach, 70(4), 21-28.

Lamb, M. P., J. a. Nittrouer, D. Mohrig, and J. Shaw (2012), Backwater and river plume controls on scour upstream of river mouths: Implications for fluvio-deltaic morphodynamics, $J$. Geophys. Res. Earth Surf., 117(F1), 1-15, doi:10.1029/2011JF002079.

Lane, E. W. (1955), The Importance of Fluvial Morphology in Hydraulic Engineering, Am. Soc. 
Civ. Eng. Proc., 81(745), 1-17.

Lario, J., C. Zazo, C. J. Dabrio, L. Somoza, J. L. Goy, T. Bardaji, and P. G. Silva (1995), Recent Holocene Record on Spit Bars and Deltas Sediment of South Input Spain, J. Coast. Res., SI $17,241-245$.

Larson, M., H. Hanson, and N. C. Kraus (1987), Analytical solutions of the one-line model of shoreline change, US Army Waterw. Exp. Stn., Vicksburg.

Leonardi, N., A. Canestrelli, T. Sun, and S. Fagherazzi (2013), Effect of tides on mouth bar morphology and hydrodynamics, J. Geophys. Res. Ocean., 118(9), 4169-4183, doi:10.1002/jgrc.20302.

Leonardi, N., A. S. Kolker, and S. Fagherazzi (2015), Interplay between river discharge and tides in a delta distributary, Adv. Water Resour., 80, 69-78, doi:10.1016/j.advwatres.2015.03.005.

Leopold, L. B., and M. G. Wolman (1960), River Meanders, Geol. Soc. Am. Bull., 71(6), 769, doi:10.1130/0016-7606(1960)71[769:RM]2.0.CO;2.

Lesser, G. R., J. A. Roelvink, J. A. T. M. Kester, and G. S. Stelling (2004), Development and validation of a three-dimensional morphological model, Coast. Eng., 51, 883-915, doi:10.1016/j.coastaleng.2004.07.014.

Limber, P. W., K. B. Patsch, and G. B. Griggs (2008), Coastal Sediment Budgets and the Littoral Cutoff Diameter: A Grain Size Threshold for Quantifying Active Sediment Inputs, J. Coast. Res., 2, 122-133, doi:10.2112/06-0675.1.

List, J. H., and A. D. Ashton (2007), A circulation modeling approach for evaluating the conditions for shoreline instabilities, in Coastal Sediments '07, edited by N. C. Kraus and J. D. Rosati, pp. 1-14, American Society of Civil Engineers, New Orleans, LA.

Lorenzo-Trueba, J., and A. D. Ashton (2014), Rollover, drowning, and discontinuous retreat: Distinct modes of barrier response to sea-level rise arising from a simple morphodynamic model, J. Geophys. Res. Earth Surf., 119(4), 779-801, doi:10.1002/2013JF002941.

Maldonado, A. (1975), Sedimentation, Stratigraphy, and Development of the Ebro Delta, Spain, in Deltas: Models for Exploration, edited by M. Lou Broussard, pp. 311-338, Houston Geological Society, Houston.

Mariotti, G., F. Falcini, N. Geleynse, M. Guala, T. Sun, and S. Fagherazzi (2013), Sediment eddy diffusivity in meandering turbulent jets: Implications for levee formation at river mouths, $J$. Geophys. Res. Earth Surf., 118(3), 1908-1920, doi:10.1002/jgrf.20134.

Maselli, V., and F. Trincardi (2013), Man made deltas., Sci. Rep., 3, 1926, doi:10.1038/srep01926. 
Meyer-Peter, E., and R. Müller (1948), Formulas for Bed-Load Transport, in Proceedings of the 2nd Meeting of the International Association for Hydraulic Structures Research, pp. 39-64, Stockholm.

Mikeš, D. (2010), The upper cenozoic evolution of the Duero and Ebro fluvial systems (NSpain): part I. paleogeography; part II. geomorphology, Open Geosci., 2(3), 420-432, doi:10.2478/v10085-010-0017-4.

Mikhailova, M. V. (1995), Sediment Balance in Nontidal River Mouths and Method of Calculation of Protruding Delta Formation, Water Resour., 22(5), 502-510.

Milliman, J. D., and R. H. Meade (1983), World-Wide Delivery of River Sediment to the Oceans, J. Geol., 91(1), 1-21, doi:10.1086/628741.

Milliman, J. D., K. L. Farnsworth, P. D. Jones, K. H. Xu, and L. C. Smith (2008), Climatic and anthropogenic factors affecting river discharge to the global ocean, 1951-2000, Glob. Planet. Change, 62(3-4), 187-194, doi:Doi 10.1016/J.Gloplacha.2008.03.001.

Muñoz, I., and N. Prat (1989), Effects of river regulation on the lower Ebro river (NE Spain), Regul. Rivers Res. Manag., 3(1), 345-354, doi:10.1002/rrr.3450030132.

Murray, A. B. (2003), Contrasting the goals, strategies and predictions associated with simplified numerical models and detailed simulations, in Prediction in geomorphology, edited by P. R. Wilcock and R. M. Iverson, pp. 151-165, American Geophysical Union, Washington DC, USA.

Murray, A. B. (2007), Reducing model complexity for explanation and prediction, Geomorphology, 90(3-4), 178-191, doi:10.1016/j.geomorph.2006.10.020.

Nardin, W., and S. Fagherazzi (2012), The effect of wind waves on the development of river mouth bars, Geophys. Res. Lett., 39(12), L12607, doi:10.1029/2012g1051788.

Nardin, W., G. Mariotti, D. A. Edmonds, R. Guercio, and S. Fagherazzi (2013), Growth of river mouth bars in sheltered bays in the presence of frontal waves, J. Geophys. Res. Earth Surf., 118(2), 872-886, doi:10.1002/jgrf.20057.

Nelson, C. H. (1990), Estimated post-Messinian sediment supply and sedimentation rates on the Ebro continental margin, Spain, Mar. Geol., 95(3-4), 395-418, doi:10.1016/00253227(90)90126-5.

Nienhuis, J. H., A. D. Ashton, P. C. Roos, S. J. M. H. Hulscher, and L. Giosan (2013), Wave reworking of abandoned deltas, Geophys. Res. Lett., 40(22), 5899-5903, doi:10.1002/2013GL058231.

Nienhuis, J. H., A. D. Ashton, W. Nardin, S. Fagherazzi, and L. Giosan (2015a), Breaking-wave driven sediment bypassing of river mouths: mechanisms and effects on delta evolution, in 
The Proceedings of the Coastal Sediments 2015, edited by P. Wang, J. Rosati, and J. Cheng, World Scientific Pub Co Inc, San Diego, USA.

Nienhuis, J. H., A. D. Ashton, and L. Giosan (2015b), Steering of deltaic channels through river mouth bypassing and alongshore sediment transport, Prep.

Nienhuis, J. H., A. D. Ashton, and L. Giosan (2015c), What makes a delta wave-dominated?, Geology, 43(6), 511-514, doi:10.1130/G36518.1.

Nittrouer, J. A., and E. Viparelli (2014), Sand as a stable and sustainable resource for nourishing the Mississippi River delta, Nat. Geosci., 7(5), 350-354, doi:10.1038/ngeo2142.

NOAA (2015), NOAA GSHHG Coastline, Natl. Geophys. Data Cent. Available from: http://www.ngdc.noaa.gov/mgg/shorelines/shorelines.html

Olsen, J., N. J. Anderson, and M. F. Knudsen (2012), Variability of the North Atlantic Oscillation over the past 5,200 years, Nat. Geosci., 5(11), 808-812, doi:10.1038/ngeo1589.

Orton, G. J., and H. G. Reading (1993), Variability of deltaic processes in terms of sediment supply, with particular emphasis on grain size, Sedimentology, 40(3), 475-512, doi:10.1111/j.1365-3091.1993.tb01347.x.

Paola, C., P. L. Heller, and C. L. Angevine (1992), The large-scale dynamics of grain-size variation in alluvial basins, 1: Theory, Basin Res., 4(2), 73-90, doi:10.1111/j.13652117.1992.tb00145.x.

Paola, C., R. R. Twilley, D. A. Edmonds, W. Kim, D. Mohrig, G. Parker, E. Viparelli, and V. R. Voller (2011), Natural processes in delta restoration: application to the Mississippi Delta., Ann. Rev. Mar. Sci., 3(1), 67-91, doi:10.1146/annurev-marine-120709-142856.

Parker, G. (1978), Self-formed straight rivers with equilibrium banks and mobile bed. Part 1. The sand-silt river, J. Fluid Mech., 89(01), 109-125, doi:10.1017/S0022112078002505.

Parker, G. (1991), Selective Sorting and Abrasion of River Gravel. I: Theory, J. Hydraul. Eng., 117(2), 131-147, doi:10.1061/(ASCE)0733-9429(1991)117:2(131).

Parker, G. (2004), 1D Sediment Transport Morphodynamics with Applications to Rivers and Turbidity Currents, ebook: hydrolab.illinois.edu/people/parkerg/morphodynamics_ebook.htm, Minneapolis.

Pelnard-Considère, R. (1956), Essai de theorie de l'Evolution des Formes de Rivage en Plages de Sable et de Galets, 4th Journees l'Hydraulique, Les Energies la Mer, Quest. III, vol. 1.

Pranzini, E. (2001), Updrift river mouth migration on cuspate deltas: two examples from the coast of Tuscany (Italy), Geomorphology, 38(1-2), 125-132, doi:10.1016/S0169$555 x(00) 00076-3$. 
Puertos del Estado (2015), Wave Buoy data from Puertos del Estado, Available from: Www.puertos.es

Rao, M. A., S. Ramamurthy, B. M. Shah, and V. H. Rao (2006), Recent morphological changes along the Krishna Delta shoreline, J. Geol. Soc. india, 67(5), 629-635.

Ray, R., G. Egbert, and S. Erofeeva (2005), A Brief Overview of Tides in the Indonesian Seas, Oceanography, 18(4), 74-79, doi:10.5670/oceanog.2005.07.

Ribberink, J. S. (1987), Mathematical modelling of one-dimensional morphological changes in rivers with non-uniform sediment, Delft University of Technology.

van Rijn, L. C. (1993), Principles of Sediment Transport in Rivers, Estuaries and Coastal Seas, 1st ed., Aqua Publications, Amsterdam.

Roberts, H. H. (1997), Dynamic changes of the Holocene Mississippi River delta plain: The delta cycle, J. Coast. Res., 13(3), 605-627.

Rodriguez, A. B., M. D. Hamilton, and J. B. Anderson (2000), Facies and evolution of the modern Brazos Delta, Texas: wave versus flood influence, J. Sediment. Res., 70(2), 283295, doi:10.1306/2dc40911-0e47-11d7-8643000102c1865d.

Roelvink, J. A., A. Boutmy, and J. Stam (1998), A simple method to predict long-term morphological changes, in Coastal Engineering 1998, edited by B. L. Edge, pp. 3224-3237, ASCE, Copenhagen, Denmark.

Rossetti, D. de F., S. P. Polizel, M. C. L. Cohen, and L. C. R. Pessenda (2015), Late PleistoceneHolocene evolution of the Doce River delta, southeastern Brazil: Implications for the understanding of wave-influenced deltas, Mar. Geol., 367, 171-190, doi:10.1016/j.margeo.2015.05.012.

Rovira, A., and C. Ibàñez (2007), Sediment management options for the lower Ebro River and its delta, J. Soils Sediments, 7(5), 285-295, doi:10.1065/jss2007.08.244.

Rowland, J. C., M. T. Stacey, and W. E. Dietrich (2009), Turbulent characteristics of a shallow wall-bounded plane jet: experimental implications for river mouth hydrodynamics, J. Fluid Mech., 627, 423, doi:10.1017/S0022112009006107.

Rowland, J. C., W. E. Dietrich, and M. T. Stacey (2010), Morphodynamics of subaqueous levee formation: Insights into river mouth morphologies arising from experiments, J. Geophys. Res., 115(F4), F04007, doi:10.1029/2010jf001684.

Sabatier, F., G. Maillet, M. Provansal, T.-J. Fleury, S. Suanez, and C. Vella (2006), Sediment budget of the Rhône delta shoreface since the middle of the 19th century, Mar. Geol., 234(1-4), 143-157, doi:http://dx.doi.org/10.1016/j.margeo.2006.09.022. 
Sabatier, P., L. Dezileau, C. Colin, L. Briqueu, F. Bouchette, P. Martinez, G. Siani, O. Raynal, and U. Von Grafenstein (2012), 7000years of paleostorm activity in the NW Mediterranean Sea in response to Holocene climate events, Quat. Res., 77(1), 1-11, doi:10.1016/j.yqres.2011.09.002.

Sánchez-Arcilla, A., J. a. Jiménez, H. I. Valdemoro, and V. Gracia (2008), Implications of Climatic Change on Spanish Mediterranean Low-Lying Coasts: The Ebro Delta Case, J. Coast. Res., 242(2), 306-316, doi:10.2112/07A-0005.1.

Schumm, S., and R. Lichty (1963), Channel widening and flood-plain construction along Cimarron River in southwestern Kansas, Geol. Surv. Prof. Pap., 352-D(D), 71-88.

Sedrati, M., P. Ciavola, and C. Armaroli (2011), Morphodynamic evolution of a microtidal barrier, the role of overwash: Bevano, Northern Adriatic Sea, J. Coast. Res., SI 64(ICS2011), 696-700.

Simeoni, U., G. Fontolan, U. Tessari, and C. Corbau (2007), Domains of spit evolution in the Goro area, Po Delta, Italy, Geomorphology, 86(3-4), 332-348, doi:http://dx.doi.org/10.1016/j.geomorph.2006.09.006.

Snow, R. S., and R. L. Slingerland (1987), Mathematical modeling of graded river profiles, $J$. Geol., 95(1), 15-33.

Somoza, L., A. Barnolas, A. Arasa, A. Maestro, J. G. Rees, and F. J. Hernandez-Molina (1998), Architectural stacking patterns of the Ebro delta controlled by Holocene high-frequency eustatic fluctuations, delta-lobe switching and subsidence processes, Sediment. Geol., 117(1-2), 11-32, doi:10.1016/S0037-0738(97)00121-8.

Soriano, M. A. (1989), Infilled valleys in the central Ebro Basin (Spain), CATENA, 16(4-5), 357-367, doi:10.1016/0341-8162(89)90020-9.

Sotillo, M. G., A. W. Ratsimandresy, J. C. Carretero, A. Bentamy, F. Valero, and F. GonzálezRouco (2005), A high-resolution 44-year atmospheric hindcast for the Mediterranean Basin: contribution to the regional improvement of global reanalysis, Clim. Dyn., 25(2-3), 219 236, doi:10.1007/s00382-005-0030-7.

Stanley, D. J., and A. G. Warne (1994), Worldwide Initiation of Holocene Marine Deltas by Deceleration of Sea-Level Rise, Science (80-. )., 265(5169), 228-231, doi:10.1126/science.265.5169.228.

Stanley, D. J., and A. G. Warne (1998), Nile Delta in Its Destruction Phase, J. Coast. Res., 14(3), $795-825$.

Suarez, B. E. S. (2004), The Sinú river delta on the northwestern Caribbean coast of Colombia: Bay infilling associated with delta development, J. South Am. Earth Sci., 16(7), 623-631, 
doi:10.1016/j.jsames.2003.10.005.

Syvitski, J. P. M. et al. (2009), Sinking deltas due to human activities, Nat. Geosci., 2(10), 681686, doi:10.1038/Ngeo629.

Syvitski, J. P. M. M., and Y. Saito (2007), Morphodynamics of deltas under the influence of humans, Glob. Planet. Change, 57(3-4), 261-282, doi:10.1016/j.gloplacha.2006.12.001.

Syvitski, J. P. M. P. M., and J. D. D. Milliman (2007), Geology, Geography, and Humans Battle for Dominance over the Delivery of Fluvial Sediment to the Coastal Ocean, J. Geol., 115(1), 1-19, doi:10.1086/509246.

Tanaka, H. (2003), Mathematical modelling of morphological change at a river mouth, in International conference on estuaries and coasts, pp. 87-98, Hangzhou, China, China.

Tanaka, H., F. Takahashi, and A. Takahashi (1996), Complete closure of the Nanakita River mouth in 1994, in Coastal Engineering Proceedings, vol. 25, edited by B. L. Edge, pp. 4545-4556, ASCE, Orlando, USA.

Tanner, W. F. (1958), The equilibrium beach, Trans. Am. Geophys. Union, 39(5), 889, doi:10.1029/TR039i005p00889.

Thorndycraft, V. R., and G. Benito (2006), The Holocene fluvial chronology of Spain: evidence from a newly compiled radiocarbon database, Quat. Sci. Rev., 25(3-4), 223-234, doi:10.1016/j.quascirev.2005.07.003.

Trouet, V., J. Esper, N. E. Graham, A. Baker, J. D. Scourse, and D. C. Frank (2009), Persistent Positive North Atlantic Oscillation Mode Dominated the Medieval Climate Anomaly, Science (80-. )., 324(5923), 78-80, doi:10.1126/science.1166349.

Turowski, J. M., D. Rickenmann, and S. J. Dadson (2010), The partitioning of the total sediment load of a river into suspended load and bedload: a review of empirical data, Sedimentology, 57(4), 1126-1146, doi:10.1111/j.1365-3091.2009.01140.x.

Vella, C., T. J. Fleury, G. Raccasi, M. Provansal, F. Sabatier, and M. Bourcier (2005), Evolution of the Rhone delta plain in the Holocene, Mar. Geol., 222, 235-265, doi:Doi 10.1016/J.Margeo.2005.06.028.

Vericat, D., and R. J. Batalla (2006), Sediment transport in a large impounded river: The lower Ebro, NE Iberian Peninsula, Geomorphology, 79(1-2), 72-92, doi:10.1016/j.geomorph.2005.09.017.

Vericat, D., R. J. Batalla, and C. Garcia (2006), Breakup and reestablishment of the armour layer in a large gravel-bed river below dams: The lower Ebro, Geomorphology, 76(1-2), 122-136, doi:10.1016/j.geomorph.2005.10.005. 
Viparelli, E., O. E. Sequeiros, A. Cantelli, P. R. Wilcock, and G. Parker (2010), River morphodynamics with creation/consumption of grain size stratigraphy 2: numerical model, J. Hydraul. Res., 48(6), 727-741, doi:10.1080/00221686.2010.526759.

de Vriend, H. J., W. T. Bakker, and D. P. Bilse (1994), A morphological behaviour model for the outer delta of mixed-energy tidal inlets, Coast. Eng., 23(3-4), 305-327, doi:10.1016/03783839(94)90008-6.

Warrick, J. A., and P. L. Barnard (2012), The offshore export of sand during exceptional discharge from California rivers, Geology, 40(9), 787-790, doi:10.1130/G33115.1.

van der Wegen, M., B. E. Jaffe, and J. A. Roelvink (2011), Process-based, morphodynamic hindcast of decadal deposition patterns in San Pablo Bay, California, 1856-1887, J. Geophys. Res., 116(F2), F02008, doi:10.1029/2009JF001614.

Wolinsky, M. A., D. A. Edmonds, J. Martin, and C. Paola (2010), Delta allometry: Growth laws for river deltas, Geophys. Res. Lett., 37(21), L21403, doi:10.1029/2010GL044592.

Wolman, M. G., and J. P. Miller (1960), Magnitude and frequency of forces in geomorphic processes, J. Geol., 68(1), 54-74.

Wright, L. D. (1976), Morphodynamics of a wave-dominated river mouth, in Coastal Engineering Proceedings 1976, pp. 622-626.e2.

Wright, L. D. (1977), Sediment Transport and Deposition at River Mouths - Synthesis, Geol. Soc. Am. Bull., 88(6), 857-868, doi:10.1130/0016-7606(1977)88<857.

Wright, L. D., and J. M. Coleman (1973), Variations in morphology of major river deltas as functions on ocean wave and river discharge regimes, Am. Assoc. Pet. Geol. Bull., 57(2), $370-398$.

Wright, S., and G. Parker (2005), Modeling downstream fining in sand-bed rivers. I: formulation, J. Hydraul. Res., 43(6), 613-620, doi:10.1080/00221680509500381.

Xing, F., A. J. Kettner, A. Ashton, L. Giosan, C. Ibáñez, and J. O. Kaplan (2014), Fluvial response to climate variations and anthropogenic perturbations for the Ebro River, Spain in the last 4000years., Sci. Total Environ., 473-474, 20-31, doi:10.1016/j.scitotenv.2013.11.083.

Zenkovich, V. P. (1967), Processes of Coastal Development, 1st ed., edited by J. A. Steers, Oliver \& Boyd, Edinburgh. 